\title{
Collaborative and cross-company project management within the automotive industry using the Balanced Scorecard
}

\author{
Klaus Dieter Niebecker \\ Thesis submitted for the degree of \\ Doctor of Philosophy
}

University of Technology, Sydney 2009 


\section{Abstract}

Cross-company product development projects are often managed without clearly defined project goals and without an alignment of these goals to an organisations strategy and objectives. With a shift towards more decentralised and distributed development teams, and an increasing level of collaboration, project transparency is reduced and status measurement more difficult due to a lack of transparency. To overcome these difficulties, the quality of collaboration in the automotive manufacturing industry needs to be improved. The understanding of unifying goals and of the mutual purpose to produce new products is essential for efficient and effective collaboration.

A methodological study in the automotive industry as part of this research lead to the conclusion that a strategic scorecard method based on the Balanced Scorecard concept by Kaplan and Norton is capable to improve cross-company project management and reduce existing difficulties in typical product development collaboration, such as communication or collaborative risk management. A common definition of project goals, leading and lagging indicators to measure the status, and defining corrective action are core elements of the Collaborative Project Scorecard concept.

This thesis identifies the current problems and difficulties in automotive project management and explores solutions to improve its efficiency and effectiveness based on the Collaborative Project Scorecard. It is shown how the concept is derived from business strategies for an improved alignment of project goals with business objectives. A project impact analysis facilitates the development of project strategy maps to increase transparency of goal impact interdependencies. Furthermore, based on the results of workshops, surveys, and interviews the Collaborative Project Scorecard concept is applied to typical automotive product development projects and the identified advantages and limitations are evaluated by an application to a crosscompany project of an automotive supplier and a manufacturer. The development of the Collaborative Project Scorecard is followed by a software implementation of the results. The integration of a collaborative project management model that has a focus on time, task and communication management enables the project manager to create operational indicators that can be controlled on a strategic level by the Collaborative Project Scorecard. Additionally, it is shown how risk management and performance 
assessment are supported by the concept. Advantages, benefits, and limitations of the methodology are identified and further application scenarios suggested. 


\section{CERTIFICATE OF AUTHORSHIP/ORIGINALITY}

I certify that the work in this thesis has not previously been submitted for a degree nor has it been submitted as part of requirements for a degree except as fully acknowledged within the text.

I also certify that the thesis has been written by me. Any help that I have received in my research work and the preparation of the thesis itself has been acknowledged. In addition, I certify that all information sources and literature used are indicated in the thesis.

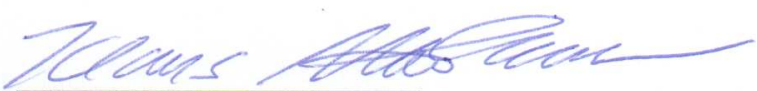

Signature of Candidate 


\section{Preface}

The automotive industry has undergone great structural changes in the last years. An increasing number of project partners that are required for the development and manufacturing of a vehicle has also changed the way automotive projects are managed. The industry requires adapted methods to improve performance of crosscompany and collaborative projects and to reduce product recalls and project failures. This research was dedicated to find a new path for the future by designing a concept that can be adapted to a wide range of projects and organisational requirements. As the concept has been developed within this research project its evaluation is limited to chosen project types and to selected areas of project management. The fundamental structure of the Collaborative Project Scorecard allows an organisation and project partnership to adopt the concept in various ways ranging from simple stand alone solutions in pilot projects to a complete integration to project portfolio and business management. The concept alone is no guarantee for success and improvement as it depends on a careful consideration of several aspects. Some of them are related to the organisation itself and its management structure and project types, others to the selection of relevant objectives and correspondent measures. While project management experience and skills cannot be replaced by a method, a framework such as part of the Collaborative Project Scorecard can support beginners and experts to focus on the relevant goal achievements by linking operational tasks to an overall strategy. 


\section{Acknowledgement}

During the last three years of my research project I have met many inspiring people who understood the challenges of a $\mathrm{PhD}$ and supported me with their innovative ideas and help in various different ways. A network of research partners and friends was created that will hopefully sustain and grow stronger. Research is not possible without other people, their guidance, advice, and motivation to understand your goals and objectives. My special thanks go to David Eager, my principle supervisor and research partner over those three years. David supported me in any possible aspect with strong dedication, patience, and humour. He made my time as a research student enjoyable and fascinating by opening doors to new experiences in my life. I am also thankful to Bruce Moulton, my alternate supervisor at UTS, who helped me to commence my PhD at UTS from the very beginning and who always had the right advice how to improve my work.

A number of coincidences brought me to another great person, Klaus Kubitza, who was the chairman of the ProSTEP iViP Collaborative Project Management project in Germany. Klaus made it possible to continue my research with the BMW Group in Germany and the USA. He was also highly dedicated to create the necessary environment within the organisation that allowed me to carry out my research without any boundaries. His continuous care and great understanding for my research needs were indispensable for the success of this project. My gratefulness goes to him and to the whole BMW Group in Germany, the department of processes, methods, and tools for product projects in particular, and the BMW Group in the U.S., where I always found open minds and cooperativeness to answer my questions and great curiosity to participate in workshops and interviews. At this time I also want to mention Joachim Taiber, head of the IT Research Centre in South Carolina, and the workshop and interview team from plant 10. Without them the contributions to the research project in South Carolina could not have been achieved. My special thanks go to Maximilian Kissel, my Master student at that time, who has greatly contributed to the concept development and workshops in South Carolina. He made our concept discussions very productive and his creativity influenced the quality of this research. He was also an essential team member to implement the CPS concept together with Microsoft and supported me with his work as a research partner and friend. In this context I would like to thank the project partners from DräxImaier USA and Juergen Frank in particular. 
Without their co-operation some of the methods and tools could not have been evaluated.

The research has continuously been carried out in a wide network of research partners. Major contributions were developed thanks to the support of Reinhard Wagner, chairman of the Automotive Chapter of the German Project Management Association. Reinhard gave me the opportunity to organise relevant chapter workshops to develop the concept and he also supported me in publishing and presenting major parts of the research activities. He was also a driving force that initiated the idea of the Collaborative Project Scorecard. Hence, my thanks go to the members of the GPM e.V. Automotive Chapter who participated in the two major workshops.

In addition, I would like to express my thankfulness to the contribution of the postgraduate students of the course Managing Projects at UTS who I supervised for their final assignment from 2006 to 2008 and the administrative support of Phyllis Agius from the Faculty of Engineering and IT. Finally, I also want to thank my family and my friends for their understanding and helpfulness during these sometimes eventful times. 


\section{Table of Contents}

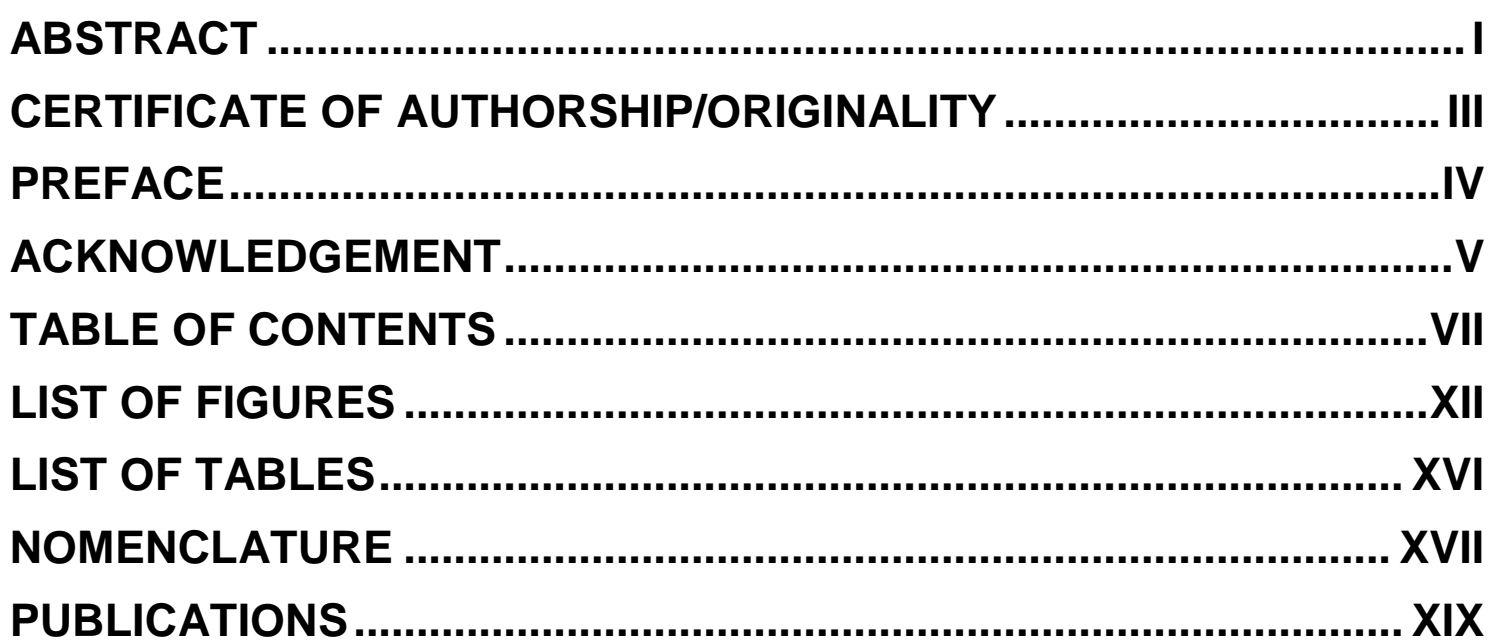

1 INTRODUCTION ............................................................................. 1

1.1 RESEARCH BACKGROUND AND SIGNIFICANCE .......................................... 2

1.1.1 Changes and developments in the automotive industry ......................... 3

1.1.2 The Balanced Scorecard approach to project management .................. 4

1.2 RESEARCH OBJECTIVES AND STEPS ............................................................. 5

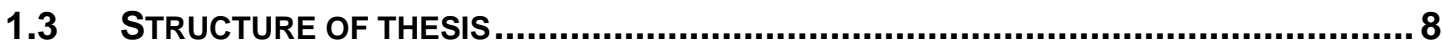

2 THEORETICAL BACKGROUND TO PROJECT MANAGEMENT .. 10

$2.1 \quad$ HISTORY OF PROJECT MANAGEMENT .......................................................... 10

2.1.1 Relation to management science .................................................... 11

2.2 DEFINING PROJECTS AND PROJECT MANAGEMENT ...................................... 12

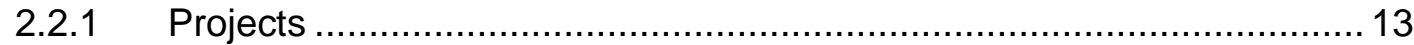

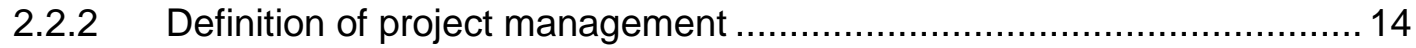

2.2.2.1 Project management characteristics ......................................... 14

2.2.2.2 Kerzner's definition of project management ............................... 15

2.2.3 Modern project management ........................................................ 16

2.2.3.1 Agile project management ..................................................... 17

2.2.3.2 Project management second order ......................................... 18

2.3 PROJECT MANAGEMENT METHODS, TOOLS, AND STANDARDS $\ldots \ldots \ldots \ldots \ldots \ldots \ldots \ldots . \ldots \ldots \ldots \ldots$

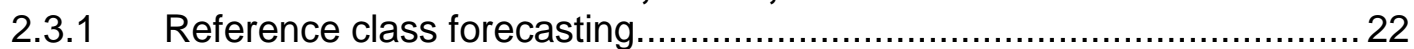

2.3.2 Project management associations ................................................... 23

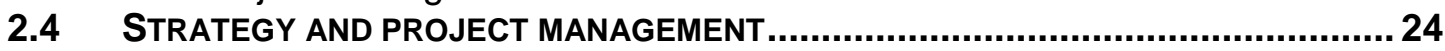

2.4.1 Creating a strategy-focused project organisation ............................... 25

3 PROJECT MANAGEMENT IN THE AUTOMOTIVE INDUSTRY ..... 26

3.1 DEVELOPMENTS IN THE AUTOMOTIVE INDUSTRY .............................................2

3.1.1 The role of project management in the automotive sector..................... 28

3.1.2 Project management dimensions..................................................... 29

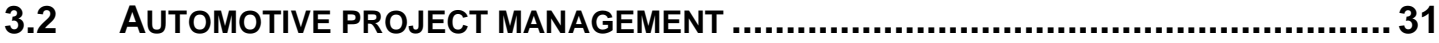

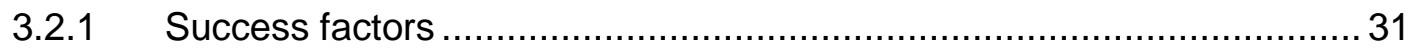

3.2.2 Automotive organisational management structures ........................... 32

3.2.2.1 Engineering and the project management office ........................... 34

3.2.3 Project failures in the automotive industry..................................... 35

3.3 PRODUCT DEVELOPMENT AND PROJECT MANAGEMENT IN THE AUTOMOTIVE

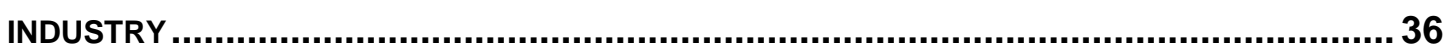

3.3.1 Project and product development cycles........................................... 37 
3.3.2 From definition to project and maturity stage control............................39

3.3.2.1 Definition phase ................................................................... 40

3.3.2.2 Project planning and control .................................................. 41

3.3.2.3 Project maturity control ........................................................ 42

3.4 CHANGE, CLAIM AND CONFIGURATION MANAGEMENT .....................................4 44

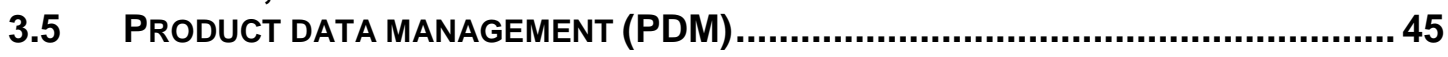

4 CROSS-COMPANY PROJECT MANAGEMENT ................................46

4.1 DEFINITION OF COLLABORATIVE AND CROSS-COMPANY PROJECT MANAGEMENT 47

4.2 VIRTUAL TEAMS IN PROJECT MANAGEMENT ...............................................49

4.2.1 Definition of virtual project teams ................................................... 49

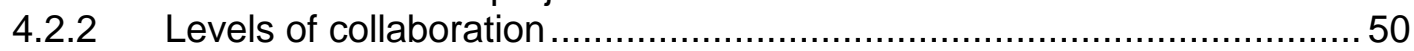

4.2.3 Collaboration as a key to business success........................................ 51

4.2.3.1 Early identification of collaboration benefits ............................... 52

4.2.3.2 The definition of collaborative standards as a key to success.........53

4.3 VIRTUAL TEAMS AND PRODUCT DEVELOPMENT PROJECTS ...............................53

4.3.1 Distributed product development ................................................. 53

4.3.1.1 Cooperation model for distributed product development ................55

4.3.2 Communication as a driving force................................................... 55

4.4 CULTURAL ASPECTS: LIMITATIONS AND CHANCES .......................................56

4.4.1 Cross-cultural development projects......................................... 57

4.5 GENERAL DIFFICULTIES IN CROSS-COMPANY PROJECT MANAGEMENT ...............57 57

4.5.1 Change towards complex projects ............................................ 58

4.5.2 Technologies as a driver for virtual teams......................................... 60

4.5.3 New processes need adaptation to distributed work environment..........61

4.6 CROSS-COMPANY PROJECT MANAGEMENT IN THE AUTOMOTIVE INDUSTRY .........61

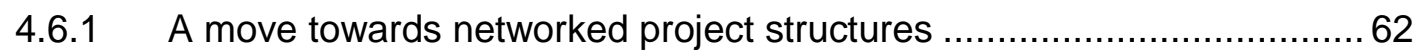

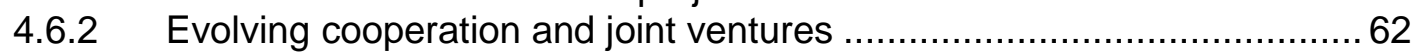

4.6.2.1 Chances and risks in cooperation..............................................63 63

4.6.2.2 Value creation and success factors of existing cooperation .............63 63

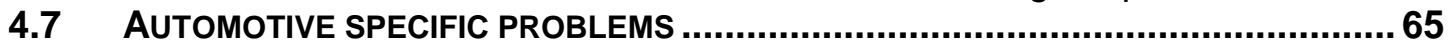

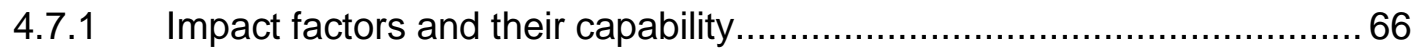

4.7.2 Ways to overcome difficulties in automotive project management .........67

4.8 ACTIVITIES OF AUTOMOTIVE ASSOCIATIONS ...................................................68

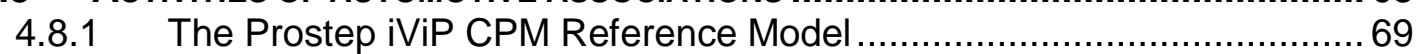

4.8.1.1 Introduction to the CPM Reference Model .....................................69 69

4.8.1.2 Methods, tools and processes for cross-company project

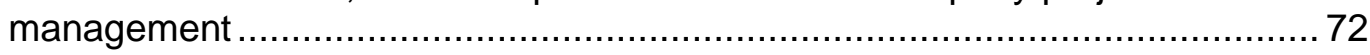

4.8.1.3 Benefits of the CPM Reference Model ....................................... 73

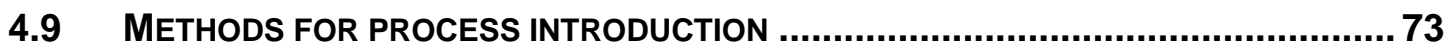

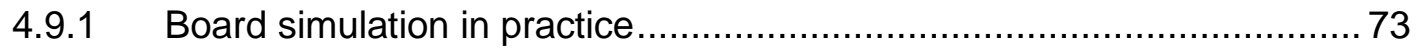

4.9.2 Example: development of the ProSTEP iViP CPM Reference Model..... 74

\section{RESEARCH METHODOLOGY AND PLAN ...................................75}

5.1 SCIENTIFIC APPROACH TO RESEARCH METHODOLOGY....................................75

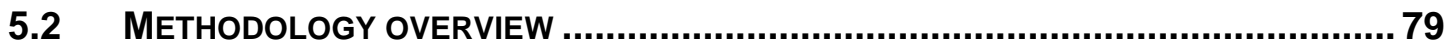

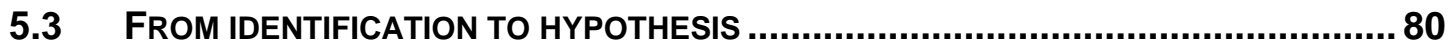

5.3.1 Analysis of a manufacturer and additional interviews .......................... 80

5.3.2 Research questions, objectives and hypothesis................................. 83

5.3.2.1 From research questions to research objectives......................... 84

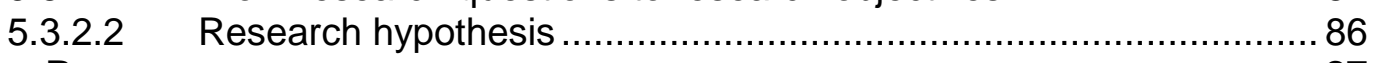

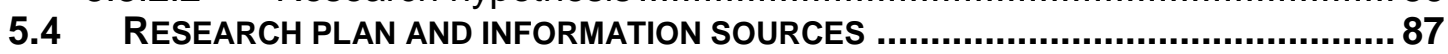

5.4.1 Research activities on an international level .................................... 88

5.4.2 Milestones and information sources................................................ 88 
5.4.3 A variety of core methods as part of the CPS methodology .................. 89

5.4.4 Continuous development, adaptation and improvements......................90

\section{BALANCED SCORECARD AND PROJECT MANAGEMENT ........ 92}

6.1 STRATEGIC APPROACH TO PROJECT MANAGEMENT...........................................93

6.1.1 Managing by objectives and Hoshin Process..................................... 93

6.2 THE BALANCED SCORECARD FOR STRATEGY BASED MANAGEMENT..................94

6.2.1 Recent Balanced Scorecard study results ........................................ 97

6.2.1.1 The Balanced Scorecard and IT support .................................. 99

6.2.2 Strategy Maps .......................................................................... 100

6.3 MANAGING PROJECTS BASED ON THE BALANCED SCORECARD ......................101

6.3.1 Project team performance and strategic project selection.................... 102

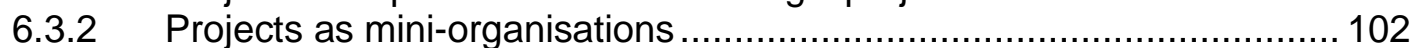

6.4 THE PROJECT SCORECARD ..................................................................... 103

6.4.1 Structure and organisational integration of the Project Scorecard........ 104

6.4.1.1 Structure of a PSC................................................................ 104

6.4.1.2 Organisational integration of a PSC........................................ 105

6.4.1.3 Project Strategy Map and Impact Matrix Analysis ........................ 106

6.4.2 Key performance indicators for project scorecards ............................ 109

6.4.2.1 Examples of KPIs for a Project Scorecard ................................. 109

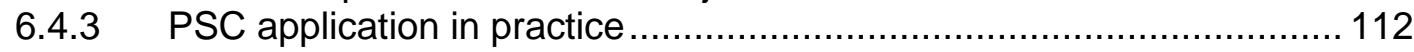

6.4.3.1 Risk management aspects ................................................. 113

6.4.3.2 Balanced and Project Scorecards for supply chain management . 113

6.4.4 The Project Scorecard concept as an adaptive approach .................... 114

6.4.4.1 Adoption of Six Sigma and management frameworks................. 114

6.5 THE BALANCED SCORECARD FOR CROSS-COMPANY PROJECT MANAGEMENT.. 115

6.5.1 A new approach to collaborative and networked project environments 115

6.5.2 Performance measurement as a key condition for effective project

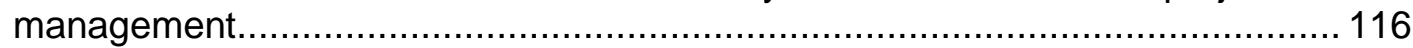

6.5.3 X-engineering requires a holistic view............................................ 116

6.5.4 A need for a Collaborative Project Scorecard ................................... 117

\section{THE CONCEPT OF THE COLLABORATIVE PROJECT}

SCORECARD ................................................................................ 118

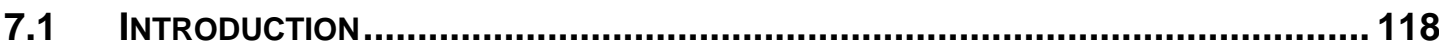

7.1.1 Goals of the Collaborative Project Scorecard ................................... 120

7.1.2 Characteristics of the CPS........................................................... 120

7.2 Structure of the Collaborative Project SCORECARD........................... 121

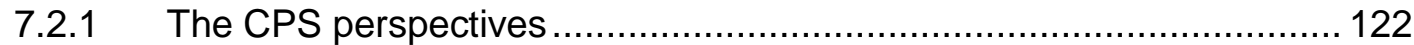

7.2.1.1 Definition of the CPS perspectives ......................................... 123

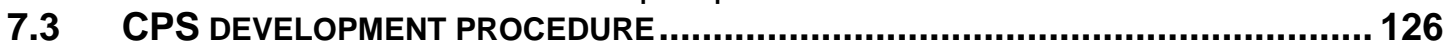

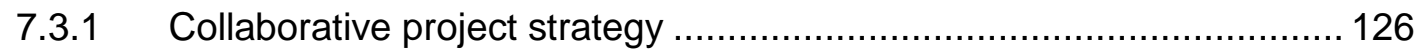

7.3.2 From Common goal definition to corrective action ............................... 128

7.4 INTEGRATION OF THE CPS INTO PROJECT NETWORKS AND ENVIRONMENTS..... 130

7.4.1 Reducing relationships to one-to-one partnerships ..............................130

7.5 ORGANISATIONAL INTEGRATION OF A CPS................................................ 133

7.5.1 Creating a common vision and a strategic framework......................... 133

7.6 THE CPS FOR PROJECT PORTFOLIO AND PARTNERSHIP MANAGEMENT..............135

7.7 THE PROJECT IMPACT MATRIX AND STRATEGY MAP .....................................136

7.7.1 The collaborative project impact matrix analysis ................................ 136

7.7.2 Developing a collaborative project strategy map................................ 138

7.8 INTEGRATING SOFT FACTS FOR SUSTAINABLE COLLABORATION........................139

8 THE CPS FOR AUTOMOTIVE PROJECTS .................................. 142 


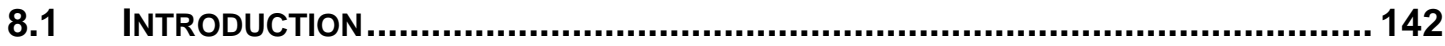

8.2 CONCEPT ADAPTATION TO AUTOMOTIVE ENVIRONMENT ................................. 143

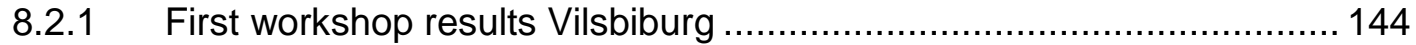

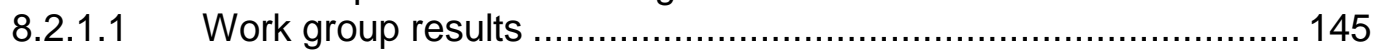

8.2.1.2 Feedback results ............................................................... 146

8.2.2 Second workshop results Erfurt ................................................ 147

8.2.2.1 CPS development and adaptation procedure model.................... 148

8.2.2.2 Introducing a CPS to an organisation ...................................... 150

8.2.3 Automotive industry surveys ....................................................... 151

8.2.3.1 First automotive survey................................................... 151

8.2.3.2 Second automotive survey ................................................ 152

8.2.3.3 Results of the second survey ............................................... 153

9 THE CPS FOR AN AUTOMOTIVE SUPPLIER AND OEM ............158

9.1 PROJECT PARTNER SELECTION CRITERIA (STEP 1 TO 2) ................................. 159

9.2 BRIEFING AND DISCUSSING THE CPS CONCEPT (STEP 3) .............................. 161

9.3 CHOICE OF PROJECT PHASE (STEP 4) ....................................................... 161

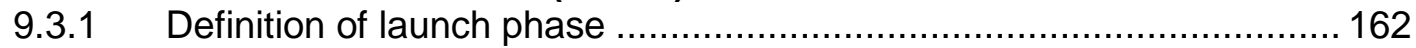

9.3.2 Change management phase ...................................................... 163

9.4 DEFINITION OF OWN PROJECT STRATEGIES AND OBJECTIVES (STEP 5) ............. 165

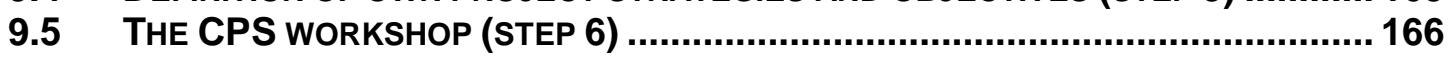

9.5.1 Expectations, goals and agenda of CPS workshop........................... 166

9.6 The Strategic Collaborative Project Scorecard and Collaborative

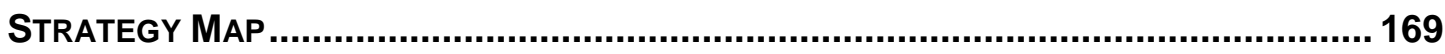

9.7 THE CPS FOR CHANGE AND LAUNCH MANAGEMENT ...................................172

9.8 DISCUSSION OF RESULTS AND WORKSHOP QUESTIONNAIRE (STEP 7) ...............177

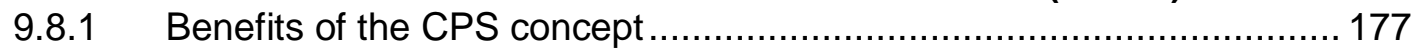

9.8.2 Barriers and efforts of the CPS concept.......................................... 178

9.8.3 Conclusion of research pilot project in the USA .............................. 178

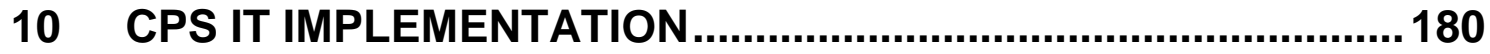

10.1 INTRODUCTION TO IT IMPLEMENTATION ...................................................... 180

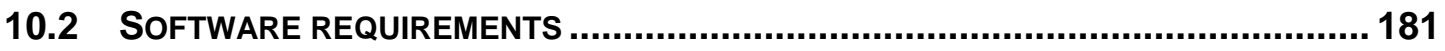

10.2.1 Selection criteria of chosen tool ................................................... 181

10.3 CPS IMPLEMENTATION WITH MS PERFORMANCE POINT $2007 \ldots . . . . . . . . . . . . . . . . . . .184$

10.3.1 Alternative software consideration and limitations.............................. 184

10.3.2 Functionality of MS Performance Point Server 2007 .............................. 185

10.3.3 Meeting the CPS requirements ................................................. 186

10.3.3.1 Identified deficiencies of the system ........................................ 187

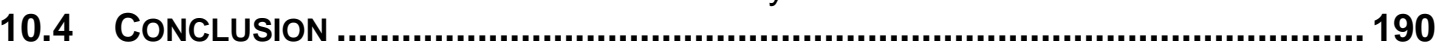

10.4.1 Efforts and benefits of an IT implementation ..................................... 191

11 INTEGRATING A COLLABORATIVE MANAGEMENT MODEL INTO THE CPS ............................................................................. 192

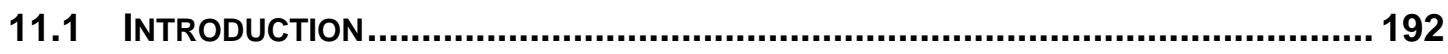

11.2 THE PROSTEP IVIP CPM REFERENCE MODEL AS A SOURCE FOR OPERATIONAL

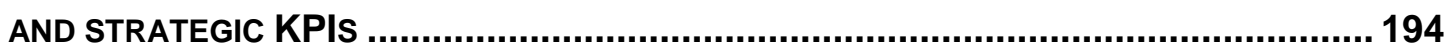

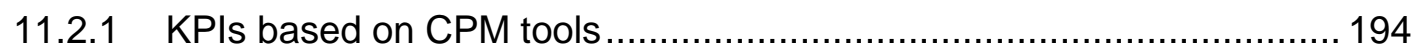

11.2.2 KPIs based on CPM processes ................................................... 196

11.2.3 Combining CPM processes and tools for operational KPIs ................... 196

11.3 COMMENTS ON THE INTEGRATED APPROACH ............................................. 198

\section{ASSESSING PERFORMANCE OF CROSS-COMPANY}

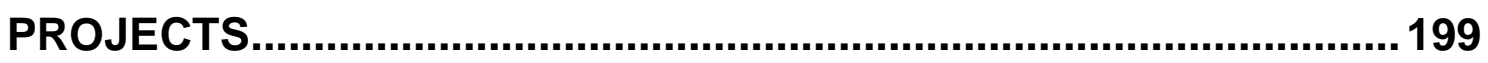


12.1 ASSESSMENT OF COLLABORATIVE PROJECTS BASED ON PROJECT EXCELLENCE

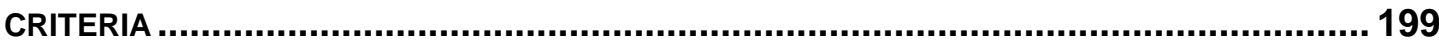

12.1.1 Mapping the assessment criteria and sub criteria with the Project

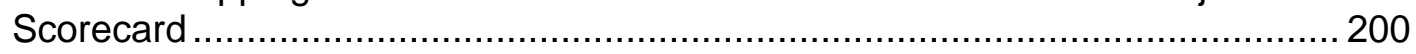

12.1.2 Mapping the Project Excellence Model with the Collaborative Project

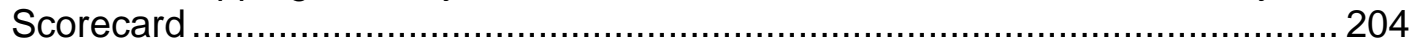

12.2 REMARKS ON CPS PERFORMANCE ASSESSMENT ........................................ 208

13 COLLABORATIVE PROJECT RISK MANAGEMENT WITH A COLLABORATIVE PROJECT SCORECARD...................................210

13.1 INTRODUCTION TO PROJECT RISK MANAGEMENT ............................................ 211

13.2 PROJECT RISK MANAGEMENT IN THE AUTOMOTIVE INDUSTRY ..........................211

13.3 A BALANCED SCORECARD APPROACH TO RISK ........................................ 215

13.4 RISK MANAGEMENT WITH A PROJECT SCORECARD .................................... 215

13.5 COLLABORATIVE PROJECT RISK MANAGEMENT WITH A CPS ..........................216

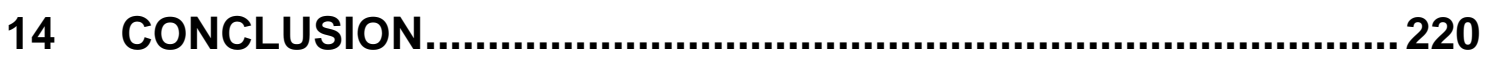

14.1 DifFICULTIES IN AUTOMOTIVE COLLABORATIVE PROJECT MANAGEMENT ...........220

14.2 THE BALANCED SCORECARD APPROACH TO COLLABORATIVE PROJECT

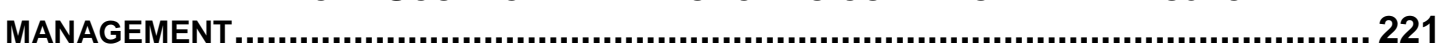

14.3 STEPS TOWARDS AN ACHIEVEMENT OF THE RESEARCH OBJECTIVES ................ 221

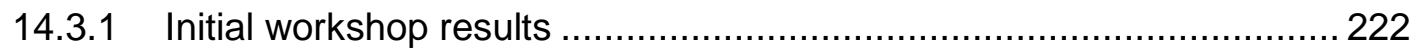

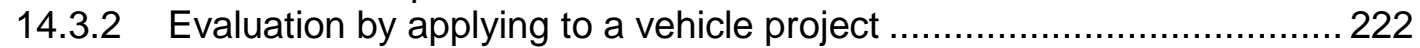

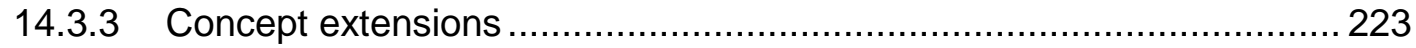

14.4 FINAL REMARKS AND RECOMMENDATION ON FUTURE RESEARCH ...................... 224

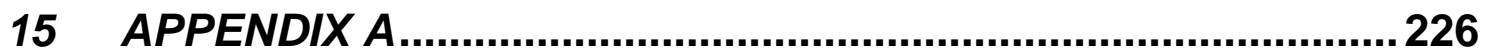

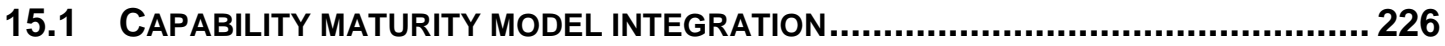

15.2 PROJECTS IN CONTROLLED ENVIRONMENTS (PRINCE2) .................................227

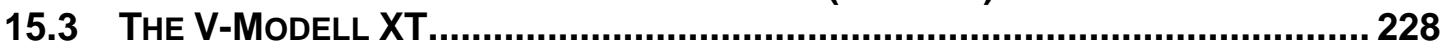

15.4 INTERNATIONAL ORGANISATION FOR STANDARDIZATION (ISO) ...................... 229

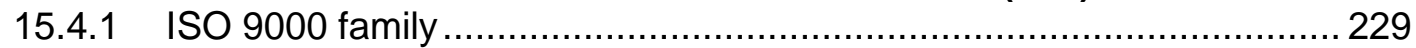

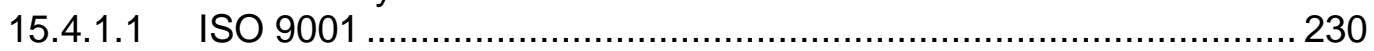

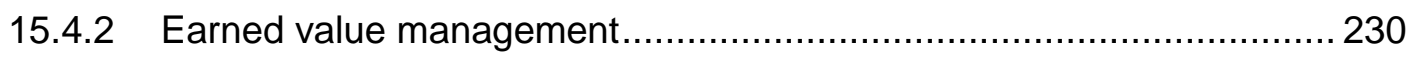

15.5 PROCESS WORKFLOW “EXECUTE ESCALATION”............................................ 231

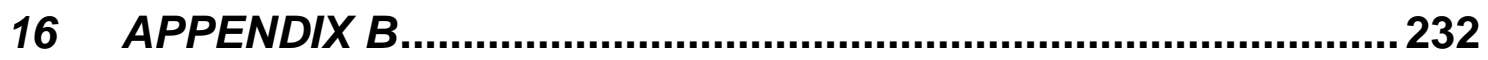

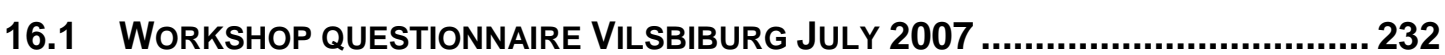

16.2 PROJECT SCORECARD SURVEY QUESTIONNAIRE (GPM) .............................2 238

16.3 Collaborative PROJECt SCORECARD SURVEY QUESTIONNAIRE (ONLINE).... 246

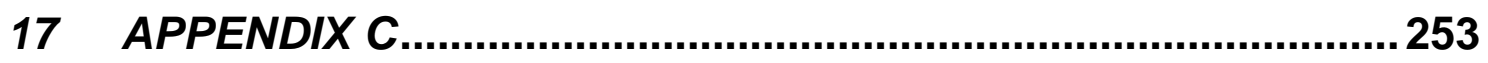

17.1 AGENDA OF THE CPS WORKSHOP 11TH MARCH $2008 \ldots \ldots \ldots \ldots \ldots \ldots \ldots \ldots . . . . . . . . . . . . . . . . . . . .253$

17.2 Original Strategy Map of the Strategic Collaborative Scorecard

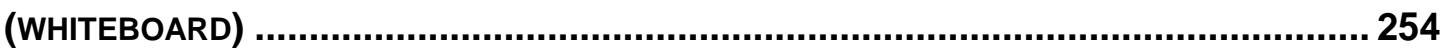

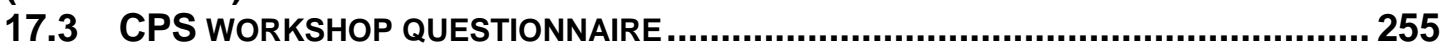

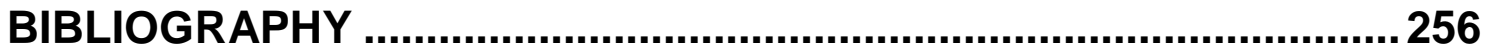




\section{List of Figures}

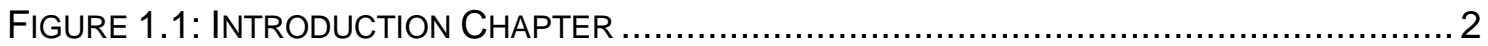

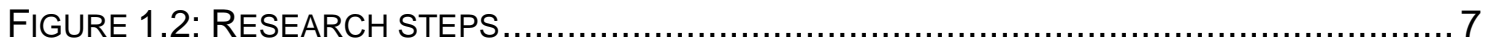

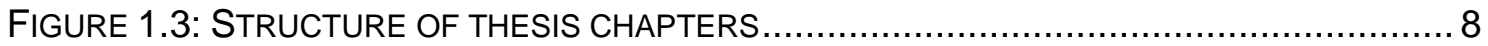

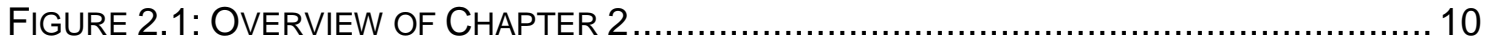

FIGURE 2.2: PURITANISM INFLUENCING TODAY'S PROJECT MANAGEMENT (WHITTY, 2007) 12

FIGURE 2.3: SELECTIVE PERCEPTION OF PROJECTS (RIETIKER, 2006, P. 24) .................... 13

FIGURE 2.4: A PROJECT AS AN OPEN SYSTEM (RIETIKER 2006, P. 25) ............................ 14

FIGURE 2.5: MAPPING OF PROJECT MANAGEMENT PROCESS GROUPS (PMI, 2004, P. 39-40)

FIGURE 2 6: THE WATERFALI MODEL (HASS, 2007, P 1) $\ldots$

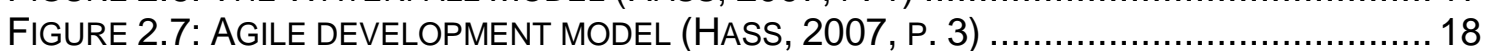

FIGURE 2.8: ARCHITECTURE AND PROCESS MODEL PM 2ND ORDER (SAYNISCH, 2007, P. 7)

.

FIGURE 2.9: SYSTEMIC ARCHITECTURE AND PROCESS MODEL OF PM $2^{\text {ND }}$ ORDER

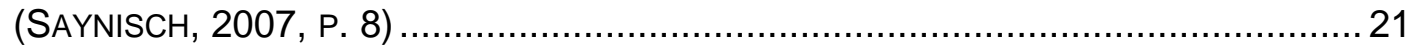

FIGURE 2.10: THE PRINCIPLES OF A STRATEGY FOCUSED ORGANISATION

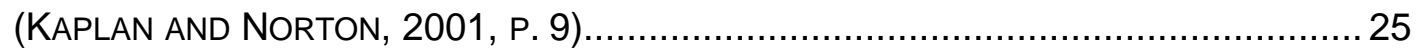

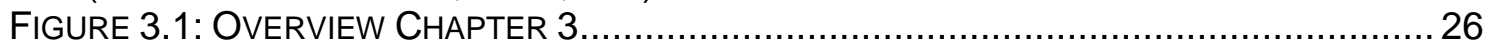

FiguRE 3.2: NUMBER OF PRODUCT RECALLS IN GERMANY (HAB AND WAGNER, 2006, P. 3)

FIGURE 3.3: INTERACTION BETWEEN IMPACT FACTORS ON PROJECT MANAGEMENT

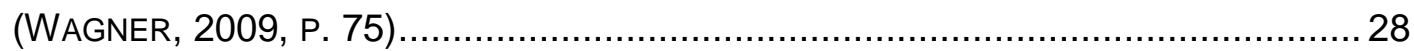

FIGURE 3.4: GPM PROJECT MANAGEMENT SURVEY RESULTS ................................... 29

FIGURE 3.5: GPM SURVEY RESULTS OF GOAL ACHIEVEMENT, BUDGET AND TIME ADHERENCE

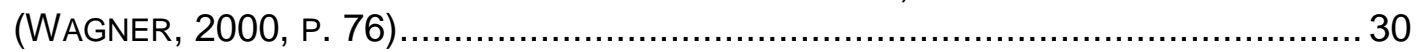

FIGURE 3.6: FROM HIERARCHICAL TOWARDS NETWORKED PROJECT STRUCTURES (HAB AND WAGNER, 2006, P. 256) …........................................................... 31

FIGURE 3.7: MATRIX ORGANISATION OF A VEHICLE MANUFACTURER (HAB AND WAGNER,

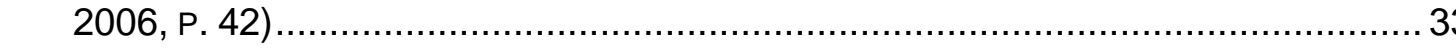

FIGURE 3.8: THE PROJECT MANAGEMENT OFFICE TASKS AT STRATEGIC AND OPERATIONAL

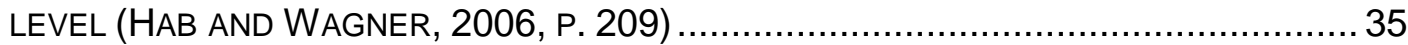

FIGURE 3.9: REASONS FOR PROJECT FAILURES (ENGEL AND HOLM, 2007) ..................... 36

FIGURE 3.10: INTERRELATION OF PRODUCT DEVELOPMENT PHASES (HAB AND WAGNER,

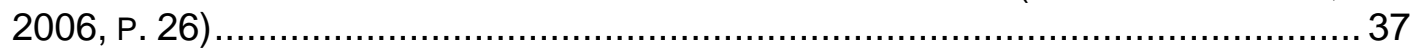

FIGURE 3.11: PROJECT MANAGEMENT CONTROL CYCLE AND PRODUCT DEVELOPMENT

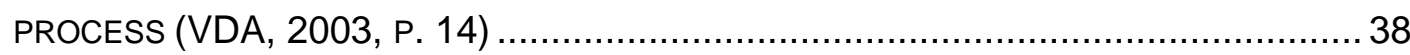

FIGURE 3.12: INTERACTION OF PROJECT MANAGEMENT AND TECHNICAL PRODUCT DEVELOPMENT PROCESSES (HAB AND WAGNER, 2006, P. 27) ............................... 39

FIGURE 3.13: FROM KICK-OFF TO PLANNING WORKSHOP (HAB AND WAGNER, 2006, P. 109)

FIGURE 3.14: POSSIBLE DEFINITION OF TRAFFIC LIGHTS FOR QUALITY GATE CONTROL (HAB AND WAGNER, 2006, P. 146) ............................................................ 42

FIGURE 3.15: STEPS OF THE 8D METHOD (HAB AND WAGNER, 2006, P. 165) ................... 43

FIGURE 3.16: SIMPLIFIED ILLUSTRATION OF A PROJECT COCKPIT .................................. 43

FIGURE 4.1: OVERVIEW OF CHAPTER 4 ……...................................................... 46

FIGURE 4.2: PROJECT CLASSIFICATION SCHEME (EVARISTO ET AL., 1999, P. 277) ........... 48

FIGURE 4.3: HIERARCHY OF COLLABORATION (CHEN ET AL., 2002, P. 8) ..........................51

FIGURE 4.4: COOPERATION MODEL OF DISTRIBUTED PRODUCT DEVELOPMENT (GIERHARDT, 2001, P.56) .............................................................. 55 
FIGURE 4.5: FACTORS THAT INFLUENCE THE SUCCESS OF CROSS-BORDER PROJECTS

(LEUNG ET AL., 2005).

FIGURE 4.6: DEVELOPMENT OF PRODUCTION AND VALUE CREATION CHAIN TOWARDS MORE

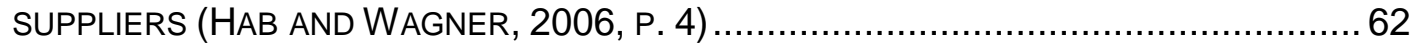

FIGURE 4.7: HIERARCHY AND VALUE CREATION OF EXISTING COOPERATION (MERCER AND TUM, 2005).....

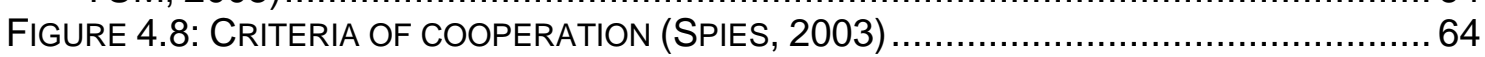

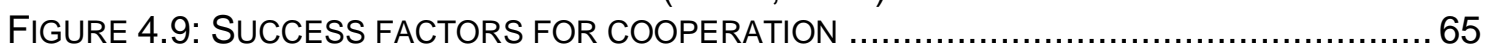

FIGURE 4.10: C3PM MODEL (PANDER AND WAGNER, 2005, P. 25) ...............................6 66

FIGURE 4.11: SATISFACTION OF STUDY PARTICIPANTS WITH RESPECT TO IMPACT FACTORS (WAGNER AND PANDER, 2005, P. 41).

FIGURE 4.12: CAPABILITY OF IMPACT FACTORS TO IMPROVE CROSS-COMPANY COLLABORATION (WAGNER AND PANDER, 2005, P. 43) .........................................67

FIGURE 4.13: CPM REFERENCE MODEL SCOPE (PROSTEP IVIP, 2007A, P.III) .................. 70

FIGURE 4.14: RELATION BETWEEN PRODUCT DEVELOPMENT PROCESS AND PROJECT MANAGEMENT ON A COLLABORATIVE LEVEL (PROSTEP IVIP, 2007A, P. 9) ................. 71

FIGURE 4.15: INTERACTION CHAIN TO INTEGRATE AN ENTERTAINMENT SYSTEM OF A PARTNER (PROSTEP IVIP, 2007A, P. 22) ..................................................... 71

FiguRE 4.16: StRUCTURE OF THE DATA EXCHANGE MODEL (PROSTEP IVIP, 2007B, P.2).. 72

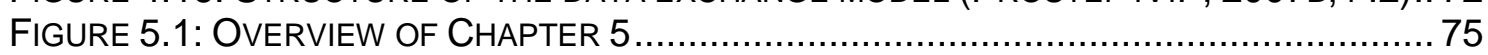

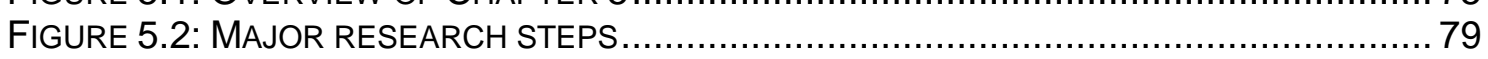

FIGURE 5.3: STEPS TOWARDS RESEARCH QUESTIONS, OBJECTIVES, AND HYPOTHESIS ..... 81

FIGURE 5.4: STEPS TOWARDS RESEARCH QUESTIONS AND OBJECTIVES .......................... 83

FIGURE 5.5: FROM RESEARCH QUESTIONS TO OBJECTIVES ...................................... 84

FIGURE 5.6: PHASES OF RESEARCH OBJECTIVES .................................................... 85

FIGURE 5.7: FROM RESEARCH QUESTIONS TO HYPOTHESIS TESTING ............................ 86

FIGURE 5.8: PROJECT PHASES AND PROJECT MANAGEMENT LIFE CYCLE (ON THE BASIS OF:

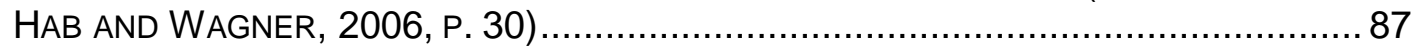

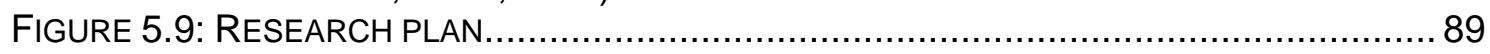

FIGURE 5.10: SET OF DEVELOPED METHODS FOR CPS METHODOLOGY .......................... 90

FIGURE 6.1: OVERVIEW OF CHAPTER 6 .............................................................. 92

FIGURE 6.2: SEVEN STEPS OF THE HOSHIN PLANNING PROCESS (JOLAYEMI, 2008, P. 298)

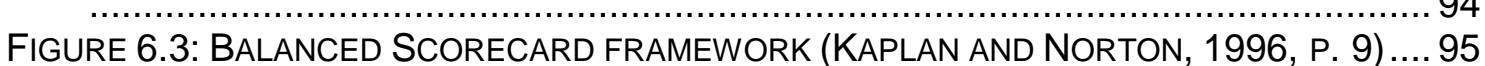

FIGURE 6.4: SIMILAR STRATEGIES AS COMPETITION ............................................... 97

FIGURE 6.5: STRATEGY IMPLEMENTATION CONSIDERED AS STRENGTH OR WEAKNESS ......98

FIGURE 6.6: NUMBER OF BSC A SINGLE ORGANISATION HAS IMPLEMENTED .....................99

FIGURE 6.7: SATISFACTION WITH OFFICE TOOL SET FOR MANAGEMENT TASKS .................100

FIGURE 6.8: SAMPLE STRATEGY MAP .......................................................... 101

FIGURE 6.9: FOUR LEVELS OF A PROJECT SCORECARD (SELDERS AND MAERKLE, 2003, P.3)

FIGURE 6.10: PROJECT SCORECARD FRAMEWORK ................................................ 105

FIGURE 6.11: DERIVATION OF A PSC (NIEBECKER ET AL., 2008A, P. 372) .......................... 106

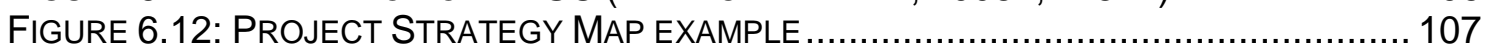

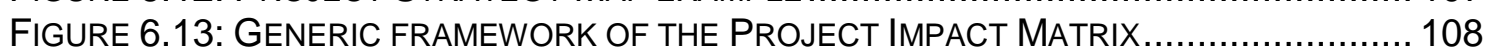

FIGURE 6.14: EXAMPLE OF OBJECTIVES AND KPIS FOR AN AUTOMOTIVE PRODUCT

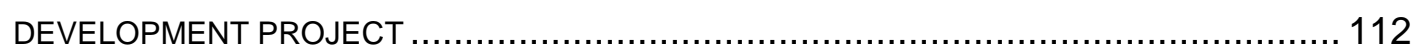

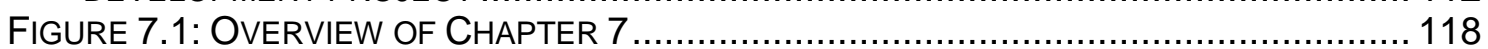

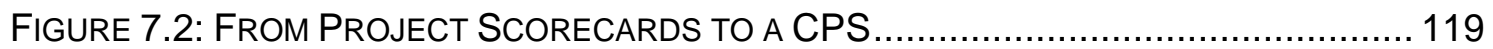

FIGURE 7.3: CHARACTERISTICS OF THE CPS ..................................................... 121

FIGURE 7.4: THE FRAMEWORK OF THE COLLABORATIVE PROJECT SCORECARD ............. 123

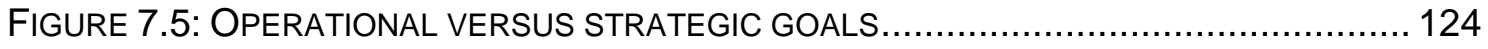

FIGURE 7.6: SHORT VERSUS LONG TERM PROSPECTS........................................... 124

FIGURE 7.7: PROJECT RESULTS VERSUS PROCESSES .......................................... 125 
FIGURE 7.8: PROCEDURE TO DEVELOP A CPS. 126

FIGURE 7.9: RELATION BETWEEN STRATEGY AND PROJECT MANAGEMENT (SCHELLE, 2008, P.135)

FIGURE 7.10: DEFINING COMMON GOALS

FIGURE 7.11: RISK MANAGEMENT AS AN INTEGRATED PART OF THE CPS ...................... 130

FIGURE 7.12: A SINGLE CPS FOR ALL PROJECT PARTNERS .................................... 131

FIGURE 7.13: REDUCTION TO ONE-TO-ONE CPS RELATIONSHIPS ............................ 131

FIGURE 7.14: POSSIBLE NETWORK CONSTELLATIONS FOR THE INSTALLATION OF A CPS . 132

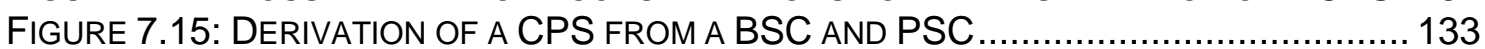

FIGURE 7.16: STRATEGIC COLLABORATIVE SCORECARD (OEM-SUPPLIER) ...................... 134

FIGURE 7.17: STRATEGIC SCORECARD AND CPS APPLICATION ..................................... 135

FIGURE 7.18: THE STRATEGIC PARTNERSHIP SCORECARD ..................................... 136

FiguRE 7.19: FRAMEWORK OF THE COLLABORATIVE PROJECT IMPACT MATRIX (CPIM).. 137

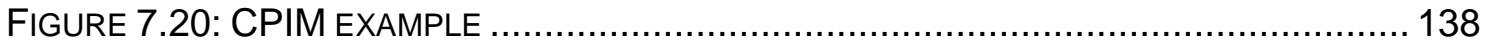

FIGURE 7.21: EXAMPLE OF A COLLABORATIVE PROJECT STRATEGY MAP (CPSM) ...........139

FIGURE 7.22: TEMPLATE TO MEASURE PROJECT TEAM TRUST ................................... 140

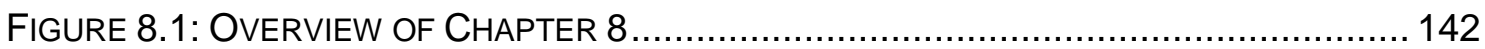

FIGURE 8.2: DEVELOPMENT STEPS TOWARDS AN AUTOMOTIVE CPS ........................... 143

FIGURE 8.3: WORKSHOP QUESTIONNAIRE RESULTS VILSBIBURG JULY $2007 \ldots \ldots \ldots \ldots \ldots . . . . . .147$

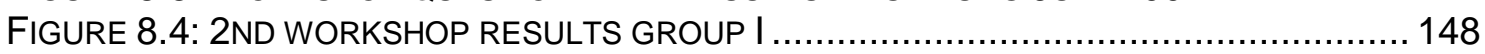

FIGURE 8.5: PROCEDURE MODEL TO ADAPT AND CHANGE A CPS ............................. 149

FIGURE 8.6: SATISFACTION OF EXISTING PROJECT MANAGEMENT TOOLS FOR INFORMATION

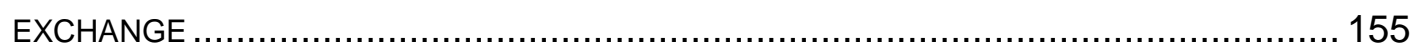

FIGURE 8.7: BENEFITS OF A CPS COMPARED TO ITS EFFORTS................................. 156

FIGURE 8.8: IMPACT OF CPS ON PROJECT TRANSPARENCY ...................................... 156

FIGURE 8.9: IMPROVEMENT OF ALIGNMENT OF PROJECT WITH BUSINESS OBJECTIVES ..... 157

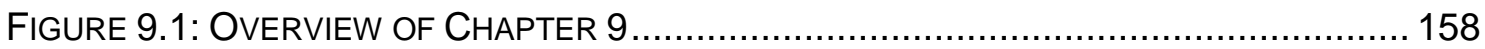

FIGURE 9.2: EIGHT STEP APPROACH OF THE RESEARCH PILOT PROJECT IN THE USA ...... 159

FIGURE 9.3: CRITERIA FOR A PROJECT PARTNER TO DEVELOP A CPS IN A PILOT PROJECT

FIGURE 9.4: APPLICATION OF A CPS TO EACH PROJECT PHASE

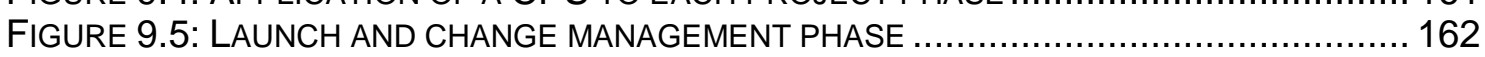

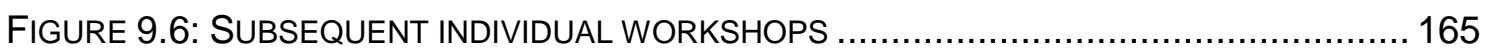

FIGURE 9.7: SWOT ANALYSIS RESULTS OF THE INDIVIDUAL WORKSHOPS ......................... 166

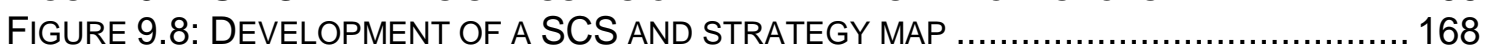

FIGURE 9.9: PROCEDURE OF THE CPS WORKSHOP ............................................... 169

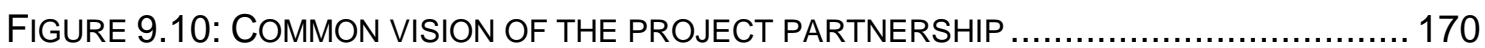

FIGURE 9.11: THE STRATEGIC COLLABORATIVE SCORECARD .................................... 170

FIGURE 9.12: STRATEGY MAP OF THE STRATEGIC COLLABORATIVE SCORECARD ............171

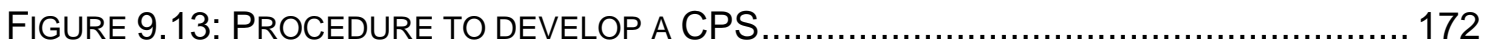

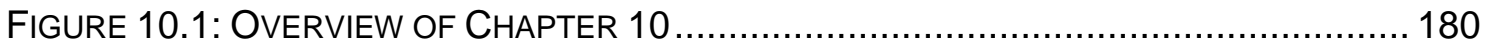

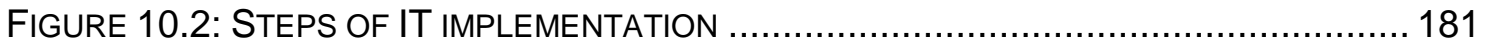

FIGURE10.3: WORKFLOW CAPACITY REQUIREMENTS .......................................... 182

FIGURE 10.4: SHARED DATA BETWEEN OEM AND SUPPLIER TO CREATE KPIS ................. 183

FIGURE 10.5: ARCHITECTURE OF LAB ENVIRONMENT FOR CPS IMPLEMENTATION ............ 184

FIGURE 10.6: SYSTEM COMPONENTS OF THE MS PERFORMANCE POINT SERVER 2007

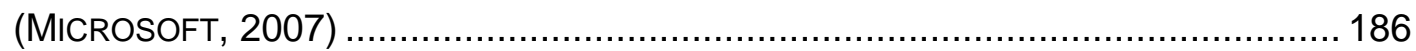

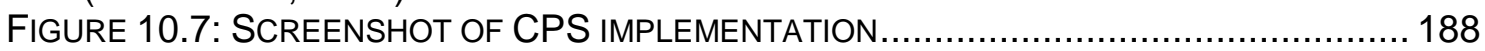

FIGURE 10.8: GRAPHICAL PLOT OF PPM VALUES IN TIME ..................................... 189

FIGURE 10.9: ADVANTAGES AND DISADVANTAGES OF SELECTED TOOL FOR CPS CONCEPT

FIGURE 10.10: CHRONOLOGICAL EVALUATION OF EFFORTS AND BENEFITS OF AN IT

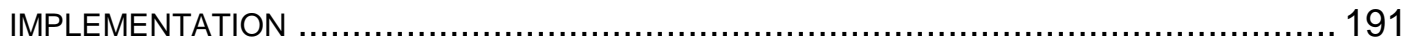

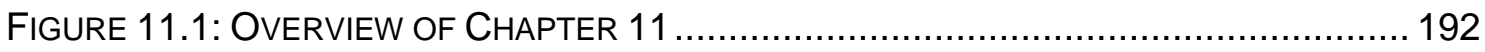


FIGURE 11.2: INTERACTION OF CPS AND PROSTEP IVIP REFERENCE MODEL ON STRATEGIC AND OPERATIONAL LEVEL (NIEBECKER ET AL., 2008C, P. 10) ................. 194

FIGURE 11.3: KPIS BASED ON CPM TOOLS FOR PROJECT RESULT PERSPECTIVE............. 195

FIGURE 11.4: CREATION OF KPIS FOR THE PROCESS PERSPECTIVE BASED ON CPM PROCESSES .

FIGURE 11.5: CPM COMMUNICATION MATRIX (BASED ON PROSTEP IVIP, 2007A, P. 55) 197

FIGURE 11.6: PART OF CPM ISSUE LIST TEMPLATE (PROSTEP IVIP 2007A, P.53) .......... 197

FIGURE 11.7: EXAMPLES OF KPIS BASED ON CPM FOR COLLABORATION AND LEARNING \&

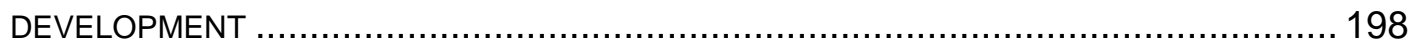

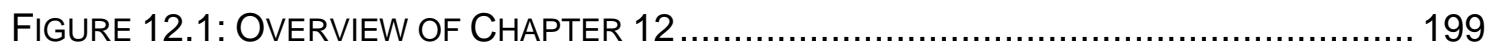

FIGURE 12.2: FRAMEWORK OF THE PROJECT EXCELLENCE MODEL (IPMA, 2008) ..........200

FIGURE 12.3: MAPPING OF THE PROJECT SCORECARD PERSPECTIVES WITH THE PROJECT EXCELLENCE MODEL .......................................................................... 201

FIGURE 12.4: INTEGRATION OF PROJECT EXCELLENCE ASSESSMENT INTO A PROJECT SCORECARD (NIEBECKER ET AL., 2008B, P. 4) ................................................ 203

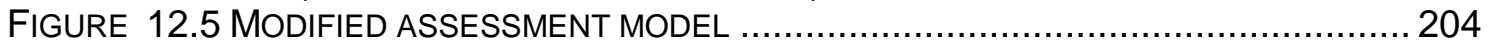

FIGURE 12.6: MODIFIED MAPPING OF CRITERIA WITH A CPS (NIEBECKER ET AL., 2008B, P.

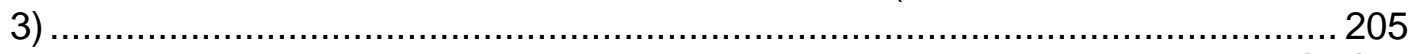

FIGURE 12.7: INTEGRATING COLLABORATIVE PROJECT ASSESSMENT RESULTS INTO A CPS (NIEBECKER ET AL., 2008B, P. 5) ................................................................. 206

FIGURE 13.1: OVERVIEW OF CHAPTER 13 ........................................................ 210

FIGURE 13.2: RISK MANAGEMENT PROCESS IN THE AUTOMOTIVE INDUSTRY (SCHUH, 2000, P. 181) 213

FIGURE 13.3: DEVELOPMENT PROCESS FMEA AS AN EXTENSION TO TRADITIONAL PROCESS FMEA. 213

FIGURE 13.4: RISK MANAGEMENT WITH A COLLABORATIVE PROJECT SCORECARD ..........2 217

FIGURE 13.5: RISK OCCURRENCE AND CPS RISK MANAGEMENT PROCEDURE..................2 218

FIGURE 13.6: CPS RISK MANAGEMENT CATEGORY EXTENSION ...............................218

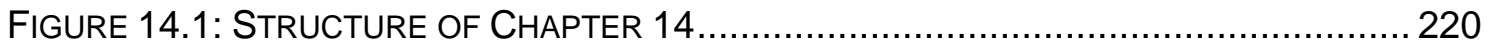

FIGURE 15.1: CMMI PROCESS AREAS AND MATURITY LEVELS ….............................226

FIGURE 15.2: PROCESS WORKFLOW "EXECUTE ESCALATION" (PROSTEP IVIP 2007A, P. 51)

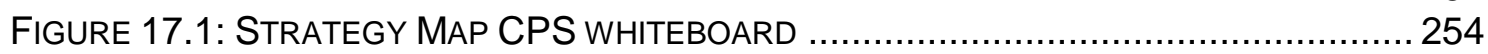




\section{List of Tables}

TABLE 2.1: THE FOUR WORLDS OF PM 2ND ORDER (SAYNISCH, 2007) ..........................20

TABLE 4.1: COLLABORATION FRAMEWORK (NUNAMAKER ET AL., 2000) ............................50

TABLE 4.2: ORGANISATIONAL STRUCTURE OF PRODUCT DEVELOPMENT

(PRASAD, 1996, P. 397).

TABLE 4.3: STRATEGIC ISSUES IN DISTRIBUTED DEVELOPMENT (NIDIFFER ET AL., 2005,

P. 69)

TABLE 4.4: ISSUES IN DISTRIBUTED DEVELOPMENT (NIDIFFER ET AL., 2005, P. 69) ............59

TABLE 4.5: TECHNICAL AND SECURITY ISSUES IN DISTRIBUTED DEVELOPMENT

(NIDIFFER ET AL., 2005, P. 69) .... 60

TABLE 5.1: RESEARCH PARADIGMS (GUBA AND LINCOLN, 1994) AND (MCPHAIL AND PERRY,

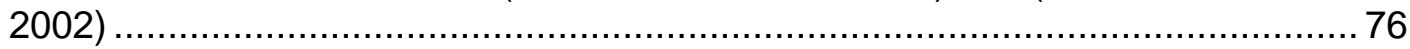

TABLE 5.2: SELECTION OF AN APPROPRIATE RESEARCH METHODOLOGY (YIN, 2002) ........ 78

TABLE 6.1: KEY PERFORMANCE INDICATORS OF A BSC COMPARED TO A PROJECT SCORECARD …................................................................................... 110

TABLE 6.2: KPIS FOR A PROJECT SCORECARD WITH RESPECT TO TYPE, CALCULATION METHOD, AND ESTIMATION EFFORT............................................................. 110

TABLE 6.3: OTHER KPIS FOR A PROJECT SCORECARD WITH RESPECT TO TYPE, CALCULATION METHOD, AND ESTIMATION EFFORT........................................... 111

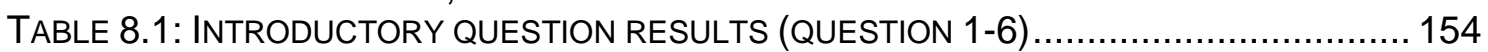

TABLE 9.1: PROJECT RESULTS LAUNCH MANAGEMENT CPS ..................................... 173

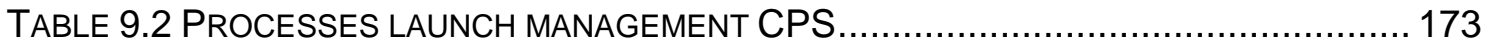

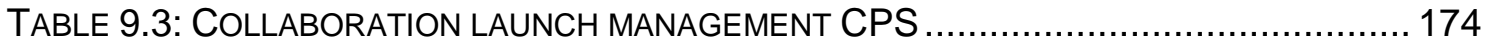

TABLE 9.4: LEARNING AND DEVELOPMENT LAUNCH MANAGEMENT CPS ....................... 174

TABLE 9.5: PROJECT RESULTS CHANGE MANAGEMENT CPS …............................... 175

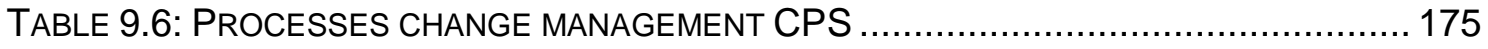

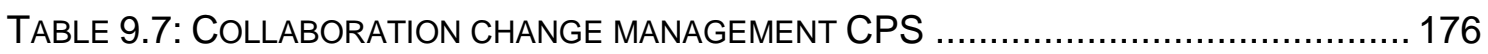

TABLE 9.8: LEARNING AND DEVELOPMENT CHANGE MANAGEMENT CPS ......................176

TABLE 12.1: MAPPING OF PSC OBJECTIVES WITH PROJECT EXCELLENCE CRITERIA ........202

TABLE 12.2: MAPPING OF CPS OBJECTIVES WITH PROJECT EXCELLENCE CRITERIA ........207

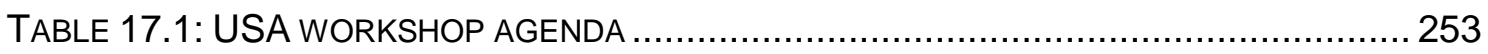




\section{Nomenclature}

\begin{tabular}{|c|c|}
\hline AIAG & Automotive Industry Action Group \\
\hline AIPM & Australian Institute of Project Management \\
\hline APA & American Planning Association \\
\hline APM & Agile Project Management \\
\hline APQP & Advanced Product Quality Planning \\
\hline ARC & Appraisal Requirements for CMMI \\
\hline AS & Active Sum \\
\hline ASAM & Association for Standardization of Automation and Measuring Systems \\
\hline BMW & Bayerische Motorenwerke \\
\hline BSC & Balanced Scorecard \\
\hline C3PM & Cross-Company-Collaboration Project Management \\
\hline CCPM & Critical Chain Project Management \\
\hline CCTA & Central Computer and Telecommunications Agency \\
\hline CMMI & Capability Maturity Model Integration \\
\hline CPIM & Collaborative Project Impact Matrix \\
\hline CPM & Critical Path Method \& Collaborative Project Management \\
\hline CPS & Collaborative Project Scorecard \\
\hline CPSM & Collaborative Project Strategy Map \\
\hline DFA & Design for Assembly \\
\hline DFM & Design for Manufacturing \\
\hline DIN & Deutsches Institut fuer Normung \\
\hline DMU & Digital Mock Up \\
\hline EDM & Engineering Data Management \\
\hline EFQM & European Foundation for Quality Management \\
\hline GM & General Motors \\
\hline GPM & German Project Management Association \\
\hline $\mathrm{IAO}$ & (Fraunhofer) \\
\hline IPMA & International Project Management Association \\
\hline IRNOP & The International Research Network on Organizing by Projects \\
\hline ISO & International Organisation for Standardization \\
\hline IT & Information Technology \\
\hline JIS & Just in Sequence \\
\hline JIT & Just in Time \\
\hline
\end{tabular}




\begin{tabular}{|c|c|}
\hline KGI & Key Goal Indicator \\
\hline $\mathrm{KI}$ & Key Indicator \\
\hline KPI & Key Performance Indicator \\
\hline LOB & Line of Balance \\
\hline $\mathrm{MbO}$ & Managing by Objectives \\
\hline $\mathrm{MbP}$ & Managing by Policy \\
\hline MOST & Mission, Objectives, Strategies, and Tactics \\
\hline NGO & Non-governmental Organisation \\
\hline OEM & Original Equipment Manufacturer \\
\hline OGC & Office of Government Commerce \\
\hline OSM & Office of Strategy Management \\
\hline PA & Process Area \\
\hline PDM & Product Data Management \& Precedence Diagram Method \\
\hline PDP & Product Development Process \\
\hline PE & Project Excellence \\
\hline PERT & Program Evaluation and Review Technique \\
\hline PMBoK & Project Management Book of Knowledge \\
\hline PMI & Project Management Institute \\
\hline PMO & Project Management Office \\
\hline PS & Passive Sum \\
\hline PSC & Project Scorecard \\
\hline QDX & Quality Data Exchange \\
\hline QFD & Quality Function Deployment \\
\hline ROCE & Return on Capital Employed \\
\hline $\mathrm{ROI}$ & Return on Investment \\
\hline SCS & Strategic Collaboration Scorecard \\
\hline SE & Simultaneous Engineering \\
\hline SIG & Special Interest Group \\
\hline SPICE & Software Process Improvement and Capability Determination \\
\hline SPSC & Strategic Partnership Scorecard \\
\hline SPSM & Strategic Project Strategy Map \\
\hline SWOT & Strengths, Weaknesses, Opportunities, and Threats \\
\hline TQM & Total Quality Management \\
\hline VDA & Verband der Automobilindustrie \\
\hline WBS & Work Breakdown Structure \\
\hline
\end{tabular}




\section{Publications}

\section{Conference proceedings:}

Niebecker, K., Eager, D. and Kubitza, K. (2007), "A strategy based scorecard for crosscompany project management in the automotive industry, Proceedings of the ICAN Conference, $29^{\text {th }}-30^{\text {th }}$ November 2007, Sydney, Australia.

Niebecker, K., Eager, D., Kubitza, K. and Plischke, D. (2008), "Integrating a collaborative management model into a project scorecard for efficient cross-company project management, Proceedings of the AIPM Conference, $12^{\text {th }}-15^{\text {th }}$ October 2008, Australian Institute of Project Management, Canberra, Australia.

Niebecker, K. and Wagner, R. (2008), "Effizientes Steuern in unternehmensübergreifenden Projektstrukturen mit der Collaborative Project Scorecard“, Proceedings of the International German Project Management Forum, PMForum, $22^{\text {nd }}$ $23^{\text {rd }}$ October 2008, Wiesbaden, Germany.

Niebecker, K. and Plischke, D. (2008), "Collaborative Project Management (CPM) in der Automobilindustrie“, Proceedings of the International German Project Management Forum, PMForum, $22^{\text {nd }}-23^{\text {rd }}$ October 2008, Wiesbaden, Germany.

Niebecker K., Eager, D., Wagner, R. and Kubitza, K. (2008), "Efficient project management and performance assessment of cross-company projects with a collaborative project scorecard, Proceedings of the IPMA World Congress, $9^{\text {th }}-12^{\text {th }}$ November 2008, International Project Management Association, Rome, Italy.

\section{Journals:}

Niebecker, K., Eager, D. and Kubitza, K. (2008), "Improving cross-company project management performance with a collaborative project scorecard", International Journal of Managing Projects in Business, Emerald Group Publishing Limited, vol. 1, no. 3, p. 368-386. 


\section{Magazines:}

Wagner, R. and Niebecker, K. (2008), "Die Collaborative Project Scorecard (CPS) als zentrales Tool zur Steuerung unternehmensübergreifender Projekte“, projektMANAGEMENT aktuell, $2^{\text {nd }}$ edition, Nuernberg, Germany.

Niebecker, K, Wagner, R. and Plischke, D. (2008), "Unternehmensuebergreifende Zusammenarbeit verbessern - die Collaborative Project Scorecard (CPS)“, ProjektMagazin, edition 18/2008, Germany. 


\section{Introduction}

The number of project oriented organisations has globally increased and the impact of successful projects on the profit-loss status has been widely recognised. The heightened pressure to ensure the reduction of costs and shorter product development life cycles has lead to a complex network of virtual teams that work together around the globe (Rad and Levin, 2003).

Many industry sectors have gone through a structural change towards complex project networks where project teams are geographically dispersed and several industry partners are involved in the development, production or sales of new products. Due to a steadily growing competition in the market, the number and percentage of automotive suppliers contributing to the value creation chain has highly increased and will still continue to rise. Therefore, cross-company projects and virtual teams have become essential to the future success of a car manufacturer (Hab and Wagner, 2006). Organisations and associations within the industry have already begun to develop standardised methods and processes to improve the efficiency and effectiveness of cross-company project management. However, many problems are still not solved and new methods are required to address the industry's challenges, difficulties, and opportunities of today and tomorrow.

The development and validation of a strategy based method to plan, monitor, and control collaborative and cross-company projects in the automotive industry was part of a research project at the Faculty of Engineering and IT of the University of Technology, Sydney. The research activities were primarily conducted at the BMW Group facilities in Germany and the USA but also in collaboration with the Automotive Chapter of the German Project Management Association (GPM e.V.) and the ProSTEP iViP Association in Darmstadt. The method adopted was the Collaborative Project Scorecard (CPS), a concept that includes procedures and tools that aim to improve the planning, monitoring and control of cross-company and collaborative projects based on identified problems within the industry.

This chapter includes a short introduction to the research background and significance with a focus on the automotive industry sector. The proposed method of a Balanced Scorecard applied to project management is briefly described and followed by the 
research objectives and relevant steps to achieve them. This is further discussed in Chapter 5 in more detail. The last section of this chapter contains a description of the thesis structure and illustrates where the reader can find the major elements of the research project. Figure 1.1 illustrates the contents of this chapter.

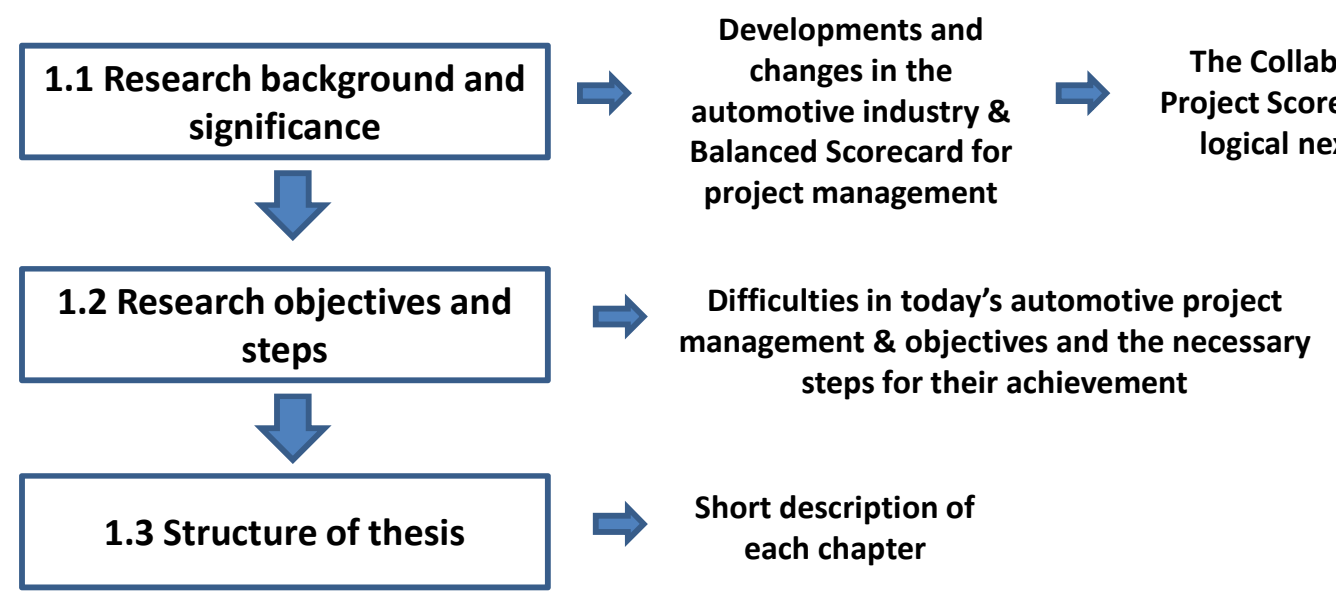

FIGURE 1.1: INTRODUCTION CHAPTER

\subsection{Research background and significance}

Different time zones and cultural aspects are some of the reasons that limit communication between project teams and make it difficult to maintain control on the quality and scope of the projects. The use of virtual teams has become reality mainly due to an improved communication technology as teams are no longer limited by physical boundaries. Business opportunities to support strategic goals are not bound to a geographic location anymore and resources can be chosen from a large pool with immediate access. Virtual teams have a number of different names, such as modules, clusters, learning networks, boundariless organisations, cross-company or collaborative project teams, and are often classified into domestic, overseas, foreign or global project environments (Gray and Larson, 2006). Project based activities are the fundament of the virtual organisation as it means working in a limited time frame with geographically dispersed teams. Complex products are often a result of a collective effort and centrally managed by the product integrator who controls product contributors and suppliers (Bourgault et al., 2002). However, next to product integrators or network managers who control a distributed team there are also coequal partnerships such as joint venture projects. Responsibilities are then distributed among various stakeholders and project members. 
The effects of a globalising world also change the practice of engineering, which is partially due to the development of new communication technology. High competition on the international market has forced many companies to distribute their teams around the globe, and considerable advances in information technology have lead to a dispersed product development, production, or sales. In addition, management functions are no longer bound to a single location. Product design, as an example, will increasingly use web-based systems with open standards that improve communication and engineering prediction in early stages of the project. With this technology the time required for a detailed product design can be decreased by a third (Dryer et al., 2003).

Especially, organisations with a focus on product development aim to reduce costs by dislocating project teams to other countries and to gain and use region specific knowhow. The rise in geographically distributed projects is a trend that can be found in different industry sectors. For example, the IT, construction, and automotive sectors have experienced a dramatic change in their project structures in recent years but also the financial sector has realised that it is necessary to focus on worldwide collaboration as it is a key driver to sustainable project success (Deutsche Bank Research, 2005). The IT industry began early with the use of virtual project teams but a lack of standardised methods and processes to manage those teams has caused a high number of project failures (Prikladnicki et al., 2002).

\subsubsection{Changes and developments in the automotive industry}

Unlike many other industry sectors, the automotive industry has begun with the development of cross-company standards several years ago. This was caused by the allocation of components, modules, and even whole vehicle models to external project partners due to an increased international competition. Cost and time reduction, as well as the relocation of know-how lead to a role change of the Original Equipment Manufacturer (OEM) to a network manager (Hab and Wagner, 2006). The fundamental change from top down processes to a network organisation and the distribution of competencies required new methods and processes, which had to be developed collaboratively. Whereas some of the difficulties could have been solved, such as standards for quality data exchange (VDA QDX) others still require more focus and industry commitment. A study of the Automotive Chapter of the German Project Management Association identified areas that require improvement for successful crosscompany project management. Next to general frameworks for cultural differences, 
individual capabilities and the clarification of project goals are some of the areas that have an impact on project performance and are still not sufficiently addressed by the automotive industry (Wagner and Hab, 2006). Ambiguously defined goals, low transparency of project structures, inadequate allocation of responsibilities, and insufficient integration of project stakeholders followed by a missing alignment of project goals with business strategies are often caused by differing interests of the participating companies (Pander and Wagner, 2005). These problem areas need more industry attention and fundamental research to overcome present and future constraints of cross-company project management. A detailed analysis of cross-company project management difficulties with a focus on the automotive industry can be found in Chapter 4.

\subsubsection{The Balanced Scorecard approach to project management}

The Balanced Scorecard is a management system that incorporates a balanced set of financial and non-financial measures and translates "a business unit's mission and strategy into tangible objectives and measures" (Kaplan and Norton, 1996, p. 10). Therefore, it is a strategic management system that manages strategy over the long run. A project oriented organisation implements its strategies with initiatives and projects and often categorises its units in program, project portfolio, and project management divisions. Whereas project portfolio management is on a strategic level, program and project management is on an operative one. Although, the Balanced Scorecard has been demonstrated to be an efficient concept to manage a business (Kaplan and Norton, 2001), its application to project management by translating a project strategy into project objectives and measures has been investigated by only few researchers. However, it could be demonstrated that the performance of project teams can be improved by an application of a Balanced Scorecard to project management (Norrie and Walker, 2004). Furthermore, the project oriented Balanced Scorecard refocuses the way projects are managed as project and internal business processes are aligned with the "core values and practices of the organisation" (Stewart, 2001, p. 47). Additionally, project managers begin to understand the impact of a project's success on their organisation and realise the interdependency to success between the project, project portfolio, and organisation. Chapter 5 further describes the current research progress on the application of a Balanced Scorecard to project management which is often called the Project Scorecard (PSC). 
Due to the increasing number of distributed project teams, the application of the Balanced Scorecard to cross-company and collaborative projects is a consequent step towards the future demands of project management. The definition of commonly agreed project goals and measures that are aligned with each company's project strategy is relevant to the future success of both project partners. Research is necessary to investigate the advantages, disadvantages, and limitations of this approach, and to develop a set of methods that helps the companies to implement and operate the concept that is, henceforward, called the Collaborative Project Scorecard (CPS). In 2002, some researchers believed it was "clearly too early in the investigation process to claim that a comprehensive list of metrics has been, or can be, established" for an application of the Balanced Scorecard to distributed project management (Bourgault et al., 2002, p.4), however, since then Norrie and Walker (2004) have contributed to a significant development of the concept that provides a fundament to proceed with a cross-company application. Performance measurement of virtual teams is essential to evaluate the status and progress of a distributed project. A strategic alignment enables the commitment of a target system for a networked project environment. The application of a CPS is a logical consequence that has not been discussed in current literature yet (Horvath, 2003). Therefore, the development of the CPS is the main element of this research project. Chapter 4 includes a detailed analysis of existing research related to the Collaborative Project Scorecard.

The objectives of the CPS research project were derived from the identified industry demand to develop a new concept that incorporates the definition of common project goals, ensures the alignment of these goals with business strategies, integrates stakeholders, and enables efficient monitoring and control of cross-company projects. The results of a BMW internal analysis, interviews, and an automotive study conducted by the Automotive Chapter of the GPM e.V. were the foundation of the research questions and objectives. Subsequent workshops, surveys, and interviews supported the development of the CPS methodology.

\subsection{Research objectives and steps}

A literature review of cross-company project management and an analysis of interviews within the automotive industry identified major difficulties and weaknesses in project management methods, practices and procedures. Some of them are deficiencies in defining and clarifying project goals, low project transparency and flexibility in project 
organisation, and a different understanding of applied technologies that impedes collaboration in the vehicle development. Whereas some of these results are based on an automotive study conducted by the GPM e.V., the following aspects are a short summary of the deficiencies according to an internal study and additional interviews at a major German OEM as part of this research project:

- Deficiencies in defining and clarifying project goals.

- Low transparency and flexibility in project organisation.

- Status of project maturity not clearly defined and evaluation difficult.

- Project management methods and processes are not entirely integrated.

- Project goals not clearly defined and aligned with business strategies.

- Stakeholders not sufficiently integrated.

- Undefined documentation processes.

- Low project transparency and cause-and-effect relationships not clear and not transparent.

- Risk management methods of collaborative product development projects are not sufficiently developed.

- Corrective action often not pre-defined.

- Methods and processes for monitoring and control of time, task, risks, resources, scope, and communication management not sufficiently integrated.

The goal of this research project was to develop a methodology that addresses the identified problems and creates opportunities to improve the management of crosscompany projects with a focus on planning, monitoring and control. This lead to the definition of the following research objectives:

- Detailed identification of difficulties with a focus on the project phases of planning, monitoring and control of cross-company projects in the automotive industry.

- Development of a methodology that addresses the problems of:

- Low transparency and flexibility in project organisation.

- Defining and clarifying project goals.

- Alignment of project goals with business strategies.

- Stakeholder integration. 
- Integrated monitoring and control of relevant project management areas, such as time, task, risk, resources, scope, corrective action and target management.

- Identification and evaluation of project status.

- $\quad$ Agreed corrective action and control measures.

After analysing the strengths and weaknesses of the Balanced Scorecard application to project oriented organisations, the adaptation of the concept to a collaborative and networked project environment was a logical step for a performance improvement of cross-company and collaborative project management. The Project Scorecard (PSC) has been demonstrated to improve performance of project teams and to align project objectives with business strategies. Therefore, the development and implementation of a Collaborative Project Scorecard (CPS) as a further step to improve cross-company project management is the core of the research hypothesis. After the methodology was developed it was then applied to an automotive project and adapted to the requirements of an automotive manufacturer followed by a partial implementation of the CPS methodology with an IT solution. The results of the project application and IT implementation were analysed and the concept extended with other management and assessment models. Figure 1.2 illustrates the research steps that are further described in Chapter 5.

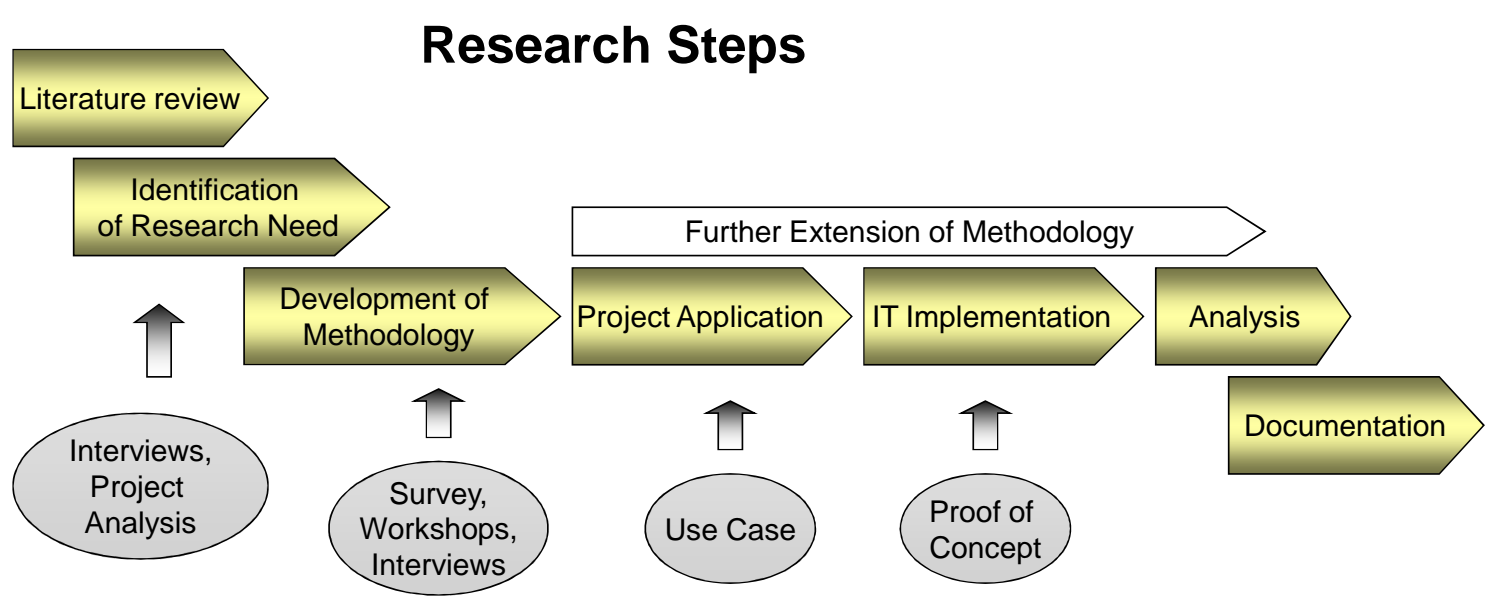

FIGURE 1.2: RESEARCH STEPS

The main contributions of the research project are, next to the application of the impact matrix to project and cross-company project management, the CPS methodology and its further extension with the ProSTEP iViP CPM Reference Model, the GPM/IPMA Project Excellence Model, and an integrated approach to collaborative risk management. 


\subsection{Structure of thesis}

The thesis is structured into four major parts. The first part is the introduction to the research topic (Chapter 1), to the theoretical background of project management in general (Chapter 2), and to project management in the automotive industry in particular (Chapter 3). Both chapters identify recent difficulties in project management and illustrate why cross-company projects have become significant for an organisation's success. Figure 1.3 illustrates how the thesis is structured with respect to the chapters.

\section{Structure of Chapters}

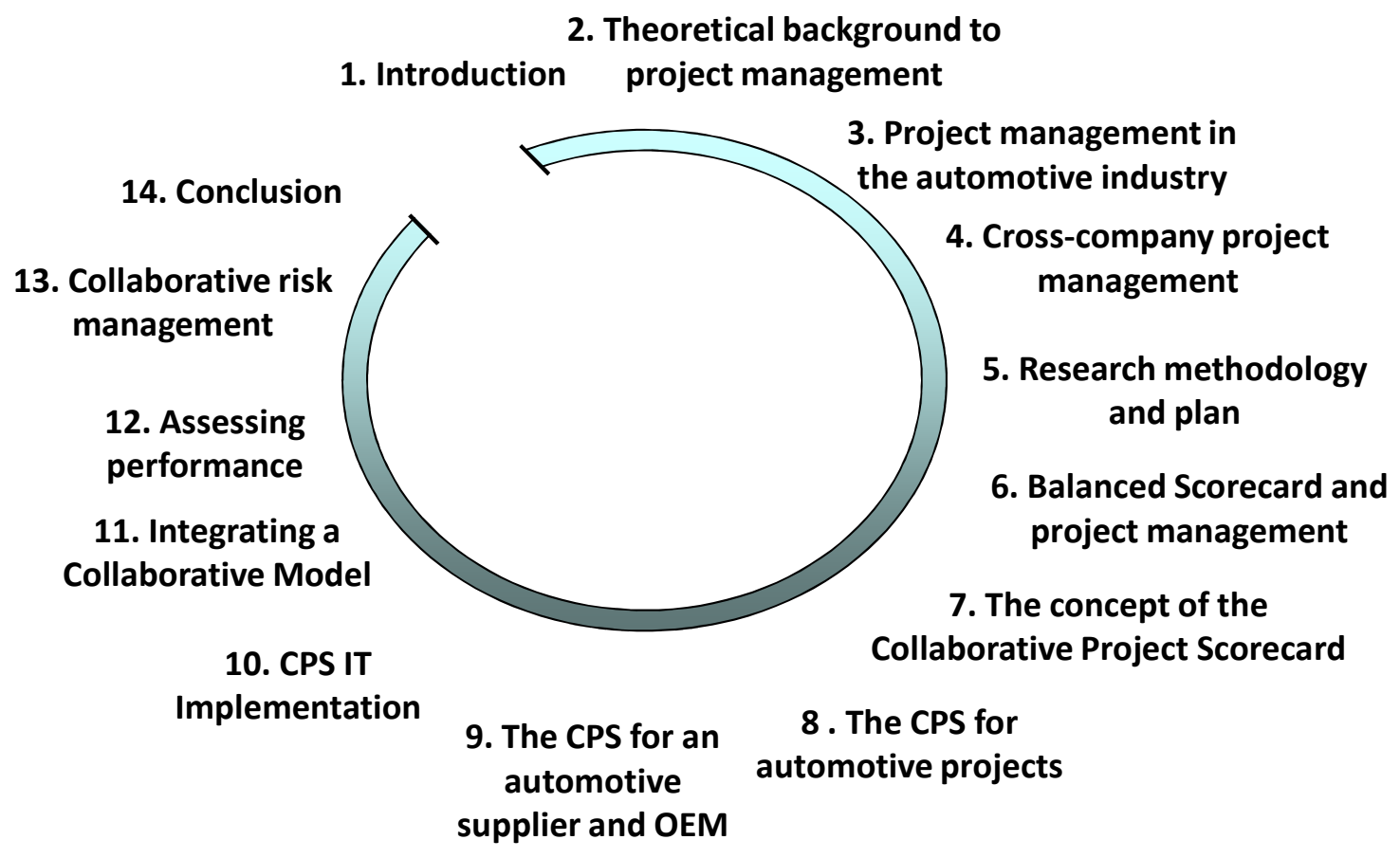

FIGURE 1.3: STRUCTURE OF THESIS CHAPTERS

An introduction to cross-company project management, difficulties and developments in the automotive industry are presented in Chapter 4 . This leads to the assumption that the Balanced Scorecard concept may provide an efficient and effective approach to enhance project management by an application on a project management and crosscompany project management level and is described in Chapter 6. This chapter also includes a literature review of existing scorecard approaches to project and crosscompany project management and includes the evaluation of the demand for the development of a sophisticated concept for collaborative projects based on the Balanced Scorecard. 
The scientific contribution of the research area begins with Chapter 6, e.g. with the application of an impact matrix for developing a project strategy map. The research approach, methodology, and hypothesis can be found in Chapter 5 .

The main elements of the concept developed in this research, the Collaborative Project Scorecard, are illustrated in Chapter 7. Based on those main elements further concept development results within the automotive industry are documented in Chapter 8 including the results of the GPM e.V. Automotive Chapter workshops, surveys, and interviews. The results of an application of the CPS concept to a collaborative project of an OEM and a supplier in the USA are presented in Chapter 9 including a detailed discussion about its benefits and limitations. Experiences with an IT implementation as part of a proof of concept can be found in Chapter 10.

Finally, the CPS concept was extended with several other management methods. The integration of a collaborative project management reference model (ProSTEP iViP CPM Reference Model) to create collaboration relevant KPIs and objectives (Chapter 11), and the integration and modification of a project assessment model (Project Excellence Model) for cross-company projects (Chapter 12) is followed by a chapter about the opportunities and concept ability to integrate project risk management methods for improved efficiency due to the mitigation of collaborative risks (Chapter 13). The last chapter includes a final conclusion and a recommendation on future research relevant to ensure a sustainable application and improvement of the CPS concept. 


\section{Theoretical background to project management}

Project management has developed from different fields of application since the development of human made tools and buildings. Theoretical approaches have been diverse and often are a competitive advantage of an organisation. This chapter gives an overview of existing and future project management methods that are relevant to understand the classification of the CPS concept presented in Chapter 7. This chapter begins with a short introduction to the history of project management and its relation to management science (Figure 2.1).

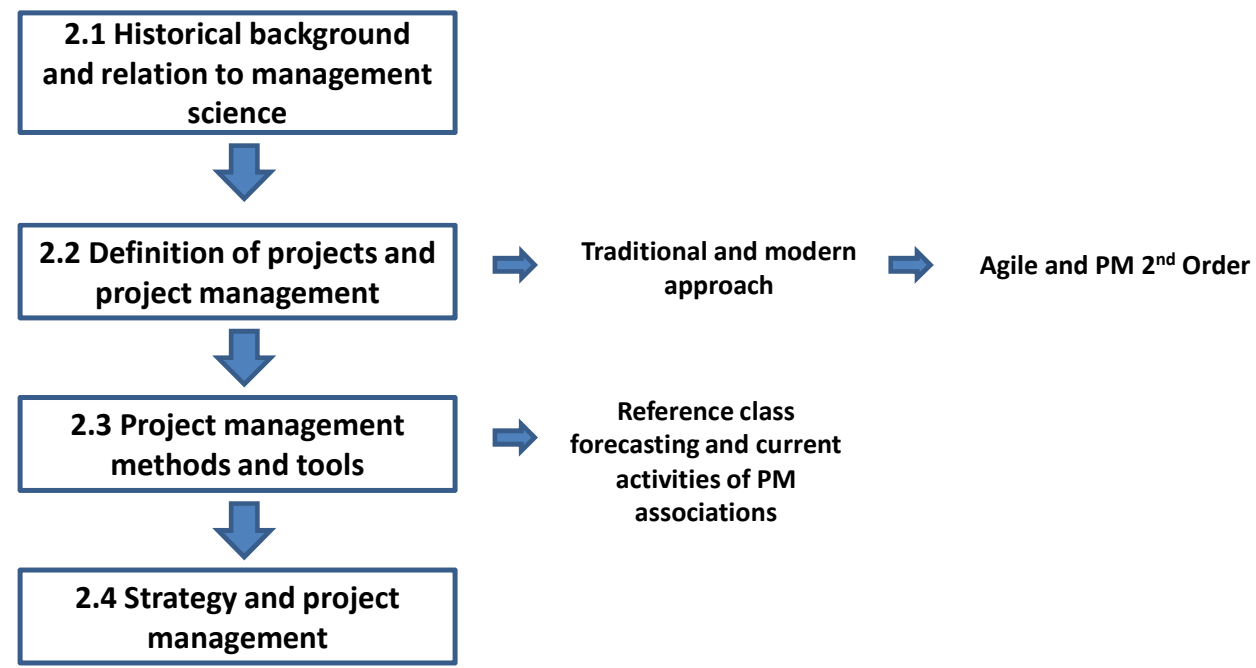

FIGURE 2.1: OVERVIEW OF CHAPTER 2

This is followed by a definition of projects and project management including traditional, conventional, and modern approaches, such as agile project management and project management $2^{\text {nd }}$ order. Some recent developed methods and tools in project management science are illustrated and activities of project management associations included. Finally, the strategic approach to project management by strategy focussed organisations complement this chapter.

\subsection{History of project management}

Projects have been undertaken for millennia including the ancient Egyptians who constructed the pyramids already 4500 years ago. Sun Tzu wrote about strategy and planning nearly 2500 ago that every battle is a project to be first won, and then fought. In the latter half of the $20^{\text {th }}$ century, people started to talk about project management. 
Beginning with the industrial revolution, management science evolved through the $19^{\text {th }}$ and $20^{\text {th }}$ centuries. Various processes and techniques were developed, such as the Gantt Chart by Henry Gantt in 1917, the flow-line scheduling in the 1930s that was used to schedule the construction of the Empire State Building, and the Line of Balance (LOB) technique developed by the Goodyear Company in the 1940s and later adopted by the U.S. Navy for programming and control of repetitive and non-repetitive projects. Construction, engineering, or defence are some of the early fields of project management applications. With Henry Gantt the discipline became an accepted field of science.

The modern era of project management started in the 1950s when project managers used Gantt charts, the Program Evaluation and Review Technique (PERT), the Critical Path Methods (CPM), and other new methods to manage time, tasks, or costs. Whilst CPM and PERT use the same general approach (both include the activity-on-arrow network diagram), PERT has a focus on time as the key variable, whereas CPM fixes time and varies the cost of achieving the target time.

The invention of the "iron triangle" that includes cost, time and output by Martin Barnes in 1969 in the UK supported a relatively precise cost and scope control. With the foundation of the Project Management Institute (PMI) in 1969, an association to serve the interests of the industry, processes and techniques were documented and published in the Guide to the Project Management Body of Knowledge first in 1981.

\subsubsection{Relation to management science}

Management science evolved in the $19^{\text {th }}$ and $20^{\text {th }}$ centuries in response to an upcoming increase of innovation in business and society. The origin of project management can be traced back to the protestant reformation of the $15^{\text {th }}$ century when the Protestants and later the Puritans introduced ideas that included reductionism, individualism, and the protestant work ethic. These ideas were later incorporated into two key philosophies: the Liberalism and the Newtonianism. Liberalism included the general ideas of capitalism and the division of work. Figure 2.2 shows the development of project management since the time of the Puritanism (Whitty, 2007). 


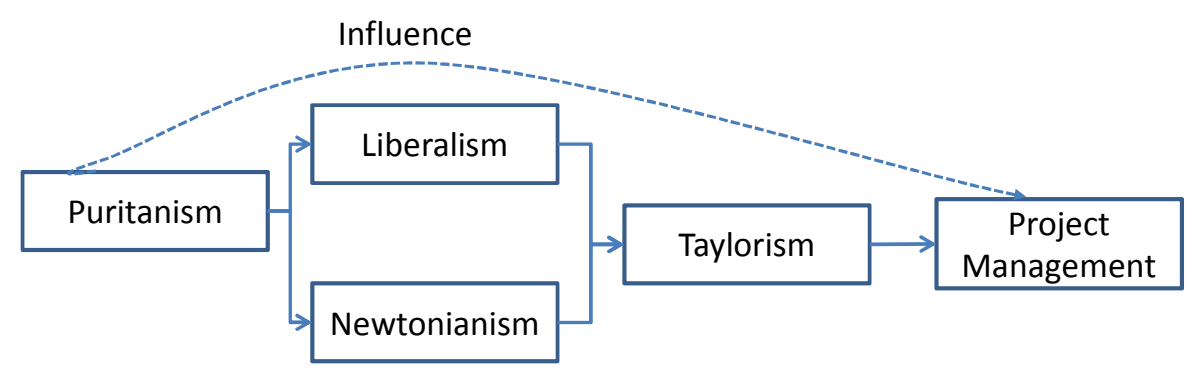

FIGURE 2.2: PURITANISM INFLUENCING TODAY'S PROJECT MANAGEMENT (WHITTY, 2007)

Newtonianism marked the time of scientific enquiry and Newton understood the world as a harmonious mechanism that is controlled by a universal law. Robert Owen and Charles Babbage realised in the $19^{\text {th }}$ century that people should not be considered as simple machinery and, therefore, introduced improved working conditions.

All of these philosophies had an impact on the scientific management theories by Taylor who was undoubtedly influenced by Quaker who came from Puritanism. Taylor worked in a capitalistic society and applied the scientific approach of Newtonianism when he developed the classical school of scientific management. Further insights into the classical school, scientific management, the late evolved human relations school in the 1920s that was followed by the human resource school and systems theory (1940s) and contingency view in the 1960s has been extensively analysed by Weaver (Weaver, 2007). Weaver argues that since the 1960s, new management viewpoints have emerged. Some of them include quality management, reengineering, chaos theory, and project/program and portfolio management.

\subsection{Defining projects and project management}

When it comes to the definition of projects and project management, different ways that describe the discipline can be found in the literature. The next two sections include the traditional and modern definitions of project and project management. One great difference of the modern view from the traditional one is that projects are usually managed in an open system where uncertainty limits the possibility of planning a project and where complex dependencies can lead to unforeseen events that cannot longer be managed by risk management alone. 


\subsubsection{Projects}

According to Gray and Larson (2006, p.4 ) "a project is a complex, non-routine, one-time effort limited by time, budget, resources, and performance specifications designed to meet customer needs", whereas the satisfaction of the customer needs are rated as the major goal of an organisation. The main characteristics of a project are defined as having an established objective, a defined life span with a beginning and an end, involvement of departments and professionals, a unique task, and specific cost, time, and performance requirements.

According to the Project Management Body of Knowledge (PMBoK), a project is defined as temporary with a beginning and an end, and it creates unique products, services, or results with progressive elaboration (PMI, 2005). Kerzner (2003) defines a project as any series of activities and tasks with a specific objective to be completed within certain specifications, with a defined start and end date, limited funds, and that include human and nonhuman resources, and have a multifunctional character.

There are several aspects that influence a project during its life time. Rietiker (2008) understands projects as open systems and as an integrated part of a greater whole. He emphasises that we need to change our understanding of projects from closed systems to open systems as we can only understand the characteristics of a project in the context of its environment (Gharajedaghi, 1999). He also argues that a selective perception of a project leads to a selective action in project management (Figure 2.3).

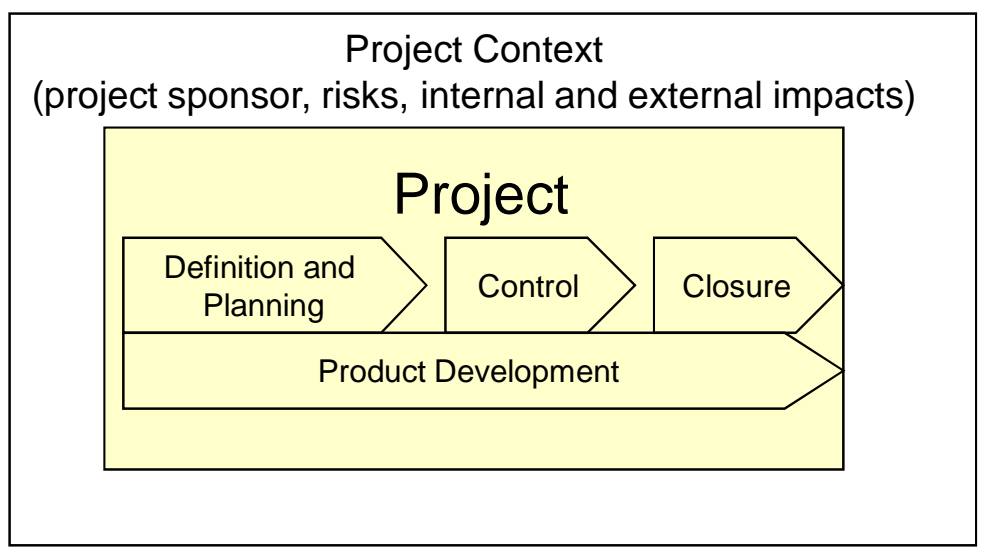

FIGURE 2.3: SELECTIVE PERCEPTION OF PROJECTS (RIETIKER, 2006, P. 24)

Rietiker (2006) identified in his research critical factors that have an impact on projects. Stakeholder, suppliers, competition, clients, project members, government, NGOs and 
investors are "claim groups", whereas society, nature, technology, and economy are "environmental spheres" of a business enterprise. Figure 2.4 shows the interaction of a project with its environment and illustrates the systemic understanding of a project as an open system.

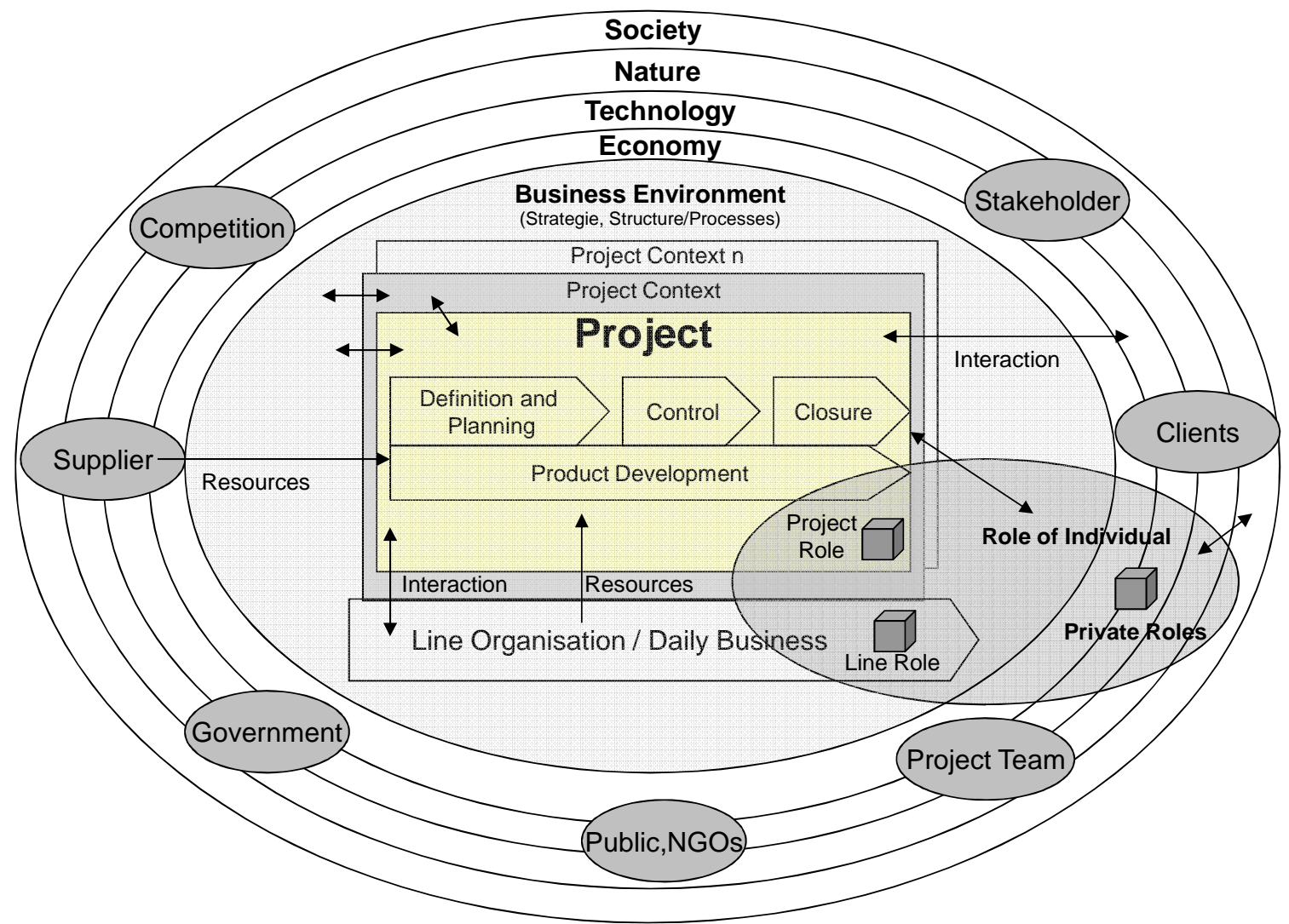

FIGURE 2.4: A PROJECT AS AN OPEN SYSTEM (RIETIKER 2006, P. 25)

\subsubsection{Definition of project management}

Project management in general can be described as the application of knowledge, methods, and techniques to project activities to meet prior defined project requirements, and therefore, to achieve project goals (Gray and Larson, 2002). The PMBoK describes it as "the application of knowledge, skills, tools and techniques to project activities to meet project requirements" (PMI, 2005, p.8).

\subsubsection{Project management characteristics}

Project management is typically structured into several phases and processes. According to the Project Management Institute, project management processes are 
categorised into initiating, planning, executing, monitoring, controlling, and closing processes (PMI, 2005). Gray and Larson (2002) use the term project life cycle, which passes sequentially through four different stages: defining, planning, executing, and delivering whereas monitoring and controlling processes are included in the executing stage. During the implementation of a project, some of the processes or stages are never completed and need to go through a continuous loop until the project moves to the closing or delivering stage. Deviations during the execution of a project identified in the monitoring process may cause a change of the project plan or corrective action. Figure 2.5 illustrates how the Project Management Process Groups are mapped to the Plan-Do-Act-Check cycle.

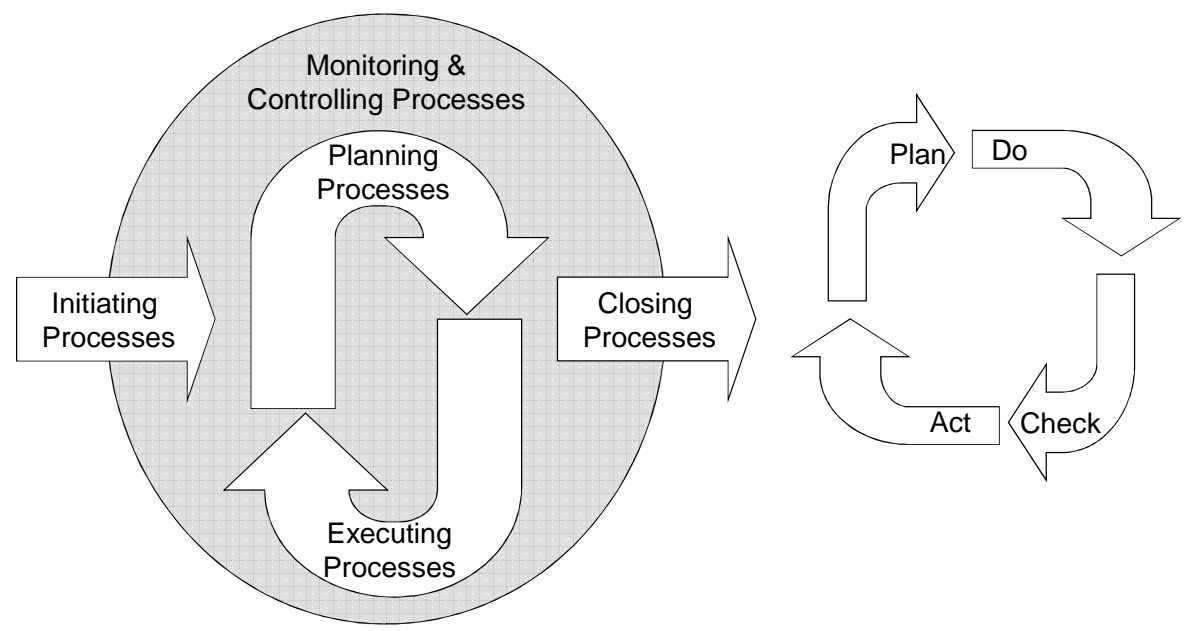

FIGURE 2.5: MAPPING OF PROJECT MANAGEMENT PROCESS GROUPS (PMI, 2004, P. 39-40)

Prince 2 is a project management methodology that was initially developed by the Central Computer and Telecommunications Agency in 1989 (Prince) as a UK government standard and has become a leading international standard (OGC, 2005). It describes project management as "the planning, monitoring and control of all aspects of the project and the motivation of all those involved in it to achieve the project objectives on time and to the specified cost, quality and performance", whereas the German Standard DIN 69901 defines it as the entirety of managerial functions, organisation, techniques, and tools necessary to execute a project (DIN 69901, 1987).

\subsubsection{Kerzner's definition of project management}

Kerzner understands project management in the context of project planning and monitoring only, where planning includes the definition of work requirements, the quantity and quality of work, and the resources needed. Project monitoring means 
tracking the progress, comparing actual outcome to predicted outcome, analysing the impact, and making adjustments. A successful project is described as achieved within time and cost at desired performance or technology level, utilising assigned resources effectively and efficiently, and accepted by the customer.

Kerzner lists a number of benefits from project management but also identified threats to a project, such as project complexity, organisational restructuring, project risks, changes in technology, forward planning and pricing, or customer's special requirements and scope changes. He realised that many events cannot be foreseen and describes project management in the following sentence: "project management is the art of creating the illusion that any outcome is the result of a series of predetermined, deliberate acts when, in fact, it was dumb luck" (Kerzner, 2003, p. 4). He understands that project management is designed to increase the efficiency how work is done and that companies need to be structured to allow a horizontal and vertical communication flow to achieve successful projects. Based on that assumption his definition is: "project management is the planning, organizing, directing, and controlling of company resources for a relatively short-term objective that has been established to complete specific goals and objectives. Furthermore, project management utilises the systems approach to management by having functional personnel (the vertical hierarchy) assigned to a specific project (the horizontal hierarchy)" (Kerzner, 2003, p. 4).

\subsubsection{Modern project management}

Modern project management is characterised by the assumption that our environment is unstable and events are no longer entirely predictable. Traditional project management in contrary assumes that project life cycle phases are recognizable, tasks completed in sequence, and tools well understood.

In contrast to modern project management, traditional project management is often limited due to the fact that projects do not follow a sequential flow and that clients experience difficulties in completely stating all relevant requirements in an early stage of the project.

This model is called the waterfall model and shown in Figure 2.6. 


\section{Waterfall Model}

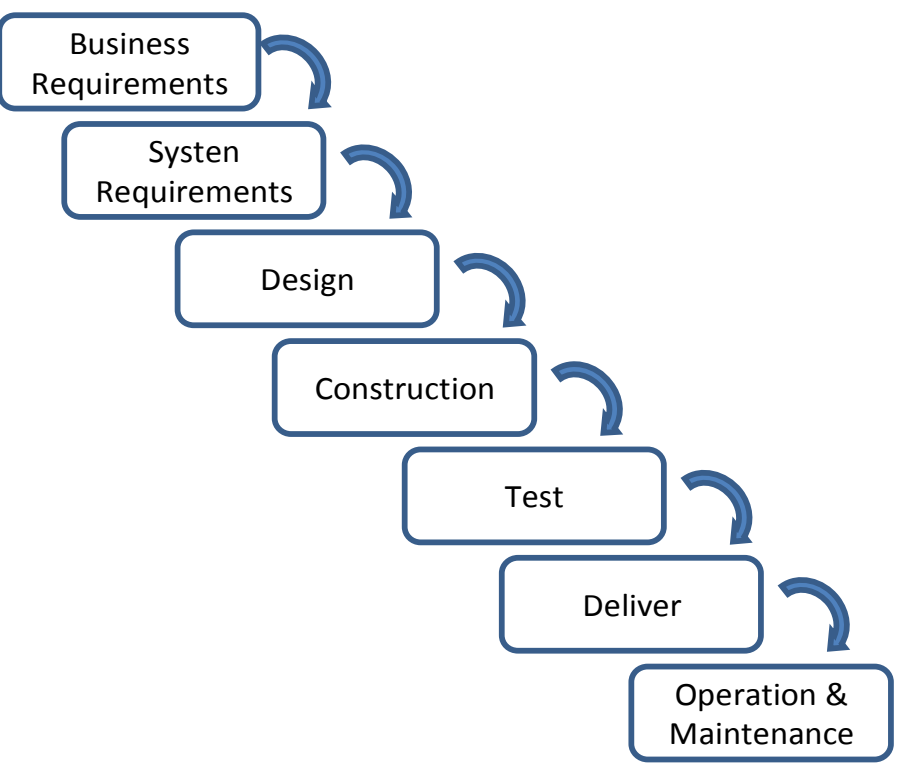

Figure 2.6: The WATERfall Model (HASS, 2007, P. 1)

The change towards complex project structures that are interconnected and interdependent has caused a constant change of the environment and the understanding of a project as an open system. Project alliances with strategic suppliers, rapidly changing technologies and global competition have had an impact on modern project management (Hass, 2007). Especially, the IT industry has experienced a dramatic change due to geographically dispersed software development teams and has searched for new solutions to work more efficiently under these new circumstances. Agile project management was one of the answers to complex and rapidly changing project environments in the IT industry, whereas project management second order (PM $2^{\text {nd }}$ Order) is a new approach that aims to extend traditional project management with new methods based on the evolutionary and chaos theory, and other theories such as the theory of complex systems (Saynisch, 2007).

\subsubsection{Agile project management}

Agile project management (APM) includes an iterative process where project stakeholder and members of a product development project (usually a software product) actively work together to identify the objectives and prioritise the functionality of a product. Software development projects are well known for constant change requests, and agile methods are necessary to ensure the participation of the customers, 
designers, and developers even when they are geographically dispersed. The iterative planning and development cycles enable the project team to constantly evaluate the product development and integrate feedback from the project stakeholders (in Figure 2.7 shown as review lessons learned). Lessons are learned from each iteration step and working methods can be improved.

The agile development model shown in Figure 2.7 and illustrates the iterative approach of this method.

\section{Agile Development Model}

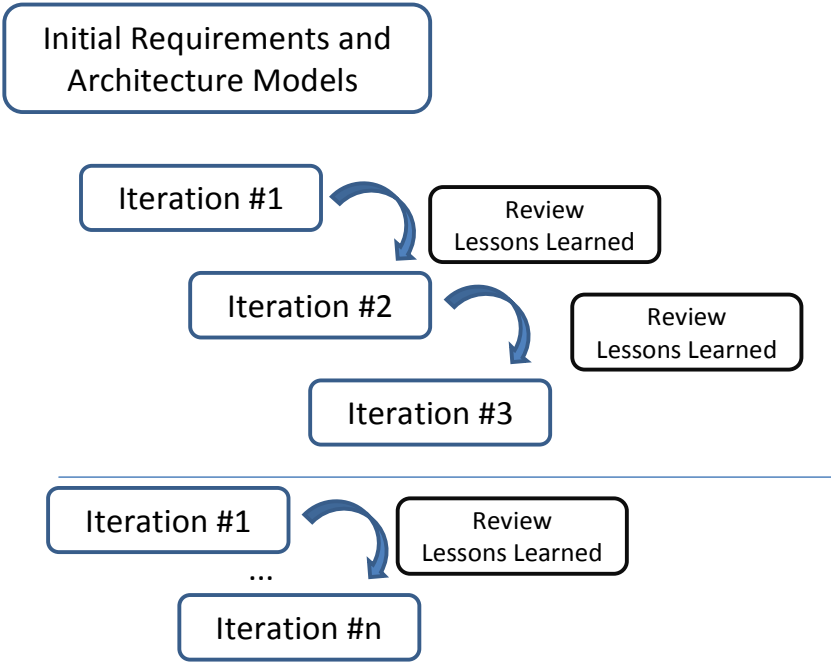

FiguRE 2.7: AGILE DEVELOPMENT MODEL (HASS, 2007, P. 3)

APM has emerged directly from software development, unlike traditional project management that has its origins in the construction, engineering or defence industry. Several key elements are included in APM and are called agile management components. Visual control, co-located high performance teams, test-driven development, collaborative development, feature-driven development, leadership and collaboration rather than command and control, move from cost to revenue focus, and lessons learned are the components and part of the fundamental techniques of APM (Hass, 2007).

\subsubsection{Project management second order}

Based on new insights into social science, such as the evolutionary and chaos theory, theory about self-organisation, synergetic, brain research, social systems theory, and 
theory of complex systems, project management $2^{\text {nd }}$ order (PM $2^{\text {nd }}$ order) is the result of the research programme "beyond frontiers of traditional project management" (Saynisch, 2004). The rapid increase of complex and new technologies, innovations in industrial and social sciences were the reason to find new methods to minimise an increasing loss in project management efficiency.

PM $2^{\text {nd }}$ order extends the traditional concept with an approach that is predicated on systemic-evolutionary (self-organizing), system-technological (constructive), and determined principles. It integrated the traditional approach (PM $1^{\text {st }}$ order) with the research results of the research programme mentioned above. During 12 years of research from 1990 to 2002 several scientists have explored and developed theories that support the management of complex projects and are an integrated part PM $2^{\text {nd }}$ order. $\mathrm{PM} 2^{\text {nd }}$ order assumes that traditional project management is based on linear, mechanical, mono-causal, non-dynamic structures and underlie the Cartesian causality and Newtonian logic. The simultaneous and synchronous acting of evolutionary dynamics, antipoetic systems, chaotic and self-organisational processes are not considered in traditional project management. To overcome the difficulties of our new environment, $P M 2^{\text {nd }}$ order integrates two cybernetic cycles, the cybernetic $2^{\text {nd }}$ order (observer/manager inside of the system) based on the trans-classical logic (Jaafari, 2003) and the cybernetic $1^{\text {st }}$ order (observer/manager outside of the system) that is based on the classical logic of Aristotle. The result is a dual cybernetic and complementary cycle principle that is shown in Figure 2.8.

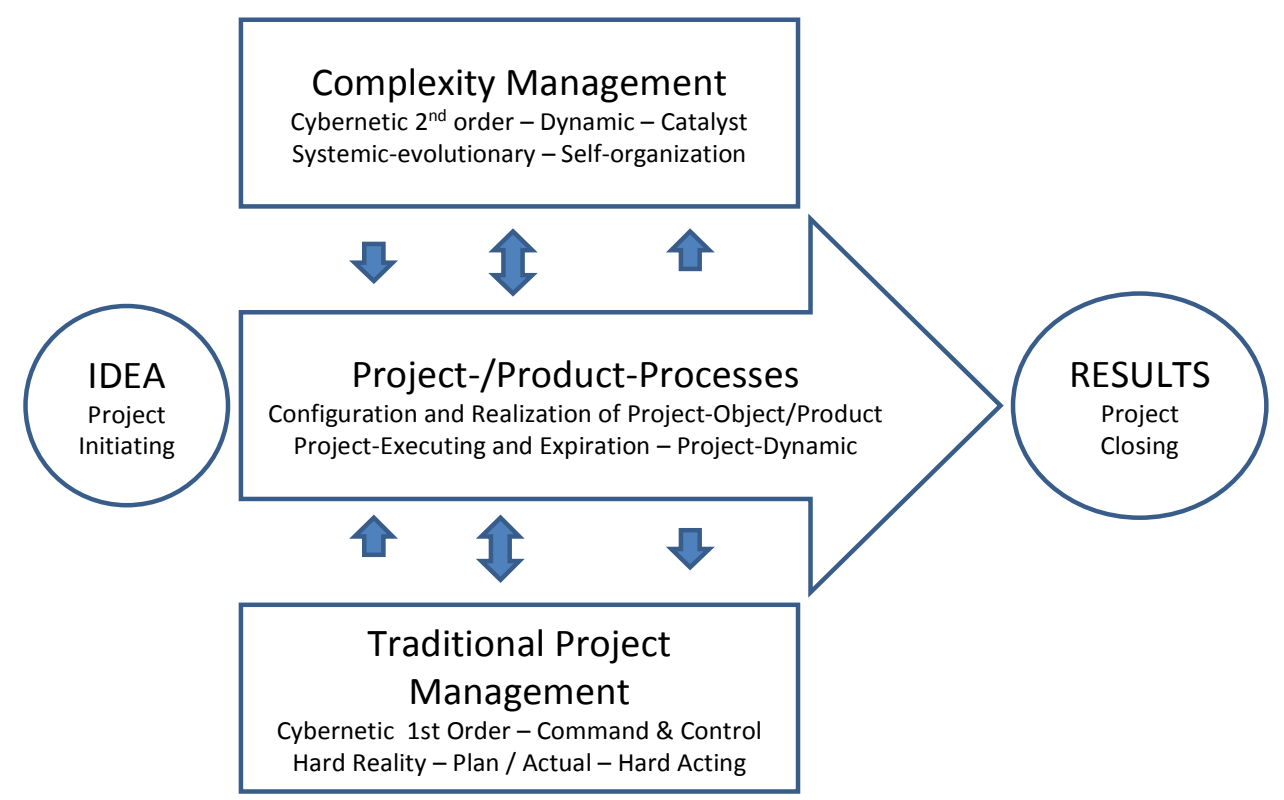

Figure 2.8: ARCHITECTURE AND PROCESS MODEL PM 2ND ORDER (SAYNISCH, 2007, P. 7) 
Four WORLDs describe the architecture of PM $2^{\text {nd }}$ order and a detailed description of each WORLD is shown in Table 2.1.

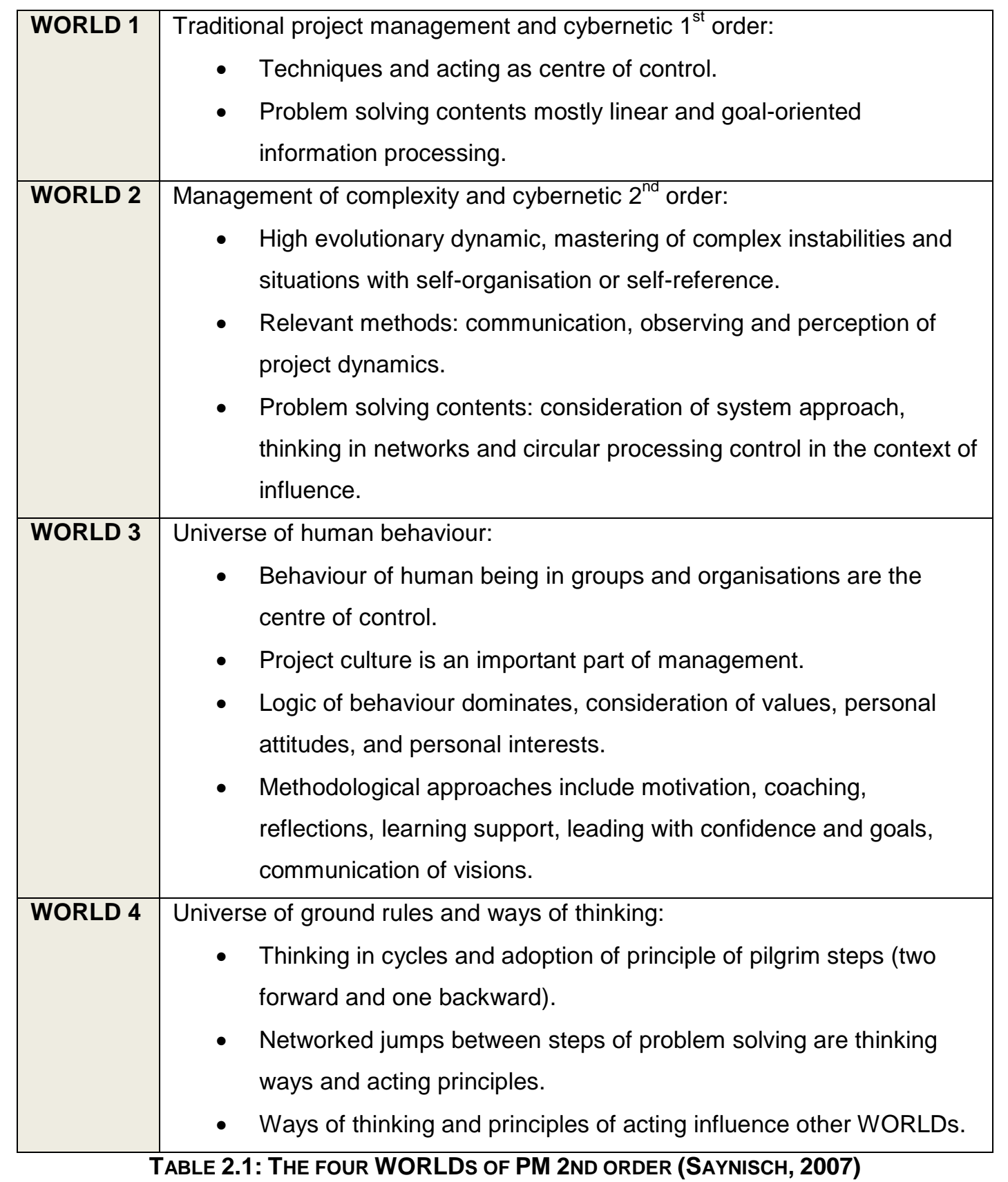

WORLD 1 is represented by traditional project management and WORLD 2 by complexity management. WORLD 3 is described by the universe of human behaviour, and WORLD 4 by the universe of ground rules and ways of thinking.

Figure 2.9 illustrates the interaction of the four WORLDs and represents the systemic architecture and process model of PM 2nd order. 


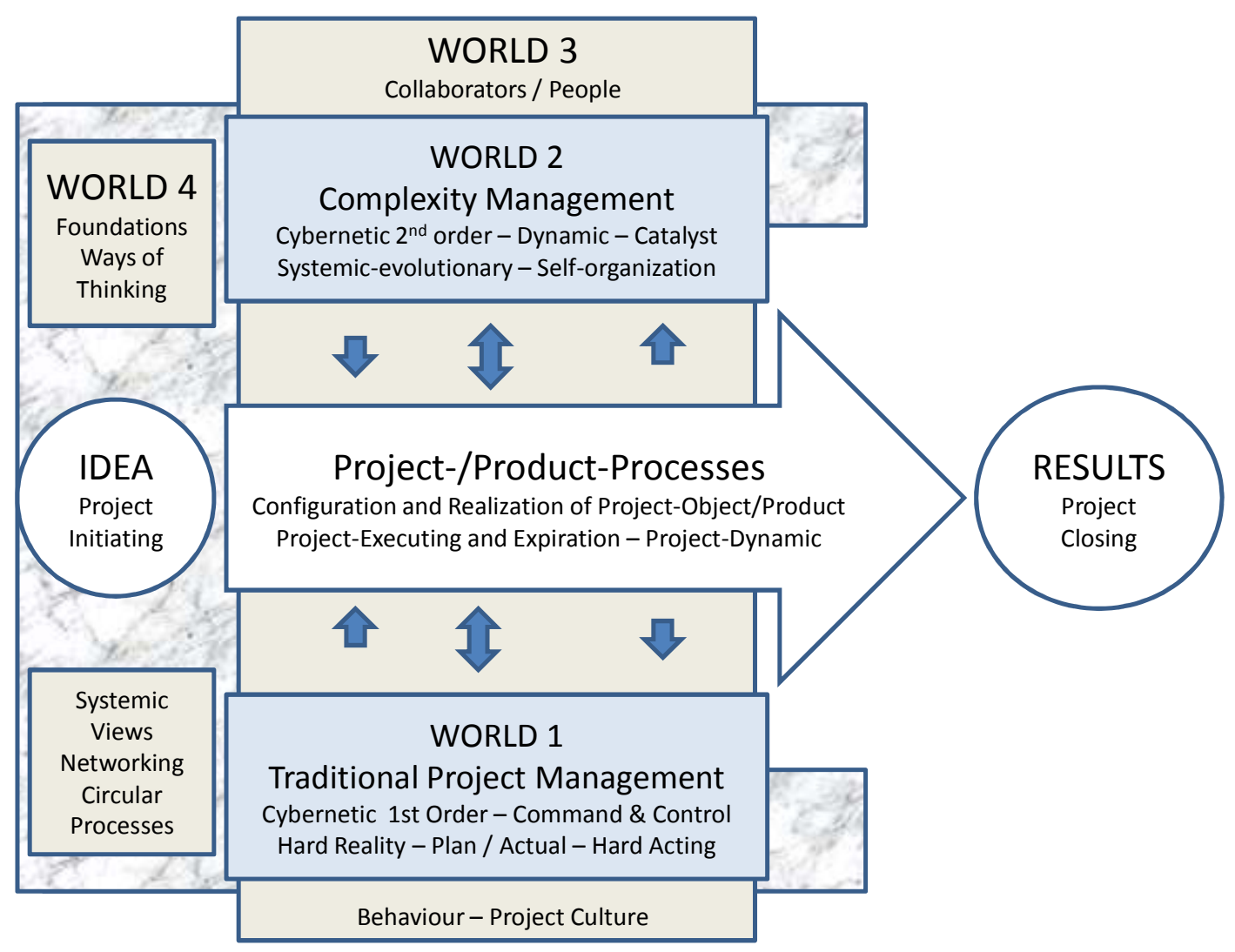

FIGURE 2.9: SYSTEMIC ARCHITECTURE AND PROCESS MODEL OF PM $2^{\text {ND }}$ ORDER

(SAYNISCH, 2007, P. 8)

Saynisch (2007) further illustrates the potential use of PM $2^{\text {nd }}$ order and its implementation in different project types. Additionally, principles, methods, and processes are described and demonstrated in a real life project.

\subsection{Project management methods, tools, and standards}

The establishment of structures, frameworks, and tools to achieve reliable and efficient project structures has lead to the development of several project management methods and standards. The popularity of methodologies grew rapidly from the beginning of the 1970s until the 1980s but has shifted from organisations purchasing methodologies from commercial vendors towards adopting the use of maturity models such as Capability Maturity Model (Weaver, 2007). Well known models to measure the maturity of an organisation are the Capability Maturity Model Integration (CMMI) developed by the SEI in the US, P2MM Prince2 Maturity Model (OGC, UK), OPM3 Organisational Project Management Maturity Model (PMI, USA), P3M3 Portfolio, Programme, and Project Management Model (OGC, UK), P2M3 Programme and Project Management Model (OGC, UK), PMMM Project Management Maturity Model (Kerzner, USA), or the German 
Project Excellence Model (GPM/IPMA, Germany). All maturity models provide processes or process models, such as the V-Modell XT that includes project management methods, processes, and tools originally developed within the German defence industry. The core of all methodologies is its process descriptions. The processes are usually implemented by the consistent use of templates, forms and software, and the methodology is supported and developed by a project management office $(\mathrm{PMO})$.

Next to methodologies and models there are also single methods for specific project management areas, such as the critical path method that has a focus on project planning, or tools such as the Work Breakdown Structure (WBS) that supports the project manager to structure work packages and tasks. Appendix A includes a more detailed description of the Capability Maturity Model Integration (CMMI), projects in controlled environments (Prince2), the V-Modell XT, ISO 9000 Family (including ISO 900), and earned value management and earned value performance measurement.

\subsubsection{Reference class forecasting}

The reference class forecasting method was endorsed by the American Planning Association (APA) in April 2005. This method is based on the theories of decision making under uncertainty that won the 2002 Nobel Prise in economics.

Most of the project estimation is inaccurate and makes the project very risky. According to research by Bent Flyvbjerg (2006), inaccuracy of the estimation is not derived from the technical or imperfect data and model. He argues that if it was due to a lack of data or imperfect data and models, then accuracy should be improved over time. Therefore, substantial efforts have been made to improve data and estimation methods. The explanation for the inaccuracy can be better understood when viewed in psychological and political terms. Psychological explanation towards inaccuracy is the optimism bias. Most of the estimators judge the future events in an optimistic way, probably due to overconfidence and insufficiency in distributional information, and tend to underestimate constraints that might occur in the actual performance. On the other hand, the political explanation is a strategic misrepresentation, which means that most estimators deliberately and strategically overestimate the benefits and underestimate the costs to gain approval of their project. This behaviour is called planning fallacy as people underestimate the costs, completion times and risks of planned action whereas they 
overestimate the outcomes and benefits. The reference class forecasting method bypasses the human bias and includes the optimism bias and strategic misrepresentation that usually underpin the inaccuracy while making decisions under uncertainty. It is a method to produce unbiased forecasts of human judgment that leads to an increased accuracy of the forecasts compared to conventional forecasting methods. In order to obtain unbiased forecasts and to cure the planning fallacy, the method uses an outside view by applying the distributional information from other projects similar to that being estimated (Flyvbjerg, 2006).

The reference class forecasting method in a project requires these three steps:

- Identification of a relevant reference class of past, similar projects. The class must be broad enough to be statistically meaningful, but narrow enough to be comparable with the specific projects.

- Establishing a probability distribution for the selected reference class. This requires access to credible, empirical data for a sufficient number of projects within the reference class to make statistically meaningful conclusions.

- Comparing the specific project with the reference class distribution, in order to establish the most likely outcome for the specific project.

It is clear that the reference class forecasting method does not aim to forecast the specific uncertain events that affect the project, but instead, it places the project in a statistical distribution of outcomes from the class of reference projects. The method may work well when it deals with the optimism bias as the root cause of inaccuracy. Optimism bias is a self-deception, which means an honest mistake while forecasting. Whereas, if the cause of inaccuracy is due to strategic misrepresentation, which means the inaccuracy is deliberately made, the potential for reference class forecasting is low as there is no interest to improve accuracy (Flyvbjerg, 2006).

\subsubsection{Project management associations}

Several associations and organisations have been founded to develop best practices, standards, and new methods for more efficient and effective project management. Most of these organisations act on an international level, whereas national organisations are usually members of international associations that work together on a global level. The two biggest international organisations are the Project Management Institute (PMI) in 
the US and the International Project Management Association (IPMA) with its seat in Switzerland. As an example, the German Project Management Association (GPM) and the Australian Institute of Project Management (AIPM) are members of the IPMA. The PMI has local chapters at several locations worldwide and consists of special interest groups (SIG) that focus on industry specific areas such as the IT or financial sector. Other associations are the International Research Network on Organising by Projects (IRNOP) that was founded in 1993 and aims to connect researchers in countries all over the world with a background in business, economics, or engineering and who have a common interest in project organisations, projects or temporary systems.

\subsection{Strategy and project management}

Strategies and the implementation of strategic concepts have recently become more important for business organisations. The expertise to implement strategies is an essential competence to differentiate with competing enterprises and to ensure longterm competitive advantage (Horvath and Partner, 2005). Despite an improvement in strategy deployment due to further developments of methods and tools, there is still a great need for action (Rietiker, 2008). According to a study of the Wharton Business School and the Gartner Group, managers are educated in strategic planning but not in its implementation. Other major structural and process related reasons are that strategy implementation is considered as a task of middle and lower management, it takes more time and human resources, and it is more complex than the development of a strategy. Additionally, it is a long-term process and not a single and short-term feasible action programme (Hrebiniak, 2005). Primarily, strategies are implemented by projects and initiatives; therefore, the alignment of project goals with business strategies is an essential step for an effective and efficient strategy implementation. Hrebiniak identified four critical strategic planning aspects that influence its success:

- Solid planning and clearly focussed strategy.

- Business and departmental strategies need to be consistently and selfsupporting.

- Strategic goals need to be translatable into operative, measurable targets.

- Requirements of strategy and its successful implementation need to be understood. 


\subsubsection{Creating a strategy-focused project organisation}

Kaplan and Norton (2001) identified that organisations have difficulties in implementing well-formulated strategies and that the execution of strategy is more important than the quality of the strategy itself. They demonstrated that the Balanced Scorecard can help organisations to overcome difficulties in executing their strategy and they defined five principles that characterise an organisation as strategy focused. They also argue that the Balanced Scorecard is a means to align and focus resources on strategy, such as the executive team, business units, human resources, information technology, and budgets as well as capital investments.

The five principles of a strategy focused organisation are "translate the strategy to operational teams", "align the organisation to the strategy", "make strategy everyone's everyday job", "make strategy a continual process", "mobilise change through executive leadership", and are further described in Figure 2.10.

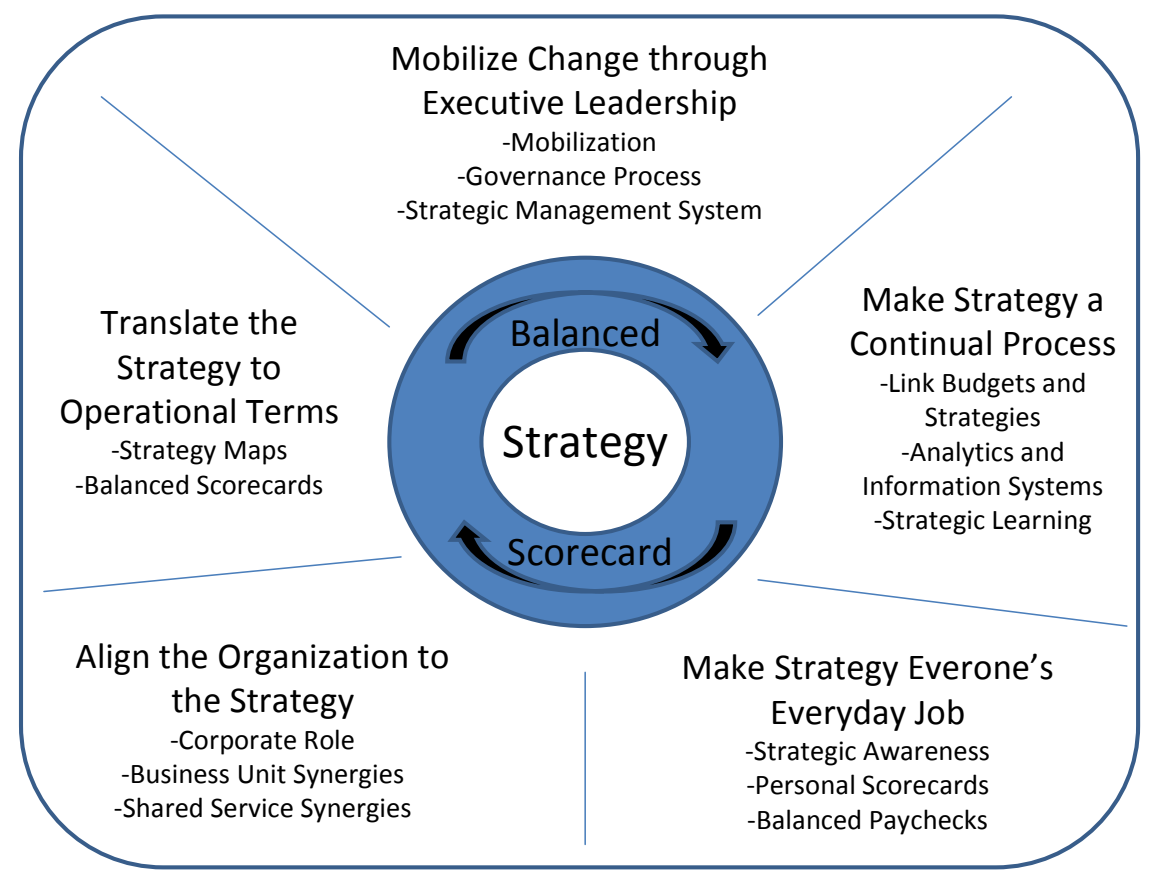

FIGURE 2.10: THE PRINCIPLES OF A STRATEGY FOCUSED ORGANISATION

(KAPLAN AND NORTON, 2001, P. 9)

Although, Kaplan and Norton's theoretical work regarding the strategy focused organisation is based on only four case studies, they argue that the "application and performance breakthroughs are by no means limited to these examples, these industries, or even the companies for which we served as consultants" (Kaplan and Norton, 2001, p. 17). 


\section{Project management in the automotive industry}

Since the first automobiles were manufactured, the automotive industry has developed to one of the most important industries worldwide. Approximately $15 \%$ of the global gross national product accounts to the industry, and manufacturers, suppliers, and service providers underlie constant dynamic changes of business and project structures. The saturation of the market has lead to an enormous pressure upon cost, time to market, and product quality. In such times, project management is an essential discipline to stay competitive and survive economic crisis sustainably ( $\mathrm{Hab}$ and Wagner, 2005). This chapter begins with an introduction to the recent development in automotive project management followed by a section that identifies success factors but also reasons for project failures in the last years (Figure 3.1).

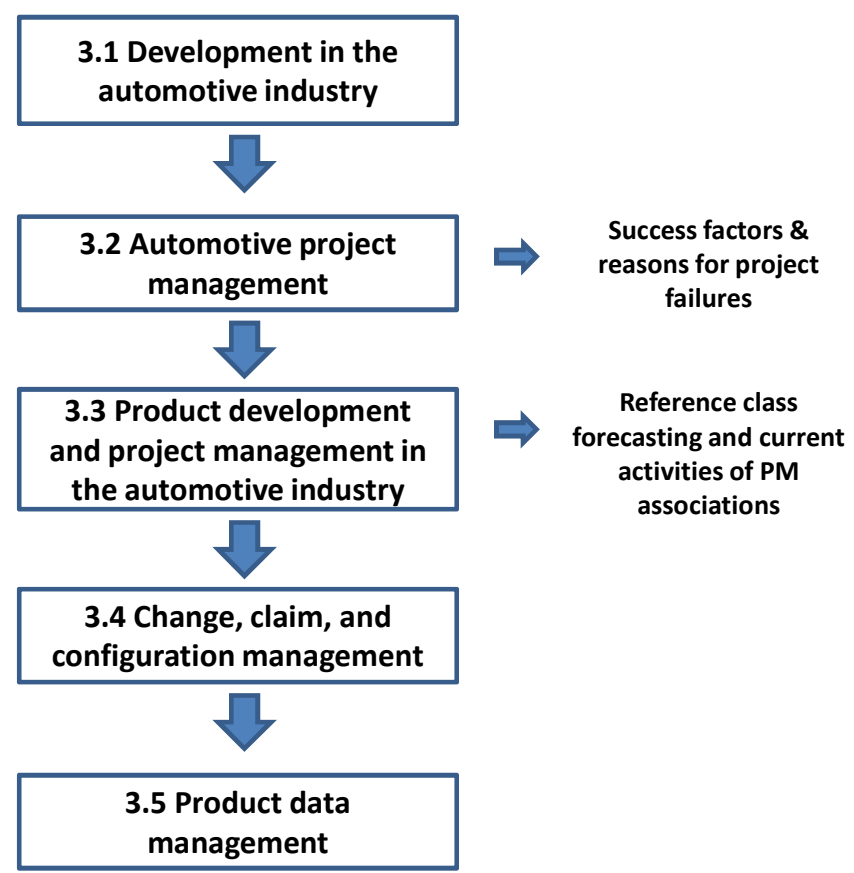

Figure 3.1: OVERVIEW CHAPTER 3

The subsequent three sections give an introduction to product development, change, claim, and configuration management, as well as product data management in the automotive industry. These disciplines are relevant elements of automotive project management and are also important to understand the interaction with the Collaborative Project Scorecard. 


\subsection{Developments in the automotive industry}

In the USA, Japan, and Western Europe the automotive industry is one of the major industry sectors that contributes to the gross domestic product. Asian and Eastern European countries have recently experienced an enormous growth in that sector. Worldwide, more than nine million people are employed in the industry and produced 57 Million cars equivalent to $15 \%$ of the world's gross domestic product in 2003. In Germany, the number of automobiles has tripled to 45 Million (2005) compared to 1970 and the density has increased from 229 to 540 cars per 1000 citizens. Although, the density of cars will continue to increase simultaneously followed by a price increase, there is a sense of crisis and uncertainty in the Germany automotive industry caused by a perception of change and reformation (Ebel et al., 2004).

The stagnation in North America, Japan and Western Europe cannot be compensated by emerging markets such as China or India yet. Therefore, the industry is under considerable strain that causes a demand for shorter project life cycles by decreasing prices, higher quality standards, and improved technology. One of the results was the enormous rise of product recalls (Figure 3.2) that was caused by faulty product development processes and deficient management (Hab and Wagner, 2006).

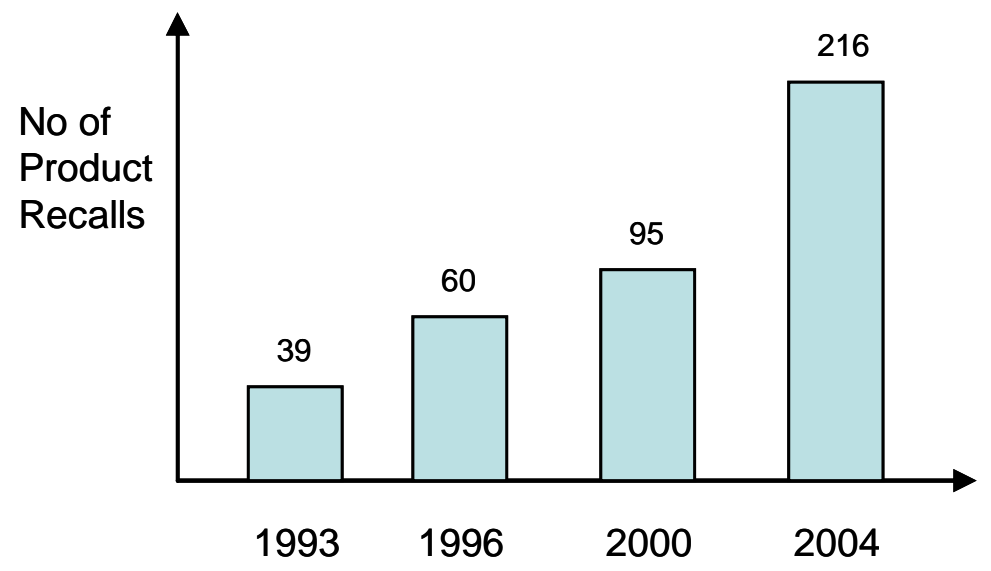

Figure 3.2: Number OF PROduct ReCAlLS IN GeRmany (HAB AND WAGNeR, 2006, P. 3)

Other major impact factors are financial crises and recessions that cause production lines to stop for weeks and threatens car manufacturers with insolvency, e.g. General Motors (GM) due to the economic recession in late 2008 and early 2009. 


\subsubsection{The role of project management in the automotive sector}

Since 1964, the number of independent manufacturers has decreased from 56 to 12 corporate groups with similar development in the supplier industry. According to a study of the Mercer Management Consulting and the Fraunhofer Gesellschaft in Munich, the number of suppliers will decrease from 5500 in 2002 to 2800 in 2015 (FAST 2015, 2004). The saturation of the market caused a development of numerous new models, versions and special editions to attract customers. Whereas the strategy has been successful for some manufacturers, it has also caused an increased complexity within the product development processes and after-sales-services. Various interaction and influences on project management need to be considered as project management has to focus on the demands of the market and also the demands of a chosen strategy. Strategy should clearly demonstrate which function is taken by project management in a manner that all project members clearly understand the manager's decision. Project management plans and controls the operational execution of projects by targeting the goals and considering respective cost and time lines. In order to fulfil this task, several processes and organisational structures need to be coordinated. Additionally, cultural prerequisites need to be created for an effective and efficient collaboration of different business units or partner companies within the supply chain.

Figure 3.3 illustrates the interaction between impact of culture, strategy, structure, and processes on project management, whereas " $q$ " stands for quality, "t" for time, and "c" for cost.

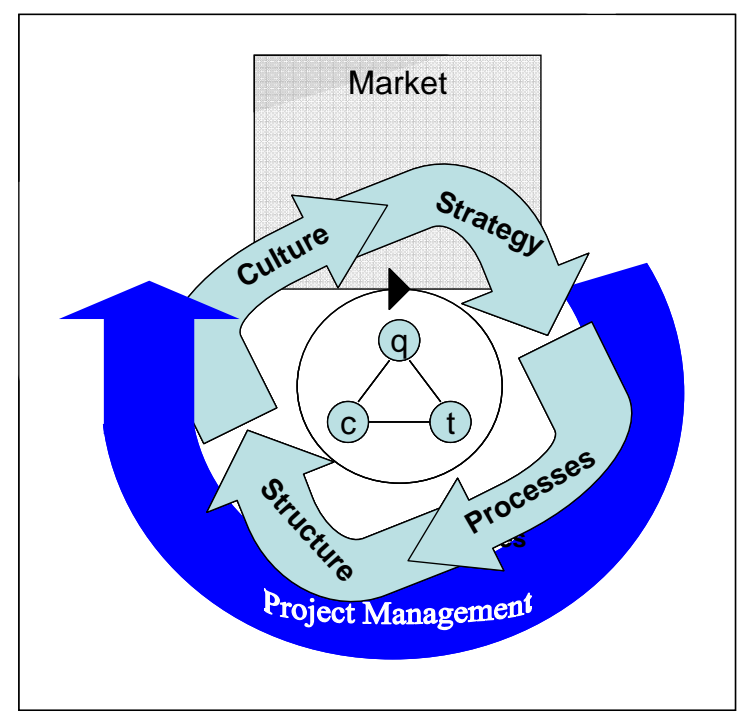

FIGURE 3.3: INTERACTION BETWEEN IMPACT FACTORS ON PROJECT MANAGEMENT

(WAGNER, 2009, P. 75) 
As the strategic challenges for manufacturers and suppliers increase, project management also has to face new challenges and requirements to satisfy the growing demands of customers in terms of quality, functionality, and cost of a vehicle. Not only the newest technologies are requirements of the customers but also driving comfort, safety, driving power, and low emission. This has lead to shorter development cycles and a growing number of models.

\subsubsection{Project management dimensions}

High quality, lower prices, and decreasing budgets at shortened time to market cycles limit the freedom of action of the manufacturers. In 2006 a research group of the German Project Management Association performed a survey within the German automotive industry to identify the current situation of major trends in project management. More than sixty companies participated in the survey. Among those companies were Audi AG, BMW AG, Daimler, and Volkswagen as OEMs, and Autoliv, DräxImaier, Hella, and Siemens VDO as suppliers together with various service providers. Based on the results of this survey, thirteen experts participated in intensive interviews to verify the survey results and to give recommendations on how to improve project management. Figure 3.4 shows the overall results in all dimensions of strategy, innovation and learning, processes and standards, methods and tools, partnership, employees, and leadership and categorised into "importance", "existence", and "realization".

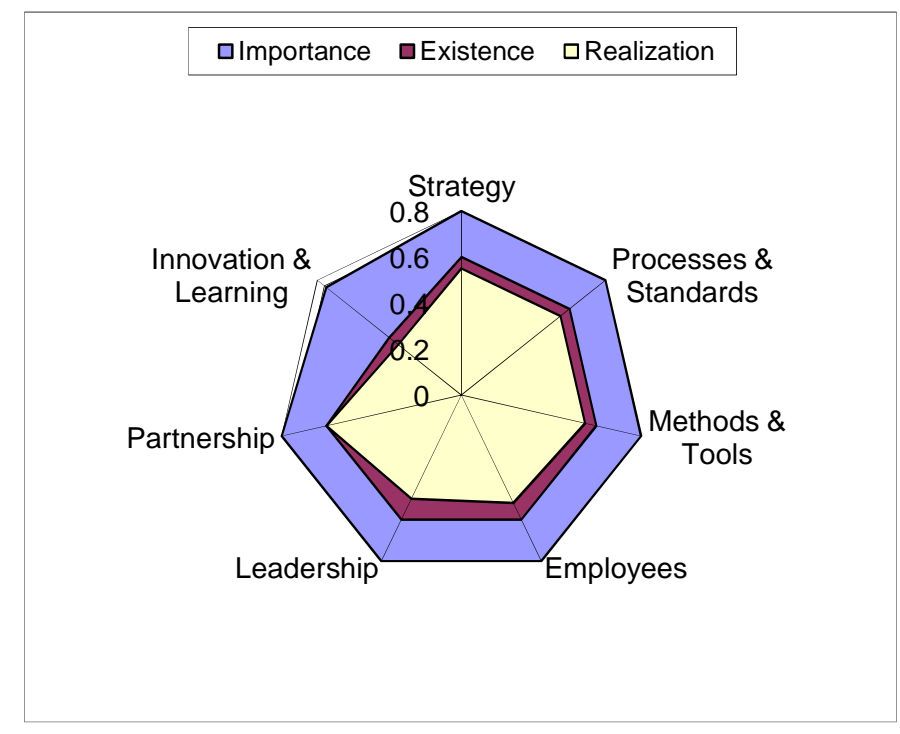

FIGURE 3.4: GPM PROJECT MANAGEMENT SURVEY RESULTS 
Although, all areas need improvement, innovation and learning needs more attention according to the survey participants.

Figure 3.5 illustrates the performance of project management in the German automotive industry, where approximately $70 \%$ of the survey participants are satisfied with their goal achievement within $90 \%$ of their projects; however, only $8 \%$ are satisfied with their goal achievement in $100 \%$ of their projects.

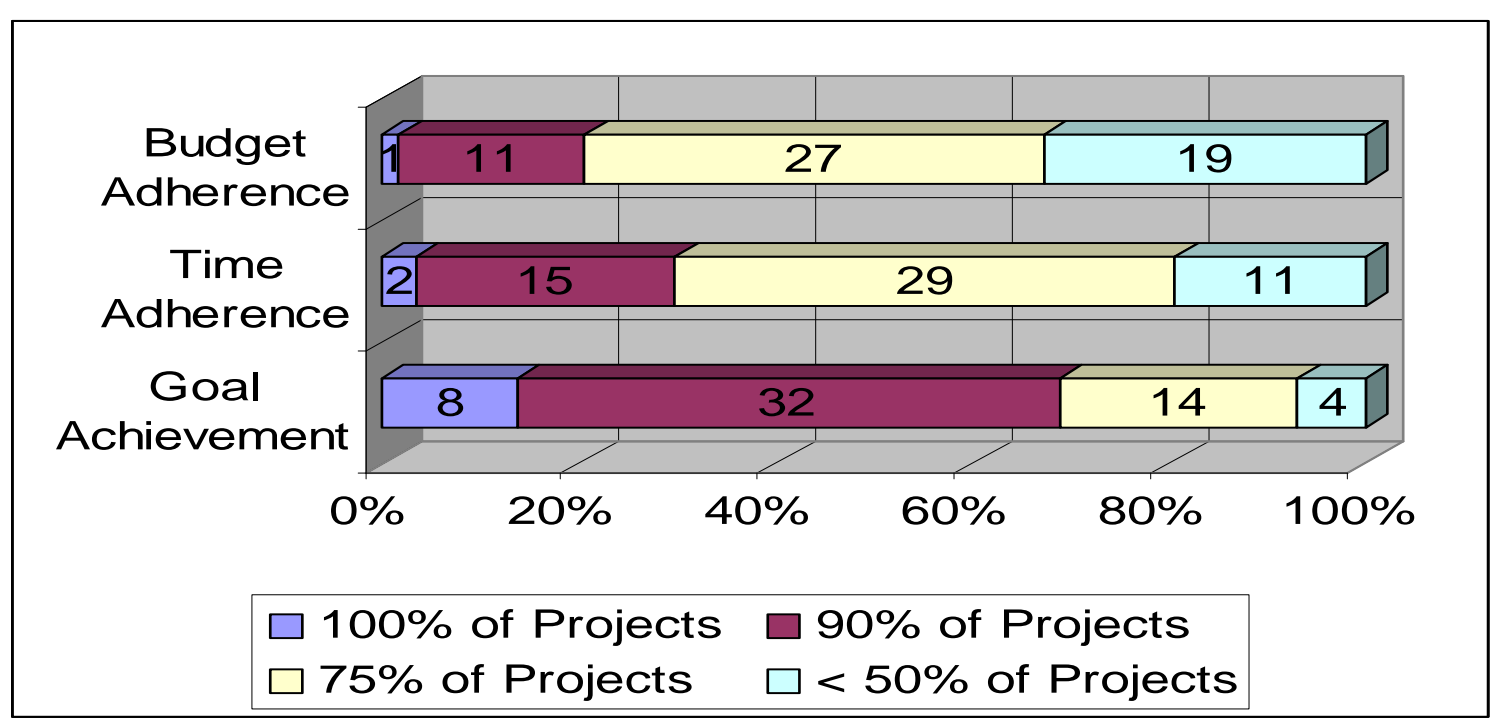

FIGURE 3.5: GPM SURVEY RESULTS OF GOAL ACHIEVEMENT, BUDGET AND TIME ADHERENCE

(WAGNER, 2000, P. 76)

To achieve more efficiency in project management, companies need to evaluate their performance regularly to be able to improve their capabilities and abilities, and to implement new processes and a culture of innovation and learning (Hab and Wagner, 2006).

The increase of complexity in automotive product development has also changed the project structures from a hierarchical to a networked structure as shown in Figure 3.6. 


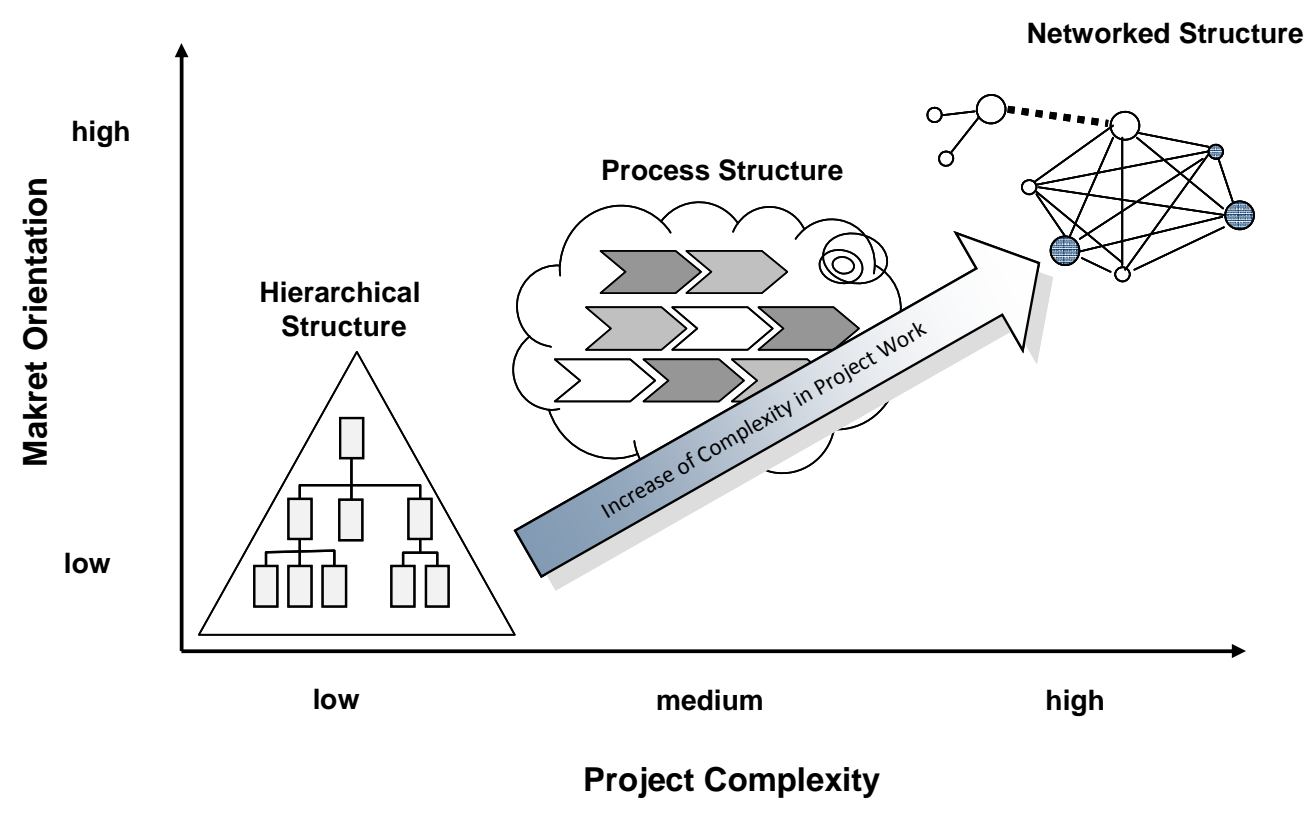

FIGURE 3.6: FROM HIERARCHICAL TOWARDS NETWORKED PROJECT STRUCTURES

(HAB AND WAGNER, 2006, P. 256)

A study of the GPM and the PA Consulting Group in 2007 revealed that unclear requirements and goals were named by $57.3 \%$ of the survey participants as reasons for project failures. The next section illustrates the problems and difficulties in automotive project management in more detail.

\subsection{Automotive project management}

The management of automotive projects is characterised by a strategic change towards networked project structures. Cooperation and communication are two of four success factors described by Bullinger et al. (2003). Difficulties in communication are major reasons for project failure and the automotive organisational management structures aim to reduce those problems. One possible solution is the implementation of a project house. The next sections describe these aspects in more detail.

\subsubsection{Success factors}

According to Bullinger et al. (2003), there are four critical success factors, which have an impact on processes, structure, culture, and strategy in an automotive project: 
1. Focus and Innovation: focus on market demands and own strengths and core competencies with innovative products.

2. Coordination and Integration: coordination and integration of processes and structures, strengthening of project management and flexible integration of project partner processes.

3. Cooperation and Interaction: development of trust, fair distribution of chances and risks, common agreement on goals.

4. Communication and Information: communication is a core factor for success.

The four critical success factors are also called key indicators (KI) for a successful management of vehicle projects. The Kls are part of a KI-Success Model that is a holistic approach to project management and assumes that not only software solutions and methods are success criteria but also market demands and the related strategic procedural structures, as well as cultural impact factors.

\subsubsection{Automotive organisational management structures}

An automotive company has usually implemented a matrix organisation consisting of two dimensions, the functional line (vertical) including sales, development, design, production, etc., and projects in the horizontal line. In some companies project management and the project management process represent an additional virtual organisation and is called project office. This office takes over administrative tasks and evaluates and implements project management methods. Due to the development towards networked project structures, the organisation has to integrate project partners that usually work within a matrix organisation, too. Figure 3.7 shows the matrix organisation of a typical vehicle developer and manufacturer. 


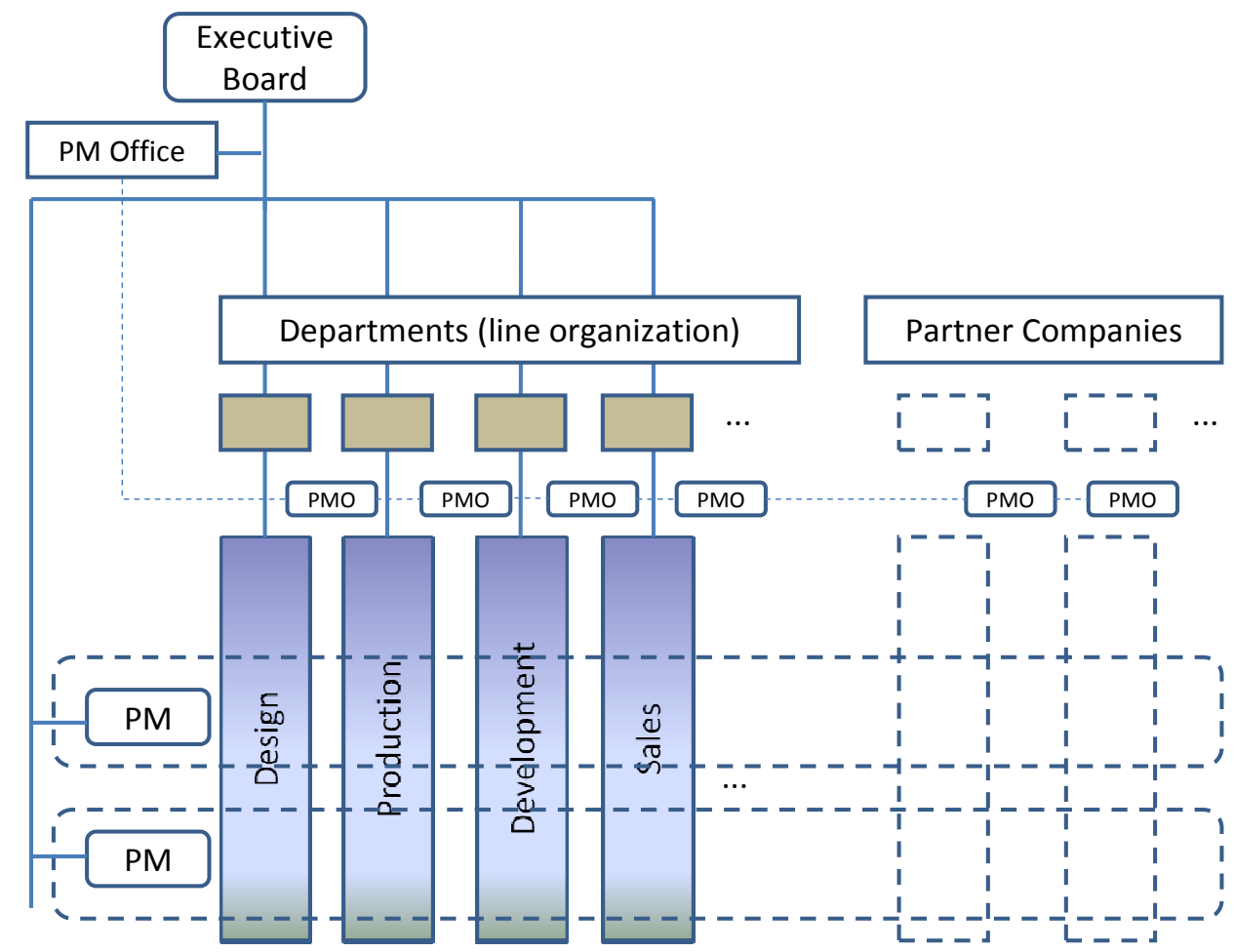

FigURE 3.7: MATRIX ORGANISATION OF A VEHICLE MANUFACTURER (HAB AND WAGNER, 2006, P. 42)

The integration of project partners is a challenge for a network manager as each partner has its own processes and time lines that need to be synchronised. An early discussion about common project goals and technical concepts is essential to manage the complexity of such projects. The traditional concepts of simultaneous engineering, line and project management need to be adapted to the new environment. There is a shift from functional teams in line projects towards autonomous project teams. The new organisation is called "project house" where functional and cross-company activities are controlled and synchronised and project members of the participating enterprises work together. The advantage of the project house is that information can be exchanged quickly and solutions for problems and conflicts can be found more effectively due to an improved communication. However, as a project house is established only for the time of the project there are significant costs and high efforts to ensure confidentiality involved. Additionally, common processes still need to be defined and cultural differences identified (Hab and Wagner, 2006). Other problems are that specific project management standards or procedures are often implemented but project managers do not refer to these standards or obviously do not apply them. One of the reasons is that project management standards are developed externally and do not always meet the specific requirements of the companies' projects. Standards need to be designed and implemented by an internal team of experts and should be adaptable to the different 
types of projects. In cross-company and collaborative projects these standards have to be synchronised with standards being used in the automotive industry (Wagner, 2005).

\subsubsection{Engineering and the project management office}

Simultaneous Engineering (SE) is adopted in most of the projects in the automotive industry (Dixius, 1998). Within the SE core team, specifications, solutions, and decisions are coordinated that are related to the whole vehicle and its interfaces between the modules and main functional groups at the level of technical project management. Each module, depending on the complexity, includes a sub structure that requires another team. During the development process of a sub module or each functional group, the relevant departments work together by focusing on the specific process. The coordination of those teams is managed by an interdisciplinary and process oriented SE team that consists of a deputy from each division.

Next to Simultaneous Engineering other methods are necessary to manage the complex processes of a vehicle development. A global goal definition, e.g., is not sufficient as the objectives and requirements of the components and functions of the product need to be defined on several levels and scales. For the detailed definition of the technical project goals, the Quality Function Deployment (QFD) has been proven as a powerful method (Gessner, 2001). The product divisions define project goals in a two stage process. In the first stage, the goals are identified during a goal finding process. After that the team develops a project goal catalogue that quantifies and translates the goals into technical requirements. During the first stage, the development of a system consisting of several hierarchical lists, tables, and matrices (House of Quality) takes place. The goal agreement process in the second stage completes the project goal catalogue and ascertains the goal targets in the subsequent process chain.

Projects that run parallel in the context of multi project management are common in the automotive industry and the sum of all projects is defined as the project portfolio. Several projects that share similar goals and strategies, e.g., same client or product line, are summarised in a program. Project portfolio, program, and multi project management are relevant disciplines in the automotive industry that require a complex organisational structure. A multi and division project management office, and a project portfolio board that controls the divisions and steering committees are relevant elements of such organisation (Hab and Wagner, 2006). The strategic project management office at the 
level of the executive management board coordinates the project portfolio, the program office at the level of the division management coordinates the program management, and the project office assists in project coaching and control. The structure and tasks at each level is shown Figure 3.8.

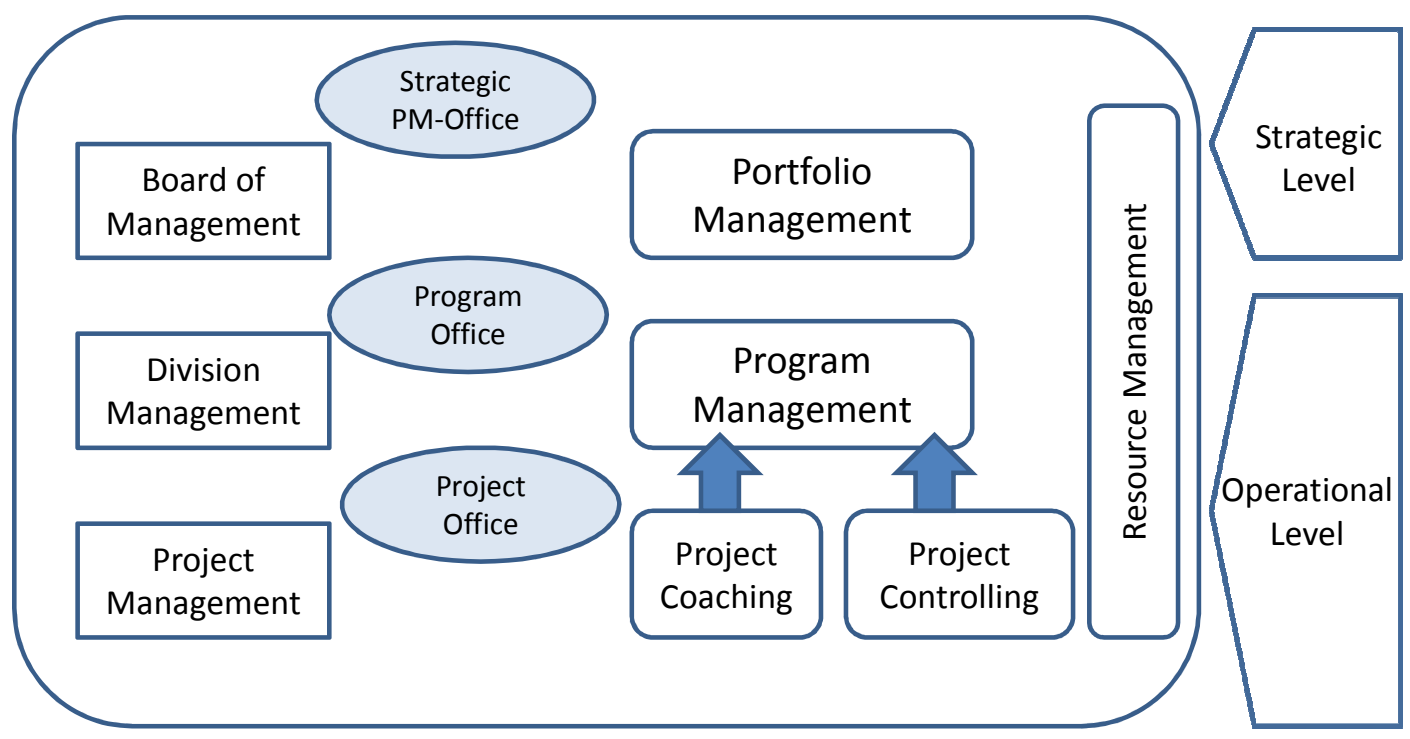

FIGURE 3.8: THE PROJECT MANAGEMENT OFFICE TASKS AT STRATEGIC AND OPERATIONAL LEVEL

(HAB AND WAGNER, 2006, P. 209)

\subsubsection{Project failures in the automotive industry}

A study of the GPM and the Fraunhofer Institute (IAO) in 2003 identified that there is still a $30 \%$ room for improvement to optimise the product development in the automotive industry, and project management plays a significant role in the improvement potential (Hab and Wagner, 2005). One reason is that many companies are not aware of the strategic significance of project management. A study of the PA Consulting Group and the GPM in 2007 revealed that a lack in communication caused $61 \%$ of the projects to fail, which is followed by $57.3 \%$ due to unclear requirements and project goals. Figure 3.9 shows the results of the joint study. 


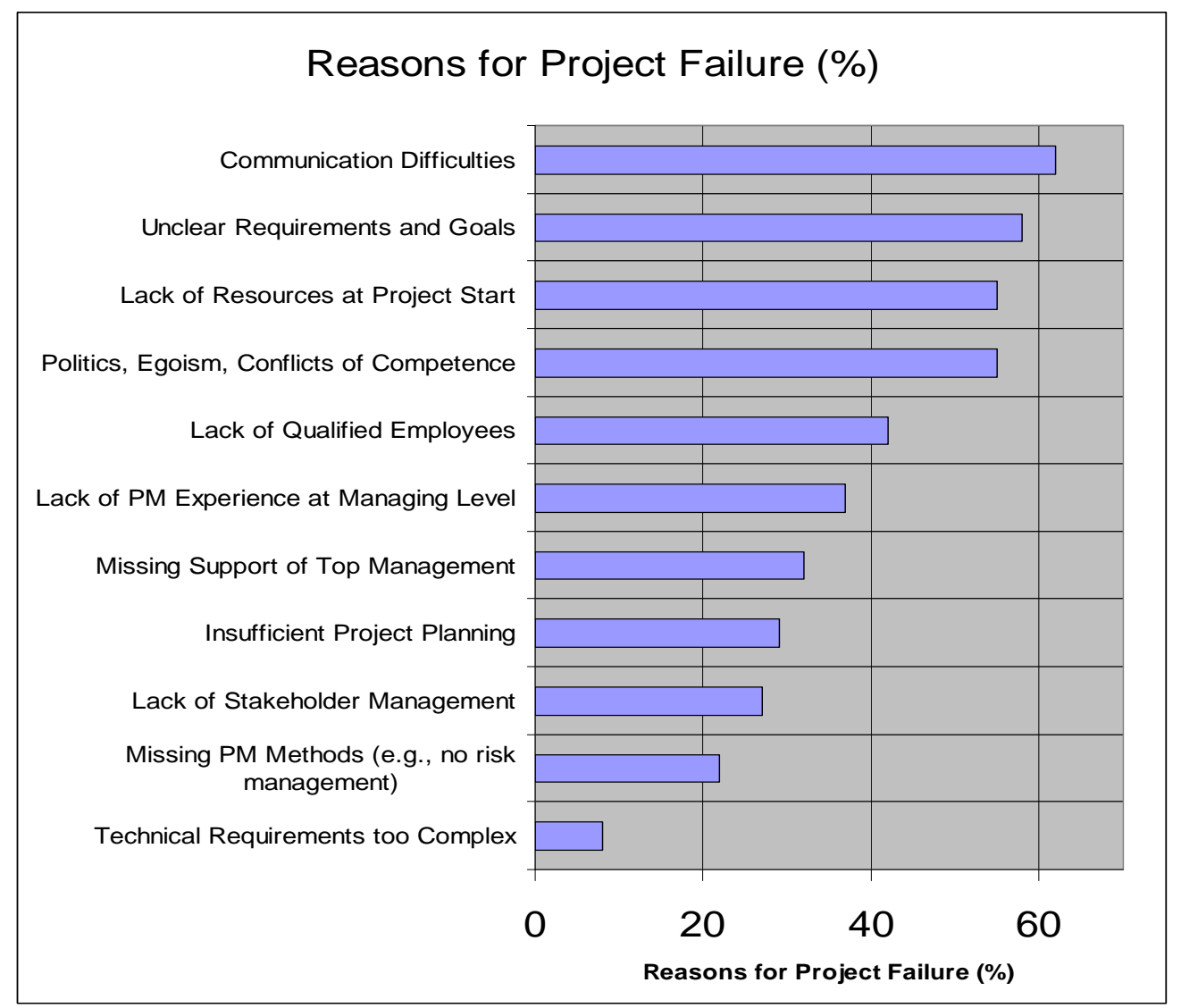

FIGURE 3.9: REASONS FOR PROJECT FAILURES (ENGEL AND HOLM, 2007)

Most of the study participants were project managers from the automotive industry $(17 \%)$, followed by the mechanical and plant engineering industry $(13 \%)$ and financial services (Engel and Holm, 2007).

The networked project structures require more effective and efficient methods of project management as the project environment underlies more dynamics and unforeseen changes. From the beginning of a project, project goals need to be clear for all project partners including responsibilities, tasks, competencies, and organisational regulations between manufacturer and supplier. A systematic change management, front-loading, and standardised processes supported by IT may support the project team to achieve higher efficiency (Hab and Wagner, 2006).

\subsection{Product development and project management in the automotive industry}

Project management and product development processes constantly interact. At specific milestones and synchronisation points project management coordinates product 
development. The next sections illustrate both disciplines and show their interdependencies in the automotive industry.

\subsubsection{Project and product development cycles}

The control of the product development process and the production in the automotive industry requires a detailed project management process. The project management controls all relevant development phases to achieve the required quality and to stay in time and budget. Product data management, continuous collision control by digital mock up (DMU), Failure Mode and Effects Analysis (FMEA), change, tolerance, and interface management, as well as maturity stage control are elements of the technical development process to be controlled by project management.

Every project can be structured into several phases: definition, planning, control and change, and closure. The interrelations of these phases are shown in Figure 3.10.

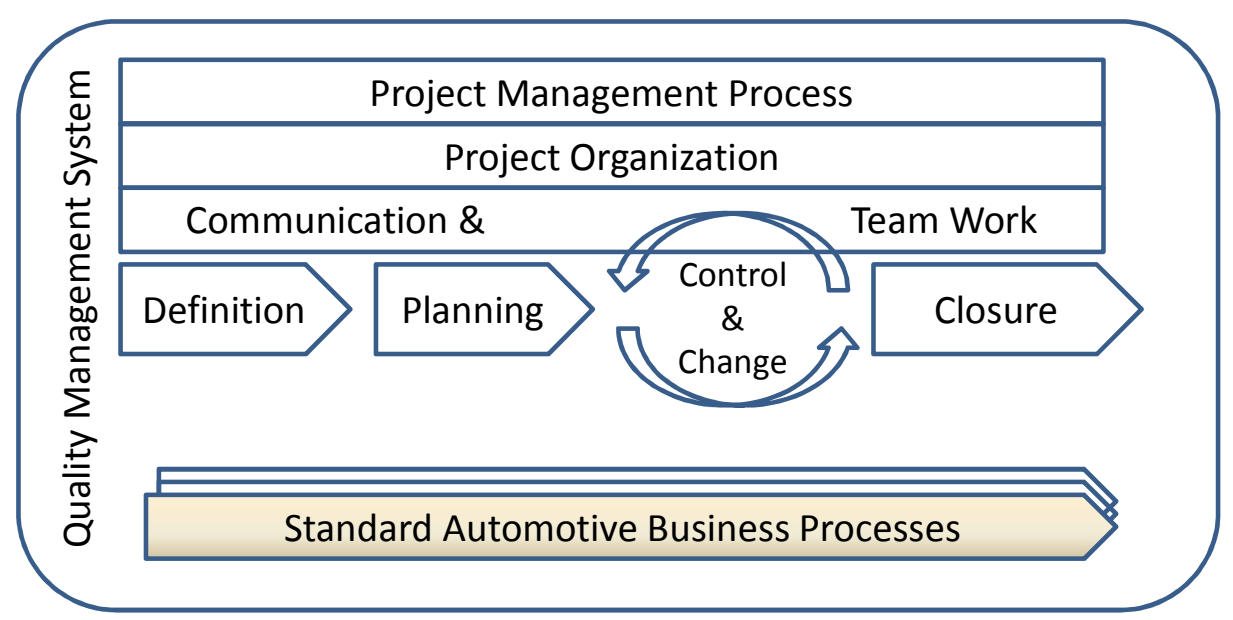

FiguRE 3.10: INTERRELATION OF PRODUCT DEVELOPMENT PHASES (HAB AND WAGNER, 2006, P. 26)

Project management coordinates the activities necessary to meet the demands of the "magic triangle" of costs, quality and time, as well as product data management, error prevention due to Failure Mode and Effects Analysis, change management and quality gate control. Typically, a project begins with an order and an initialisation phase to define and plan the necessary tasks to successfully deliver the project results. The project management control cycle can be described as a continuous loop of executing, monitoring and control and planning of those activities until the project is finalised (Figure 3.11). 


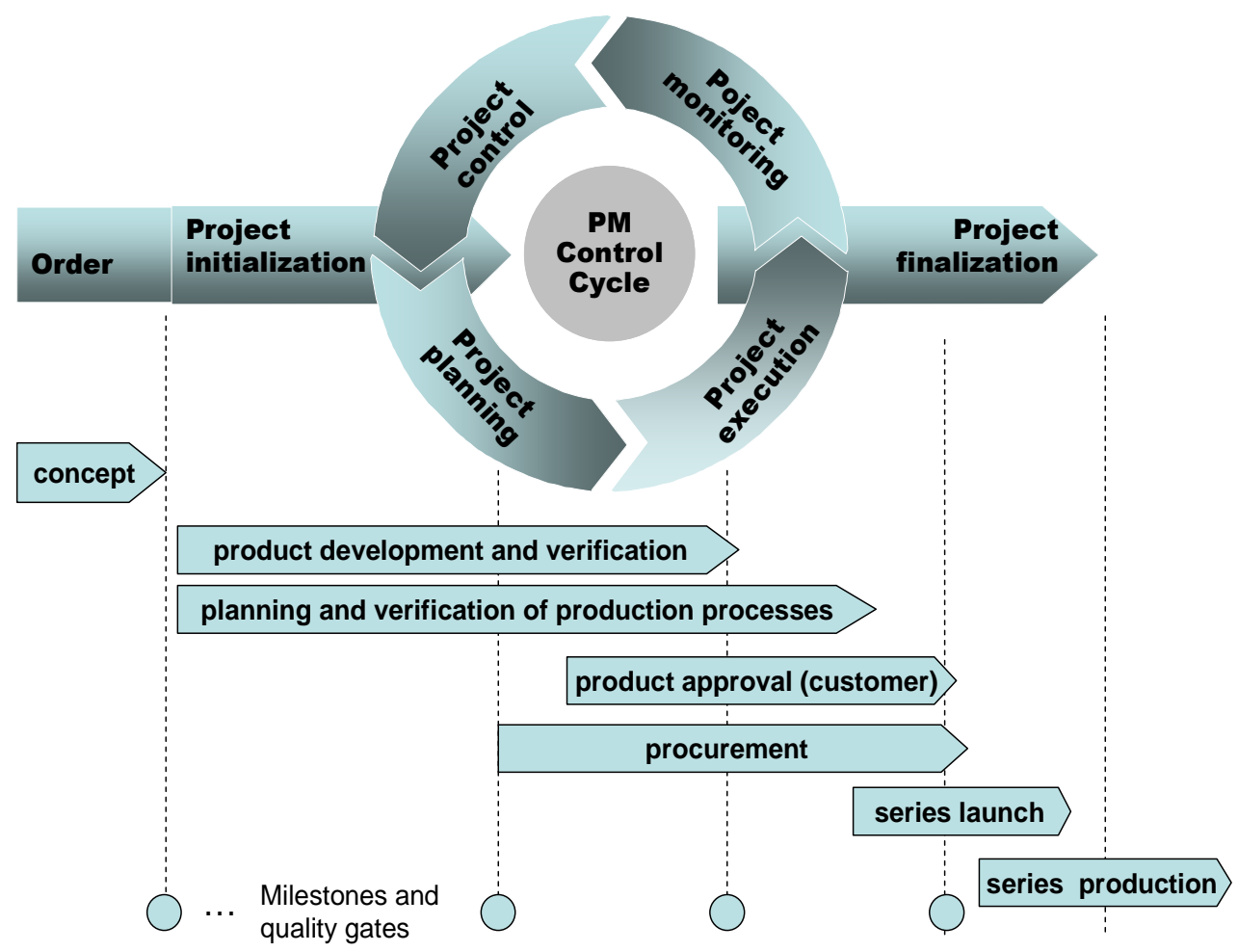

Figure 3.11: ProJect MANAGEMENT CONTROL CYCLE AND PRODUCT DEVELOPMENT PROCESS (VDA, 2003, P. 14)

Parallel to the project management phases, leading processes such as project organisation, communication and team work are relevant for a successful project closure. These leading processes sometimes have more impact on project success than assumed by automotive project managers (Wolf et al., 2006). Quality management standards, such as VDA 6, QS9000, APQP, and ISO 16949 have overlapping elements and due to a pressure to obtain certifications, many automotive firms have adopted the application of the project management phases as shown in Figure 3.11.

The core business of project management in the automotive industry is to plan and control the vehicle development process with respect to goals, objectives, resources, cost, and time. According to VDA (2003), the project management processes and the technical product development processes constantly interact as illustrated in Figure 3.12 . 


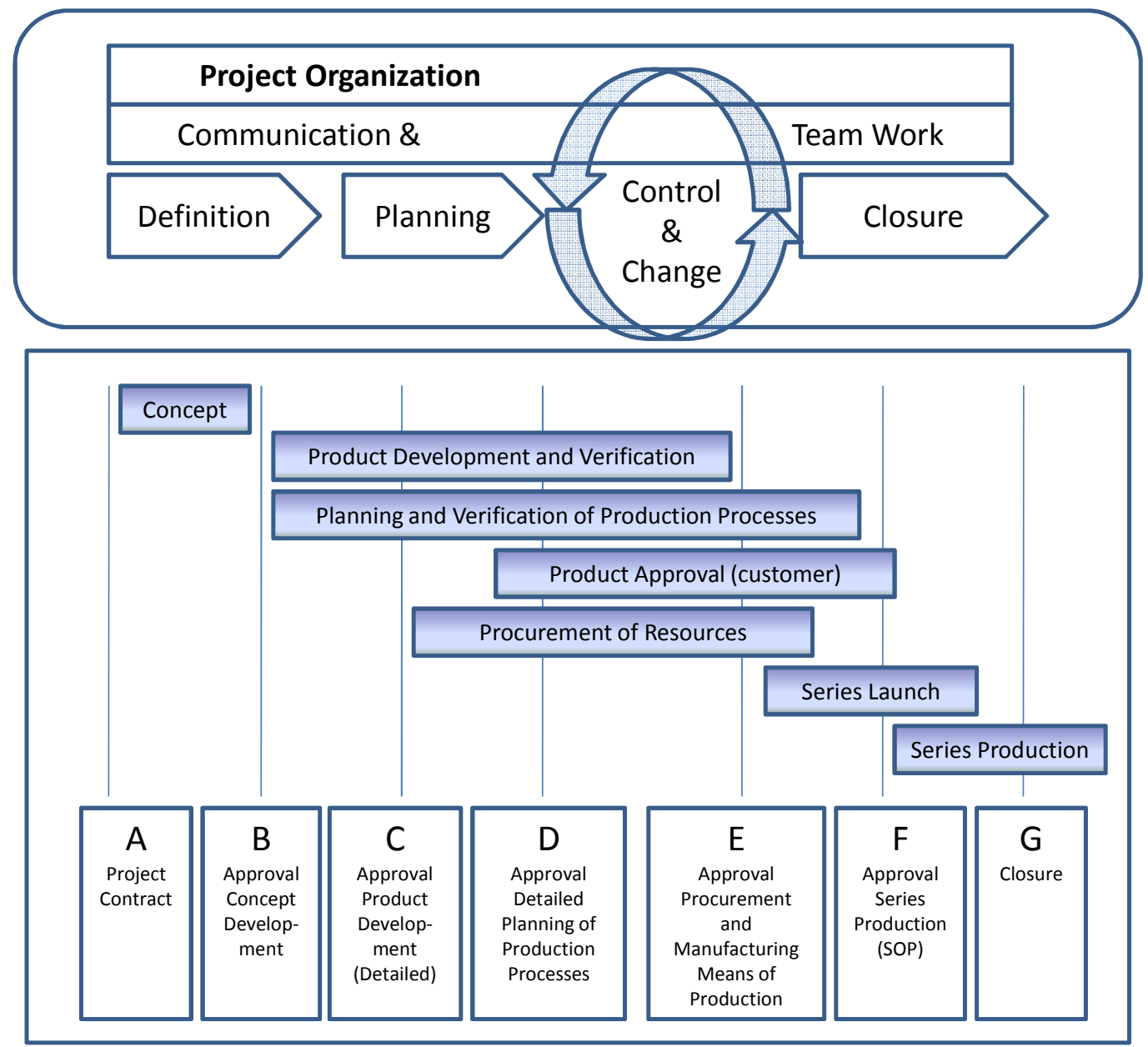

FIGURE 3.12: INTERACTION OF PROJECT MANAGEMENT AND TECHNICAL PRODUCT DEVELOPMENT PROCESSES (HAB AND WAGNER, 2006, P. 27)

Reliable and stable technical processes are an essential requirement for a successful project management and in most automotive companies these processes are already adopted on a standardised level. Parallel to the product development process, the manufacturing facilities need to be established. Milestones and synchronisation points are necessary to coordinate all parallel and subsequent processes. Quality gates are top milestones that define important steps and phases during the vehicle development. The definition of milestones in the early development phase of a project facilitates the implementation of strategic decisions in the offer phase for a coordinated tender and project start approval (Hab and Wagner, 2006).

\subsubsection{From definition to project and maturity stage control}

A project typically begins with a definition phase. Next to other tasks, project goals and specification documents are defined in this phase. The planning phase includes a more 
detailed approach and the objectives are structured into work packages. Project control ensures that all defined tasks, procedures, processes, etc. are within the defined and planned corridor. A maturity stage control supports the monitoring and evaluation of the current project status. The next sections describe the project management phases and control methods in more detail.

\subsubsection{Definition phase}

The definition phase of a vehicle project includes the clarification of project goals as part of the tender or specification document. Product specifications, quality, target and delivery dates (time), cost and strategies are approved in this phase. Responsibilities are clarified in an organisational chart as well as information flow and directions. Structures, such as milestone plans and a product and production facility structure facilitate the development of project transparency. Front-loading as a project management strategy, an analysis of the project environment, risk analysis, time and budget planning, requirements analysis, lead user analysis, benefit analysis, product, process and system FMEA, design for assembly (DFA), design for manufacturing (DFM), House of Quality, and network plan techniques are all elements of the project definition phase. The phase and milestone plan categorises the project into single steps and are part of the stage gate process (Kerzner, 2003).

Quality gates structure the product development process (PDP) into phases that allow the evaluation of the project status at each gate. Indicators and measurements define the requirements whether a gate can be passed or not. Synchronisation points support the coordination between manufacturers, suppliers, and development partners. At predefined times, the maturity of the development status is assessed and necessary decisions are made. Milestones and synchronisation points are also relevant indicators for progress control as the defined measurements indicate whether a certain deliverable is achieved or additional measures have to be taken. The internal kick-off meeting informs the business divisions and the responsible work package manager about contents, objectives, structures, organisation, and time plan of the project. It also officially initiates the project within the organisation. The external kick-off meeting with the project partners is relevant to clarify the contract deliverables, interfaces, and responsibilities during the project. The next step is the elaboration of the project plan. 


\subsubsection{Project planning and control}

A planning workshop helps the project team to develop the plan and to familiarise with the project members. This is especially important if the project team members are geographically dispersed during the project duration. Part of this workshop is the structuring of the project and work packages to reduce complexity. In a further step, tasks are summarised in a timely manner to define detailed work packages. After estimating the effort for each work packages they are delivered to the responsible work package manager to approve target values for resources and cost, as well as duration and cycle times for the time plan. Figure 3.13 shows the relevant steps of the planning workshop including the kick-off workshop in the definition phase.

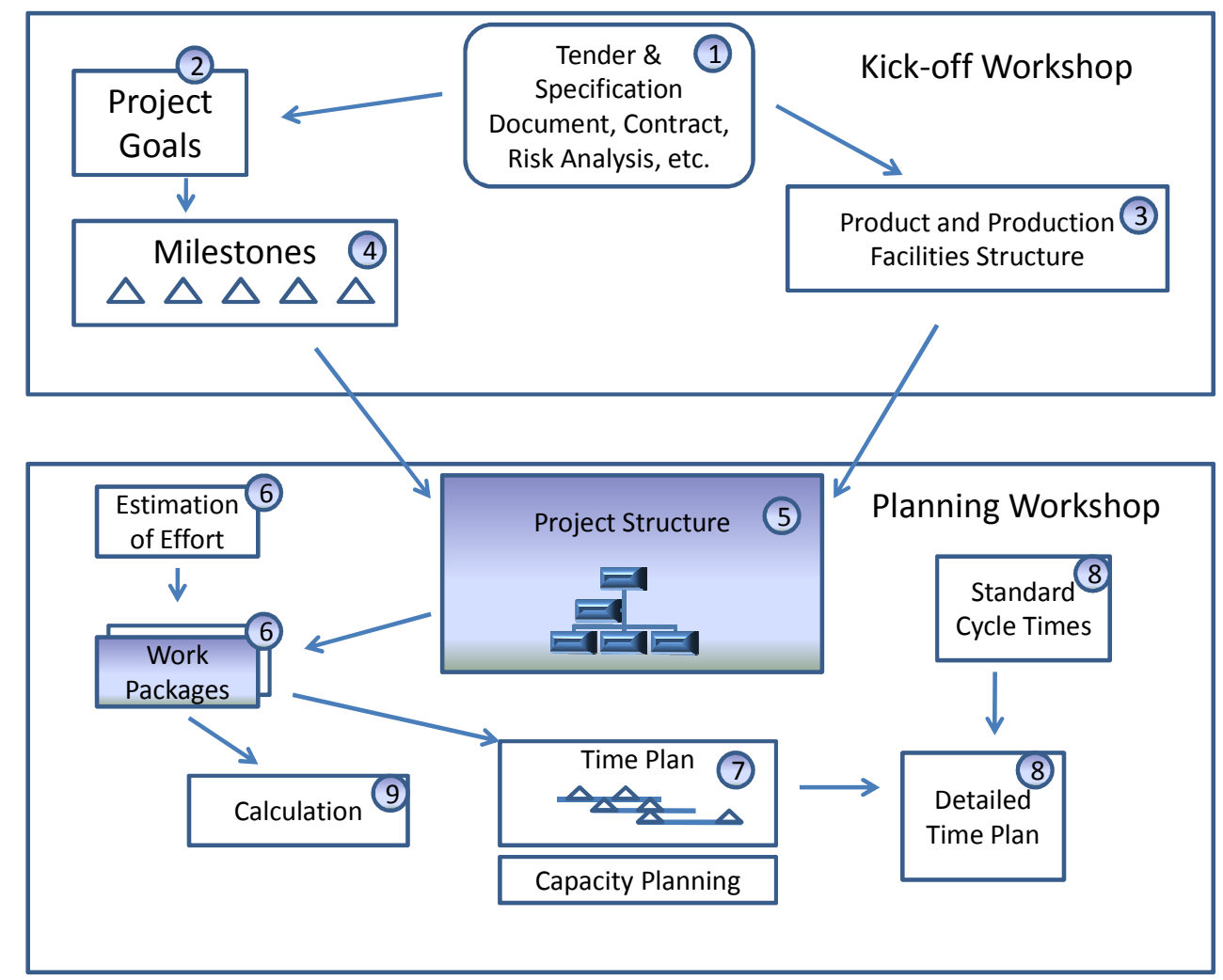

FIGURE 3.13: FROM KICK-OFF TO PLANNING WORKSHOP (HAB AND WAGNER, 2006, P. 109)

The result of the planning workshop is the project structure plan that is the basis for project planning and control with regard to cost, time and tasks. It includes all necessary tasks and work packages and categorises the activities into work units regarding to the milestones. A detailed time plan, cost plan and calculation, risk management (risk analysis: risk identification and evaluation, risk measures and success control) with a risk management process, risk checklists (technical, commercial, organisational risks) are part of the project planning phase. 
Project control is characterised by a continuous monitoring and control of milestones, cost, project objectives, and tasks. As in most automotive projects deviations from the initial plan occur, change and claim management are required. The project management control cycle that was described in the previous section includes a steady control of the target and actual project status (variance analysis/target-actual comparison). Traffic signals (red, yellow, green) indicate whether a milestone or quality gate can be passed or the target may possibly or certainly not be achieved if corrective action is not implemented. A possible definition of the traffic light indicators is shown in Figure 3.14.

\begin{tabular}{|l|l|}
\hline SIGNAL & Definition \\
\hline RED & $\begin{array}{l}\text { Actual deviates from target value: there is } \\
\text { no corrective action plan available }\end{array}$ \\
\hline GREEN & $\begin{array}{l}\text { Actual deviates from target value: there is } \\
\text { an approved corrective action plan } \\
\text { available }\end{array}$ \\
\hline Actual and target value are corresponding
\end{tabular}

FIGURE 3.14: POSSIBLE DEFINITION OF TRAFFIC LIGHTS FOR QUALITY GATE CONTROL

(HAB AND WAGNER, 2006, P. 146)

The evaluation of progress also includes the estimation of future target values. A milestone trend analysis (MTA) is useful to visualise the results in time and to identify major trends that allows for preventative action.

\subsubsection{Project maturity control}

Stage maturity control of the product and processes is relevant to measure the actual progress of a project and product. Indicators that measure the maturity can be fixed, such as weight, manufacturing cost, quality, or they can depend on time (output indicators), e.g. approvals, launch curves, or vehicle testings. Input indicators to evaluate efficiency of a development process can be the resource consumption or the cost increase of a project. 
Deviations from the indicator's target value need to be controlled with corrective action and measures. The 8D (8 Disciplines) Method is one possibility to identify the unknown reasons for a deviation. The steps are shown in Figure 3.15.

D1: Assemble a cross-functional team of experts

D2: Define the problem

D3: Implement and verify interim containment actions (ICAs) as needed

D4: Identify and verify root cause

D5: Choose and verify permanent corrective actions (PCAs). preventive actions are also chosen.

D6: Implement and validate permanent corrective actions

D7: Prevent recurrence of the problem/root cause

D8: Recognize the efforts of the team

Figure 3.15: STEPS OF THE 8D METHOD (HAB AND WAGNER, 2006, P. 165)

Project reporting ensures the information flow between the project team and the stakeholders or steering committee. Standardised reporting measures and indicators are developed to evaluate the current status with regard to the business plan. Usually, these reports are produced on a monthly basis. Other means of communicating the project status are dashboards, generally supported by IT solutions. They are also called project cockpits and typically include a cost control diagram, milestone trend analysis, review iteration, and degree of completion (Wildemann, 2004). A systematic illustration is shown in Figure 3.16.

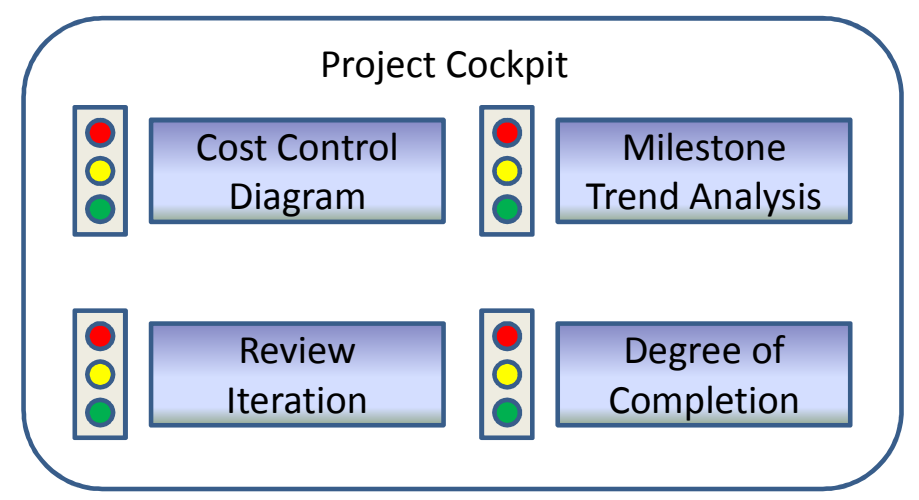

Figure 3.16: SimPLIFIEd ILLUSTRATION OF A PROJECT CoCKPIT

Traffic lights indicate the current status of each indicator or measurement. The project cockpit is an efficient monitoring tool and the scope of the cockpit can be extended by other relevant project objectives and status relevant information. The Project Scorecard 
(PSC) that is described in Chapter 6 in more detail is a possible extension to the project cockpit as it integrates methods based on the Balanced Scorecard. The major difference is that not only hard facts, such as cost, are integrated but also soft facts that, for example, describe the quality or performance of team work.

\subsection{Change, claim and configuration management}

Changes occur frequently in a vehicle project and are partially caused by the application of Simultaneous Engineering that aims to achieve shorter product life cycles. Other reasons are the current speed of changes in innovation; therefore, relevant changes need to be managed during the development and also during the production phase of a vehicle. Changes are defined agreed commitments of a new state instead of the former state and its related transformation (Lindemann et al., 1998). Causes for change can be divided into changes due to mistakes or functional difficulties, and changes caused by new customer requests or new laws and regulations, new technologies or materials.

Claim management includes the monitoring and control, documenting, and defence of requests by the customer or client that were not approved in the project contract. In automotive projects claims typically concern design or component changes, time changes, quality problems or delayed approvals. Claim management documents the demands and requirements of the organisation or of the own project and defends the organisation's demands against the project partner (Kuehnel et al., 2002).

In a complex and dynamic project change is inevitable. Configuration management does not consider changes as avoidable disturbances but as chances to improve the development, procurement, and production process. It controls the change processes of a project and ensures documentation so that the product and its structure are generated and contents and scope of the project are updated with regard to the project plan. Therefore, configuration management increases transparency and quality sustainably (Saynisch, 2006). Configuration management is divided into configuration identification, configuration monitoring (change management), configuration auditing, and configuration documentation. 


\subsection{Product data management (PDM)}

The documentation of project data and an ensured access to current and updated information is relevant for an efficient project cycle management. Systems for product data management (PDM) or engineering data management (EDM) typically include product descriptions, illustrations of technical and organisational business processes and, therefore, functionalities of project management. Next to project planning and control, such systems also include functionality for change management. Information flow is realised by a work flow manager that coordinates the relevant activities for each project member and documents all operations automatically. Due to an increased team oriented work environment, the development and design engineer is more and more involved in the planning, procurement, and production process. Therefore, the engineer needs new methods for decision support. The newly developed PDM systems for product development and life cycle management include an additional scope of electronic engineering, supply chain management and configuration management (Eigner and Stelzer, 2004). Status reports or dashboards represent the current project or even program status. Documentation of operations between project partners is also a part of the Advanced Product Quality Planning And Control Plan (APQP) that requires a system support for the documentation process (AIAG, 1995). 


\section{Cross-company project management}

In the centre of virtual organisations are project-based activities that act in a time limited framework of distributed project teams. Complex products are generally the result of collective effort in a networked project environment where the product integrator acts as a network manager or central hub and coordinates product contributors, suppliers, and other project partners. The increase of distributed projects creates new challenges with respect to coordination and control functions, as well as information technologies and interpersonal effects (Bourgault et al., 2002).

This chapter begins with a definition of collaborative project management and defines the role of virtual teams in project management and in product development projects in particular. Cultural aspects are important factors that can influence a cross-company project. Together with increasingly complex projects and work environments that are globally networked difficulties arise. The automotive industry has some specific difficulties and impact factors that cause problems and are also part of this chapter. Figure 4.1 shows how this chapter is structured in detail.

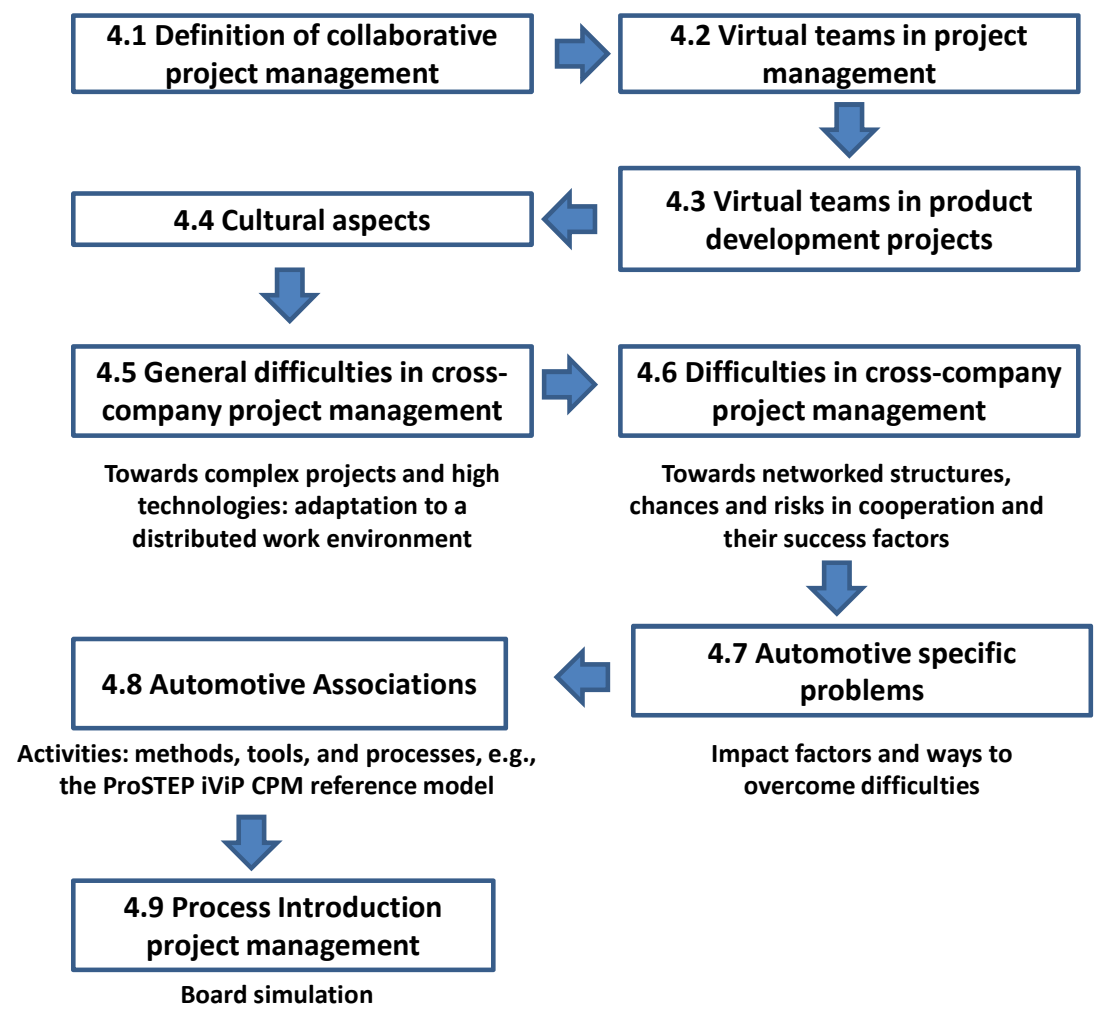

FIGURE 4.1: OVERVIEW OF CHAPTER 4 
The automotive specific problems and ways to overcome them are followed by the current activities of major German automotive associations. As an example, the ProSTEP iViP Collaborative Project Management (CPM) reference model is presented. This model is also relevant to Chapter 11 where the integration with the Collaborative Project Scorecard is discussed. The development of new and adapted processes is necessary to manage projects successfully today and also in the future. However, the introduction of new processes faces several problems. Board simulation is a way to facilitate a method or process introduction and is part of the last section of this chapter.

\subsection{Definition of collaborative and cross-company project management}

Traditional project management has a focus on single projects and at single locations. In this environment project inputs and outputs are more important than the project activities itself (Turner, 2000). Traditional project management also emphasises the scheduling, planning and tracking activities (Evaristo et al., 1999) and the project management paradigm began shifting due to the increasing number of distributed and geographically dispersed projects that involve team members from different organisations, locations, and cultural backgrounds (Jonsson, 2001). The impact of communication technologies (Walther, 1997) as well as trust and motivation on the effectiveness of collaboration needs greater attention to be prepared for the future development (Warkentin et al., 1999). Some reasons and principal forces for project teams that become more and more distributed are advances in technology and the need for larger and more complex systems, as well as the need for companies to become more competitive (Nidiffer, 2005).

Current and future project management has rather a focus on project work and processes. Collaboration is essential for its success and project management fundamentals are changing due to business and technological drivers. The challenge of virtual project management supports collaboration among team members working at different locations, time zones or across different organisations.

Evaristo and Fenema classified projects into seven different types that are predicated on two dimensions of single versus multiple projects and single versus multiple sites (Figure 4.2). 


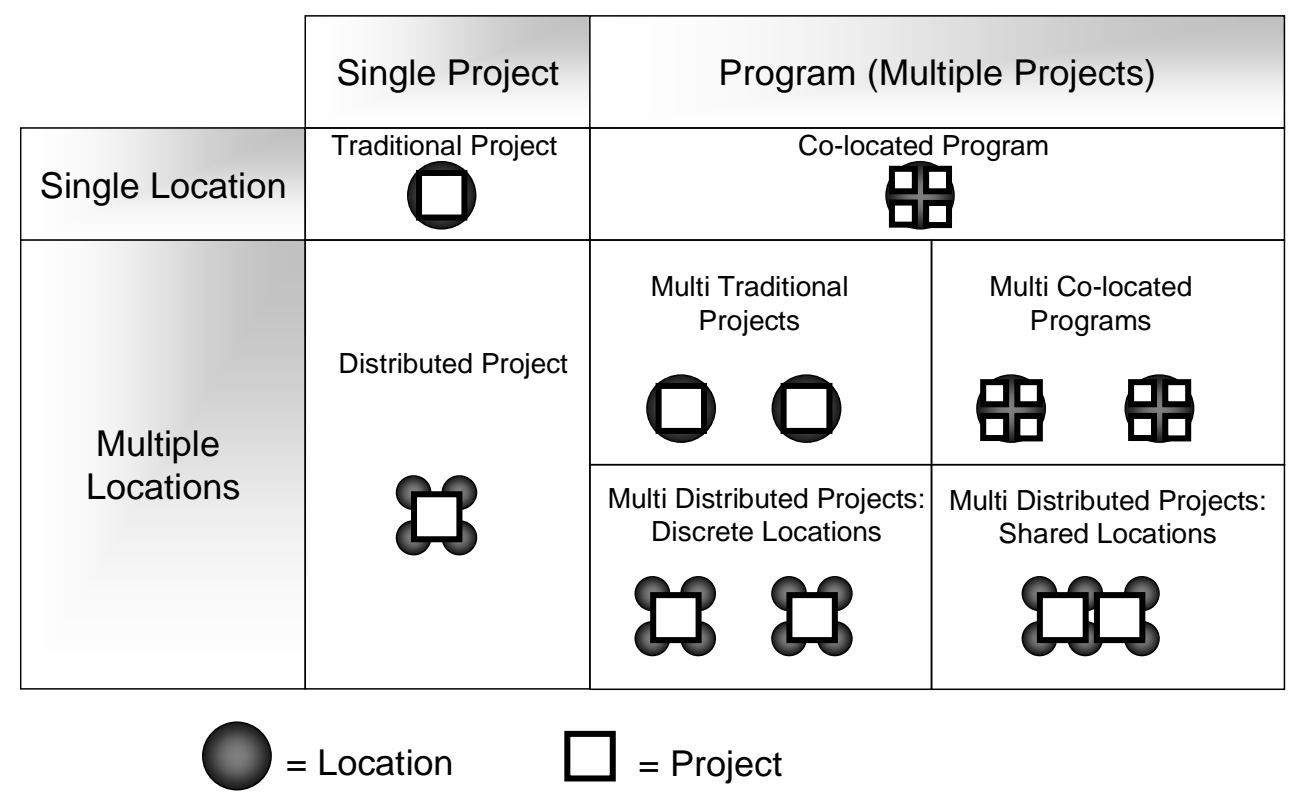

Figure 4.2: Project CLASSIFICATION SCHEME (Evaristo ET AL., 1999, P. 277)

Evaristo et al. (1999) assume that the critical difference between a distributed and a traditional project are related to the coordination mechanism and that traditional project management emphasises the management of single projects at a single location with a focus on scheduling. Collaborative project management is defined as any projectoriented collaboration between two and more project teams. These teams can either be from the same organisation or distributed over several different organisations or companies. Therefore, a project that acts between different divisions located at different geographical locations and/or over different time zones of a single organisation can be considered as a collaborative project.

When a project acts across different organisations and companies, it can be defined as a cross-company project that also includes the characteristics of a collaborative project. Major differences are that cross-company projects tend to be more complex and face more difficulties and constraints. Some of them are information protection, management of innovation, and different business processes that require the definition of standardised interfaces and common process for collaborative project management. Cross-company project management is often defined as cross-company collaboration project management (C3PM) as it includes also the collaboration aspects as previously defined. 


\subsection{Virtual teams in project management}

Mayer (1998) describes the virtual team as a team that is composed of people who are distributed across buildings, states, and countries. Mayer also noted that the virtual organisation is the model for corporations in the future. The Project Management Institute showed results in 2001 that $21 \%$ of the respondents worked on a project involving multiple states or provinces, and $15 \%$ worked on projects involving multiple continents (PMI, 2001). One of the reasons for this transformation is that employees, suppliers, and manufacturers are not located in the same city but rather in different locations and continents with different time zones. Rad (2003, p.1) also believes that "global projects with virtual teams have emerged as vehicles by which the cost and duration of projects can be reduced while maintaining a reasonable control on the quality and scope of the projects".

\subsubsection{Definition of virtual project teams}

Virtual teams may also be defined as team members who are geographically dispersed and work collaboratively on the same project. These team members can be members of the same company or organisation, or members of two or more companies working in a cross-company project and at different locations. In that case, project deliverables are distributed and project management is partially or fully decentralised. Project planning, monitoring and control methods of virtual teams differ from conventional techniques and different factors influence their performance (Akilesh et al., 2002).

Gray and Larson (2002) define projects consisting of virtual team members as "international projects" and according to them the number of international projects continues to increase. Kahn (2005) also realises the increase of virtual teams in the development of products. This increase of virtual project environments requires the development of new methods to manage barriers due to the distance of project members but also due to cultural aspects. Additionally, knowledge management and information protection is facing essential changes in the planning and monitoring process. 


\subsubsection{Levels of collaboration}

Collaboration can be categorised into different levels. A major framework that is widely accepted is the collaboration framework developed by Nunamaker et al. (2000). It consists of five different levels: communicative, collective, coordinative, and concerted and is shown in Table 4.1.

\begin{tabular}{|c|c|c|c|c|c|}
\hline Levels & $\begin{array}{l}\text { Nature of } \\
\text { efforts }\end{array}$ & $\begin{array}{c}\text { Team } \\
\text { productivity }\end{array}$ & Process/tasks & Applications & Metaphors \\
\hline Communicative & $\begin{array}{c}\text { dialog and } \\
\text { common } \\
\text { understanding, } \\
\text { dominated or } \\
\text { egalitarian, } \\
\text { information } \\
\text { sharing, non } \\
\text { task oriented. }\end{array}$ & minimal & $\begin{array}{l}\text { informal/ semi- } \\
\text { formal } \\
\text { communication, } \\
\text { conversational, } \\
\text { chaotic, } \\
\text { unstructured, } \\
\text { uncoordinated. }\end{array}$ & $\begin{array}{c}\text { email, chat, } \\
\text { notes/ } \\
\text { databases, news } \\
\text { groups, } \\
\text { computer- } \\
\text { mediated } \\
\text { communication. }\end{array}$ & $\begin{array}{l}\text { huddle, } \\
\text { hallway } \\
\text { meeting, } \\
\text { coffee clutch. }\end{array}$ \\
\hline Collective & $\begin{array}{l}\text { individual, } \\
\text { separate, } \\
\text { piece-meal } \\
\text { tasks. }\end{array}$ & $\begin{array}{l}\text { sum of individual } \\
\text { performances }\end{array}$ & $\begin{array}{c}\text { individualised } \\
\text { (start-end), minimal } \\
\text { integration. }\end{array}$ & $\begin{array}{c}\text { word } \\
\text { processing, } \\
\text { spreadsheets, } \\
\text { graphics. }\end{array}$ & sprinters \\
\hline Cooperative & $\begin{array}{l}\text { group-based, } \\
\text { uncoordinated. }\end{array}$ & $\begin{array}{c}\text { sum of individual } \\
\text { performances }\end{array}$ & $\begin{array}{l}\text { ad hoc, separate } \\
\text { tasks toward } \\
\text { common goal } \\
\text { final integration. }\end{array}$ & $\begin{array}{l}\text { net meeting } \\
\text { application } \\
\text { sharing }\end{array}$ & $\begin{array}{l}\text { hockey, } \\
\text { soccer. }\end{array}$ \\
\hline Coordinated & $\begin{array}{l}\text { sequential } \\
\text { team, } \\
\text { precedential. }\end{array}$ & $\begin{array}{c}\text { sum of } \\
\text { sequential } \\
\text { individual } \\
\text { performances }\end{array}$ & $\begin{array}{l}\text { chronological, step } \\
\text { by step, ordered, } \\
\text { hand-offs, work } \\
\text { flow oriented, } \\
\text { progressive } \\
\text { integration. }\end{array}$ & work flow & $\begin{array}{l}\text { relay, work } \\
\text { flow. }\end{array}$ \\
\hline Concerted & $\begin{array}{c}\text { mutual, } \\
\text { communal. }\end{array}$ & $\begin{array}{l}\text { sum of } \\
\text { individual, ad- } \\
\text { hoc team and } \\
\text { coordinated } \\
\text { team } \\
\text { performances }\end{array}$ & $\begin{array}{c}\text { jointly shared, } \\
\text { synchronised, } \\
\text { continuously, } \\
\text { integrative, } \\
\text { simultaneous, } \\
\text { flexible, } \\
\text { repeatable, } \\
\text { customisable. }\end{array}$ & $\begin{array}{l}\text { group support } \\
\text { systems, } \\
\text { computer } \\
\text { supported, } \\
\text { collaborative } \\
\text { work. }\end{array}$ & $\begin{array}{l}\text { crew, tug of } \\
\text { war, group } \\
\text { writing, group } \\
\text { problem } \\
\text { solving. }\end{array}$ \\
\hline
\end{tabular}

Table 4.1: Collaboration framework (Nunamaker et al., 2000)

A simpler framework reduces the five levels to three: collected, coordinated and concerted (Chen et al., 2002). The level concerted is the level that contributes with the most value to project management as it offers effective and efficient support for complexity management (Romano, 2002). The collected level is described by individual 
efforts of team members where no coordination is required for achieving productivity. Group productivity is cumulated by individual efforts and is similar to sprinters who aim to make their best individual effort. At the coordinated level, each member still contributes individually with their effort but success of some of the team members might depend on a timely achievement of deliverables produced by other team members. The success of the team depends on the coordination ability and can be described by a team of relay runners. The level of collaboration includes managing of interdependencies between activities. The coordinated level is characterised by the contribution of the whole team to the group effort as performance of any other member has an impact on the ability of all other members to the overall performance. A rowing team is a metaphor that describes this level best as all rowers have to synchronise their efforts and contribute simultaneously to achieve successful results. Figure 4.3 shows the hierarchical model of collaboration described in this paragraph.

\section{Hierarchy of Collaboration}

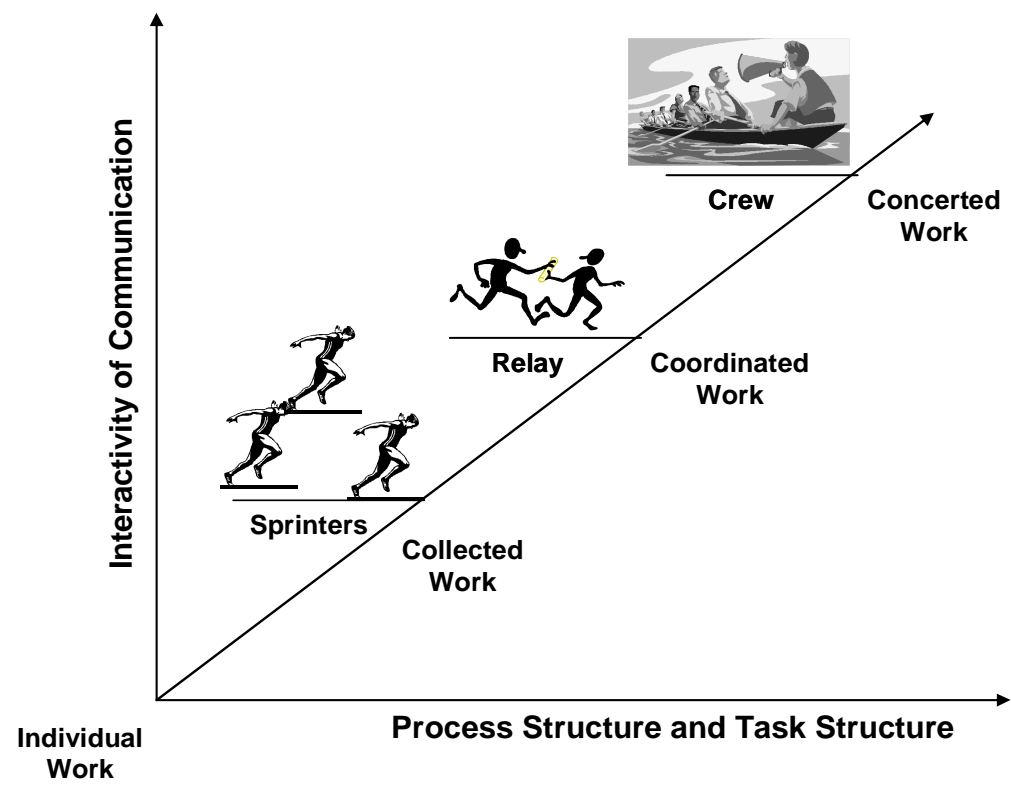

Figure 4.3: HieRARCHY OF COLLABORATION (CHEN ET AL., 2002, P. 8)

Project management at a concerted level requires effective coordination of all project members and a project management tool should support all functions involved.

\subsubsection{Collaboration as a key to business success}

Due to globalisation and growing competition on the international marketplace companies and organisations are forced to strengthen collaboration in project 
management. Major progress in information and communication technology allows a distribution of work packages and tasks but also in product development, production, sales, and important management functions. Especially, product development organisations aim to distribute and relocate parts of the development to foreign low cost countries, not only to save cost but also to use resources and local know-how more efficiently. The IT industry has begun very early with the relocation and distribution of project teams and aimed to overcome the new difficulties and challenges. However, the lack of standardised collaborative methods and processes has caused the failure of several projects in those times (Prikladnicki et al., 2004).

According to a study of the Deutsche Bank Research, $15 \%$ of the value creation chain in Germany will be characterised by temporary, cooperative, and often international value creation processes. In 2007, the contribution was only $2 \%$. The Deutsche Bank Research deduces the development from an increasing level of innovation in information technology. On the basis of a project managed by the Deutsche Bank Research in 2005, a scenario analysis was applied and several impact factors on future structural change implied. Included were dynamic factors based on identified trends (Bergheim, 2005).

\subsubsection{Early identification of collaboration benefits}

Various developments were summarised to the two major core dynamics of "configuration of the political-legal framework and use of the societal potential" and "change of business culture and value creation pattern". A main result of the Deutsche Bank Research study is that the comprehensive value creation will manifest as a "project economic System" in 2020. The "Project Economic System" is defined as a cooperative value creation in organisational and judicial independent and temporary projects. These results are based on the assumption that project cooperation boosts flexibility and innovation, as well as it limits and distributes risks between project partners. In the course of globalization, companies can only act collaboratively, i.e. cooperatively. The relevant depth of knowledge to develop new products is only ensured by efficient cooperation where individual survival can only be assured by a strong specialization. The results of the survey lead to the conclusion that organisations have to think about cooperation relevant aspects early to stay competitive in the future. One aspect, e.g., is the specific choice of a cooperation partner and the clear definition 
of roles in that cooperation. The open up of innovation processes to partners and customers is a relevant criterion of success (Bergheim, 2005).

\subsubsection{The definition of collaborative standards as a key to success}

Clearly defined rules for the distribution of rights regarding the development results need to be discussed, therefore, early development, adoptions and implementation of standards is a key to success for all involved partners. A reason for this is that partners within the "project economic system" change frequently and standards for human resource and information management as well as technical interfaces for collaborative product development, services, and systems are required. Project relevant databases need to be connected efficiently that customer data, design data, and process parameters can be exchanged safely (Hofmann et al., 2007).

\subsection{Virtual teams and product development projects}

Cross-company and virtual development teams are facing new challenges on a technical and project management level as products are increasingly developed in cross-company and geographically dispersed project teams. The section describes the aspects of distributed product development in more detail.

\subsubsection{Distributed product development}

Product development includes the holistic planning of a product life cycle that is influenced by various impacts (Birkhofer, 2000). Product development is typically structured into the phases of product planning, task clarification, product conception, product draft and product engineering.

The interaction with and integration of the product life cycle is an essential element of product development and is embedded into a structure of several levels and perspectives (Prasad, 1996). Perspectives are organisation, product, and process. The relation to the hierarchical levels is illustrated in Table 4.2. 


\begin{tabular}{|c|c|c|c|c|}
\hline & \multicolumn{2}{|c|}{ Organisation } & Product & Process \\
\hline \multirow{6}{*}{$\begin{array}{l}\text { Hierarchy } \\
\text { Levels } \\
\text { (top-down) }\end{array}$} & Business Unit & Tasks & & Modelling element \\
\hline & $\begin{array}{c}\text { Strategic business } \\
\text { Unit }\end{array}$ & $\begin{array}{l}\text { Project vision } \\
\text { and Mission }\end{array}$ & System & Process \\
\hline & sub unit & $\begin{array}{l}\text { Strategies, } \\
\text { values, } \\
\text { objectives }\end{array}$ & Sub system & Sub process \\
\hline & $\begin{array}{c}\text { Product } \\
\text { development team }\end{array}$ & $\begin{array}{c}\text { Project initiatives } \\
\text { and tasks }\end{array}$ & Components & $\begin{array}{l}\text { Activities, functional } \\
\text { chain (sub-sub } \\
\text { process) }\end{array}$ \\
\hline & Work group & Project teams & Parts & $\begin{array}{l}\text { Work procedures, } \\
\text { sub functions }\end{array}$ \\
\hline & Experts & $\begin{array}{c}\text { Team members, } \\
\text { time plans }\end{array}$ & Attribute & Activities, methods \\
\hline
\end{tabular}

TABle 4.2: Organisational StRUCtURe OF PRODUCt DeVELOPMENT (PRASAD, 1996, P. 397)

Product development within geographically dispersed project teams is often called "collaborative product design" or "collaborative product development". Gierhardt (2001) defines the distributed product development as a combination and configuration of different process elements: human beings, material, activities, methods and tools for an effective and efficient development of products. His theory is based on the principles of systems engineering (Daenzer et al., 1997).

\subsubsection{Cooperation model for distributed product development}

A cooperation model defined by Gierhardt (2001) extends the traditional understanding of visualising the interface between partners in a global and distributed product development only. It aims to represent the complex cooperation processes and correlations between a distributed environment and the process, organisational, and product level. The model describes collaborative team work of different development partners in a dispersed environment and assumes that the reason for collaboration is the solution of a development task. A major element of the model is represented by the activities of the development partners that act within five levels: the process, organisational, product, knowledge, and objective level. The second element is the distribution space where all activities take place. Figure 4.4 illustrates the cooperation model. 


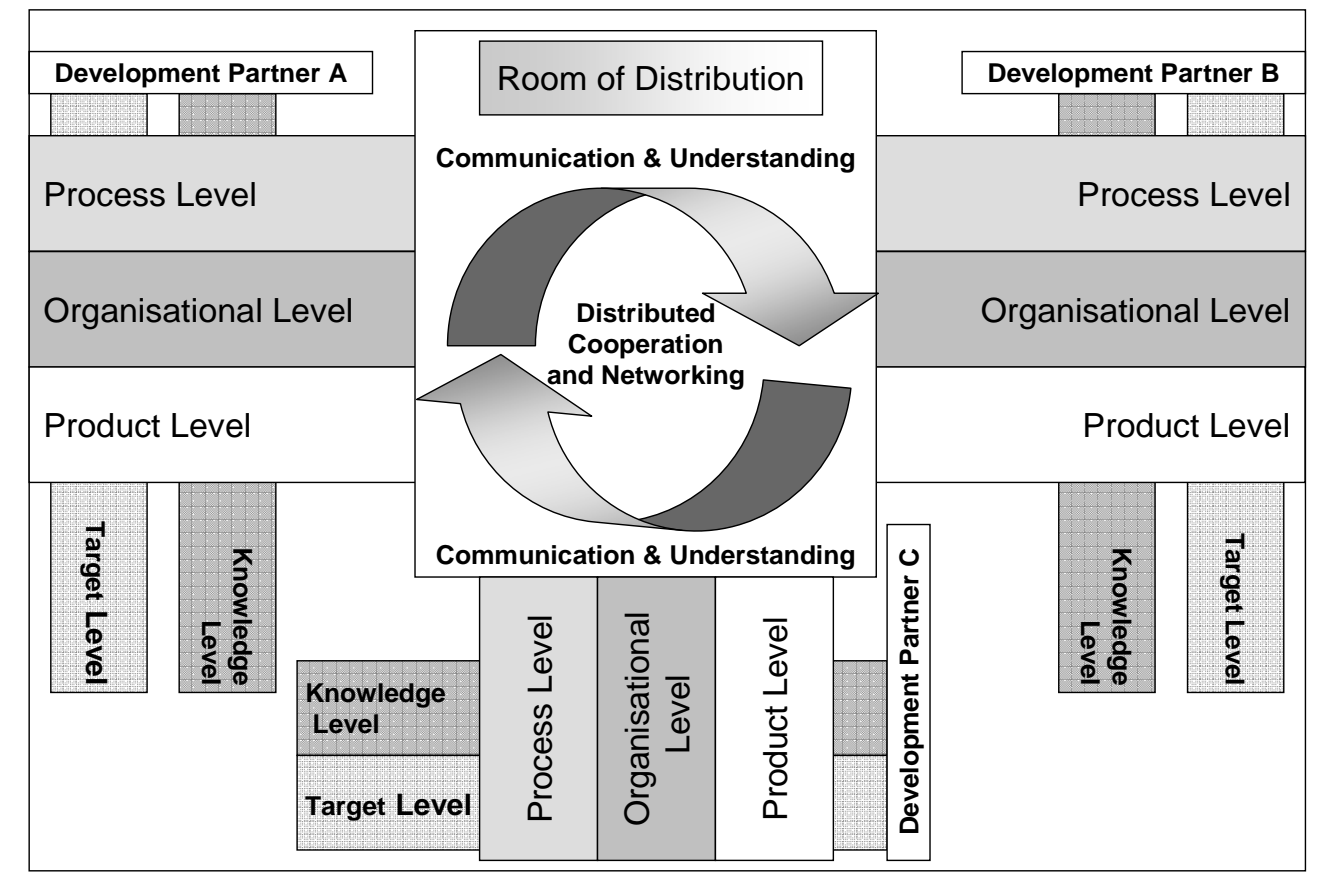

FIGURE 4.4: COOPERATION MODEL OF DISTRIBUTED PRODUCT DEVELOPMENT

(GIERHARDT, 2001, P.56)

Within the distributed cooperation, activities are networked with the distribution space; therefore, understanding is a relevant requirement for the project. Understanding is described by information as contents and communication as a transfer process. The activity level of the development partners represent the levels of the distributed product development and are the basis of cooperation due to their networked structure.

\subsubsection{Communication as a driving force}

The communication process in product development organisations is considered as a key element to improve development performance. Information exchange in geographically dispersed product development teams is of a highly interdependent nature, and the use of electronic-based communication media changed the way development teams communicate (Sosa et al., 2002). Global new product development project teams are becoming increasingly common due to a growing demand for organisations to compete in an international economy.

The management of communication in global development teams requires the capabilities of various communication mechanisms and their effective application. The results of an analysis by McDonough et al. (1999) revealed an impact of differences in country, culture, country of origin, and geographic dispersion on the demand for 
communicating information quickly that is rich and consists of different volumes. They also found that these differences have an indirect affect on communication that was caused by six factors (McDonough et al., 1999):

1. Approach used to solve problems.

2. Means used to communicate with leaders.

3. Decision-making practices.

4. Different languages spoken by team members.

5. Technological capability of the member's country of origin.

6. Extreme geographical dispersion.

Only two information mechanisms were associated with performance, which are the use of phone calls and videoconferencing. Videoconferencing has been found to have a negative relation to performance. Relevant key issues that have an impact on performance are building trust among distributed team members and the team leader and ensuring cooperation on the team (McDonough et al., 1999). Although, benefits such as cost and time savings are main reasons for the acceptance of this technology by executives, the technological complexity has been considered as an unreliable business tool. However, a new service on the marked that offers managed video conferencing may support the improvement of performance and reliability that leads to an increased user satisfaction and lower per meeting costs (Weinstein, 2004).

\subsection{Cultural aspects: limitations and chances}

The human element of a project team is in most cases an element for success in a virtual and distributed project environment. It is also a variable that is difficult to address as it deals with a change of cultural factors in areas of conflicting behaviours, processes, and technologies. New human and interpersonal skills are required to work in a distributed project environment and a shift from project management to project leadership is supported by the fact that a manager has to act in a networked world of interconnected relationships. Negotiation as a core competency for the modern project manager who balances the demands and needs of an increasingly large and diverse set of stakeholders is an essential asset (Nidiffer et al., 2005).

Herzog (2001) assumes that if a project manager employs 15 specific activities it will increase communication and build trust in a team. Management by walking around gives 
ways to management by results and Humphrey (2002) recommends various leadership activities in a team software process that includes ways to build trust, to motivate teams, and to increase teamwork. Taking into account the wide range of management activities that depend on soft skills it is obvious that cultural change as a great impact on the management of distributed work.

\subsubsection{Cross-cultural development projects}

Cross-cultural and cross-organisational development projects are characterised by team members with a large variety of cultural backgrounds and from different countries. The impact of cultural beliefs and background on individuals varies and under certain conditions, the national culture may only be of subordinate importance (Chao and Moon, 2005). Recommendations for managing cultural heterogeneity can be seen in Figure 4.5 (Connaughton and Shuffler, 2007).

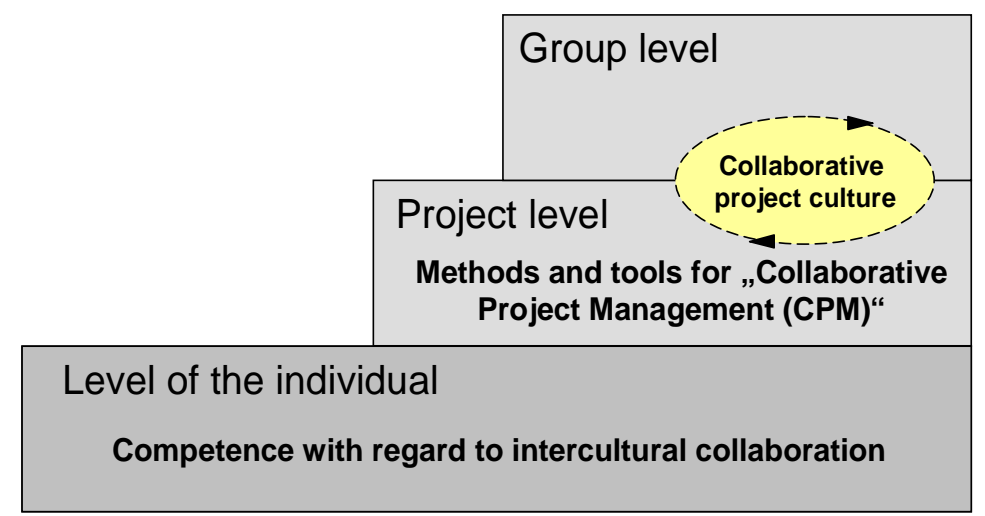

FIGURE 4.5: FACTORS THAT INFLUENCE THE SUCCESS OF CROSS-BORDER PROJECTS

(LEUNG ET AL., 2005)

\subsection{General difficulties in cross-company project management}

Recent developments and changes have also caused a change of the difficulties and problems in project management today. In the 1970s and early 1980s, projects were often delivered late and over budget and rarely met the requirements and expectations. Today, large and complex projects have forced the project manager to adapt to a new set of drivers and enablers that have an impact on the project outcome. Nidiffer et al. (2005) define complexity driver in the acquisition environment that characterise the major changes. Some of them are the increasing problem complexity as the customer acquisition model has changed its focus from requirements to objective 
capability statements, or the increasing solution complexity that is described by a shift from platform to enterprise emphasis. Other complexity drivers are increasing technical compliance, and team complexity.

\subsubsection{Change towards complex projects}

The change towards complex projects has also caused a change of project management towards a world of distributed and geographically dispersed project teams that focus simultaneously on processes, people, and technology. The Standish Chaos Report states that most project management techniques were designed for co-located project teams and that these techniques may possibly not be suitable for global and multi-site organisations (Standish Group, 1999).

Malone (2004) states that the virtual project workforce is not technology independent as high cost of communication has lead all kind of organisations to search for more efficient ways of communication. Technology itself is not considered as a solution but an enabler to change organisations and management.

The major problems of distributed project management have been identified by guided interviews with lead engineering managers in 2003 and are shown in following three tables (Table 4.3, 4.4. and 4.5). The problems are categorised into six different issues that are of strategic, project and process management, communication, cultural, technical, and security character.

\begin{tabular}{|l|l|l|}
\hline Strategic: & Potential enablers & Current constraints \\
Difficulty leveraging & - Understanding common & - Best practices are often deemed \\
available resources. & issues on distributed projects & proprietary \\
& so that stakeholders can & - Time consuming to implement \\
& anticipate and manage risks. & and maintain. \\
& - Knowledge management & \\
& systems, especially expertise & \\
& management systems. & \\
\hline
\end{tabular}

TABLE 4.3: STRATEGIC ISSUES IN DISTRIBUTED DEVELOPMENT (NIDIFFER ET AL., 2005, P. 69)

Issues related to project and process management, communication, and culture are shown in Table 4.4. 


\begin{tabular}{|c|c|c|}
\hline $\begin{array}{l}\text { Project and } \\
\text { process } \\
\text { management: } \\
\text { Difficulty } \\
\text { synchronizing work } \\
\text { between distributed } \\
\text { sites. }\end{array}$ & $\begin{array}{l}\text { - Integrated quality frameworks } \\
\text { help define synchronisation } \\
\text { points between work teams } \\
\text { - Shared workspaces for storing } \\
\text { files in centralised, accessible } \\
\text { locations paired with workflow } \\
\text { capabilities can increase } \\
\text { efficiency for distributed } \\
\text { teams. } \\
\text { - Engineering tool vendors are } \\
\text { beginning to release } \\
\text { distributed versions. }\end{array}$ & $\begin{array}{l}\text { - Complex projects often involve } \\
\text { organisations at various maturity } \\
\text { levels, making it difficult to } \\
\text { implement a standard process } \\
\text { across the project. Even } \\
\text { organisations at the same maturity } \\
\text { level might implement processes in } \\
\text { incompatible ways. Different } \\
\text { organisations might subscribe to } \\
\text { different quality frameworks all } \\
\text { together. } \\
\text { - A wide range of choices, each with } \\
\text { different user interfaces that might } \\
\text { require familiarity training can be } \\
\text { costly and time consuming to set up } \\
\text { and maintain. } \\
\text { - Still need to integrate these into a } \\
\text { real time project management } \\
\text { reporting system. }\end{array}$ \\
\hline $\begin{array}{l}\text { Communication: } \\
\text { Lack if effective } \\
\text { communication } \\
\text { mechanisms. }\end{array}$ & $\begin{array}{l}\text { - Asynchronous collaboration } \\
\text { tools (email, electronic bulletin } \\
\text { boards, voicemail, search } \\
\text { agents and change alerts, } \\
\text { etc.) } \\
\text { - Real time collaboration tools, } \\
\text { including virtual presence. } \\
\text { - Standardised, simplified } \\
\text { display of information to } \\
\text { combat information overload. }\end{array}$ & $\begin{array}{l}\text { - Loss of communication richness } \\
\text { increases the risk of } \\
\text { miscommunication } \\
\text { - Lack of bandwidth, robust security, } \\
\text { and inexpensive appliances (though } \\
\text { these issues are becoming less of a } \\
\text { challenge). } \\
\text { - Agreement required between } \\
\text { partnering organisations and with } \\
\text { customer - each has their } \\
\text { respective informational } \\
\text { requirements. }\end{array}$ \\
\hline $\begin{array}{l}\text { Cultural: } \\
\text { Conflicting } \\
\text { behaviours, } \\
\text { processes, and } \\
\text { technologies. }\end{array}$ & $\begin{array}{l}\text { - Targeted training for } \\
\text { managers and employees on } \\
\text { distributed projects. } \\
\text { - Advances in process, } \\
\text { methods, and tools. }\end{array}$ & $\begin{array}{l}\text { - Hard to quantitatively justify } \\
\text { investments in soft skills. } \\
\text { - Adaptation is difficult because } \\
\text { managers might not mind change } \\
\text { but they mind being changed. It is a } \\
\text { very conservative, risk adverse } \\
\text { environment. }\end{array}$ \\
\hline
\end{tabular}

TABLE 4.4: ISSUES IN DISTRIBUTED DEVELOPMENT (NIDIFFER ET AL., 2005, P. 69) 
Technical and security issues are shown in Table 4.5.

\begin{tabular}{|l|l|l|}
\hline $\begin{array}{l}\text { Technical: } \\
\text { Incompatible data } \\
\text { formats and exchanges. }\end{array}$ & $\begin{array}{l}\bullet \text { XML Web Services for data } \\
\text { exchange. } \\
\text { - Standards for real time } \\
\text { collaboration are converging. }\end{array}$ & $\begin{array}{l}\text { - Lack of industry wide standard } \\
\text { schema for software intensive } \\
\text { development projects. } \\
\text { - Leading standards are still being } \\
\text { defined. }\end{array}$ \\
\hline $\begin{array}{l}\text { Security: } \\
\text { Ensuring electronic } \\
\text { transmissions' } \\
\text { confidentiality and } \\
\text { privacy. }\end{array}$ & $\begin{array}{l}\text { Emerging standards for } \\
\text { secure messaging, including } \\
\text { role based security and } \\
\text { encryption technologies. }\end{array}$ & $\begin{array}{l}\text { Numerous competing standards } \\
\text { are evolving simultaneously. } \\
\text { Current offerings can be } \\
\text { expensive to administer, } \\
\text { inconvenient to use, and } \\
\text { incompatible. No solution is fail }\end{array}$ \\
& & safe, leading to difficulty \\
& & establishing appropriate limits for \\
& & sharing of intellectual property \\
& & across organisational \\
& & boundaries. \\
\hline
\end{tabular}

TABLE 4.5: TECHNICAL AND SECURITY ISSUES IN DISTRIBUTED DEVELOPMENT

(NIDIFFER ET AL., 2005, P. 69)

The evolution and development for project management towards virtual teams is a driver for a need of new and improved processes, methods, and tools that enable the team members to share common data (technical, financial, project and communication data), and that can be applied to all project life cycles from research and development, engineering, production, to support and disposal. The need to decrease project life cycle durations, the time to make decisions (improvement of a team's decision velocity) requires a new focus on the enablers of successful project management (Nidiffer et al., 2005).

\subsubsection{Technologies as a driver for virtual teams}

Tools and technologies have become an important driver to improve distributed and also cross-company project management. The rise of the internet as a universal connection between distributed locations and the growing market of collaborative tools are important elements for today's project success. Organisations have begun to leverage real-time collaboration tools that bridge the soft skills gap for distributed teams. Instant messaging, web conferencing, whiteboards, and desktop videoconferencing 
provide different communication methods than the telephone, email, or face-to-face meetings. Tools for unstructured collaboration can enhance communication by increasing communication between distant team members. A recent development in knowledge-management projects has demonstrated that relying on the strategy that if you build the system, users will follow, often leads to the adoption of expensive and later unused concepts (Nidiffer et al., 2005).

\subsubsection{New processes need adaptation to distributed work environment}

When organisations re-evaluate processes and procedures they should also re-assess existing processes with regard to their capability to use in a distributed work environment. Some may be proved as inappropriate, controlling, or confining, whereas others may require a more formalised structure to achieve higher effectiveness. Process improvement models such as CMMI have originally been developed to assess and improve the processes of a single organisation. The adherence to a single framework enables an organisation to implement common and shared processes across all of its business divisions and units. However, compliance to a single standard within the organisation may not be sufficient in an increasingly distributed environment as suppliers and project partners are part of the process, too (Nidiffer et al., 2005).

\subsection{Cross-company project management in the automotive industry}

The increasing number of cross-company product development projects has changed the collaboration models of today substantially. While partnerships and collaboration were dominated by the OEM in the past, today many collaboration projects are based on equality. Large organisations have formerly built up research and development capacities that now need to be covered by external partners. The formation of partnerships is one way to maintain reliable research and development partners, and in average an OEM in the automotive industry has about 50 development partnerships (Wildemann, 2004b). The responsibility for the management of systems, modules or vehicles is increasingly shifting towards the development partners and requires the establishment of project management know-how and capabilities to exchange project data and technical data at the partner's site. Project management capacities are the foundation to coordinate and integrate partners and suppliers. Existing outsourcing to suppliers of product or component development such as gearing systems, axes, and 
interior has now been extended to former core competencies of OEMs such as auto body or engines (Plischke, 2005).

\subsubsection{A move towards networked project structures}

Manufacturers and suppliers increasingly have to work together to stay competitive on the international market. Due to a difficult economic situation and high competition, the project structures have changed to a complex network where a significant part of the value creation moved towards a number of project partners. According to an automotive study, the contribution of suppliers changes from $65 \%$ in 2002 to $77 \%$ in 2015 (VDA, 2004) and is shown in Figure 4.6.

\section{Production of light vehicles (pieces):}

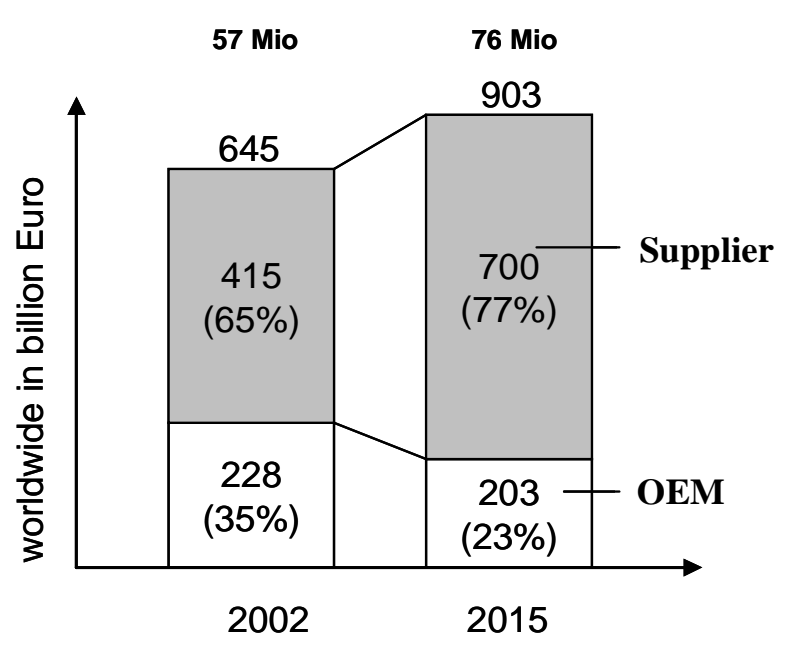

FIGURE 4.6: DEVELOPMENT OF PRODUCTION AND VALUE CREATION CHAIN TOWARDS MORE SUPPLIERS (HAB AND WAGNER, 2006, P. 4)

These suppliers were mainly independent but they had to form strategic alliances and partnerships to survive these developments. Therefore, decentralised and crosscompany project management has become and will become more important in the product development of automotive projects (Kurek, 2004). Therefore, manufacturers are taking over the role of a network manager as one of their core competencies.

\subsubsection{Evolving cooperation and joint ventures}

New cooperation and joint ventures are evolving, e.g. the joint development of a hybrid engine between BMW and Daimler or the production of the BMW X3 that was done by a 
supplier in Austria. Another cooperation project was the collaborative engine development of Ford and PSA.

\subsubsection{Chances and risks in cooperation}

Due to the competitive market and the demand for lower prices, the manufacturers are under enormous pressure that is partially passed to the supplier. Pander and Wagner (2005) named this situation "coopetition" which is a combination of competition and cooperation. They identified the chances and risks that may occur in such project environment. Some chances are the strengthening of the competitive position, the possibility to extend their market share, increase of know-how and innovation, distribution of investment costs, higher resource flexibility, and advantages in purchasing, logistics, and sales. On the other hand, risks may be a dependency on the project partners, conflicts of interests, a loss of know-how, a high effort to coordinate, a creation of new competition, liability risks, different cultures and a loss of identity.

The Asian automotive market has gone through major changes as well as new Asian manufacturers also collaborate with Western OEMs. The automotive development faces a strong variation of development cycles due to the growing importance of electronics and software. The cycle time of a change in the control software is dramatically shorter than the cycle times of the body parts and leads to an increased occurrence of changes that impacts the management of development data. Flexible and easy to use solutions can help to minimise the change effort. The new concept of collaboration causes a change from top-down processes to network organisations with clear distribution of competencies according to the specific knowledge areas (Plischke, 2005).

\subsubsection{Value creation and success factors of existing cooperation}

Cooperation in the automotive industry can be divided into the composition of partner organisations, the specific project phase of collaboration, and the technical type of collaboration, e.g., whether it is a technology collaboration or a production or sales and distribution partnership. Figure 4.7 illustrates the perspectives of hierarchical composition and value creation with respect to project phase and collaboration type of existing partnerships. 


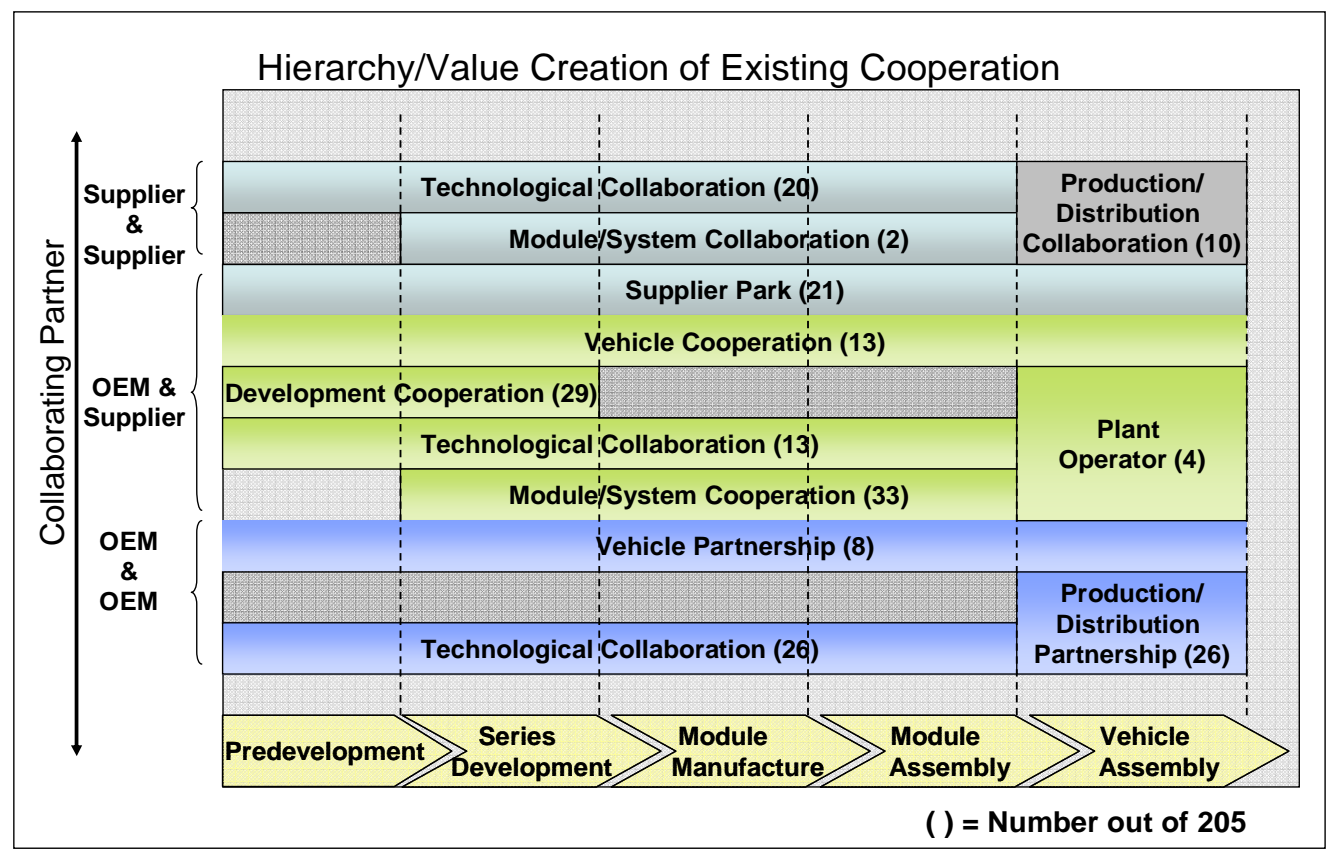

Figure 4.7: HieRARCHY AND VALUE CREATION OF EXISTING COOPERATION (MERCER AND TUM, 2005)

Supplier collaboration is dominated by technological collaboration from predevelopment until module assembly, whereas OEM and supplier collaboration has a strong focus on development and the series development until assembly of modules and systems. Joint ventures between OEMs are dominated by technological collaboration and production and distribution partnerships. However, the number of vehicle partnerships is increasing continuously.

Criteria for cooperation are the attitude of the partners and their mutual trust and empathy. However, communication is dependent on those criteria and serves as a criterion for a successful target agreement (Spies, 2003). Figure 4.8 shows the criteria of cooperation.

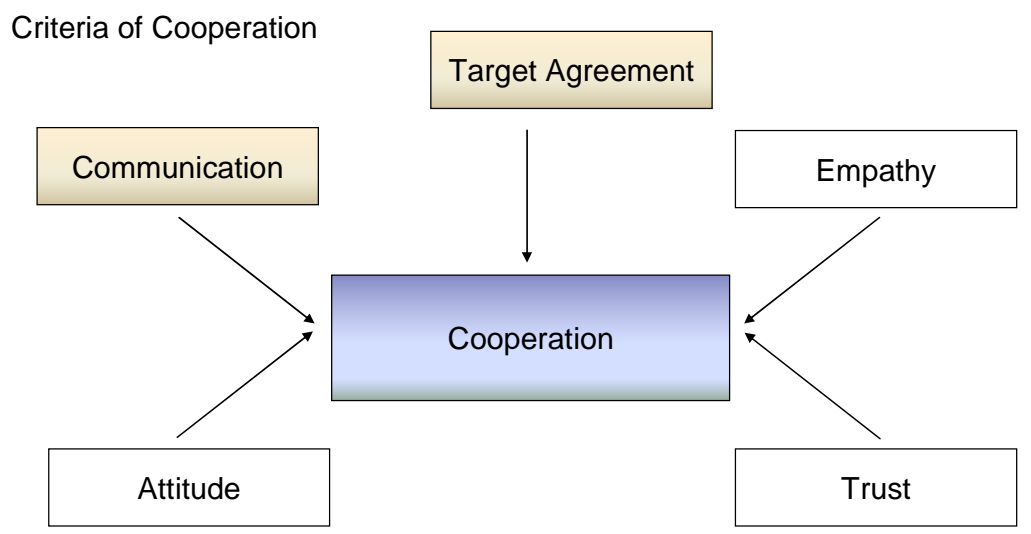

Figure 4.8: Criteria of COOPERATION (SPIES, 2003) 
Success factors for cooperation are related to several aspects. One of them is the organisation and its structure, e.g. whether it is a project focussed organisation or it applies benefit sharing. Other aspects are strategy, employees, knowledge, culture, and processes. According to an experienced project manager from a German car manufacturer, the success factors are defined as shown in Figure 4.9, whereas the OEMs, suppliers, and technology partners contribute to a value network.

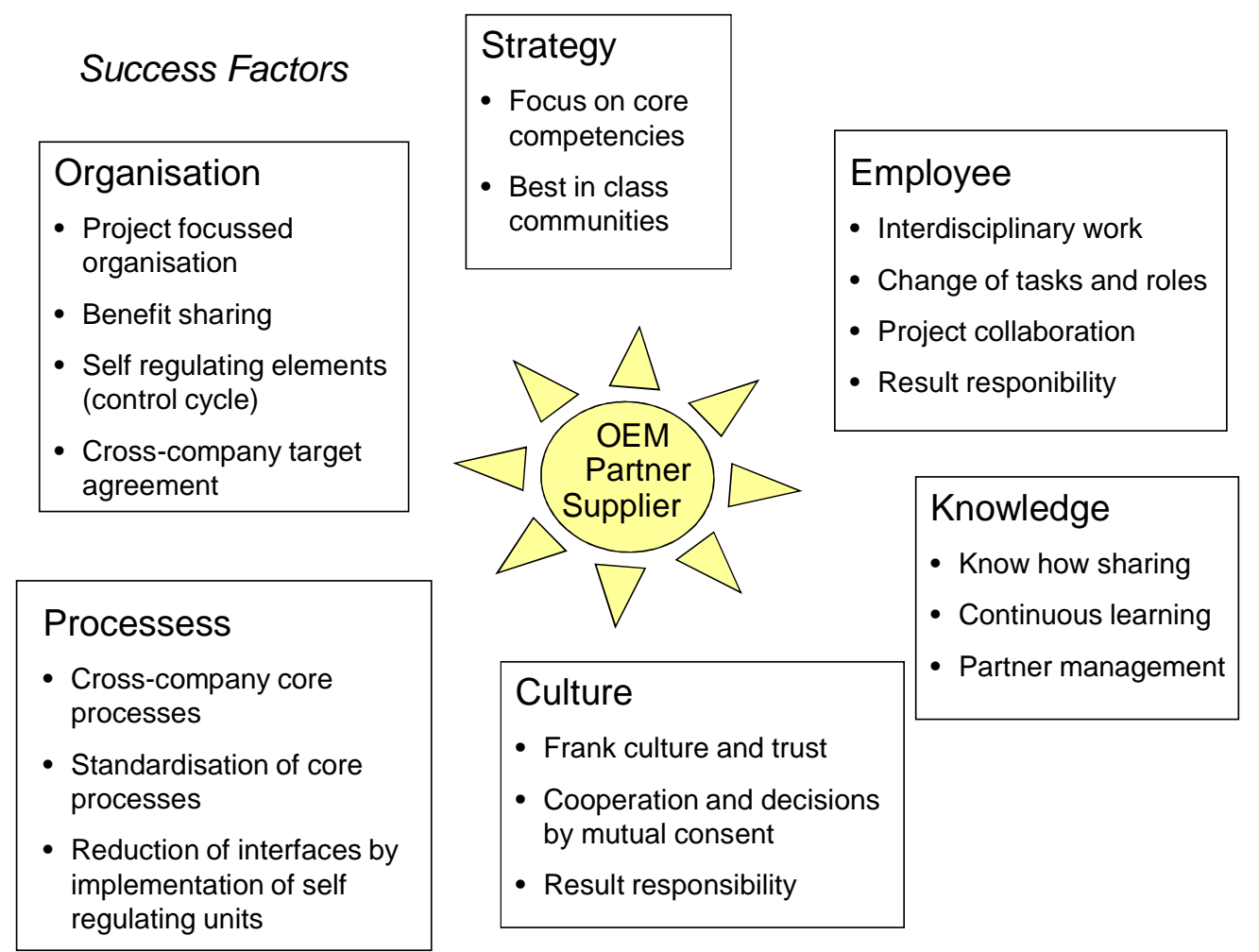

FIGURE 4.9: SUCCESS FACTORS FOR COOPERATION

\subsection{Automotive specific problems}

The situation in automotive projects can only be improved with a holistic consideration of all impact factors. Based on the system theory (Patzak, 1982), Pander and Wagner developed a framework that includes a target system to describe and specify project goals, a process system that defines activities to achieve these goals, an action system for the organisational structure, and finally an object system that has a focus on the car development (Wagner and Pander, 2005 p.23).

After adding socio-cultural impact factors to the model, six impact factors describe the C3PM Model as shown in Figure 4.10. 


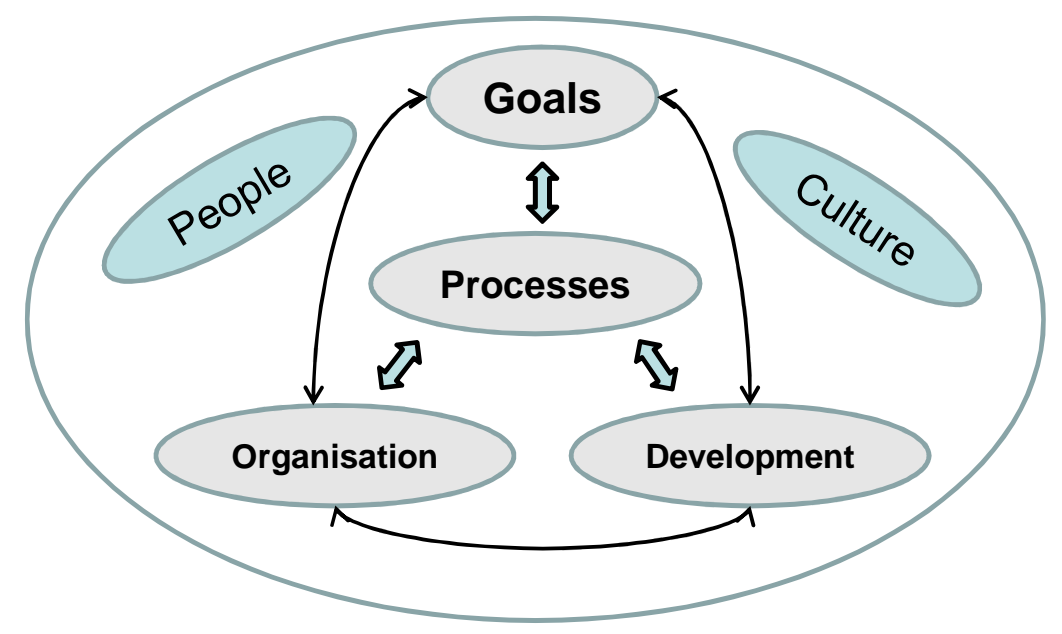

FIGURE 4.10: C3PM MODEL (PANDER AND WAGNER, 2005, P. 25)

Based on that model, a study within the automotive industry identified the major difficulties in cross-company project management:

1. Deficiencies in defining and clarifying project goals.

2. Low transparency and flexibility in project organisation.

3. Insufficient control power of project manager.

4. Difficulties in change management have impact in process control.

5. Different understanding of applied technologies impedes the collaboration in the car development.

Additionally, the study revealed that there is a higher demand for individual abilities. These abilities next to the technical skills are mostly communication skills, proactiveness, and frankness.

\subsubsection{Impact factors and their capability}

The cultural determining factor is a major factor for project success. According to a study by the PA Consulting Group and the GPM e.V. in 2007, the cultural determining factors were rated as the most unsatisfying aspects (Engel and Holm, 2007). In addition to that, process control and goal definition are still far from being good.

Figure 4.11 shows the satisfaction of the participants with respect to the six impact factors (1: very good, 6 : insufficient). 


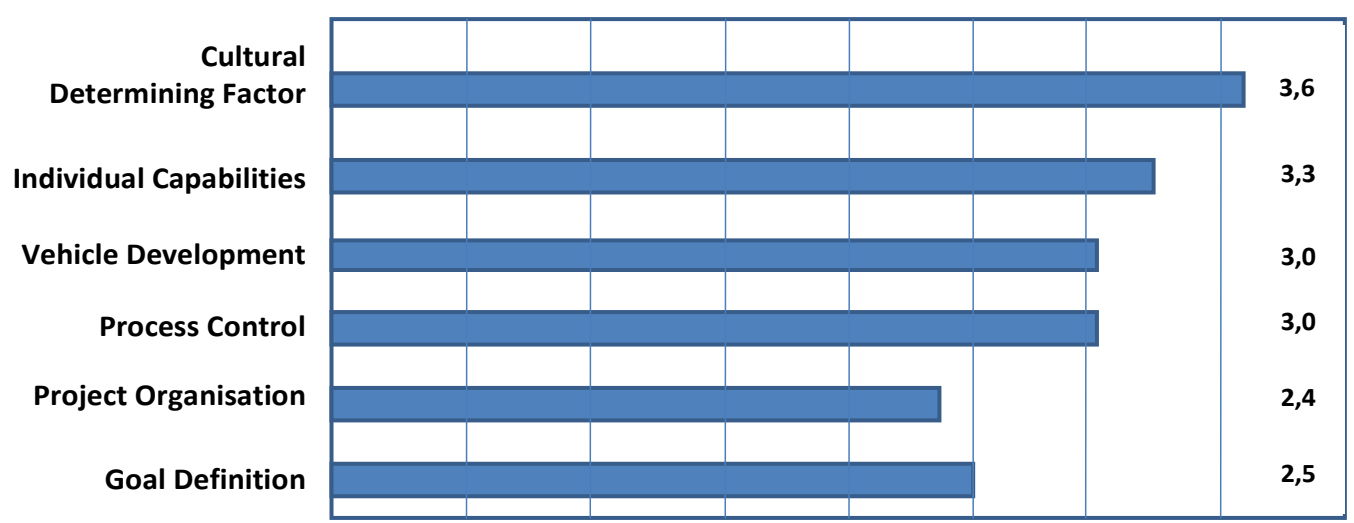

FIGURE 4.11: SATISFACTION OF STUDY PARTICIPANTS WITH RESPECT TO IMPACT FACTORS

(WAGNeR AND PANDER, 2005, P. 41)

The study by the PA Consulting Group and the GPM e.V. in 2007 revealed that $61 \%$ of the reasons for project failure are due to communication problems and $57.3 \%$ due to unclear requirements and goals (Engel and Holm, 2007). Figure 4.12 shows the importance and capability of each impact factor to improve cross-company collaboration (1: most important, 6: least important).

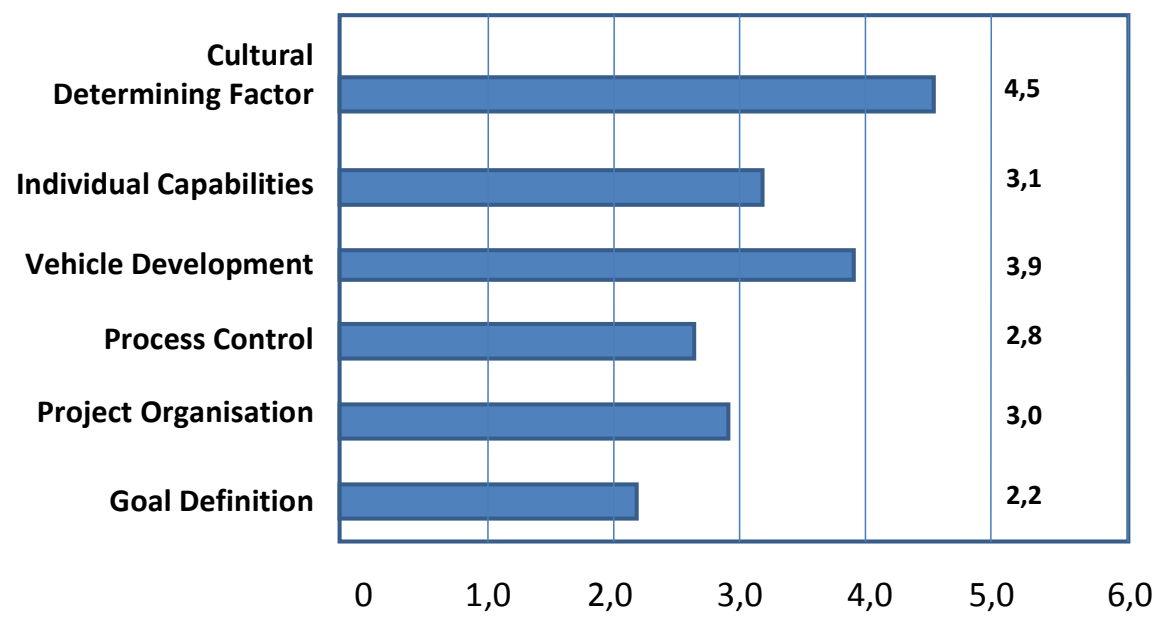

FIGURE 4.12: CAPABILITY OF IMPACT FACTORS TO IMPROVE CROSS-COMPANY COLLABORATION (WAGner ANd PANDER, 2005, P. 43)

\subsubsection{Ways to overcome difficulties in automotive project management}

Automotive companies need to address the problems mentioned in the previous section to ensure a long term and sustainable success. Several interest groups have been formed to minimise a variety of problems. Some of them are the VDA QDX project for quality data exchange, the Prostep iViP PDM project for product data management and 
the development of ISO 10303, or the Prostep iViP Collaborative Project Management Reference Model (ProSTEP iViP, 2007a).

The use of international working hours (e.g., 24h/7days, follow-the-sun) enables the project management of efficient resource usage. Product data management and engineering data management are only some of the tools next to change management required for collaborative project management. Especially, collaborative projects with North American OEMs require the use of a sophisticated document management system to follow the guidelines of Advanced Product Quality Planning and Control Plan (APQP) (AIAG, 1995).

Collaboration between manufacturers and suppliers created misunderstandings and severe conflicts as the power of several OEMs can lead to mistrust in the partnership. Different cultures need to be considered and bridged by open communication, fair negotiations and a commonly agreed framework that supports the definition of project goals. Relevant stakeholders are often not integrated in the process of project objectives definition or the tender documents. A common understanding of the product and its feasibility between the project partners differs frequently. Moreover, a common vision of the automobile project often does not exist (Pander and Wagner, 2005).

\subsection{Activities of automotive associations}

Several interest groups and partnerships have been formed to develop new project management methods and processes collaboratively. The collaborative project work requires a collaborative definition and planning of relevant methods on a domestic and international level as all of the participating members need to agree on new methodological developments. The German Organisation for Project Management (GPM), the PMI Automotive Special Interest Group, the Automotive Industry Action Group (AIAG), Prostep iViP CPM (Collaborative Project Management), Association for Standardization of Automation- and Measuring Systems (ASAM), and the German Organisation of Automotive Manufacturers (VDA) have developed groups to define and design methods and frameworks for collaborative product development and quality standards. 


\subsubsection{The Prostep iViP CPM Reference Model}

The development of project and development responsibility towards partner companies and temporary networked structures requires a stronger connection between information exchange and project coordination. Shorter development cycles and higher product complexity can only be managed by an effective cooperation with partner companies. The coordination and integration of mechanics, electronics and software becomes increasingly detailed and causes a growing number of project partners with different corporate cultures and development methods (Plischke and Vettermann, 2007).

The situation has initiated the project group "Collaborative Project Management (CPM)" of the Prostep iViP Association in 2005. The objective was to develop solutions for communication and documentation of project data, and for the control of time lines and activities in development networks. Existing standards such as PMBoK (PMI, 2004), DIN 69000ff. VDA 4.3, the Automotive Project Management Guide, and VDA 4961 provided the basis for a cross-company and collaborative reference model. It was considered as essential that each partner can still apply existing and optimised internal processes without the disclosure of core competencies. First project results were published in a recommendation that is free for download at the association's internet site (www.prostep.org).

\subsubsection{Introduction to the CPM Reference Model}

The recommendation describes the project management tasks, processes, roles, prescribed terminology, and methods to manage time, tasks and communication collaboratively (Prostep iViP, 2007a). Next to the reference model, the project group also developed a data exchange model that defines the data objects, which can be used to exchange project management information between different project management systems related to the reference model (Prostep iViP, 2007b). The reference model aims to achieve the following objectives:

- Common agreements on collaborative aspects including documentation of project activities, such as communication, documentation, and milestone agreements.

- Neutral interfaces to exchange project documents, such as time plans and activity lists. 
- A transmission path to communicate project changes to enable quick analysis of possible impacts and understanding of causes.

- Synchronised processes to monitor project status and to transmit real time project information with multi project reporting option.

The scope of the reference model is shown in Figure 4.13.

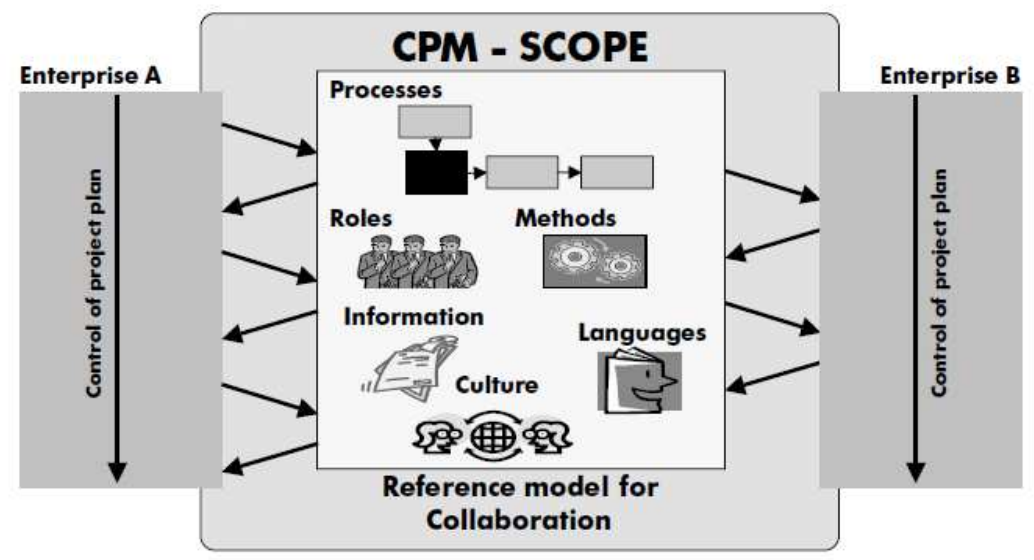

Figure 4.13: CPM RefERence Model SCOPE (ProsteP IVIP, 2007A, P.III)

The reference model is structured into three sections: the base model that includes an introduction to the methods, the application model that describes the events that initiate processes and the processes themself as well as role descriptions including the methods and tools that are necessary to transfer the project information between the partners.

Processes can be described as sequences of activities that create value, whereas, methods and tools support the processes to run effectively and efficiently. Although the technical processes have by been defined and described in considerable detail, there is still a demand for a process modelling approach within the context of cross-company networks. According to the reference model, there are two process levels: the product oriented processes that specify and create the product, and the project management processes that describe and organise project specific work. "These two process levels constantly interact during the course of a project. The PDP synchronises activities between the two process levels and project management provides the processes for bringing the project to a successful conclusion" (ProSTEP iViP, 2007a, p. 9). The base model includes the interaction model that integrates the "handshake-principle". This means that each project partner has to agree on all exchanged project information 
explicitly. Additionally, the relevant project terminology and cultural impacts are part of the base model. Figure 4.14 shows the relation between these two processes.

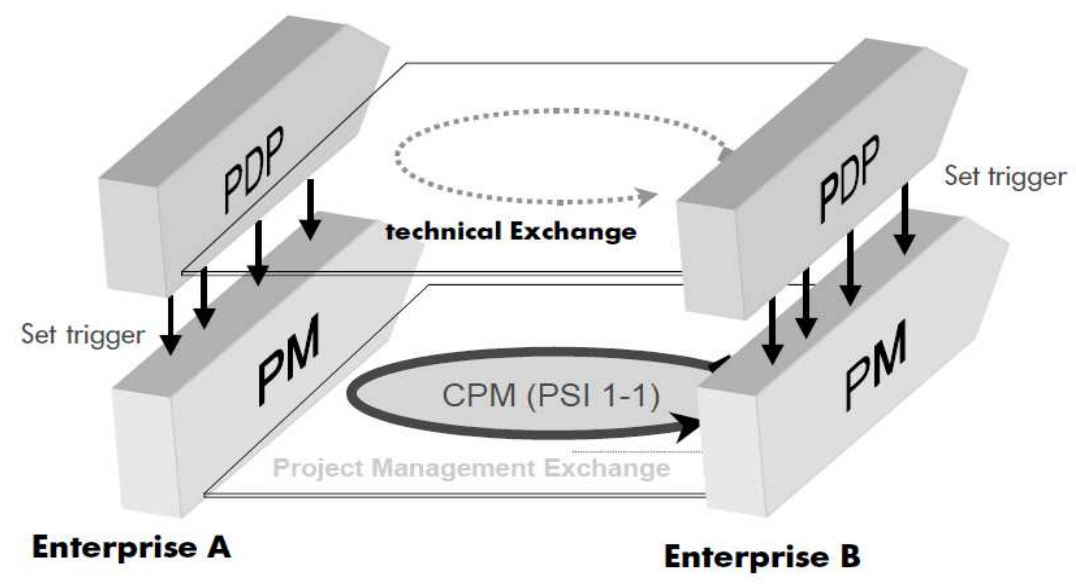

FIGURE 4.14: RELATION BETWEEN PRODUCT DEVELOPMENT PROCESS AND PROJECT MANAGEMENT ON A collaborative LeVel (Prostep iViP, 2007A, P. 9)

The application model contains all elements necessary to plan and control a CPM project. Some of them are common milestones and synchronisation points as shown in Figure 4.15.

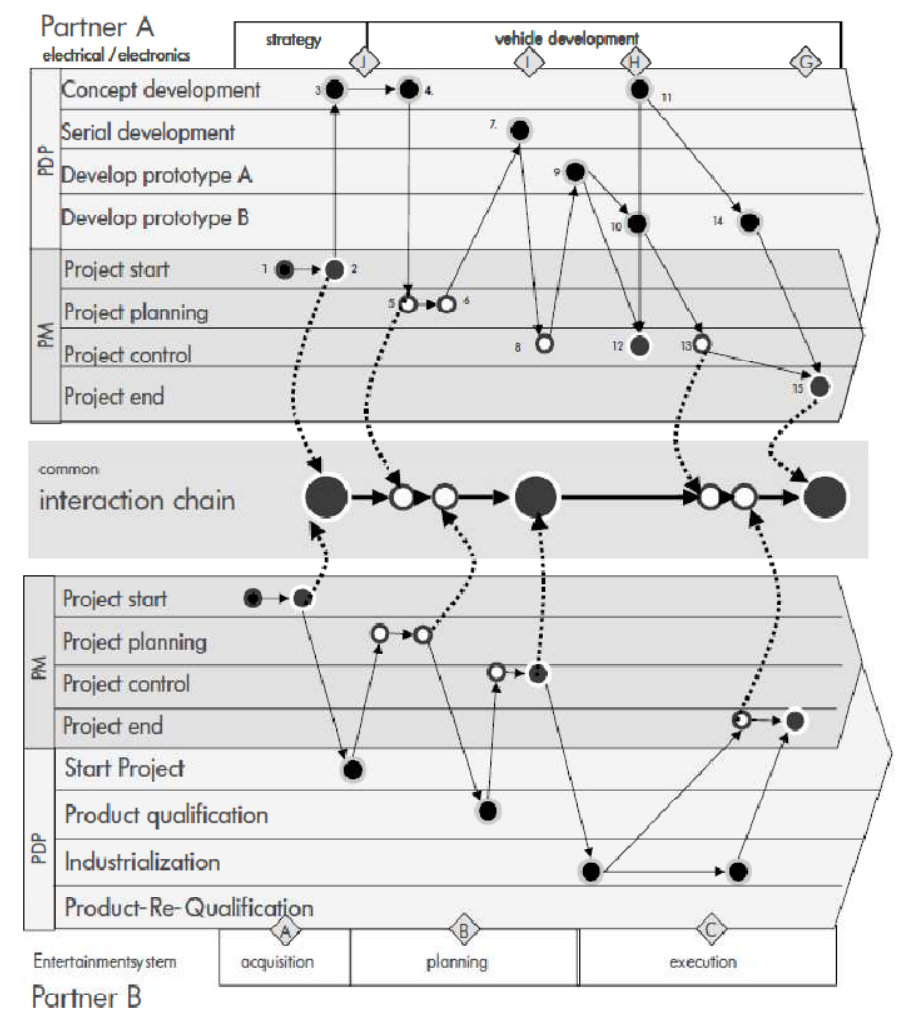

FIGURE 4.15: INTERACTION CHAIN TO INTEGRATE AN ENTERTAINMENT SYSTEM OF A PARTNER

(ProSTEP IVIP, 2007A, P. 22) 
As shown in Figure 4.15 coordination between the project partners is only relevant when an internal change has an impact on the common milestones or synchronisation points on the interaction chain.

\subsubsection{Methods, tools and processes for cross-company project management}

The CPM methods describe how to apply the tools and give recommendations on an efficient application of the processes. The three main tools of the reference model are the interaction plan, the communication matrix, and the issue list. The interaction plan is a tool for time management, whereas the communication matrix facilitates the identification of the appropriate project member to talk to for a specific topic and maps company-internal roles to the CPM role. The issue list is a common list that is used to monitor minor deviations from the original common plan and that have an impact on one of the project partners. The reference model also describes relevant processes and process workflows for project planning, execution, and control. Some of them are "initiate project", "plan project", "create communication matrix", "enable milestones", "project team change", "perform escalation", or "close development project". Appendix A includes the process description for "execute escalation" as an example. The data exchange model is the fundament to extend project management systems for a CPM application. The model is harmonised with existing standards, such as VDA QDX, OMG PLM Services or new DIN standard for a project management data model that is still in development. The data exchange model consists of two elements: the base data model and the definitions regarding exchange as part of an exchange model (Figure 4.16).

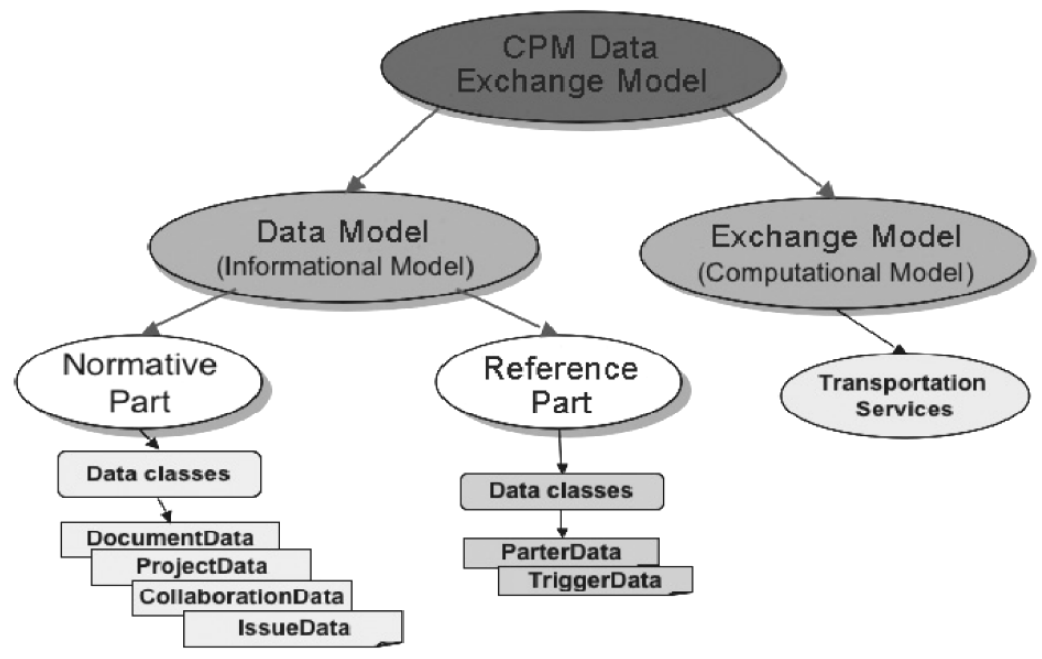

Figure 4.16: Structure of the data eXchange model (Prostep IVIP, 2007b, P.2) 


\subsubsection{Benefits of the CPM Reference Model}

The reference model improves the quality of cross-company process management with a minimum of effort due to the flexible adaptation to suit specific projects and the development of a standard that allows traceability and repeatability. Costs and time can be reduced and quality increased from individual elements of the model alone.

Reasons for cost avoidance are that communication errors and errors when transmitting information between partners are avoided, errors resulting from partners having incomplete project information are reduced, unnecessary documents are limited, and completeness is ensured. Time can be reduced by the use of existing and proven tools and processes, an avoidance of outlay that is required for the coordination between the partners, and a faster problem solving. Finally, quality can be improved by a common understanding of project management, control and collaboration, and a timely initiation of interaction between the project partners.

\subsection{Methods for process introduction}

The implementation of new methods and processes also implies certain risks, e.g. the new method or process can be incomplete or faulty when introduced to a business. An IT solution can be a useful tool to avoid difficulties and to adjust processed accordingly. To ensure the feasibility of process changes and to verify whether these changes can be adopted the application of a board simulation is a possible solution and is further described in the next section.

\subsubsection{Board simulation in practice}

Methods and process flows can be simulated on a board and users can learn and get acquainted with the changes. The simulation facilitates the understanding by visualising and also enables the users to identify mistakes or proposals for improvements in the process flow or the method itself. Steps for optimisation are, therefore, identified before a roll out has already taken place. This increases the efficiency of a new process introduction. Board simulation is also useful for seminars and courses to teach new employees before costs occur that were initiated by misinterpretations of the concept. 
The ProSTEP iViP CPM Reference Model was also developed with the help of a board simulation. Within several workshops, the standard was tested and verified.

\subsubsection{Example: development of the ProSTEP iViP CPM Reference Model}

To approve whether a standard fulfils all relevant requirements before the processes and methods are rolled out, board simulation can be a useful approach. For the simulation of the ProSTEP IVIP CPM Recommendation (PSI 1-1), a board simulation was developed by a company specialised on business simulators. It was tested against the relevant processes, interrelations, objectives, expected benefits, and the methodical tools. During the development of the simulation, many questions arose that helped to clarify the understanding and acceptance of the users. An already existent board simulation was adapted and the simulation was verified by several key users, mostly OEMs, suppliers, and consultancies. Depending on the maturity of the standard, several simulation cycles are necessary for a final evaluation and key users have to ensure that the simulation runs without errors. 


\section{Research methodology and plan}

Research steps, methodology and plan necessary to identify, develop and achieve the research objectives and to validate the hypothesis are part of this chapter. A detailed section about the applied methodology includes a first industry and literature analysis of current project management difficulties. The results of these analyses lead to the definition of the research questions and objectives. This is followed by the development of a solution, the Collaborative Project Scorecard, and its evaluation and validation. The research plan illustrates the related activities and tasks, and the research methodology section categorises these activities into a scientific methodological framework (Figure $5.1)$.

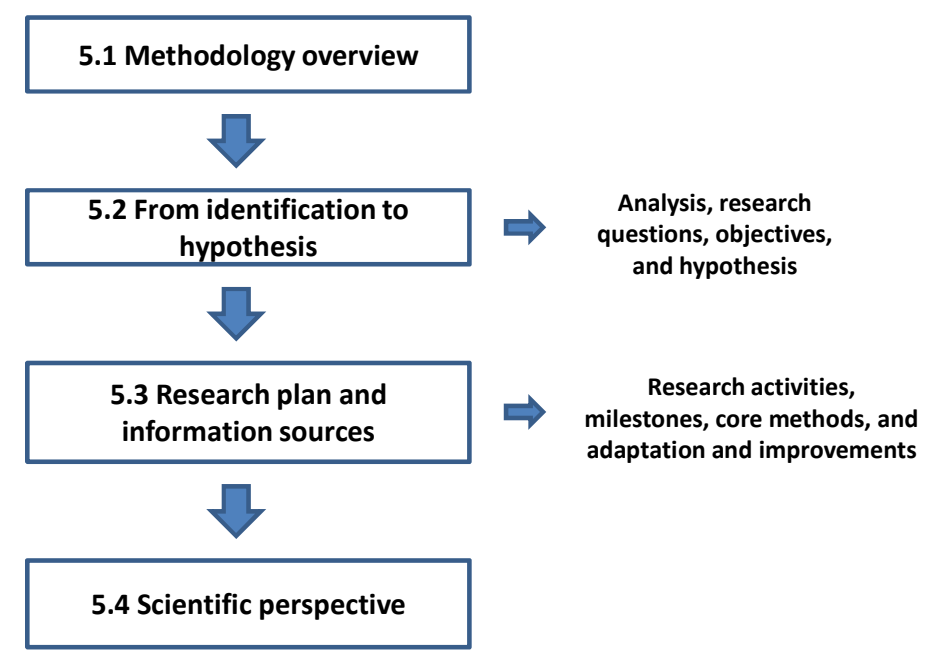

FIgURE 5.1: OVERVIEW OF CHAPTER 5

\subsection{Scientific approach to research methodology}

Due to the nature of collaborative project management research, the study operates within the scientific paradigm of critical realism (or post-positivism) by using a multimethod approach utilizing case studies and surveys.

Kuhn (1996, p.44) defined the scientific paradigm in his work "the structure of scientific revolutions" as "what is to be observed and scrutinised, the kind of questions that are supposed to be asked and probed for answers in relation to this subject, how these 
questions are to be structured, how the results of scientific investigations should be interpreted".

Guba and Lincoln "employ Kuhn's concept of paradigms as their foundation and suggest that researchers adopt assumptions in the following three areas: ontology is the fundamental assumption made about the form and nature of reality. It is concerned with the question of what aspects of the world can be researched. Epistemology pertains to the relationship between reality and the researcher and the methodology relates to the process of finding out about reality; thus methodology outlines the appropriate research tools or techniques for conducting research" (Behrend, 2004, p. 116).

Guba and Lincoln (1994) proposed four paradigms shown in the following table.

\begin{tabular}{|c|c|c|c|c|}
\hline & \multicolumn{4}{|c|}{ PARADIGM } \\
\hline ITEM & Positivism & Post-Positivism & Critical Theory & Constructivism \\
\hline Ontology & $\begin{array}{l}\text { naive realism: } \\
\text { reality is real and } \\
\text { apprehensible }\end{array}$ & $\begin{array}{l}\text { critical realism: reality } \\
\text { is real but only } \\
\text { imperfectly and } \\
\text { probabilistically } \\
\text { apprehensible; } \\
\text { triangulation from } \\
\text { many sources } \\
\text { required }\end{array}$ & $\begin{array}{l}\text { historical realism: virtual } \\
\text { reality shaped by social, } \\
\text { political, cultural, } \\
\text { economic, ethnic, and } \\
\text { gender values; } \\
\text { crystallised over time }\end{array}$ & $\begin{array}{l}\text { relativism: local and } \\
\text { specific constructed } \\
\text { realities }\end{array}$ \\
\hline Epistemology & $\begin{array}{c}\text { dualists/ } \\
\text { objectivist: } \\
\text { findings true }\end{array}$ & $\begin{array}{c}\text { modified } \\
\text { dualist/objectivist } \\
\text { findings probably true }\end{array}$ & $\begin{array}{l}\text { transactional/ subjectivist: } \\
\text { value-mediated findings }\end{array}$ & $\begin{array}{l}\text { transactional/ subjectivist: } \\
\text { created findings }\end{array}$ \\
\hline Methodology & $\begin{array}{l}\text { experiments/ } \\
\text { surveys: } \\
\text { verification of } \\
\text { hypotheses: } \\
\text { chiefly } \\
\text { quantitative } \\
\text { methods }\end{array}$ & $\begin{array}{c}\text { case studies/ } \\
\text { convergent } \\
\text { interviewing: } \\
\text { triangulation, } \\
\text { interpretation of } \\
\text { research issues by } \\
\text { qualitative and } \\
\text { quantitative methods }\end{array}$ & action research & $\begin{array}{c}\text { in-depth interviews, } \\
\text { participants observation }\end{array}$ \\
\hline
\end{tabular}

TABle 5.1: ReSearCh PARAdigms (GUBA AND LINCOLN, 1994) AND (McPhaIL AND PerRY, 2002)

Taking into account that the research used qualitative and quantitative research methods and that the methodological approach is closely linked with own professional 
experience and practice, the research becomes part of an action research and action learning approach.

Coghlan (2001) identified that managers increasingly undertake action research projects that contribute "simultaneously to basic knowledge in social science and to social action in everyday life. High standards for developing theory and empirically testing propositions organized by theory are not be to be sacrificed nor the relation to practice be lost" (Coghlan, 2001, p. 50). He concludes that managers need to be aware of the limits but also strengths of their own preunderstanding. Action research within their own organisation is seen as an "interesting and exciting research for the development of their own organization". Raelin (2001) identified that traditions support the development of the process of critical reflective practice as part of a learning experience during a project. He illustrated the "emerging theory and the eminent practicality of engaging in the public and critical reflective practice, especially arising from project-based learning" (Raelin, 2001, p. 27). He encouraged the learning from that action and to bring the stakeholders and different parties together "to generate a collective process of inquiry".

Schoen (1983) has also identified the need for reflection that means "standing back and learning from experience" (Crawford, 2006, p. 728). Schoen provided an approach to understand the way managers and practitioners use reflection to achieve their objectives in practice. This is also defined as "reflection-in-action" (Raelin, 2001, p. 19) and means that reflection occurs in a way that "in the midst of performance one reframes unanticipated problem situations in order to see experience differently". As practicing managers often deal with unforeseen situations that do not lead to a single possibility to react, Schoen thinks that these managers need to deal with these situations through to highly developed processes of reflection-in-action and reflectionon-action. Crawford (2006) supported the approach and concluded that project management education needs to address the teaching of how to become a reflective practitioner that also is aware of recent theoretical developments and research results.

As mentioned above, this study uses qualitative (case studies/interviews) and quantitative research methods (surveys) to gain deeper understanding of the causes (Snow, 1993). The qualitative method uses interactive interviewing, questionnaires, and written descriptions by participants. Results of the qualitative research will be supported by quantitative research methods, especially by the conduction of surveys. Gable (1994) studied the combination of several research methods for a single research project and recommends the measuring of "objective" and quantitative distributions of outcomes. 
Creswell and Eisenhardt suggested the application of mixed methods and case studies for new and less developed research areas (Creswell, 2002; Eisenhardt, 1989). For the development of methods for project planning, monitoring and control a qualitative approach is inevitable. Yin identified research methodologies selection criteria, which are represented in Table 5.2 (Yin, 2002).

\begin{tabular}{|c|c|c|c|}
\hline Strategy & $\begin{array}{c}\text { Form of Research } \\
\text { Question }\end{array}$ & $\begin{array}{c}\text { Requires Control } \\
\text { over behavioural } \\
\text { Events }\end{array}$ & $\begin{array}{c}\text { Focus on } \\
\text { Contemporary } \\
\text { Events }\end{array}$ \\
\hline Experiment & How, why & Yes & Yes \\
\hline Survey & $\begin{array}{c}\text { Who, what, where } \\
\text { how many, how much }\end{array}$ & No & Yes \\
\hline Archival Analysis & $\begin{array}{c}\text { Who, what, where, } \\
\text { how many, how much }\end{array}$ & No & Yes/No \\
\hline History & How, why & No & No \\
\hline Case study & How, why & No & Yes \\
\hline
\end{tabular}

TABLE 5.2: SELECTION OF AN APPROPRIATE RESEARCH METHODOLOGY (YIN, 2002)

Generally, the approach of this research is a normative approach which tries to define how things should be. Normative research aims at improvements, which means that it includes an evaluation of the present state of things and also of the direction of future development. By definition, evaluation is only possible from somebody's point of view. Normative projects start with an informative study of the problem and then continue with normative planning of the improvements and finally with practical action.

Modes of analysis can be hermeneutics, semiotics, or narrative and metaphor. With respect to the case studies, content analysis, which is a form of semiotics, will be used (Krippendorff, 1980). Within-case analysis (Miles et al., 1994) cross-case analysis (Yin, 2002), cross-cluster analysis (Eisenhardt, 1989), and conclusion and verification are necessary to analyse and evaluate the case studies. Miles and Huberman (1994) categorise the analysis of qualitative data in editing, and coding, whereas coding includes open coding, axial coding, and selective coding. This is further described in "building an inductive theory of collaboration in virtual teams: an adapted grounded theory approach" (Sarker, 2000). 


\subsection{Methodology overview}

The applied research methodology is a multi-method approach that operates within the scientific paradigm of post-positivism. Interviews, workshops, and surveys were conducted to collect data and develop methods followed by a qualitative analysis of the results. The research began with a literature review and an analysis of project management methods and practices of a chosen automotive manufacturer including additional interviews. As a result, the areas that needed major improvements were identified and a possible solution, the Collaborative Project Scorecard, was developed as a major methodological element of this research.

Workshops, surveys, and an application to a specific pilot project to obtain further results and feedback from the industry were followed by an IT implementation, an analysis, and a final documentation. Additionally, feedback from several publications and presentations at conferences influenced the development of the concept during the research project as well. Figure 5.2 shows the major steps of the research project.

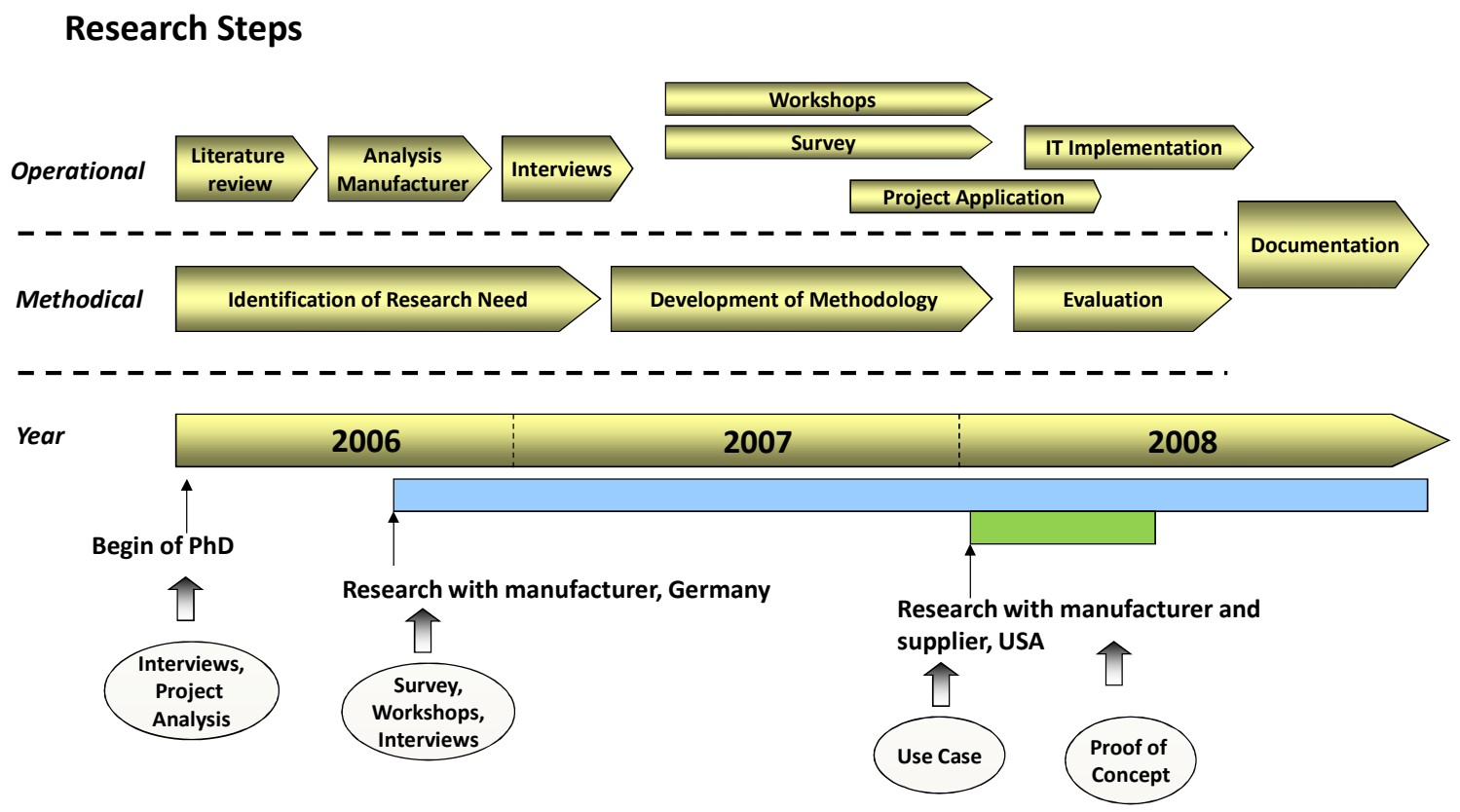

FIGURE 5.2: MAJOR RESEARCH STEPS

The identified difficulties and weaknesses in project management were compared and verified with an actual analysis of an automotive manufacturer. An existing project management analysis that was a result of a project to improve the company's project management performance was extended by additional interviews and taken as a reference to the literature review results. As already mention in Chapter 1, the concept 
of the Balanced Scorecard that is further described in Chapter 6 was applied to project management and extended with new integrated methods, such as the application of an impact matrix, and its application to cross-company project management. This is followed by a detailed adaptation of the concept to the automotive industry based on interviews, workshops, and a survey. A research pilot project where a CPS was developed for a cross-company project of an OEM and a supplier was the basis for an evaluation of its benefits and limitations when developing a CPS including the appraisal of its operation. Experiences with an IT implementation of the project results and further extensions of the CPS concept were part of the last research steps. Extensions are a combined approach with a collaborative project management reference model, a performance assessment model, and a risk management approach.

\subsection{From identification to hypothesis}

The following sections describe how the research objectives and hypothesis were derived from the identification of project management difficulties and weaknesses in the automotive industry. The identification and research proposal is mainly based on existing analyses (literature and a manufacturer analysis) and additional interviews.

\subsubsection{Analysis of a manufacturer and additional interviews}

The department for product development strategy of a German automotive manufacturer had initiated a project to improve project management effectiveness and efficiency for internal management and with external development partners. Therefore, in addition to the results of the literature review, the analysis results of this project and additional interviews (members of the ProSTEP iViP CPM project, GPM e.V. Automotive Chapter, and other experts in collaborative project management from several suppliers) were the basis to develop the research questions and objectives. The manufacturer analysis is based on 43 interviews, 30 of them were part of the manufacturer's own project management analysis based on the project experience of the project managers during the last 2 years. The interviews about their project experience were already documented at the time when this research project began. Figure 5.3 illustrates the steps towards the development of the research questions, objectives, and hypothesis. The results of 43 interviews were combined and compared with the results of the literature review to identify the major common core difficulties and weaknesses. 


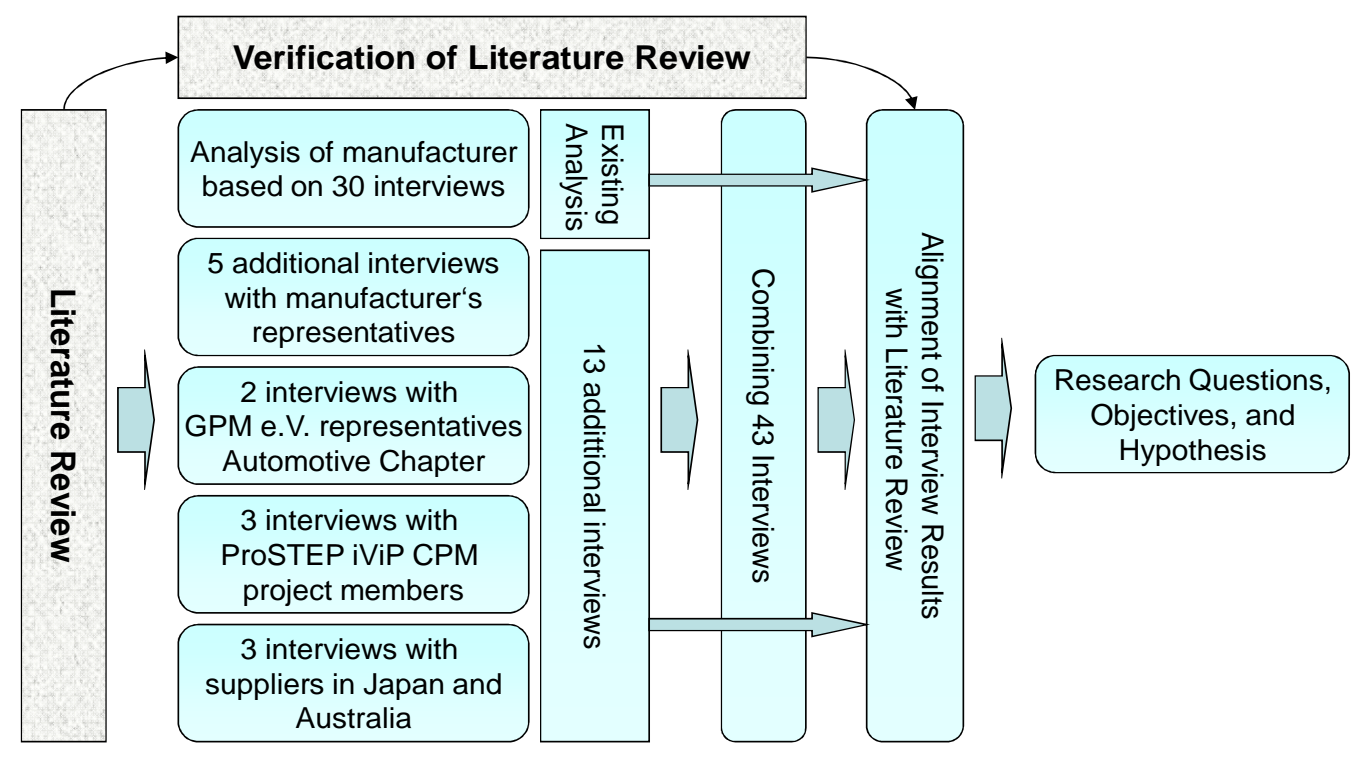

FIGURE 5.3: STEPS TOWARDS RESEARCH QUESTIONS, OBJECTIVES, AND HYPOTHESIS

Overview of conducted interviews:

- Interviews with five project managers of the chosen manufacturer from different departments (department of process and project management strategy, quality, and project management IT support).

- Interviews with representatives of the GPM Automotive Project Management Group.

- Interviews with CPM project group members (Life Cycle Engineers, Prostep AG, Actano).

- Interviews with project managers from Bosch $\mathrm{GmbH}$ in Japan, and Yokogawa in Japan and Australia.

Interview questions were addressed to the participants with relevant experience in a certain area only. Research relevant results of the manufacturer's 30 interviews that are based on vehicle projects are:

- Time and resource management are often independent processes and do not match.

- Redundant project management data storage.

- Lack of defined processes at synchronisation points, milestones, and maturity stages.

- Differing collaboration methods with different processes and tools.

- Status of project maturity not clearly defined and evaluation often not possible. 
- Project management methods are not entirely integrated.

- Relevant key performance indicators to monitor and control project activities collaboratively have not been entirely identified.

- Evaluation of project target attainability difficult.

- Lack of resource planning transparency.

- Lack of adequate change management for project schedules.

- Scope, risks, and resource management have different reporting cycles.

- Maturity stage control often missing.

Based on the 13 interviews with CPM project members, GPM representatives, and Australian and Japanese suppliers the following problems have occurred in most of the projects:

- Risk management methods of collaborative product development projects are not sufficiently developed.

- Methods and processes for monitoring and control of time, task, risks, resources, scope, and communication management are not entirely integrated and synchronised sufficiently.

- Variables and characteristics to evaluate and measure performance collaboratively have not been entirely identified.

- Project goals are not clearly defined and not aligned with business strategies.

- Stakeholder not sufficiently integrated.

- Partially defined documentation processes.

- Low project transparency and cause-and-effect relationships are often not clear and transparent.

- Corrective action often not pre-defined and, therefore, measures taken late.

The combination and selection of the difficulties and weaknesses identified by the manufacturer's analysis and the additional interviews with the literature review results determines the following core difficulties that are addressed by this research:

- Deficiencies in defining and clarifying project goals.

- Low transparency and flexibility in project organisation.

- Status of project maturity not clearly defined and evaluation difficult.

- Project goals not clearly defined and aligned with business strategies. 
- Stakeholders not sufficiently integrated.

- Undefined documentation processes.

- Low project transparency and cause-and-effect relationships not clear and transparent.

- Risk management methods of collaborative product development projects are not sufficiently developed.

- Corrective action often not pre-defined.

- Methods and processes for monitoring and control of time, task, risks, resources, scope, and communication management not sufficiently integrated.

Based on the core difficulties and weaknesses, the research questions and objectives were defined (Figure 5.4) and are further described in the following section.

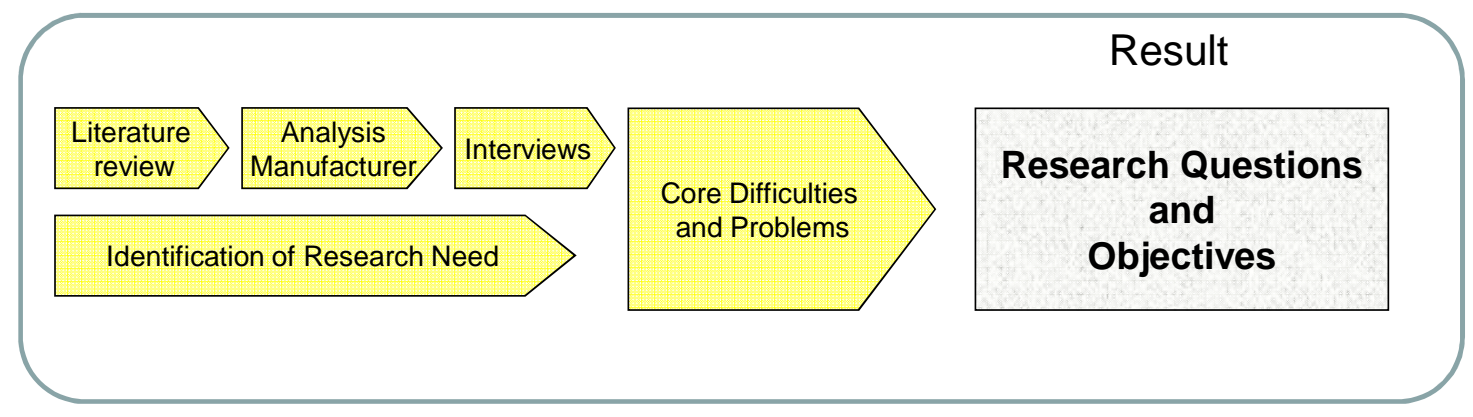

FIGURE 5.4: STEPS TOWARDS RESEARCH QUESTIONS AND OBJECTIVES

\subsubsection{Research questions, objectives and hypothesis}

Predicated on the core difficulties, the research questions can be formulated as follows:

- What method facilitates the definition and ensures a clear and common understanding of project goals early before project start?

- How can project transparency be increased so that all project partners have a clear understanding of cause-and-effect relationships of project goals and measures?

- What method ensures the definition of project maturity for an improved evaluation of the current project status?

- What methodology can integrate individual methods and processes by visualising their interrelation and dependencies?

- What method aligns project goals with business objectives and strategies? 
- How can stakeholders be integrated so that they better understand the project organisation and interdependencies in a project network?

- How can project documentation of relevant project objectives be ensured?

- What methodology enables the project manager to include risk management aspects of a collaborative and cross-company project?

- What method includes a predefinition of commonly agreed corrective action?

- How can the selected method incorporate a performance assessment of collaborative projects?

- Is the CPS methodology effective and efficient for improving the performance of collaborative teams in the automotive product development?

- If yes, what are the critical success factors that need to be considered when implementing the CPS methodology?

\subsubsection{From research questions to research objectives}

The literature review gave reason to believe that the application of a Balanced Scorecard to project management and cross-company project management in particular, may be a solution to reduce the identified difficulties and weaknesses effectively. Therefore, this research project had a focus on its application to networked project environments and an evaluation of its benefits, advantages, disadvantages, and limitations. Figure 5.5 shows the step from research questions to objectives.

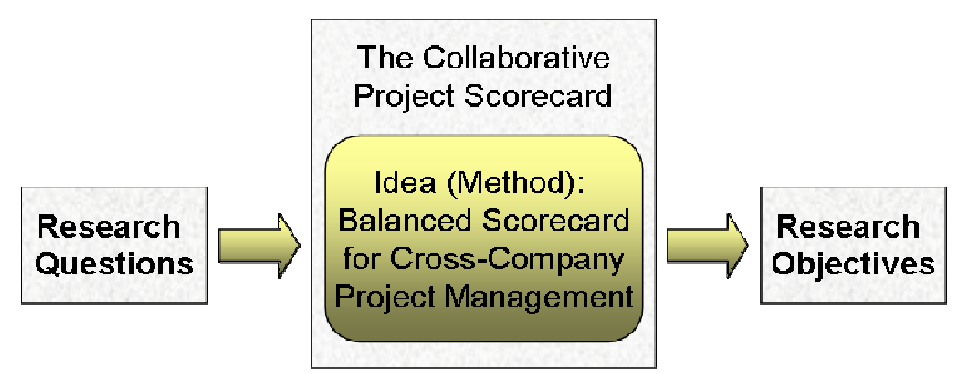

FIGURE 5.5: FROM RESEARCH QUESTIONS TO OBJECTIVES

The research objectives consist of an analysis, a method development, and an evaluation phase. In the analysis phase, the Balanced Scorecard was further investigated for its capability to be adjusted to networked project environments. Related methods, such as strategy maps and impact analysis, were analysed whether they can be applied and modified accordingly. Whereas the analysis phase is on a theoretical level (literature review and interviews) the method development phase includes 
workshops, surveys and questionnaires to allow the integration of experience and knowhow from a wide selection of project managers and strategists.

In relation to the research questions the objectives are to analyse, develop, and evaluate the Balanced Scorecard applied to cross-company project management to improve the difficulties and problems of:

- Low transparency and flexibility in project organisation and problems in defining and clarifying project goals.

- No alignment of project goals with business strategies and low stakeholder integration.

- Insufficient integrated monitoring and control of relevant project management areas, such as time, task, risk, resources, scope, corrective action and target management.

- Difficult identification and evaluation of project status and no method to predefine commonly agreed corrective action and control measures.

The evaluation phase aims to verify whether the concept reduces the weaknesses and difficulties, and whether it also impedes or improves a cross-company project in other areas. Figure 5.6 illustrates the three phases of the research objectives.

\section{Research Objectives}

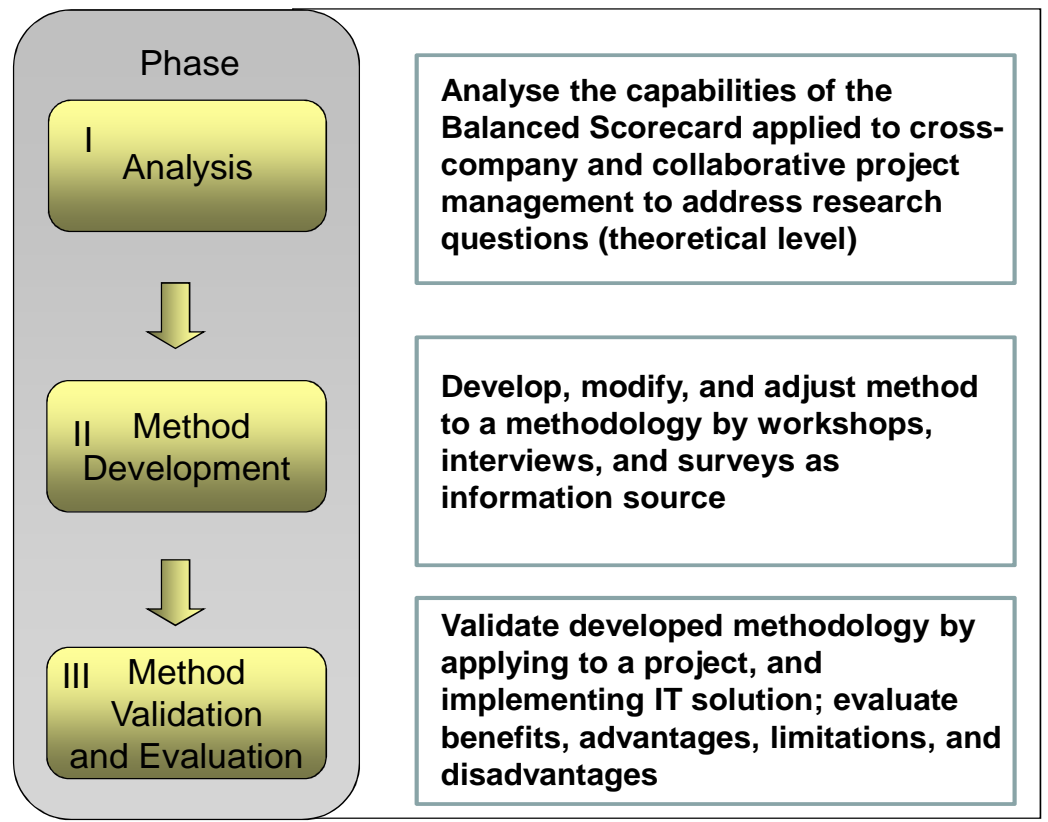

FIGURE 5.6: PHASES OF RESEARCH OBJECTIVES 


\subsubsection{Research hypothesis}

The analysis in phase one of the research objectives lead to the hypothesis that the Collaborative Project Scorecard improves the above mentioned problem areas. Testing the hypothesis within the evaluation of the methodology includes the identification of areas where the CPS also impedes and limits the performance of cross-company project management. Consequentially, it may improve areas that were not part of the identified core difficulties and weaknesses. Therefore, the hypothesis can be summarised as: "the CPS methodology is effective and efficient for improving the performance of collaborative teams in the automotive product development".

Figure 5.7 shows the relevant steps towards the achievement of the research objectives and the relation of the three phase approach to the hypothesis and the hypothesis testing.

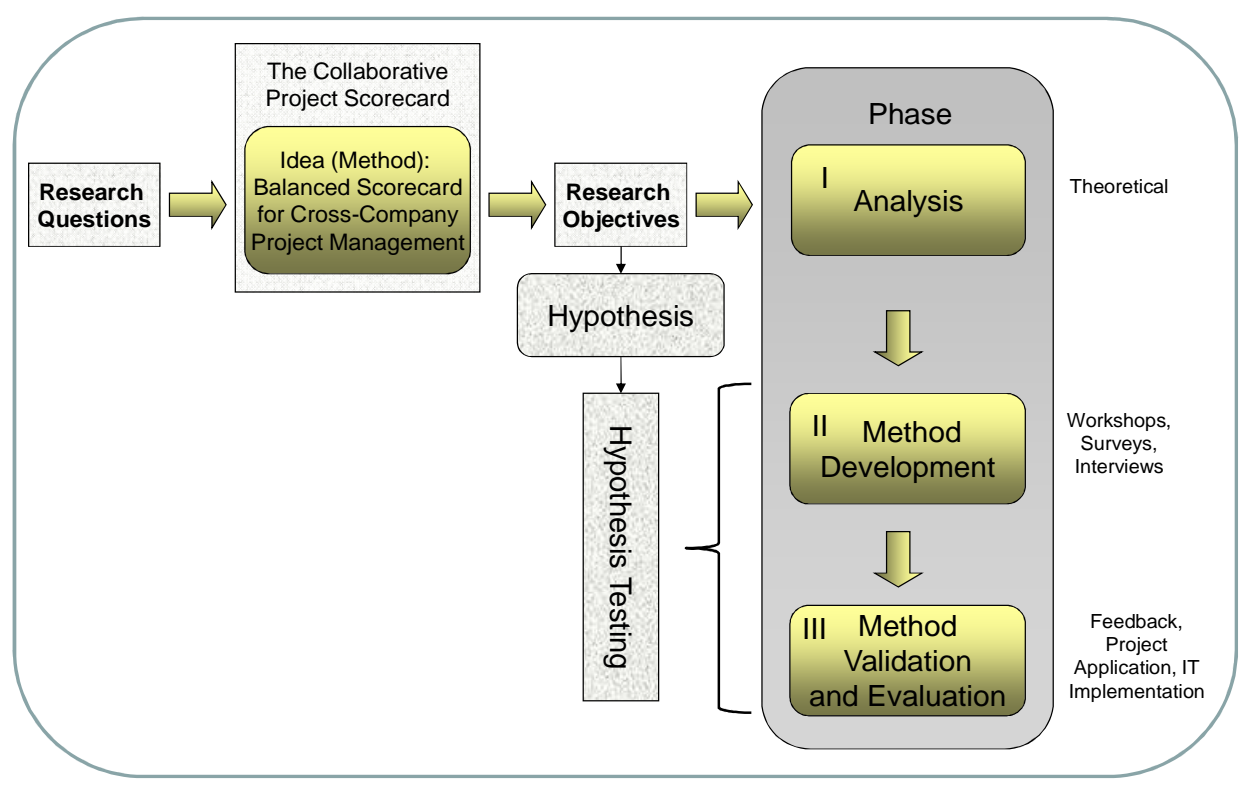

FIGURE 5.7: FROM RESEARCH QUESTIONS TO HYPOTHESIS TESTING

Theoretically, the Collaborative Project Scorecard can be applied to all project phases from concept phase and even predevelopment until project closure, however, the application within this research project is limited to the project planning, control and monitoring phase with a focus on product (series) development and pre-production as shown in Figure 5.8. 


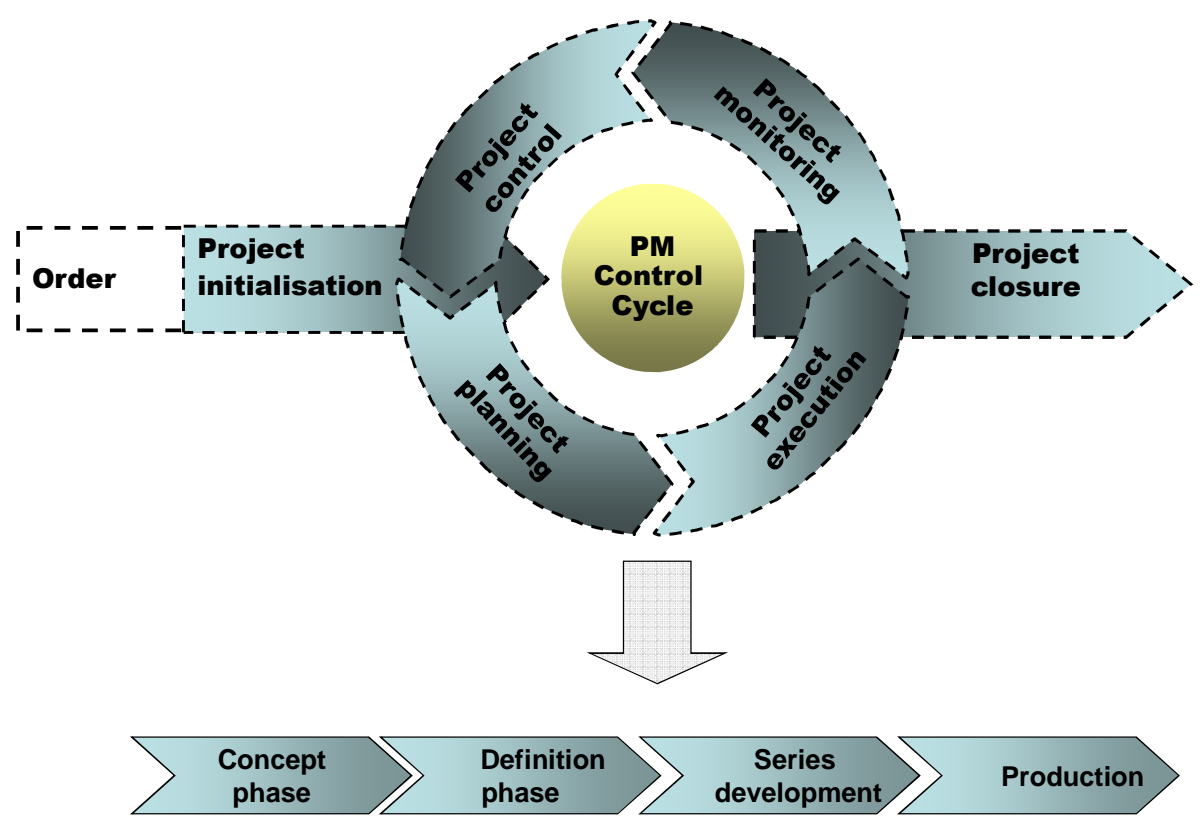

FIGURE 5.8: PROJECT PHASES AND PROJECT MANAGEMENT LIFE CYCLE (ON THE BASIS OF:

HAB AND WAGNER, 2006, P. 30)

The next section provides further details about the overall research plan including information sources with a stronger focus on the concept development and evaluation phase.

\subsection{Research plan and information sources}

The research project was initiated at the Faculty of Engineering and IT of the University of Technology Sydney in 2006. A literature review and identification of typical problems in virtual and cross-company project management with a focus on the automotive industry was the first research step. An early exchange with the ProSTEP iViP CPM project group lead to a research contract with one of their participating manufacturers in Germany in October 2006. The benefit was an official participation in the CPM project to develop methods for task, time, and communication management of collaborative projects together with 15 industry and research partners in Europe. Additionally, the research contract with the manufacturer facilitated the access to a wide selection of project managers and strategists for interviews, workshops, and surveys within the industry. 


\subsubsection{Research activities on an international level}

The established contacts with the German Project Management Association (GPM e.V) Automotive Chapter was another valuable information source as two workshops for the development of the CPS methodology were organised in 2007 at two different supplier facilities in Germany. Access to the project management community facilitated another survey to obtain relevant feedback and an assessment of the concept. The ProSTEP iViP association that has a focus on the automotive industry (next to aeronautical and aerospace organisations), and the GPM e.V. were both research partners that enriched the outcome of this research greatly.

Other research partners, such as the Bosch GmbH in Japan and Yokogawa in Japan and Australia, together with a five months research period at the German automobile manufacturer's facilities in the USA made it possible to operate the research activities on an international level.

\subsubsection{Milestones and information sources}

The first major milestones of the research project were the beginning of the project in January 2006 and the start of the research cooperation with the German manufacturer in Munich in October 2006. Business needs were identified and research questions developed based on the literature review, internal survey, and interviews. The doctoral assessment took place in March 2007 and shortly after, the cooperation with the GPM e.V. Automotive Chapter began. The two workshops were fundamental to the general concept development. In January 2008, the research at the manufacturer's plant in the USA was continued and the adaptation to the business requirements of an OEM supplier project with an IT implementation supported the evaluation and validation of the CPS concept. Next to the two GPM workshops, other workshops in the USA, surveys, and additional interviews were sources of information necessary for the concept development and evaluation. Figure 5.9 illustrates the research plan and categorises the aspects of timeline, procedure, and information source. 
Milestones, Time Line, and Information Sources:

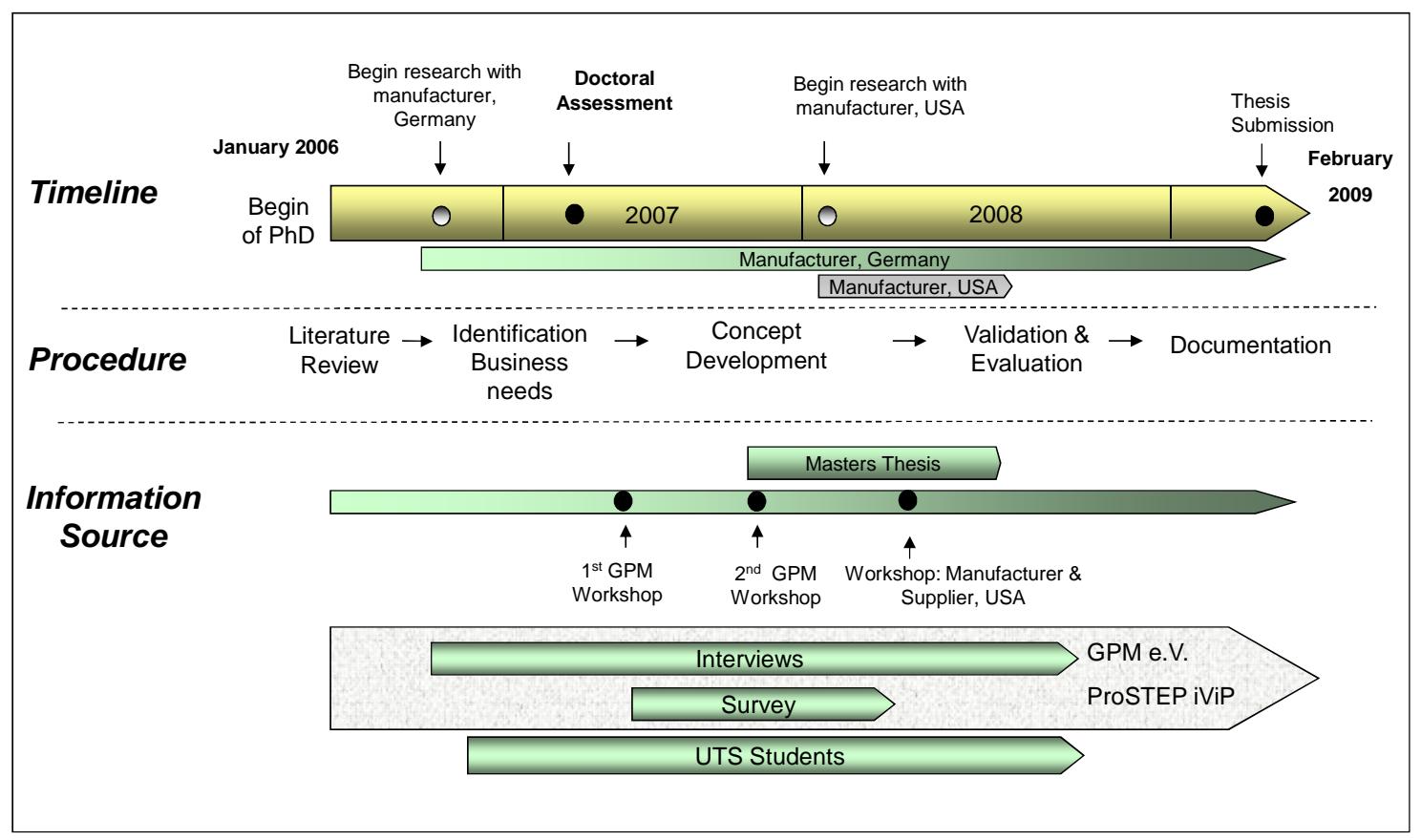

FIGURE 5.9: RESEARCH PLAN

Within the first and second GPM e.V. workshop at DräxImaier Group in Vilsbiburg and Mueller Weingarten AG in Erfurt, both German automotive suppliers, the CPS methodology was broadened by defining the four perspectives of the CPS, by developing a procedure model to introduce the CPS into a business, and by identifying relevant measures for typical automotive projects, and finally, by the application to small and medium sized businesses.

\subsubsection{A variety of core methods as part of the CPS methodology}

The application of Kaplan and Norton's strategy map to project management (Kaplan and Norton, 1996) and the development of the collaborative project impact matrix were already integrated contributions of this research project before the GPM e.V. workshops took place. Both methods are described in Chapter 7. During the research in the USA, a CPS was developed for a specific cross-company project for the launch and change management phase. A workshop, several interviews, and a survey were the basis for the results presented in Chapter 8. Additionally, the integration of collaborative risk management, the extension with a strategic framework, and the IT implementation followed by a further evaluation were the outcome of the research in South Carolina. Collaboration with the GPM Automotive Chapter and the ProSTEP iViP was again 
intensified and resulted in the development of two combined concepts with the ProSTEP iViP CPM Recommendation and the GPM/IPMA Project Excellence Model. Figure 5.10 shows the set of developed tools and methods as part of the CPS methodology.

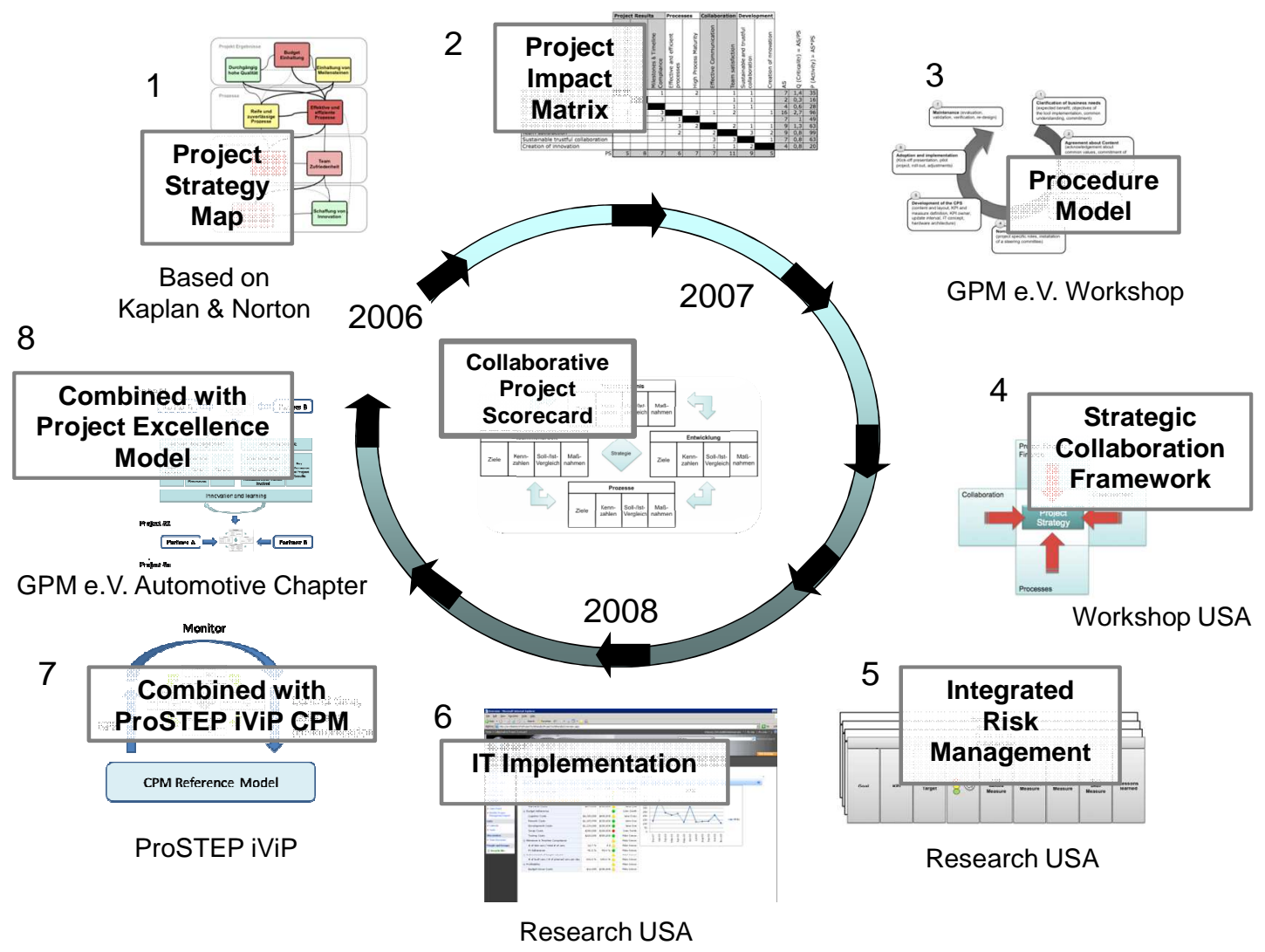

FIGURE 5.10: SET OF DEVELOPED METHODS FOR CPS METHODOLOGY

\subsubsection{Continuous development, adaptation and improvements}

During the research project, ideas and methods were constantly discussed with project managers and scientists throughout the automotive industry and other industry sectors. A broad network of project managers, associations, organisations, and universities supported the research project to develop and improve the integrated methods continuously.

Next to an extensive network within the manufacturer's facilities in Germany and the USA, the 15 ProSTEP iViP CPM project group members, the GPM e.V. Automotive Chapter network that consists of a large variety of automotive manufacturers, suppliers, system vendors, research institutes, and consultancies, the network was extended by 
several University contacts, and members of project management associations worldwide. 


\section{Balanced Scorecard and project management}

In the beginning of the 1990s David Norton and Robert Kaplan developed the Balanced Scorecard method at the Harvard University. Since then the concept has supported businesses to translate their vision and mission into operational objectives. The driving force is a balanced relationship between traditional measures and the most important factors that impact future performance. The application of the Balanced Scorecard (BSC) to project management is a strategic approach that supports the alignment of project objectives with business strategies and goals. This chapter illustrates strategic approaches in project management and identifies relevant applications of the Balanced Scorecard to project management. It also includes recent study results of the BSC application and illustrates the concept of strategy maps. Figure 6.1 shows the structure of this chapter.

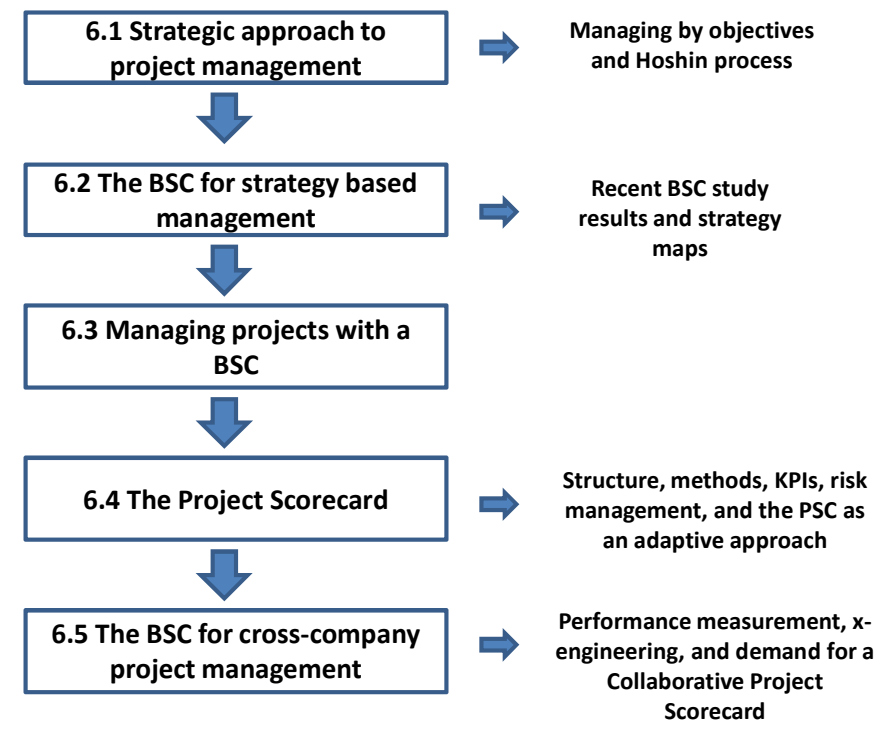

FIGURE 6.1: OVERVIEW OF CHAPTER 6

The application of a strategy map to project management is further discussed as one of the contributions of this research project. In a next step this chapter describes the application of a BSC to project management and the concept of a Project Scorecard including relevant KPIs. Performance measurement with a PSC, x-engineering, and the increasing demand for a Collaborative Project Scorecard are elements of the last section. 
The balanced consideration of different goals that cover the perspectives of financial aspects, the satisfaction of the customer's expectation and requirements, internal business processes, and aspects related to continuous learning and development enables a holistic view over all relevant business objectives. Strategic and sustainable success is also ensured by monitoring and control of financial and non-financial targets. The Balanced Scorecard is structured into the four perspectives as mentioned above and each perspective includes related objectives, which are monitored by measurable targets and defined indicators (Herde et al., 2001). These indicators are often called key performance indicators (KPIs) and in some literature there is a distinction of KPIs and key goal indicators (KGls), whereas KGls are more goal oriented indicators rather than measures for performance only. Within the following chapters, only KPIs are used to describe indicators for performance or goal achievement.

\subsection{Strategic approach to project management}

The education of strategy has become an important part of lectures and management seminars worldwide, however, the enormous growth of internet facilities and "internet euphoria" has created doubts that long term strategies are no longer implementable and quick-wins may become the dominating philosophy of many business managers. Porter (2001) thinks that operative efficiency has overshadowed strategic thinking of leading managers and emphasise the importance of strategic management.

\subsubsection{Managing by objectives and Hoshin Process}

Management by Objectives $(\mathrm{MbO})$ has its origin in the 1950s and was especially adopted by managers in the Unites States and later in Europe. A vertical top-down and bottom-up process approach harmonises the organisational objectives with those of the employees. The adaptation of leading processes to definite operational goals and the creation of an environment of target achievement and performance evaluation are the fundamentals of this management method. Target definition, control by management, short term consideration, top-down processes and vertical hierarchy are main aspects of $\mathrm{MbO}$. The origins of the Hoshin model are based on the Total Quality Management (TQM) concept that is also called Management by Policy (MbP). Extension to the TQM concepts are the gathering of all operational activities to a common vision, integration of all stakeholders, leading managers and employees, objective development with top- 
down and bottom-up processes, long-term and quality oriented process, and a vertical and horizontal hierarchy. The seven steps of the Hoshin planning process are shown in Figure 6.2.

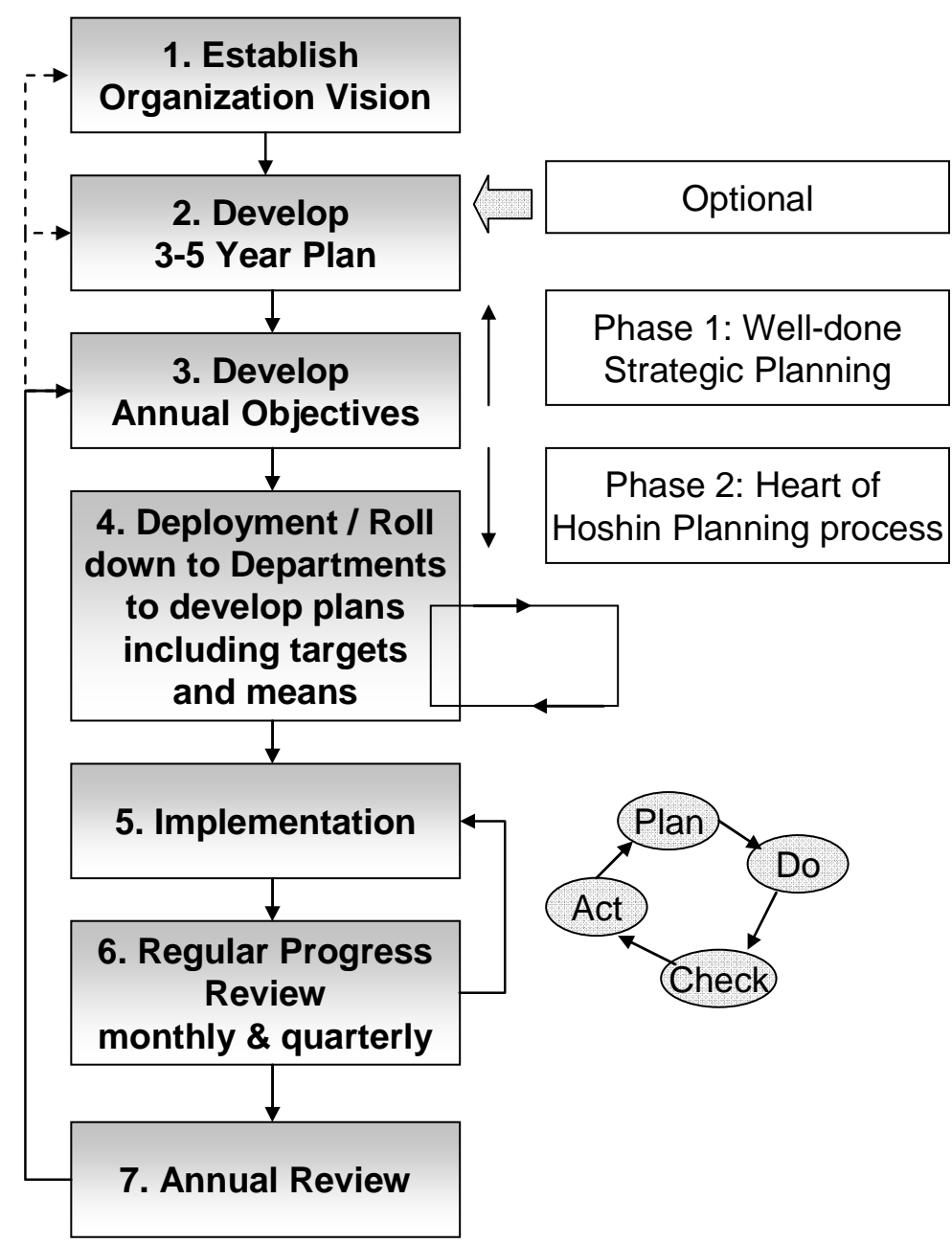

Figure 6.2: SEVEn Steps OF THE HOSHIN PLANNING PROCESS (Jolayemi, 2008, P. 298)

The objective development process is characterised by a definition of mission and vision, objectives, strategies, and tactics (MOST). Compared to $\mathrm{MbO}$, the vision definition takes place in the beginning of the process and strategic goals are implemented by vertical and horizontal hierarchical structures. The Hoshin process is finalised by an individual target agreement and regular employee agreements on individual objectives (Herde et al., 2001, p. 298).

\subsection{The Balanced Scorecard for strategy based management}

The Balanced Scorecard method developed by Kaplan and Norton in 1992 is a strategic approach and a performance management system that enables organisations to 
transform a company's vision and strategy into implementation by addressing four perspectives:

- Financial perspective (e.g., earnings per share, revenue growth, profit growth).

- Customer perspective (market share, customer satisfaction, referral rate, customer retention, etc.).

- Business process perspective (e.g., cycle time, cost of services, speed of services).

- Learning and growth perspective (effectiveness of change to technology and processes, speed and frequency of changes, adaptability, employee satisfaction, willingness to share and gain knowledge, etc.).

Figure 6.3 shows the structure of the Balanced Scorecard framework with its perspectives and core categories.

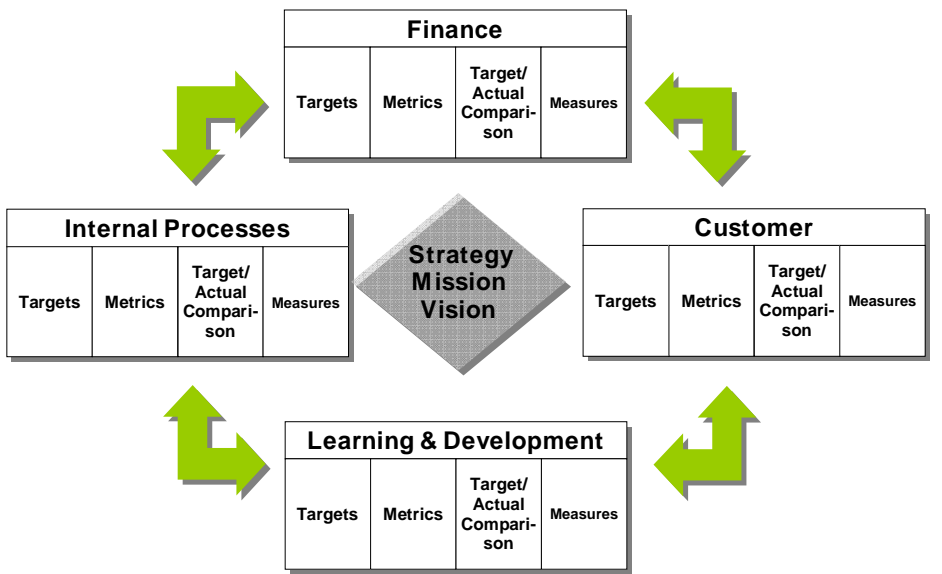

Figure 6.3: BALANCEd SCORECARD FRAMEWORK (KAPLAN AND NORTON, 1996, P. 9)

The objectives of a BSC are to ensure that measures support core values and practices of the organisation, to establish performance measures and benchmarks, to assess project health, to align measures against the project's charter, and to establish measures that are efficient and effective, consisting of outcome, action (performance drivers), and diagnostic (why an outcome or action measure is at its current level).

Kaplan and Norton (2001) cite the following benefits of the Balanced Scorecard usage:

- Focusing the whole organisation on the few key aspects needed to create breakthrough performance. 
- Helps to integrate various corporate programs. Such as: quality, re-engineering, and customer service initiatives.

- Breaking down strategic measures towards lower levels, so that unit managers, operators, and employees can see what is required at their level to achieve excellent overall performance.

The integration of the four perspectives into one picture has made the Balanced Scorecard method very successful. For each perspective of the Balanced Scorecard objectives, measures, targets, and initiatives are monitored (scored):

- Objectives: major objectives to be achieved, for example, profitable growth.

- Measures: the observable parameters that will be used to measure progress towards reaching the objective. For example, the objective of profitable growth might be measured by growth in net margin.

- Targets: the specific target values for the measures, for example, $7 \%$ annual decline in manufacturing disruptions.

- Initiatives: projects or programs to be initiated in order to meet the objective.

The financial perspective considers the relevant result indicators of an organisation, typical indicators are return on investment (ROI), return on capital employed (ROCE), economic value added, or profitability and represent the upper level objectives of all perspectives. The customer perspective represents the strategic objectives in relation to a customer or market segment and focuses on results such as indicators to measure customer satisfaction, price/performance relation, quality of a service, time factor, customer relationships, etc. The learning and development perspective, or sometimes called learning and innovation perspective, indicates the necessary future investment areas and it describes the infrastructure that enables the achievement of the other perspective's targets. Employee aspects such as motivation, flexibility, team work, learning activities, and readiness for change are indicators of this perspective. The internal business process perspective has a focus on the critical processes, which are relevant for the value creation chain of a company. Key processes are measured by productivity, cost, time, or quality indicators (Herde, 2001). 


\subsubsection{Recent Balanced Scorecard study results}

A recent study by Horvath and Partners in 2005 has identified the experience and satisfaction with the Balanced Scorecard concept of 120 companies of different industry background in Germany, Austria, and Switzerland. This was the third study that has validated the core findings of the two former studies in 2001/2002 and in 2003.

According to this study, the BSC has a positive impact on turnover and results, as well as on various non-financial measures such as quality and customer satisfaction. Two thirds of the non-governmental BSC users are convinced that the annual net income of their company has developed better than that of the competition. Also $80 \%$ of the users estimate that the benefits of a BSC are dramatically higher than the efforts needed to develop and maintain the BSC. Over two thirds of the study participants think that the BSC will be of great importance for the businesses within the next three years. $80 \%$ are also convinced that the BSC supports the strategy implementation of a business. Further results of the study demonstrate the importance of this fact as $70 \%$ of the participating companies confirm that their competition implements similar strategies. The competence to implement strategies is considered a key for a company's success and $65 \%$ of the participants believe that their strategy implementation is one of their strengths (Horvath and Partner, 2005). Figure 6.4 is based on the questions whether a company implements similar strategies as their competition.

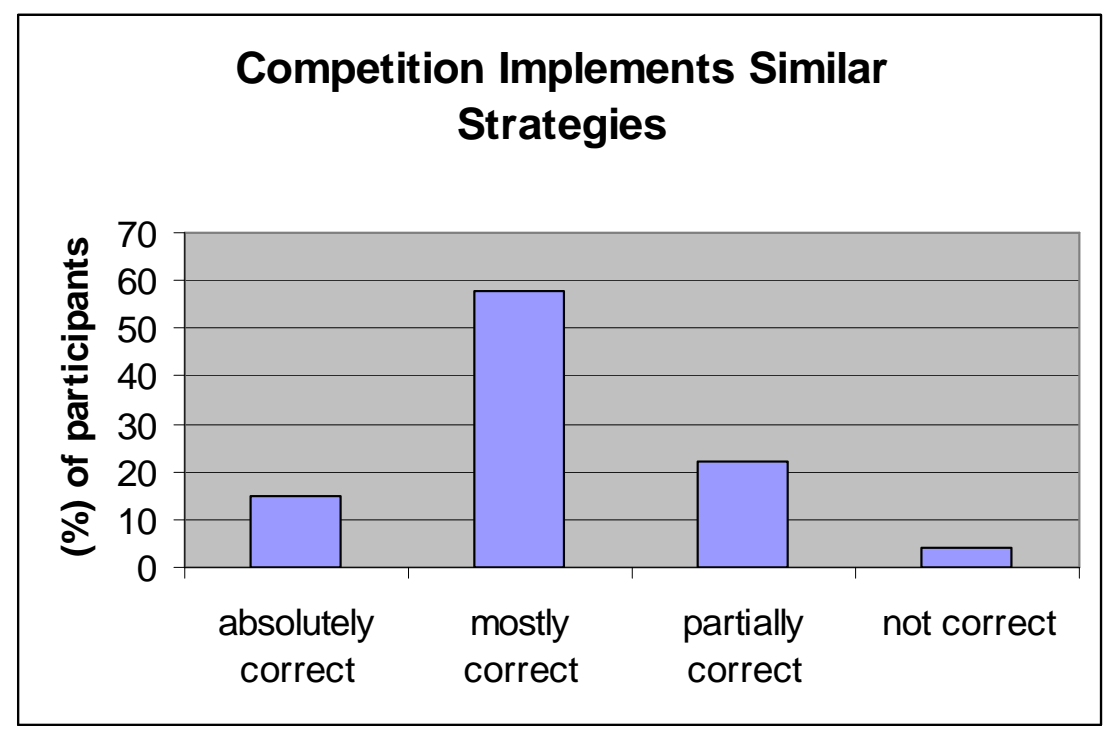

FIGURE 6.4: SIMILAR STRATEGIES AS COMPETITION 
Figure 6.5 shows whether a company considers its strategy implementation as a strengths or weakness.

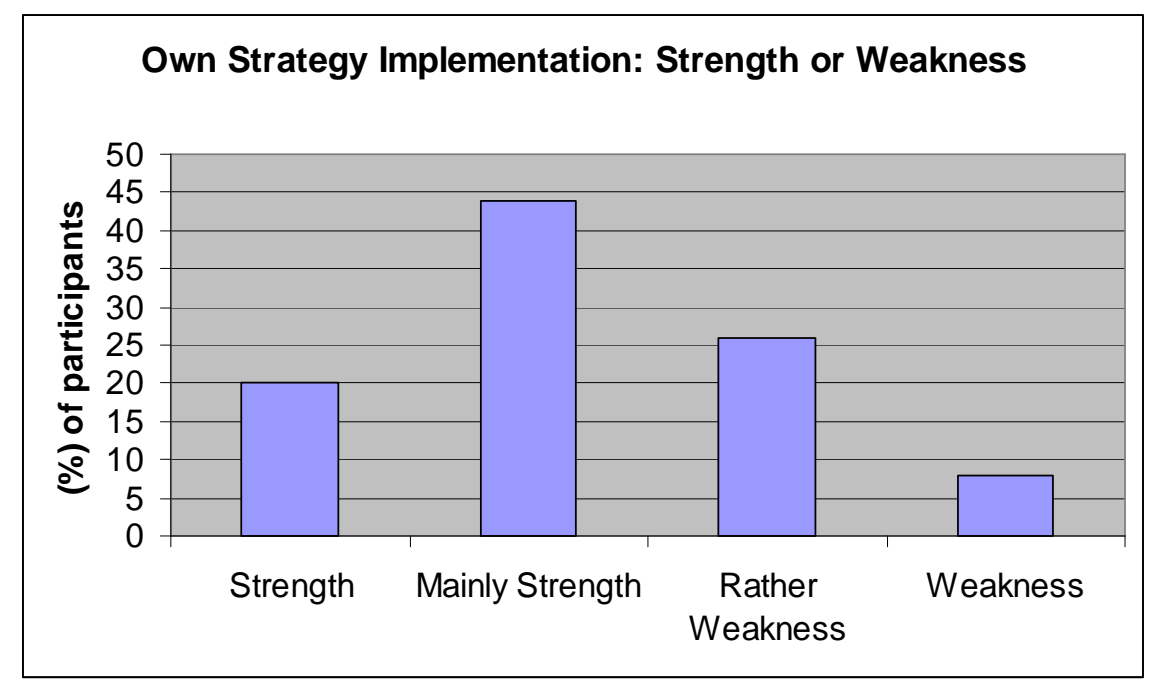

FIGURE 6.5: STRATEGY IMPLEMENTATION CONSIDERED AS STRENGTH OR WEAKNESS

The participants of the survey were non-governmental private businesses. Another result of the study is that the BSC is rather applied in earlier phases of the strategy process than before. Earlier studies showed that strategy development happened before a BSC implementation but with the increasing acceptance of strategy maps based on cause-and-effect relationships. Today, the BSC has been integrated at an earlier stage and is considered as an integrated part of a closed strategy management process. According to Horvath and Partner (2005), the Strategy Maps are only useful for small businesses as larger enterprises are structured into several business and functional departments that are embedded to an overall strategy and implement their own sub strategies derived from the overall strategy, and therefore, qualify for a BSC application. In practice, many organisations work within a system of single Balanced Scorecards as nearly two thirds of the study participants have implemented more than five and one third even more than 20 BSCs. This result corresponds with the study undertaken in 2003 with a minimal increase of the number of BSCs, which have been operationalised. Figure 6.6 shows the number of BSCs that an organisation has implemented (from 84 organisations). 


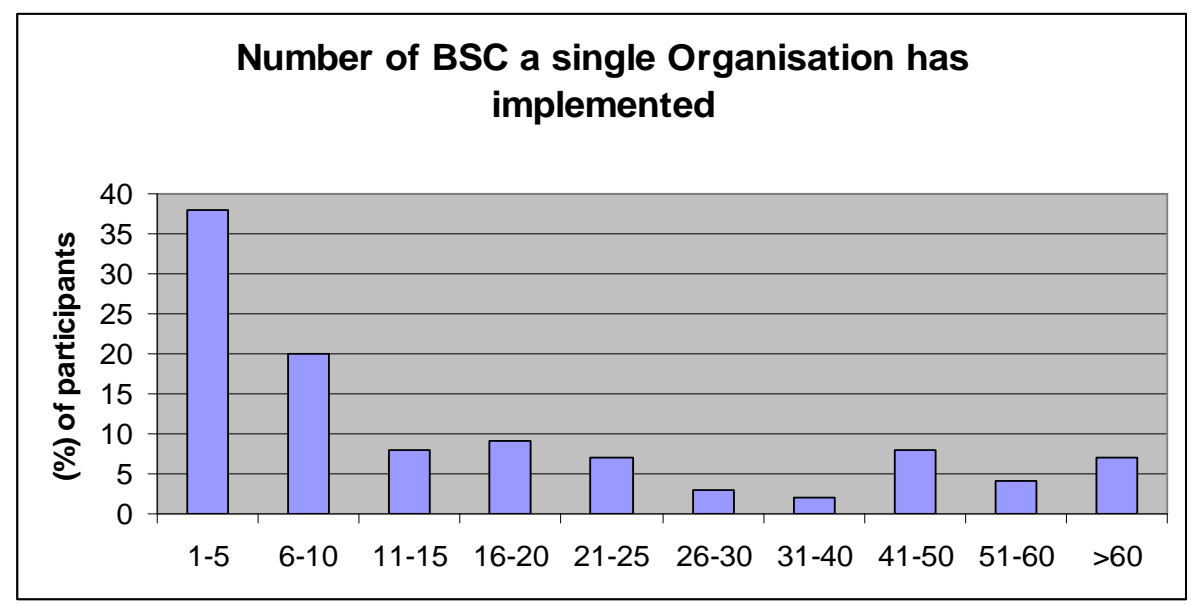

FIGURE 6.6: NUMBER OF BSC A SINGLE ORGANISATION HAS IMPLEMENTED

Despite of the increasing maturity of the BSC application there is still room for improvement applying the BSC more efficiently and effectively in many organisations. Horvath and Partner (2005) identified the following aspects as relevant steps towards an improved application of the BSC.

- A more systematic and consequent link between strategy development and BSC development.

- An improved integration of the strategic objectives (the objective systems that is represented by the BSC) with the budgeting.

- A professional application of strategy maps.

- Measurement of soft facts.

- The degree of penetration of the BSC concept and

- The search of an appropriate software solution.

- An improved harmonisation of the BSC with the concept of value, quality, and risk management.

- Alignment and a more professional selection and control of strategic project portfolios.

\subsubsection{The Balanced Scorecard and IT support}

Horvath and Partner (2005) believe that the BSC is not a reporting system but it includes one, therefore, they have chosen the IT support as a main focus of their study. The BSC produces strongly focused data in relation to the strategic objectives and 
therefore, in relation to the strategy implementation. Appropriate choice of supporting systems is an important step as the BSC includes various data and information, which have to be managed efficiently. According to their study, $74 \%$ of the participating organisations still work with Microsoft Excel and Access for their management tasks but a considerable part is not satisfied with this solution. Figure 6.7 shows that only $11 \%$ are happy with their Excel and Access solutions.

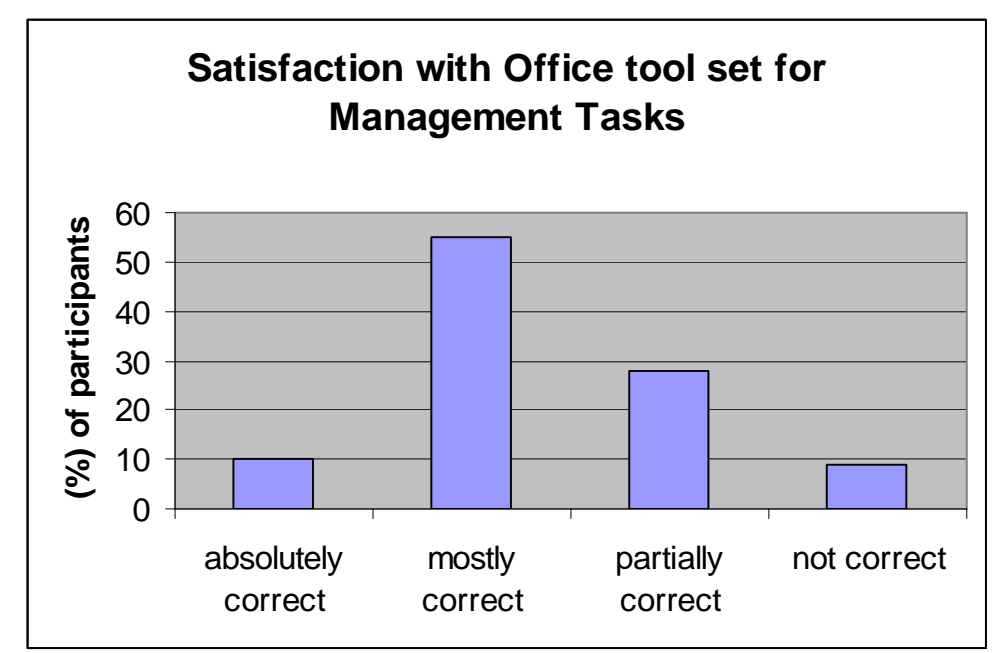

FIGURE 6.7: SATISFACTION WITH OFFICE TOOL SET FOR MANAGEMENT TASKS

\subsubsection{Strategy Maps}

A Strategy Map is a visual representation of the relationships between the different perspectives, objectives and metrics of the Balanced Scorecard. Mapping these interrelated aspects is an effective way of providing stakeholders with a macro view of an organisation's strategic priority. Executive managers can easily identify whether relevant aspects are missing, verify their assumptions and rethink priorities if necessary (Kaplan and Bower, 2004). The Strategy Map is created by visualising the different perspectives of the Balanced Scorecard to the left side and the main financial strategies across at the top. Figure 6.8 shows an example of a simplified and generic Strategy Map. 


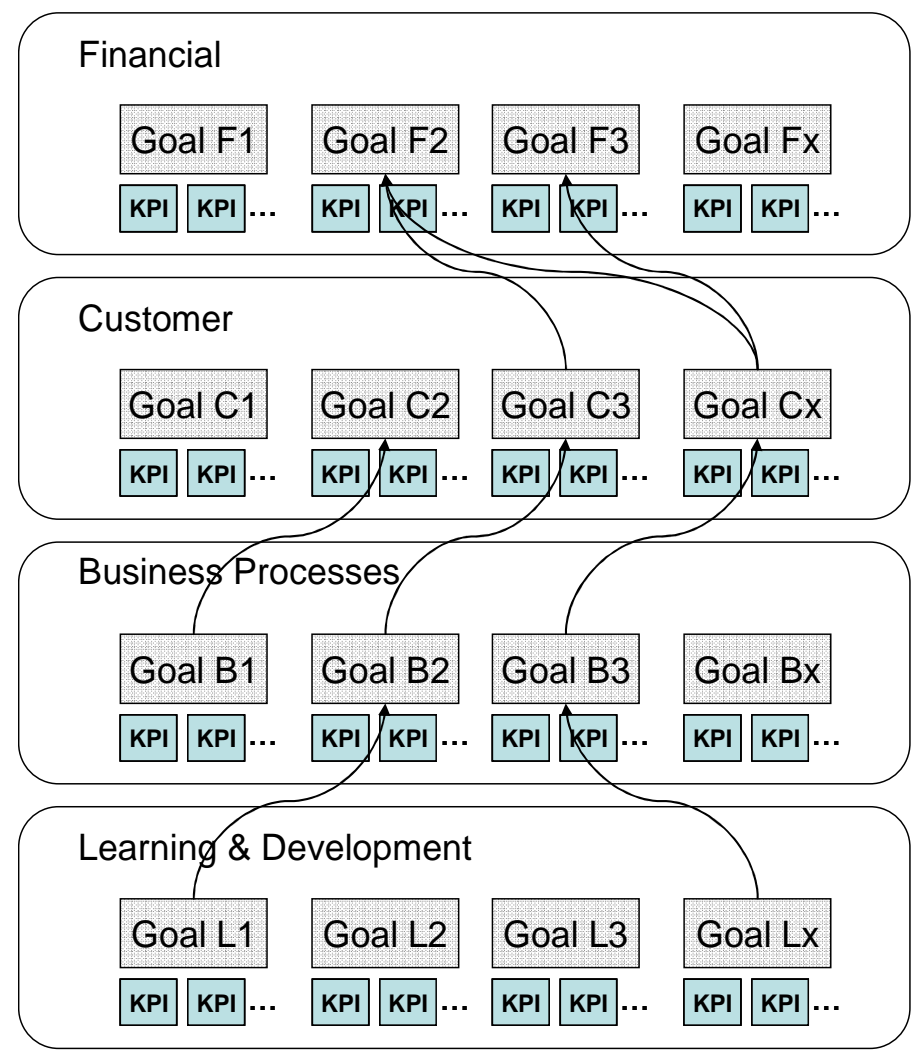

FIGURE 6.8: SAMPLE STRATEGY MAP

The objectives and metrics of each perspective are represented as boxes. Then the map is developed in a downward flow by drawing the cause-and-effect linkages between these boxes. The map shows clearly how the objectives of each perspective influence and support the overall strategic goal (Scholey, 2005).

\subsection{Managing projects based on the Balanced Scorecard}

The main focus of common and traditional scorecards used in project cockpits for project management are mainly hard facts related to time, budget and quality. These scorecards are suitable for quick performance measurement purposes with a clear focus on financial performance indicators. However, they reflect neither the non-financial, intangible world nor the total strategic alignment between project strategies and business strategies (Norrie and Walker, 2004). The changing competitive environment with increasing numbers of cross-functional work teams and rapid technological developments was demanding new management methods and tools in order to keep projects successful (Salem, 2001). 


\subsubsection{Project team performance and strategic project selection}

Norrie and Walker (2004) explored the concept of a Balanced Scorecard applied to projects to improve operational performance of project teams. They conclude that the project results can be improved by monitoring and controlling project activities more effectively. Their study provided early evidence that the Balanced Scorecard improves project management effectiveness. This is also because it facilitates the communication with internal and external project stakeholders.

Norrie (2006) further investigated the BSC approach for strategic project selection and demonstrated that the use of a strategic scoring model can enhance the understandability of project portfolio management and improve the probability of optimising the project selection for a project portfolio. Stewart and Mohamed (2001) utilised the Balanced Scorecard for IT and IS performance evaluation in the construction industry. They concluded that the BSC framework is useful to evaluate IT performance and Stewart et al. (2007, p. 517) later applied the model and could prove that "firms which provide reliable IT-systems that are well-supported and user-friendly will achieve higher IT-induced performance improvement in the operational, strategic competitiveness and benefits perspectives".

\subsubsection{Projects as mini-organisations}

Stewart (2001) has also conducted research into the application of Balanced Scorecards to project environments and identified relevant key performance indicators (KPIs) to perform project "health checks" throughout the life cycle.

Projects can be considered mini-organisations, requiring the same clarifications and benchmarks of the organisation. Stewart (2001) also states data must be collected consistently and at pre-defined times. The scores should assist the project manager to:

- Monitor critical tasks.

- Assist in tracking factors that are critical to customer satisfaction.

- Observe trends across and within projects.

- Reveal variances from established controls.

- Provide early warning signals.

- Assist in planning for continuous improvement in all BSC perspectives. 
The customer perspective looks at the market value of the project deliverable as well as stakeholder satisfaction in the project outcome. The internal business perspective incorporates the management plan that is developed during the planning phase and utilises the established processes. It evaluates the scope, timelines, performance, and costs. The financial perspective examines how the organisation looks to shareholders and if the project outcome generates the expected revenue. The innovative and learning perspective aims to achieve continuous improvement and innovation to the organisation. The scorecard must be built on communication, compliance, continuous improvement, and cooperation. A project can be considered as an organisation with a vision, and strategies to meet project objectives (Stewart, 2001).

\subsection{The Project Scorecard}

Using the Balanced Scorecard for project management, the focus of project management shifts from the traditional and financial point of view to a more holistic view. The scorecard is then often called Project Scorecard (PSC). The PSC allows project management not only to consider non-financial, intangible assets and related performance indicators, but also to ensure a better strategic fit with the overall business. Through clear cause-and-effect interrelations between the non-financial and financial performance indicators, achievements of objectives become measurable and, therefore, manageable (Stewart, 2001). This is a key advantage of the Project Scorecard. Consequently, the Balanced Scorecard can be used very broadly in the project management process, as it combines overall planning, controlling and monitoring processes.

Using a Balanced Scorecard for projects helps the project manager and stakeholders to check and validate strategies, goals and indicators against the previously established expectations. Furthermore, it supports the overall understanding of the project and hence motivation of the project team. Continuously, objectives and their level of achievement are measured in order to control the project with corrective actions. With periodical reviews, new findings can be implemented into the project process (Selders and Maerkle, 2004). 


\subsubsection{Structure and organisational integration of the Project Scorecard}

The following sections illustrate the structure of the Project Scorecard in relation to strategies, objectives, and processes and describe how the concept is integrated and incorporated into an organisation.

\subsubsection{Structure of a PSC}

The Project Scorecard can be structured into three elements: levels, cause-and-effect relationships, and indicators. The levels are business strategies, strategic project goals, project objectives (scope, quality, time, and costs), project processes and project potentials (team members, infrastructure, and external service provider). Figure 6.9 shows the hierarchical structure of the four levels as defined by Selders and Märkle (2003).

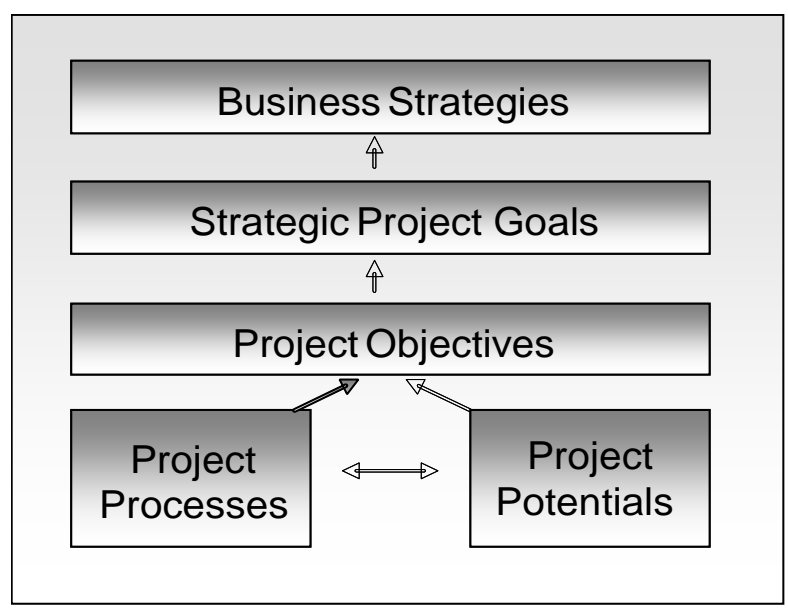

Figure 6.9: Four LEVELS OF A PROJECT SCORECARD (SELDERS AND MAERKLE, 2003, P.3)

Figure 6.10 illustrates the PSC framework. In the centre of the PSC are now project strategies that describe how the objectives can be achieved most efficiently and effectively. 


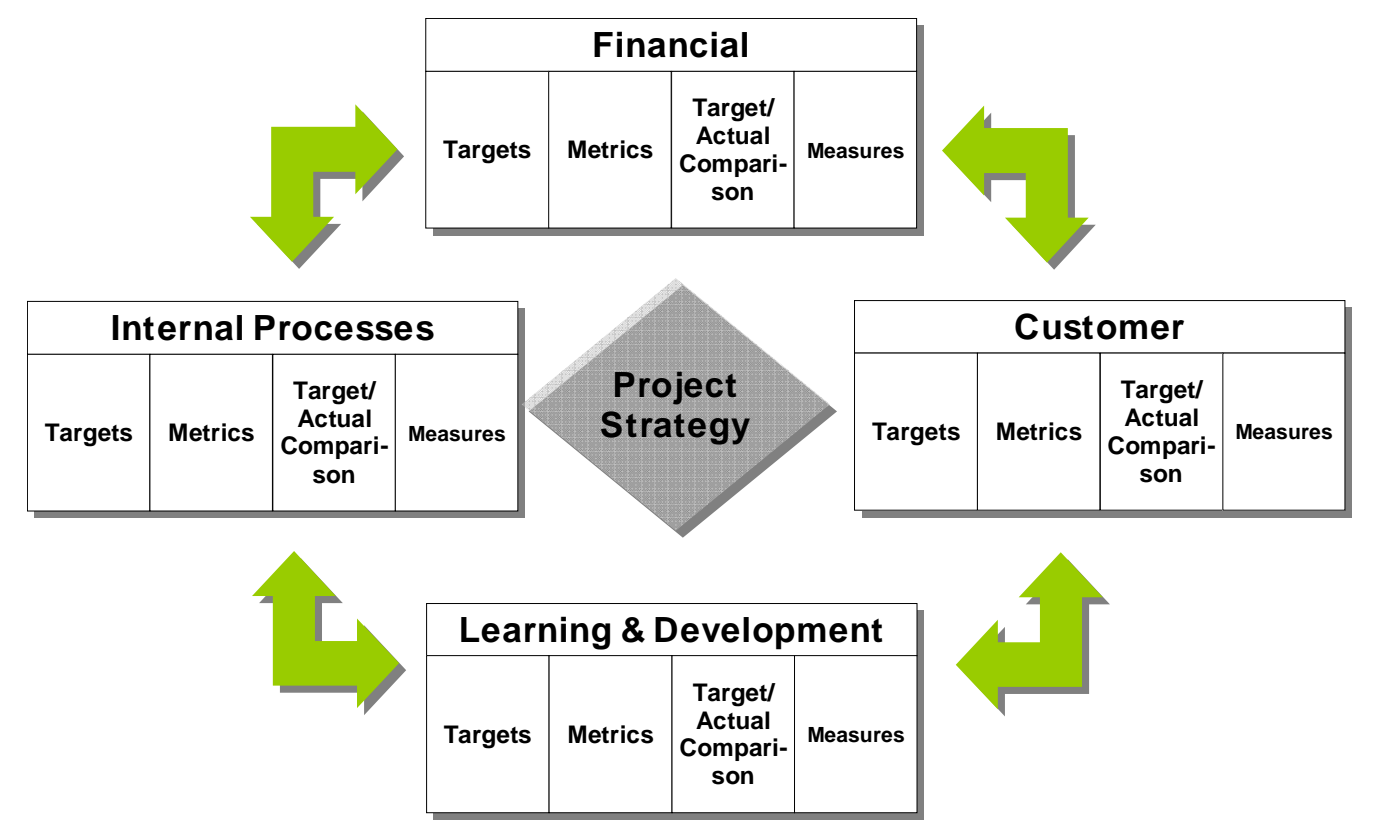

Figure 6.10: Project SCORECARD FRAMEWORK

Next to financial aspects of a project, the project results are often the most important objectives of a project. These also include financial data and objectives, however, functional requirements and milestones may become more important to a project's success. However, non-financial project result objectives are usually included in the customer perspective next to goals such as milestone or quality adherence. All perspectives are considered in a project management context, e.g., the business processes are now processes relevant to achieve the project results and objectives.

The Project Scorecard also simplifies the implementation of corrective actions as it enables the manager to better understand the consequences each decision has on the whole outcome of the project, even on parts that are not directly related to a change. In summary, it is important to understand that traditional project scorecards (project cockpits/dashboards) were used for the day-to-day management of the project, whereas the balanced approach of the PSC goes beyond that and help the project manager to fulfil their leadership role in directing the project towards its strategic destination (Lawson et al., 2007)

\subsubsection{Organisational integration of a PSC}

Project goals and strategies can be derived from the business Balanced Scorecard or the business strategic goals in several steps depending on the company's structure, for example, from the departmental, corporate project portfolio, or multi-project portfolio 
objectives. Although, a BSC that is already implemented facilitates the development of a PSC, it is not a requirement. Stewart (2001, p39) states that all projects are "built around standard business objectives for success", and identified the minimum measurements included in a Balanced Scorecard. Stewart also suggests that a BSC "should be used to measure an organisation's project portfolio rather than an individual project". This statement contradicts the assumption of the proposed method. By already implementing a BSC concept on a project level, the project portfolio manager can access the relevant key performance indicators categorised by the four perspectives of each project and align the project goals with the portfolio strategy using the same methodological approach. The advantage is a more integrated management structure with standardised reporting systems.

Figure 6.11 shows how a PSC can be derived, either from the business BSC or the project goals.

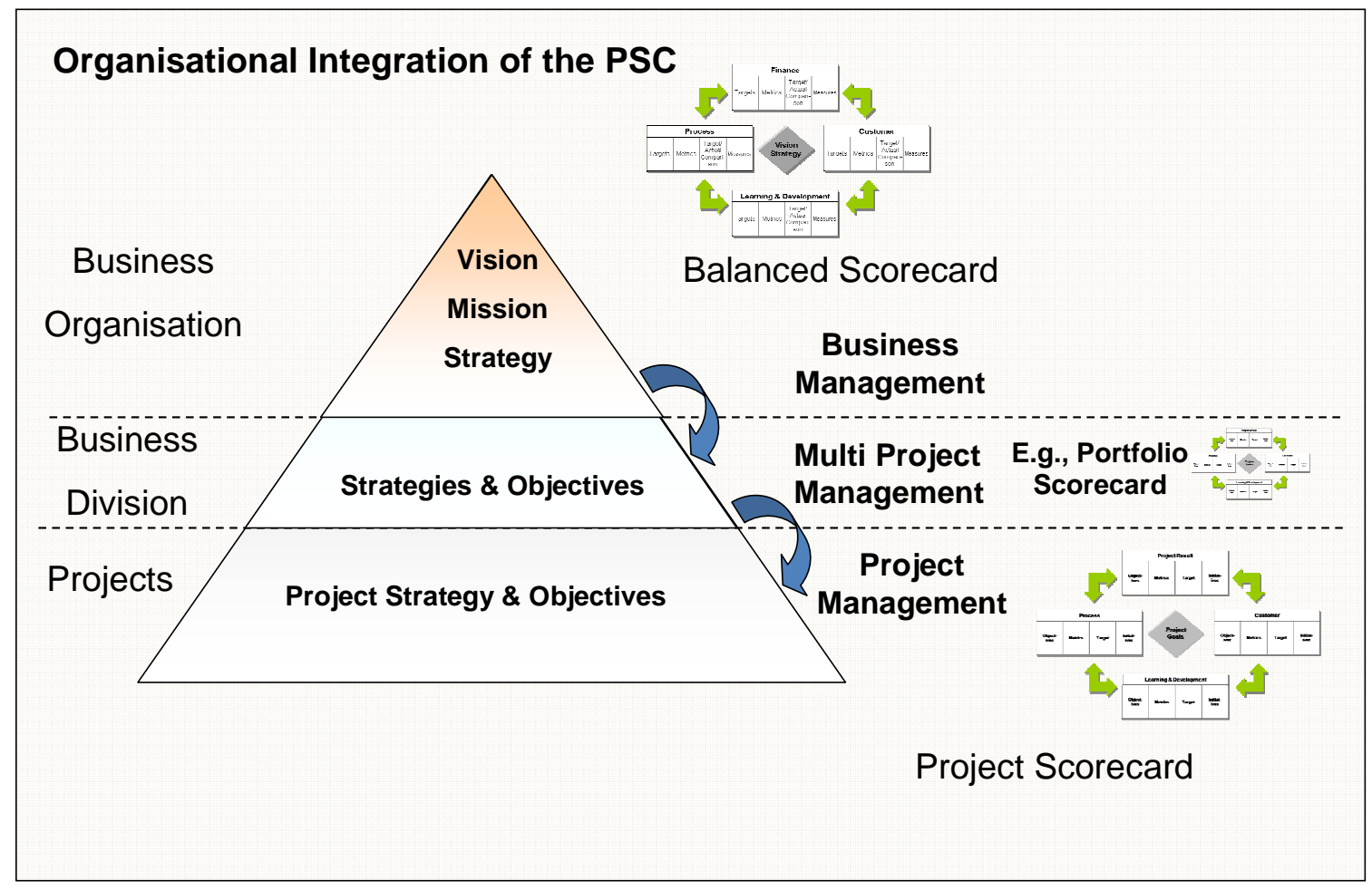

FIGURE 6.11: DeRIVATION OF A PSC (NIEBECKER ET AL., 2008A, P. 372)

\subsubsection{Project Strategy Map and Impact Matrix Analysis}

To describe the strategy of a business, a Strategy Map facilitates the visualisation of the cause and effect relationships between business objectives (Kaplan and Norton, 1996). 
To identify and illustrate these relationships of a project, the concept of a Strategy Map can be modified and, e.g., applied to a product development project.

The Project Strategy Map (PSM) is an important element of the strategic management of organisations and projects, and the measurement of historical performance and future prospects based on leading and lagging indicators for all functional areas is required for an "alignment of all parts of the organisation" (Durrani et al., 2000, p. 120). These indicators can be categorised as controllable, uncontrollable, active, and passive variables (Raschke, 2007). As there are usually more than two KPIs that measure each objective in the PSC, the identification of interdependencies and character of the KPIs can facilitate the development of Project Strategy Map. An example of possible objectives and interdependencies is shown in Figure 6.12.

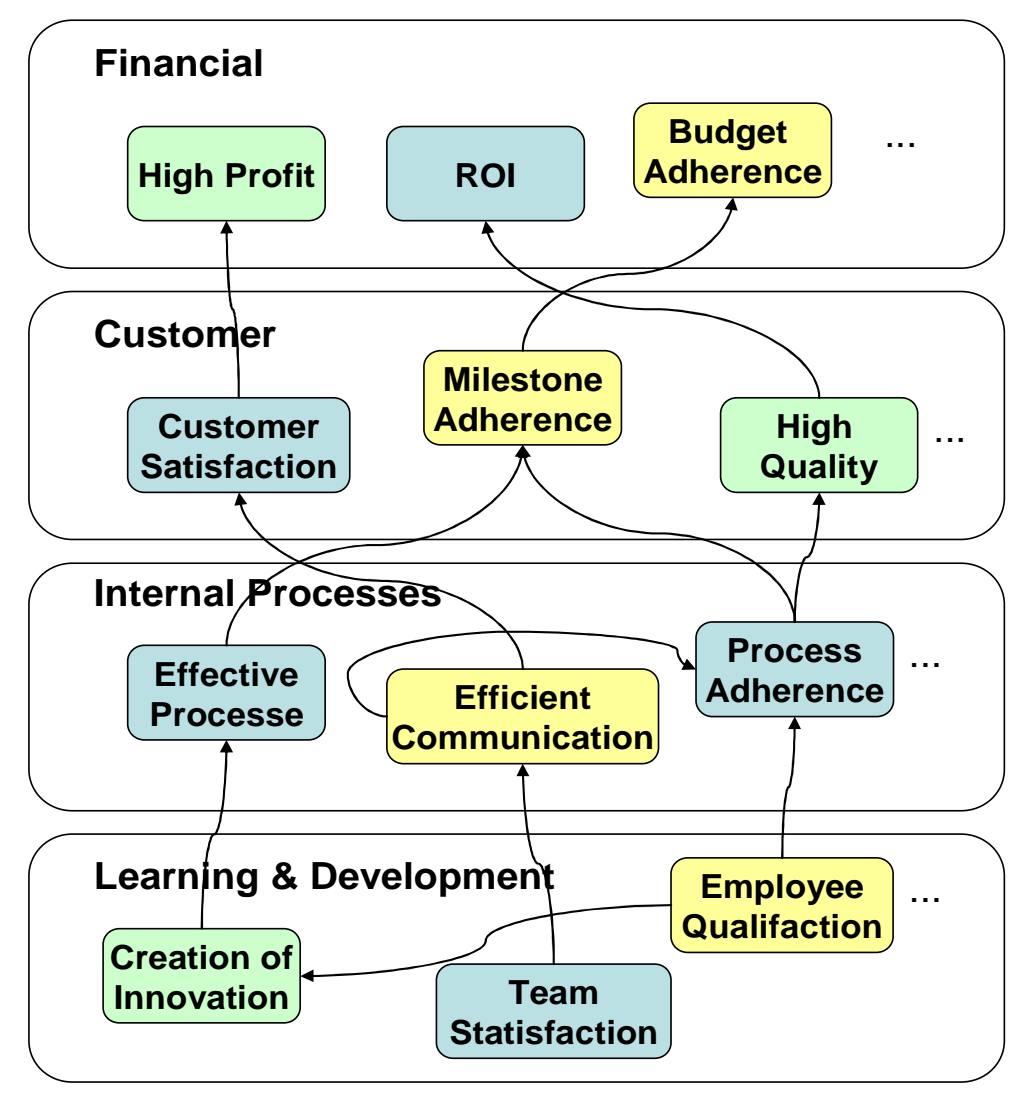

Figure 6.12: Project Strategy MaP eXample

A useful method is the impact matrix analysis that is further described in Chapter 7 when it is applied to the Collaborative Project Scorecard concept. The method uses a two dimensional matrix that includes all KPIs horizontally and vertically. A number from a scale of 0 to 3 describes whether a certain KPI has no (0) impact or strong (3) influence on another $\mathrm{KPI}$. 
The vertical sum of the numbers describes a KPI activity by an active sum, whereas the passivity can be described horizontally by a passive sum. The product of the active sum (AS) and passive sum (PS) is $P(P=A S x P S)$, where as $Q$ is the quotient of the two sums times hundred $(Q=A S \times 100 / P S)$. KPls with high values of $Q$ are active variables that have great impact on other variables. At the same time those variables are barely impacted by other KPIs. KPIs on the other hand with low values of $Q$ are rather success variables as they cannot be controlled efficiently and are of passive character. KPIs with high values of $P$ are critical variables as they strongly influence but are also strongly controlled by other KPIs. Figure 6.13 shows a generic framework of the project impact matrix.

\begin{tabular}{|c|c|c|c|c|c|c|c|c|c|c|c|c|c|c|c|c|c|c|c|c|c|c|}
\hline \multicolumn{2}{|c|}{ PASSIVE } & \multicolumn{5}{|c|}{ Financial } & \multicolumn{5}{|c|}{ Customer } & \multicolumn{3}{|c|}{ Process } & \multicolumn{6}{|c|}{ Development } & \multirow{2}{*}{\begin{tabular}{|c|}
$\begin{array}{c}\text { Sum } \\
\text { Passive }\end{array}$ \\
PS
\end{tabular}} & \multirow[t]{2}{*}{$\mathbf{Q}$} \\
\hline$\overline{\text { ACTIVE }}$ & & $\mathbf{F 1}$ & $\mathbf{F 2}$ & F3 & $\mathbf{F 4}$ & & & & & 24 & & & & & & & & D4 & D5 & & & \\
\hline \multirow{5}{*}{ 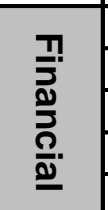 } & \begin{tabular}{|l|} 
F1 \\
\end{tabular} & & & & & & & & & & & & . & & & & & & & & 1 & 200 \\
\hline & \begin{tabular}{|l|} 
F2 \\
\end{tabular} & & & & \begin{tabular}{|l|}
1 \\
\end{tabular} & & & & & & & 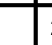 & & & & \begin{tabular}{|l|} 
\\
\end{tabular} & & & 1 & & 8 & 113 \\
\hline & \begin{tabular}{|l|}
$F 3$ \\
\end{tabular} & & & & & & & & & 3 & & & & 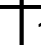 & & & & 2 & & & 6 & 117 \\
\hline & \begin{tabular}{|l|l|} 
F4 \\
\end{tabular} & & 3 & & & & & 1 & & & & & 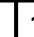 & & & & & & & & 5 & 140 \\
\hline & F5 & & & & & & & & & & & 3 & & & & & 3 & & & & 6 & 100 \\
\hline \multirow{5}{*}{ 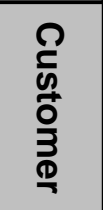 } & C1 & & & & 3 & & & & & 3 & & & & & & & & & & & 6 & 17 \\
\hline & C2 & & \begin{tabular}{|l|} 
\\
\end{tabular} & & & & & & & & & & & & & 2 & & & & & 4 & 225 \\
\hline & C3 & & & & & 1 & & & & & & & 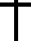 & & & & & 2 & & & 8 & 38 \\
\hline & C4 & & & 3 & & & & & & & & & & & 2 & & & & & & 5 & 120 \\
\hline & \begin{tabular}{|l|} 
C5 \\
\end{tabular} & & & & & & 1 & & & & & & & & & & & & & & 1 & 600 \\
\hline \multirow{4}{*}{ 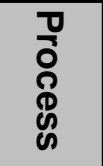 } & \begin{tabular}{|l|}
$\mathbf{P 1}$ \\
\end{tabular} & & & & & & & & & & & & & & & & & 2 & & & 2 & 300 \\
\hline & \begin{tabular}{|l|}
$\mathbf{P 2}$ \\
\end{tabular} & & \begin{tabular}{|l|}
2 \\
\end{tabular} & & & & & 2 & & & & & 7 & 1 & & & & 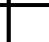 & 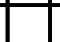 & & 5 & 100 \\
\hline & \begin{tabular}{|l|l|} 
P3 \\
\end{tabular} & & & 1 & & 2 & & & 1 & & & & & & 1 & & 2 & & & & 7 & 114 \\
\hline & \begin{tabular}{|l|} 
\\
\end{tabular} & & & & & & & & & & & 3 & & & & & & & & & 3 & 33 \\
\hline \multirow{6}{*}{ 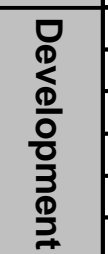 } & \begin{tabular}{|l|} 
D1 \\
\end{tabular} & 2 & & \begin{tabular}{|l|}
3 \\
\end{tabular} & & & & & & & & & & & & & & & & & 5 & 80 \\
\hline & D2 & & & & & & & 2 & & & & & 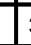 & & & & & & 3 & & 8 & 50 \\
\hline & D3 & & & & & 3 & & & & & & & & & & & & & & & 6 & 83 \\
\hline & \begin{tabular}{|l|} 
D4 \\
\end{tabular} & & 2 & & & & & 2 & & & & & & & & & & & 1 & & 5 & 120 \\
\hline & \begin{tabular}{|l|} 
D5 \\
\end{tabular} & & & & & & & 2 & 2 & & & 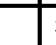 & & & 1 & & & & 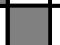 & & 8 & 63 \\
\hline & D6 & & & & 3 & & & & & & & & & & . & . & 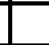 & 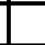 & L & & 3 & 0 \\
\hline \begin{tabular}{|c|c|} 
SUM \\
Active
\end{tabular} & AS & 2 & 9 & 7 & 7 & 6 & 1 & 9 & & & & 6 & & 8 & 4 & 4 & & 6 & & 0 & & \\
\hline $\mathbf{P}$ & & 2 & 124 & 421 & 35 & & & & & & & 12 & & & 20 & & 0 & 30 & 40 & & & \\
\hline
\end{tabular}

Figure 6.13: Generic FRAMEWORK OF THE PROJECt IMPACt MATRIX

As an example, the process indicator $P 1$ has the highest $Q$ value and is the variable with the highest impact and lowest interference, whereas the development indicator D6 has only a function as an indicator and does not influence any other variable. The financial indicator F2 has the highest value of $P$ and is, therefore, a critical variable. 
By applying the project impact matrix method, the interdependencies of the KPIs are identified and evaluated, and can be represented in a Strategy Map. For a connection of two drivers a threshold value of the related KPI intensity sum can be set to focus on the most important dependencies.

\subsubsection{Key performance indicators for project scorecards}

Key performance indicators are essential to measure and monitor the objectives of any scorecard. These characteristic metrics are typically used in business management to measure the company's performance and progress towards basic objectives and critical success factors. They serve as a basis for critical decisions, health checks (i.e., comparison between target and actual), documentation and coordination of important aspects in an organisation.

Effective KPIs are crucial for measurement and, therefore, must be generated through an involvement of all stakeholders, agreed upon before implementation, and reflect the overall organisation's goals.

\subsubsection{Examples of KPIs for a Project Scorecard}

In traditional project management KPIs were used to monitor and control essential factors that influence the "magic triangle" consisting of budget, time and quality. They also provide a solid foundation for decision making. According to Kaplan and Norton (1996) KPIs can be mainly divided into two types, leading indicators, which are performance drivers, and lagging indicators, which refer to outcome measures. In order to generate reasonable KPls it is essential that they are relevant, definable and quantifiable (e.g., measurable).

Additionally, a target value or corridor for each KPI has to be defined in order to measure the degree of achievement. A useful approach is described by the acronym 'SMART'. Each KPI needs to be specific, measurable, achievable, result-oriented and time-oriented.

Examples of some KPIs of a traditional BSC (Papalexandris et al., 2005; Eckerson, 2006) compared to modern Project Scorecards (Salem, 2001) are listed in Table 6.1, Table 6.2 and Table 6.3. 


\begin{tabular}{|c|c|c|}
\hline Perspective & Balanced Scorecard & Project Scorecard \\
\hline Financial & $\begin{array}{ll}\text { - } & \text { Profitability } \\
\text { - } & \text { Revenue growth } \\
\text { - } & \text { Economic Value Added (EVA) }\end{array}$ & $\begin{array}{ll}\text { - } & \text { Overall project budget } \\
\text { - } & \text { NPV, Payback Time, ROI } \\
\text { - } & \text { R\&D Effectiveness Index }\end{array}$ \\
\hline Customer & $\begin{array}{ll}\text { - } & \text { Market share } \\
\text { - } & \text { Customer satisfaction } \\
\text { - } & \text { Customer loyalty } \\
\text { - } & \text { Brand recognition }\end{array}$ & $\begin{array}{ll}- & \text { Achievement of quality } \\
\text { standards } \\
\text { - } & \text { Customer and project } \\
& \text { stakeholder satisfaction }\end{array}$ \\
\hline $\begin{array}{c}\text { Internal } \\
\text { Processes }\end{array}$ & $\begin{array}{ll}\text { - } & \text { Patents pending } \\
\text { - } & \text { Ratio of new products to total } \\
\text { - } & \text { Inventory turnover, stock outs } \\
\text { - } & \text { Productivity, efficiency } \\
\text { - } & \text { Risk minimisation }\end{array}$ & $\begin{array}{ll}\text { - } & \text { Overall risk index } \\
\text { - } & \text { Achievement of deliverables } \\
\text { - } & \text { on time } \\
\text { - Time to market }\end{array}$ \\
\hline $\begin{array}{l}\text { Learning } \\
\text { and Growth }\end{array}$ & $\begin{array}{l}\text { - } \quad \text { Employee satisfaction, turnover } \\
\text { rate, absenteeism } \\
\text { - } \quad \text { Training hours, leadership and } \\
\text { teamwork development programs } \\
\text { - Number of cross-trained } \\
\text { employees, knowledge sharing } \\
\text { Corporate values adoption, } \\
\text { organisational alignment, culture } \\
\text { development }\end{array}$ & $\begin{array}{ll}\text { - } & \text { Patents, papers } \\
\text { - } & \text { Project related training hours } \\
\text { - } & \text { Employees turnover rate } \\
\text { - } & \text { Ratio of internal vs. external } \\
& \text { employees }\end{array}$ \\
\hline
\end{tabular}

TABLE 6.1: KEY PERFORMANCE INDICATORS OF A BSC COMPARED TO A PROJECT SCORECARD

Table 6.2 and Table 6.3 list some KPIs typically used in project scorecards and are categorised according to their attribute of lagging or leading.

\begin{tabular}{|c|c|c|}
\hline KPI & Type & Calculation method/Estimation efforts \\
\hline $\begin{array}{c}\text { Overall project } \\
\text { budget }\end{array}$ & Lagging & $\begin{array}{ll}\text { - } & \text { Budget report produced by project office or finance } \\
\text { department } \\
\text { - } \quad \text { Low additional effort }\end{array}$ \\
\hline $\begin{array}{c}\text { NPV, Payback } \\
\text { Time, Rol }\end{array}$ & Lagging & $\begin{array}{l}\text { - Payback Time: Amount of time necessary to pay back the cost } \\
\text { of the project. } \\
\text { - } \quad \text { NPV (net present value): Reflects the time value of money by } \\
\text { calculating present value of future income or expense } \\
\text { - } \quad \text { ROI (return on investment): Project profitability calculation as } \\
\text { ratio of earning over investment }\end{array}$ \\
\hline
\end{tabular}

TABLE 6.2: KPIS FOR A PROJECT SCORECARD WITH RESPECT TO TYPE, CALCULATION METHOD, AND ESTIMATION EFFORT. 


\begin{tabular}{|c|c|c|}
\hline KPI & Type & Calculation method/Estimation efforts \\
\hline $\begin{array}{l}\text { R\&D } \\
\text { Effectiveness } \\
\text { Index }\end{array}$ & Lagging & $\begin{array}{l}\text { - Proposed by Salem: This Index is used to assess the success } \\
\text { of product development efforts (used instead of ROI) }\end{array}$ \\
\hline $\begin{array}{l}\text { Overall Risk } \\
\text { Index }\end{array}$ & Leading & 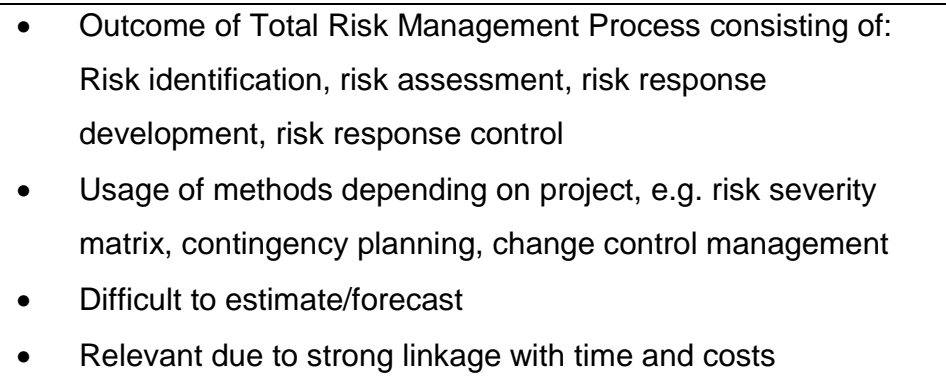 \\
\hline $\begin{array}{l}\text { Achievement of } \\
\text { deliverables on } \\
\text { time }\end{array}$ & $\begin{array}{l}\text { Leading } \\
\text { and } \\
\text { lagging }\end{array}$ & $\begin{array}{l}\text { - } \quad \text { Time related: Number of delayed days } \\
\text { - } \quad \text { Quality related: Quality assessment rate, e.g. expected vs. } \\
\text { actual achievements } \\
\text { - Easy to estimate }\end{array}$ \\
\hline Time to market & Leading & $\begin{array}{l}\text { - } \text { Time from product development to its market availability } \\
\text { - Relevant for first-of-a kind products and their immediate } \\
\text { followers } \\
\text { - Manly influenced by overall project time, which is monitored } \\
\text { (e.g. by project office), low additional estimation efforts } \\
\text { concerning marketing }\end{array}$ \\
\hline $\begin{array}{l}\text { Achievement of } \\
\text { quality } \\
\text { standards }\end{array}$ & $\begin{array}{l}\text { Leading } \\
\text { and } \\
\text { lagging }\end{array}$ & $\begin{array}{l}\text { - Quality standards measured according to established } \\
\text { methods like e.g. Six Sigma or TQM } \\
\text { - } \quad \text { Difficult to estimate }\end{array}$ \\
\hline $\begin{array}{l}\text { Customer and } \\
\text { project } \\
\text { stakeholder } \\
\text { satisfaction }\end{array}$ & Lagging & $\begin{array}{l}\text { - } \text { Customer and/or stakeholder satisfaction surveys resulting in } \\
\text { a customer/stakeholder satisfaction rate } \\
\text { - High estimation effort }\end{array}$ \\
\hline Patents, papers & Leading & $\begin{array}{ll}\text { - } & \text { Numbers of issued patents and papers published } \\
\text { - } & \text { Low estimation effort }\end{array}$ \\
\hline $\begin{array}{l}\text { Project related } \\
\text { training hours }\end{array}$ & Leading & $\begin{array}{ll}\text { - } & \text { Number of training hours dedicated to project staff } \\
\text { - } & \text { Low estimation effort, possibly HR involved }\end{array}$ \\
\hline $\begin{array}{l}\text { Employees } \\
\text { turnover rate }\end{array}$ & Leading & $\begin{array}{ll}\text { - } & \text { Number of people leaving/entering the project per quarter } \\
\text { - } & \text { Low estimation effort, possibly HR involved }\end{array}$ \\
\hline $\begin{array}{l}\text { Ratio of internal } \\
\text { vs. external } \\
\text { employees }\end{array}$ & Leading & $\begin{array}{ll}\text { - } & \text { Internal HC/External HC } \\
\text { - } & \text { Low estimation effort }\end{array}$ \\
\hline
\end{tabular}

TABLE 6.3: OTHER KPIS FOR A PROJECt SCORECARD WITH RESPECT TO TYPE, CALCULATION METHOD, AND ESTIMATION EFFORT. 
An example of project objectives and related KPIs for an automotive product development project is shown in Figure 6.14.

\begin{tabular}{|c|c|c|}
\hline 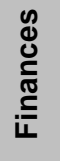 & $\begin{array}{l}\text { Project Budget } \\
\text { Increase of Business Value } \\
\text { Catgegorisation into Multi Project } \\
\text { Project Management }\end{array}$ & $\begin{array}{l}\text { human resources, share of sales, profit } \\
\text { margin, savings, ROI, expenditure }\end{array}$ \\
\hline 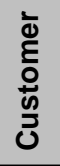 & Customer Satisfaction & $\begin{array}{l}\text { cost overrun, number of customer audits, change } \\
\text { management, process stability }\end{array}$ \\
\hline 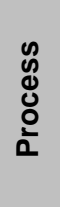 & $\begin{array}{l}\text { Adherence to Schedules } \\
\text { Innovation Enhancement } \\
\text { Minimising Risks } \\
\text { Optimisation of Project Structure } \\
\text { Quality }\end{array}$ & $\begin{array}{l}\text { adherence to delivery dates, lessons learned, number } \\
\text { of patent applications, external labour, quality indices, } \\
\text { duration of change management, product maturity, } \\
\text { post processing, percentage of overhead, number of } \\
\text { internal audits, project risk analysis }\end{array}$ \\
\hline 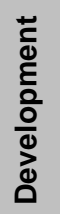 & $\begin{array}{l}\text { Employee Satisfaction } \\
\text { Employee Qualication Enhancement }\end{array}$ & $\begin{array}{c}\text { rate of employee fluctuation, travel costs, overtime, } \\
\text { index of professional experience, continuing } \\
\text { education costs }\end{array}$ \\
\hline
\end{tabular}

FIGURE 6.14: EXAMPLE OF OBJECTIVES AND KPIS FOR AN AUTOMOTIVE PRODUCT DEVELOPMENT PROJECT

\subsubsection{PSC application in practice}

The Balanced Scorecard can be applied as a tool for effective project management. It is suggested (Stewart, 2001) that approximately twenty suitable performance measures from four perspectives aligned with the Business Balanced Scorecard (or Project Management Office Balanced Scorecard) need to be chosen to build a Project Scorecard. Stewart also suggests that the chosen measures are baselined and data consistently obtained and grouped so that project health improvements can be measured and monitored on a project, portfolio and company level.

A Project Scorecard can be applied to all phases of a project from initiation and planning through execution to project closure. Stewart (2001) gives an extensive list of possible measures and discusses the importance of several criteria for each of the four perspectives and suggests associated benefits. Three benefits of those are the ability 
for the project manager to monitor critical factors, identify warning signals and take corrective action, and therefore make continuous improvements across all perspectives.

\subsubsection{Risk management aspects}

There are benefits in applying Balanced Scorecards at a company or enterprise level to focus risk management efforts on most relevant areas. Scholey (2006) has analysed the application of separate scorecards for managing risk and performance at an enterprise level and identified that it can help to simplify the scorecard design. Calandro and Lane (2006) found that at a project level, a Project Scorecard can improve project risk management by providing a risk management plan if all risks are identified and managed that affect the selected KPIs. A correctly implemented Project Scorecard facilitates and ensures consistent and regular monitoring of KPIs across all perspectives. Regular monitoring of leading KPIs can support an earlier identification of problems so that preventive or corrective action can be implemented more quickly. The Project Scorecard is a useful method that can assist the project manager to address risks in a systematic and structured way with an understanding of how risks affect key strategic objectives.

\subsubsection{Balanced and Project Scorecards for supply chain management}

In supply chain management, several companies often work collaboratively in manufacturing products and services for consumption. Intercompany collaboration requires managers and companies to work together as a team with their supply chain partners. The companies realise the downstream implications of upstream process improvements or problems. A car manufacturing plant can be brought to a halt due to production or quality problems with fastener supplies. Performance measurement systems need to be effective and provide mutual benefit to all partners in their efforts to optimise their processes and to satisfy customer needs. Supply chain management systems aim to decrease costs and risks, increase the speed to market, and ensure quality and value for the final consumer. The implementation of a Balanced Scorecard approach to supply chain management can assist partnering companies to align their efforts to support an overall strategy. Each company can adapt a Balanced Scorecard to their activities and suppliers can share KPIs with other interfacing or affected suppliers upstream or downstream in order to improve the overall quality, efficiency and reliability 
of the supply chain. Brewer (2001) suggests that Balanced Scorecards are implemented most effectively into supply chain management when considering the following steps:

- Vision and strategy formulation.

- Selecting agreed measures (KPIs), which are consistent with strategy.

- Linking and communicating the measures.

- Driving managers to achieve the desired results by establishing accountability, setting rates of improvement, creating action plans and using the Balanced Scorecard KPIs to review performance.

\subsubsection{The Project Scorecard concept as an adaptive approach}

A Project Scorecard facilitates successful project management by ensuring that project objectives are aligned with the overall business strategy. It enables a more holistic approach to project management as it takes into account different perspectives and more importantly the cause-and-effect relationships of various metrics. The Project Scorecard gives the manager a comprehensive overview of the project status and assists in identifying critical areas. It also allows the project manager to take immediate action if necessary. A PSC can, however, be difficult and time-consuming to implement. Especially, when projects are large or an immediate project start is required. It can be challenging to find the suitable objectives and indicators to measure and requires full commitment and involvement from each stakeholder. Successful implementation of a PSC also needs support from upper management, as employees may be resistant to change when established methods are altered.

\subsubsection{Adoption of Six Sigma and management frameworks}

New approaches to the Balanced Scorecard (often referred to Third-Generation Balanced Scorecards) enable existing management processes and tools to be enhanced (Cobbold and Lawrie, 2002). Various quality tools have, for example, been successfully applied in conjunction with the Balanced Scorecard. These tools can also be adopted by a PSC. Some of them are Six Sigma, the Malcolm Baldridge National Excellence Model, the EFQM Excellence Model, and International Organisation for Standardization (ISO) standards. Developed at Motorola in mid 1980's, Six Sigma is a process improvement methodology that uses statistical and other analytical measures. Due to further development of Six Sigma applications, it now includes general business 
activities, especially the ones that directly affect the customer (Ramberg, 2000). Modern Six Sigma methods place emphasis more on strategic control activities such as leadership styles and goals aimed at improving results. To be effective the Six Sigma needs to be placed in an appropriate strategic context (Wilkund and Wilkund, 2002). Six Sigma could be implemented with a Third-Generation Balanced Scorecard focusing on the long-term strategic goals of the company. The necessary objectives could be identified at a corporate level and the progress in achieving those objectives could be derived from data generated through Six Sigma measures. This method provides a useful linkage between strategy and quality initiatives.

The Malcolm Baldridge National Excellence Model and EFQM Excellence Model are frameworks that are designed to assist an organisation to achieve excellence through continuous improvement in management and processes. Both models are built on a systematic approach to analysing and improving internal processes. The evaluation can determine how the firm is faring against competitor firms or against baseline assessments. A U.K energy utility firm described how efficiently it was using a combination of EFQM Excellence Model and the Balanced Scorecard (Anderson et al., 2004). The Balanced Scorecard was used to communicate strategic results amongst the group and also was applied as a strategy implementation tool.

\subsection{The Balanced Scorecard for cross-company project management}

The application of the Balanced Scorecard to internal project management has already been investigated (Stewart and Mohamed, 2001) and recommendations on how to design the Project Scorecard have been provided. However, the application to crosscompany project management has not been considered in the literature yet (Horvath, 2003).

\subsubsection{A new approach to collaborative and networked project environments}

The BSC has been widely used for internal project performance measurement and monitoring, it provides a strategy focused view of the operation and project, whereas project management provides a tactical view of the operation. Combining these two views together creates a synergy not found in the individual views. Some of them are that the tactics enable the fulfilment of strategy and the strategy validates the tactical 
decisions (Alleman, 2003). There is reason to believe that the application of a Balanced Scorecard to a collaborative, cross-company project environment has not been considered sufficiently. One of the reasons is that its utility has not sufficiently been analysed on a general level (Diensberg, 2001). Diensberg also concludes that the BSC provides solutions for important problems which cannot be solved by conventional controlling processes. Some of them are communication deficiencies, unknown project objectives, and qualification deficiencies. O'Leary et al. (2001) concludes that we have not understood the complexity of distributed work yet and that control versus trust is still an opposing concept of our traditional management approach.

\subsubsection{Performance measurement as a key condition for effective project management}

Bourgoult et al. (2002) consider the monitoring of the project stakeholders' performance a "critical issue" and identified that little research has been done yet. Measuring performance is a "key condition" to ensure the effectiveness of project management and performance management systems need to be organised that strategic goals and objectives can be evaluated on the basis of a balanced series of metrics. They also found that most metrics describe operational functions to plan and monitor technical processes but soft facts such as client satisfaction are not considered sufficiently.

The more integrated consideration of a balanced choice of metrics leads to the Balanced Scorecard for distributed projects. But the authors conclude that "it is clearly too early in the investigation process to claim that a comprehensive list of metrics has been, or can be, established" (Bourgault et al., 2002, p.4).

\subsubsection{X-engineering requires a holistic view}

Horvath (2003) has considered the Balanced Scorecard for distributed management as part of his x-engineering approach that is related to the traditional re-engineering and applied to a virtual corporation as defined by Byrne et al. (1993, p. 99) as "a temporary network of independent companies - suppliers, customers, even erstwhile rivals - linked by information technology to share skills, costs, and access to one another's market". Compared to the traditional re-engineering approach, x-engineering includes a holistic view over the whole value creation chain of a product and emphasises the development and implementation of strategies. He sees the key to success in a precise redesign of 
the existing process structure and the development of control measures on the basis of the overall strategy.

\subsubsection{A need for a Collaborative Project Scorecard}

The Balanced Scorecard that is derived from this strategy supports $x$-engineering to focus on strategically relevant objectives. Performance measurement on the other hand enables the new designed processes to run and therefore, the "X-Balanced Scorecard" and the "X-Performance Measurement" have to be coupled. Horvath (2003) assumes that a network is created from a strategic idea and respectively strategic competitive requirements. The strategic idea needs to be defined by all network partners so that the redesign of the common value creation chain has a common basis to define strategy related measures (control and performance related) for a network performance management. Horvath also identified that the current literature has not discussed the application of a BSC to distributed organisations yet but only to single organisations. Finally, he recommends applying a BSC to a collaborative network.

Another application field of a BSC to a networked organisational environment has been examined in the field of supply chain management. The X-Balanced Scorecard has been further studied by Kaufmann (2004) and Zimmermann (2007). Kaufmann concludes that the X-BSC added transparency for the partners and that upcoming difficulty can get solved quickly and professionally, whereas Zimmermann demonstrated with his case study that the Balanced Scorecard supported the optimisation efforts within the value creation chain efficiently. However, he assumes that the BSC can hardly be applied to the whole supply chain as the disclosure of objectives and data to other partners may not be in the interest of all organisations. Although, there are only few examples for a supply chain Balanced Scorecard, Zimmermann thinks that these projects will become more important in the future. 


\section{The concept of the Collaborative Project Scorecard}

The stronger focus on collaboration in the management of projects creates new chances to improve a company's efficiency and effectiveness but also leads to several problems among the project partners. Typically, the project status and project activities are difficult to monitor and the managers on both sides lack sufficiently integrated and agreed control measures. More difficulties arise when project goals and relevant processes are not adequately defined in advance. The Collaborative Project Scorecard aims to reduce these difficulties and the concept with its methods and tools is described in this chapter (Figure 7.1).

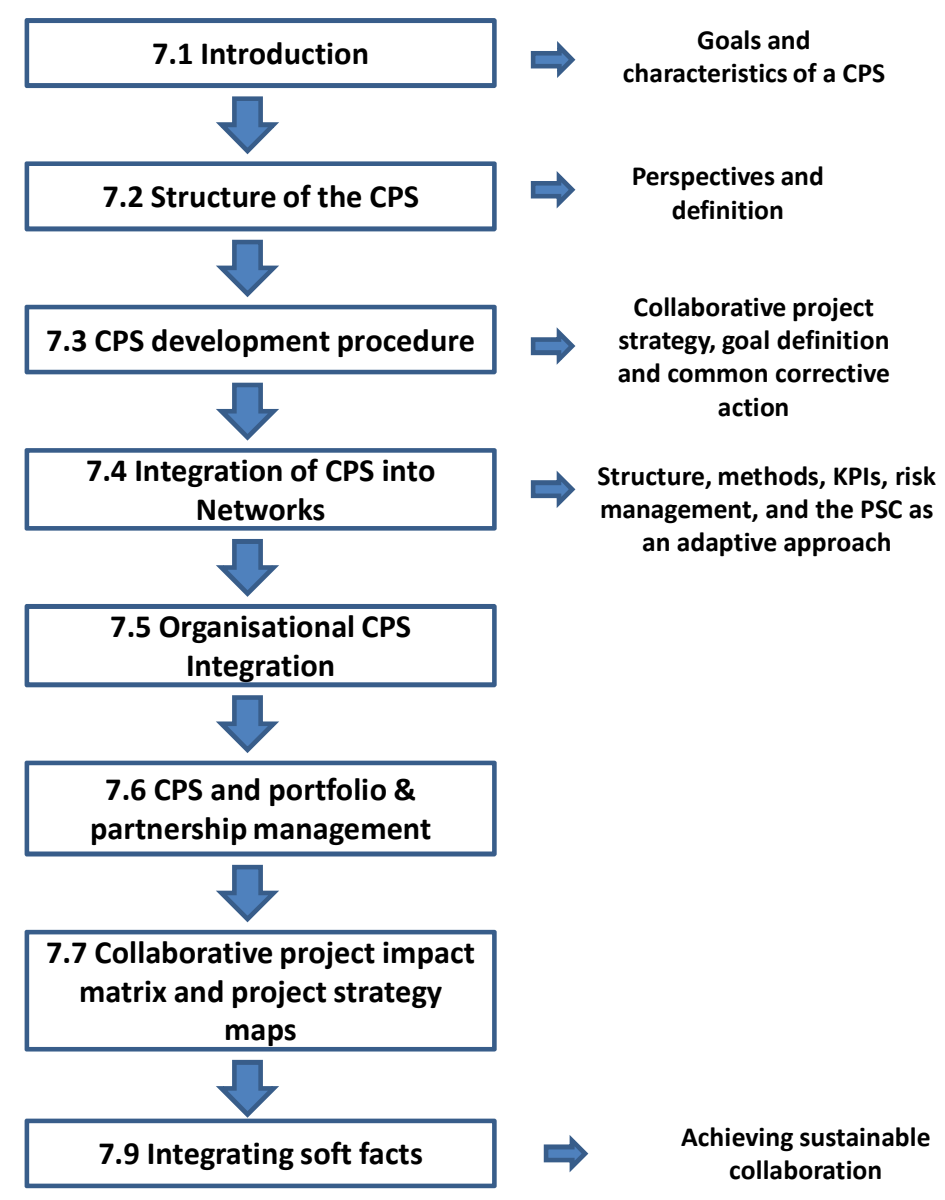

FIGURE 7.1: OVERVIEW OF CHAPTER 7

\subsection{Introduction}

The Balanced Scorecard (BSC) has been developed as a business management system that aligns vision and strategies with operational goals. These goals are 
categorised into four perspectives: the financial, customer, internal, and learning and growth perspective. Each perspective includes objectives, measures, targets, and initiatives that translate a company's vision and strategy into action (Kaplan and Norton, 1996). The implementation of strategies and business goals is often realised by initiatives or projects on a multi or single project management level. In a further step, the framework is also applicable to cross-company and collaborative projects where project teams define common goals and monitor and control them collaboratively. Figure 7.2 shows how the CPS can be derived from a Project Scorecard of two project partners. However, the CPS can be developed on the basis of mere project goals as well if one or both of the organisations have not implemented a PSC.
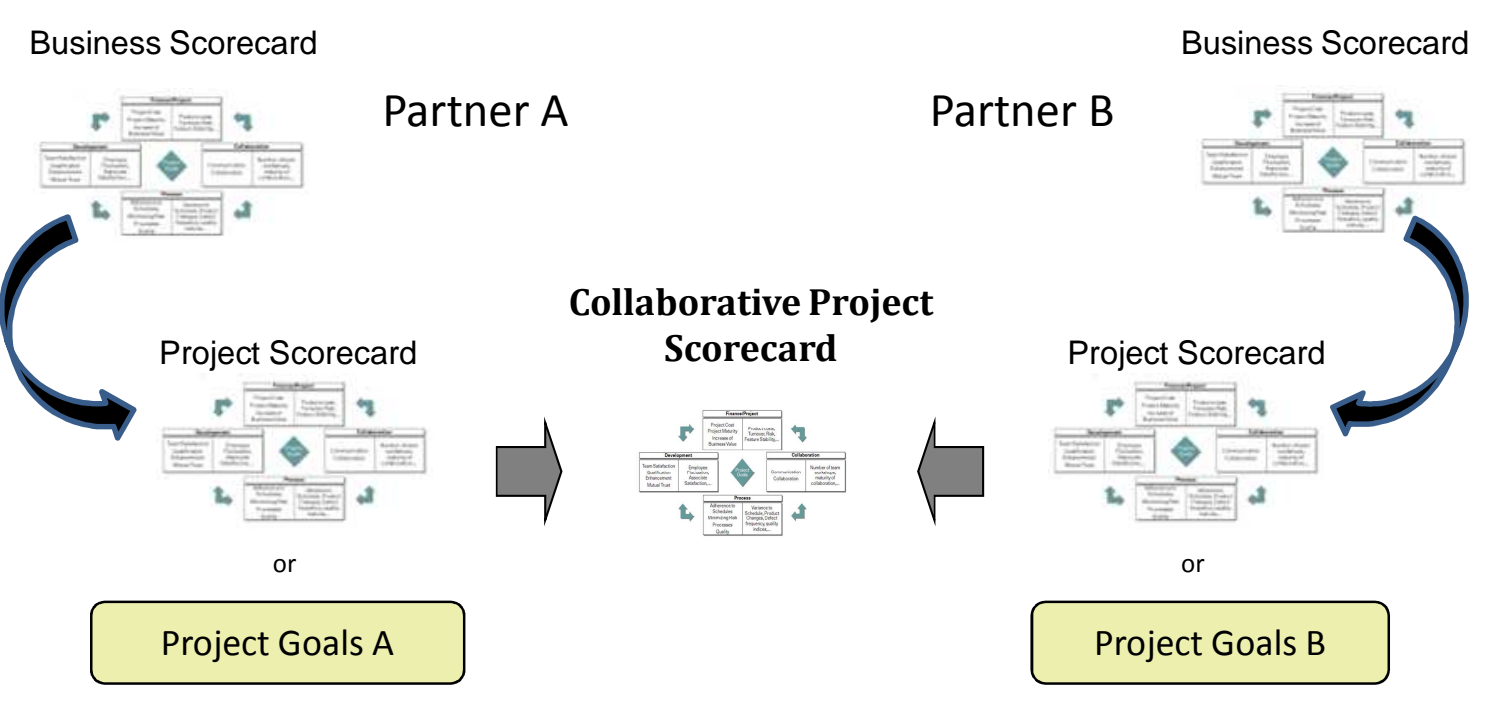

Figure 7.2: From Project SCORECARDS to A CPS

This avoids misunderstandings and ambiguity of shared project goals and common measures. Predefined corrective action supports the project managers to quickly react on upcoming difficulties.

The project partner can be either, a supplier, another department or a joint venture company. It is essential that all partners come together to discuss and clarify their common project goals and strategies before the project is already in progress. The project partners define common key performance indicators (KPIs) to measure their project targets, and at that time they also define corrective actions. This enables them to react faster on issues and manage risks more effectively and efficiently.

The CPS has the same function as a PSC but aims to increase project transparency within the project members in networked structures. It also aims to increase the 
efficiency of the monitoring and control of cross-company projects due to collaboratively defined key performance indicators, project strategies, and measures while allowing each partner to use individual internal project management processes. The project members need to develop strategy maps and define key performance indicators collaboratively. The KPIs can be exchanged and synchronised to build a CPS without threatening each company's know-how and information protection as only relevant and predefined indicators are monitored and controlled. With this concept, the alignment to business strategies and project goals of each partner can be assured, stakeholder commitment ensured, and measures defined and taken collaboratively. According to the GPM workshop results, this increases communication between the project members and reduces the risk of misunderstandings and a lack of measures when project control is urgent.

\subsubsection{Goals of the Collaborative Project Scorecard}

One goal of the Collaborative Project Scorecard is to equip the project management with a useful cockpit, which allows them to react earlier with appropriate counter measures. The concept supports the team to evaluate the actual project status, to review the development of the project, and to produce forecasts by analysing leading and lagging indicators. Especially, the understanding of coherences between all influencing factors is a key benefit of this methodology. Implemented as an IT solution, the CPS creates transparency of the current project status and improves the re-planning process by monitoring the actual project status and providing an advanced forecasting. Therefore, the CPS is assigned to a Business Intelligence methodology that does not address financial and process goals only but it broadens the view on a project by providing a framework for goal definition of collaboration for short and long-term objectives. This is fundamental to identify and explore unknown business potentials, e.g., to provide incentives in cooperative ventures.

\subsubsection{Characteristics of the CPS}

The CPS is characterised by its scalability, flexibility and adaptability to organisational requirements. Figure 7.3 gives an overview of its characteristics. 


\section{Characteristics of the Collaborative Project Scorecard}

- The CPS concept is a methodology to support the management of cross-company projects that also includes in-house collaboration (e.g., inter-departmental)

- It offers a framework for the definition of common goals, key performance indicators and measures

- Additionally, the methodology provides further tools and methods to enhance collaboration sustainably, e.g., a common risk management or collaborative project assessment

- By monitoring the actual project status and by comprising the relevant information about a project with a few key indicators, the concept can be easily transferred to a Business Intelligence tool.

- The CPS is adaptable and scalable to address small, medium, and large-sized organisations requirements

- It is extendable to existing management and business models such as EFQM, Project Excellence, ProSTEP iViP CPM, etc.

FIgURE 7.3: CHARACTERISTICS OF THE CPS

Hab and Wagner (2006) detected that lack of collaborative team development in projects results in severe consequences not only for the compliance with timelines, milestones, quality, or costs but also for the collaboration climate. The CPS strengthens this aspect and provides support to create trustful collaboration and sustainable positive team climate across the borders of organisations.

\subsection{Structure of the Collaborative Project Scorecard}

First results of analytical studies of the Collaborative Project Scorecard were derived from workshops organised by the GPM e.V. Automotive Chapter. Reasons for a more analytical study of a cross-company scorecard concept were based on an automotive study that revealed the insufficient clarification of project goals and problems in project control. This causes several problems such as time delays or budget overruns. Typical problems in the goal definition process are that goals are often defined too late in the project stage, objectives and measures are unclear, ambiguity in common goal understanding, and distrust between the partners (Pander and Wagner, 2005).

Within the scope of two workshops the Collaborative Project Scorecard concept was discussed and some typical project objectives and measures were defined for an 
automotive product development project (see Chapter 8). Next to requirements that are necessary for a successful application of the scorecard, a process model was developed that describes the steps of the project partners to define and align the scorecard (Wagner and Niebecker, 2008). Detailed results of these workshops are presented in Chapter 8.

The structure of the CPS is based on the framework of the Balanced and Project Scorecard and was modified according to the results of workshops and industry interviews. This section describes the CPS structure with respect to the perspectives and their definition.

\subsubsection{The CPS perspectives}

The four perspectives as they were defined by Kaplan and Norton have demonstrated to be beneficial to many companies and businesses, however, the scorecard should be considered as a useful framework rather than a rigid defined concept. According to Herde et al. (2001), there is no proof that the traditional four perspectives are the only necessary and sufficient ones. Therefore, the perspectives may be extended by other perspectives, such as environmental or society perspectives. Each organisation needs to identify and evaluate which perspectives are relevant for its success. The structure of the Balanced Scorecards facilitates the understanding of cause-and-effect relationships between strategic approach and operative indicators (Paessler et al., 2001).

As the CPS has a strong focus on collaboration, the customer perspective was replaced by a collaboration perspective. This was mainly due to a different understanding of the term customer in a cross-company and collaborative project. The customer can be represented in various ways. In an OEM-supplier project, typically the customer is the OEM, however the objectives of a collaborative project can be represented in all four perspectives and finally, the traditional customer objectives can be found in the project result perspective, such as product specification or quality. In an ideal project partnership the partners are their mutual customers. Both want to achieve their objectives and results. This is easier to understand in a joint venture project or collaborative project between two equal project partners.

The change from the financial perspective towards a project result perspective is mainly caused by the fact that financial aspects are often not exchanged openly as profit is still 
nothing an organisations is willing to communicate to its partners from different organisations. Therefore, the focus of this perspective is on results characterizing the upper level objectives of a project. This is typically described by the functionality of a product, quality standards, start of production (SOP), or even budgets that only include costs and not prices. Figure 7.4 shows the modified CPS framework.

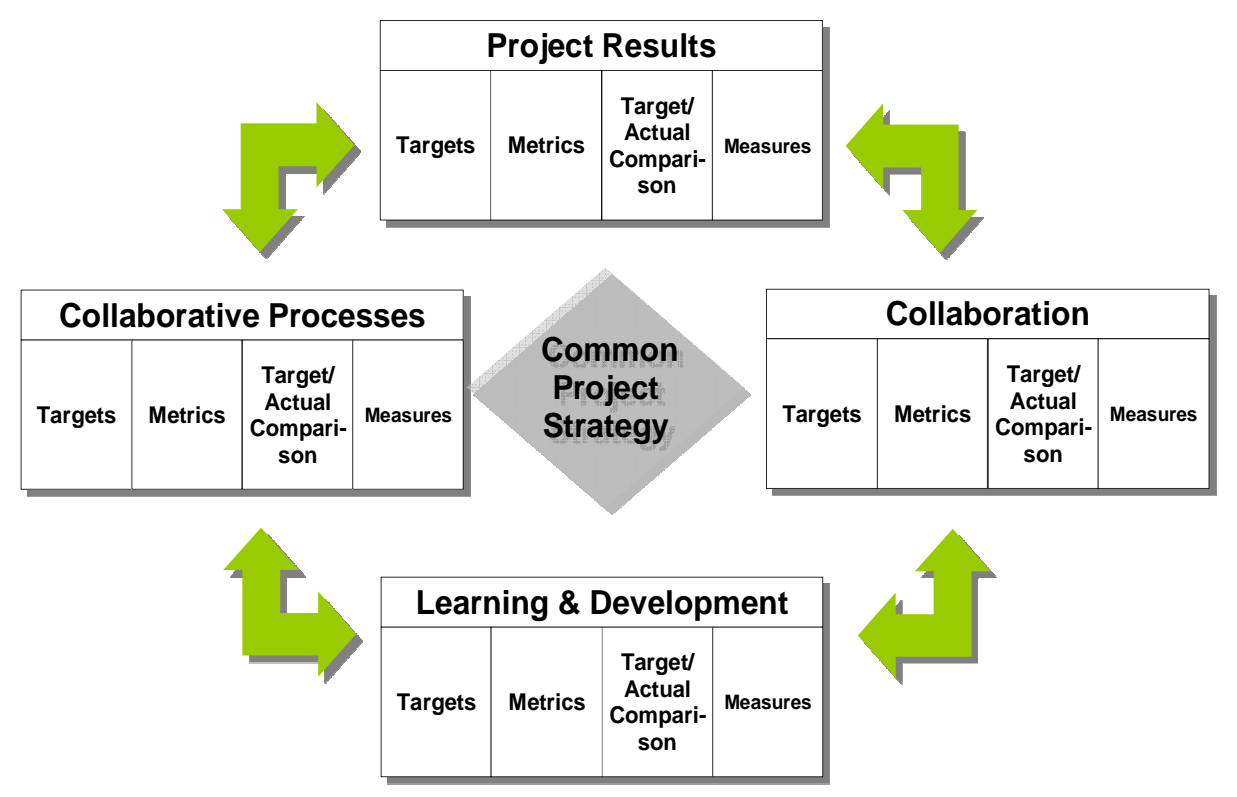

Figure 7.4: The framework of the Collaborative Project Scorecard

\subsubsection{Definition of the CPS perspectives}

Although, the definition of the perspectives is an individual choice it is essential that all project partners have a common understanding. During the research project in the US, the categorisation of the project goals into the perspectives was one of the major difficulties as everyone had a different understanding of each perspective. The common agreement on the following definition had a positive impact on further CPS developments as the time to categorise each goal could be minimised.

Project results and learning and development objectives have a more strategic character than the objectives of the collaboration and process perspective. Processes and collaboration objectives are rather operational and support the project result objectives to be achieved.

Figure 7.5 illustrates the categorization but has to be considered as guidance only rather than a strict regulation. 


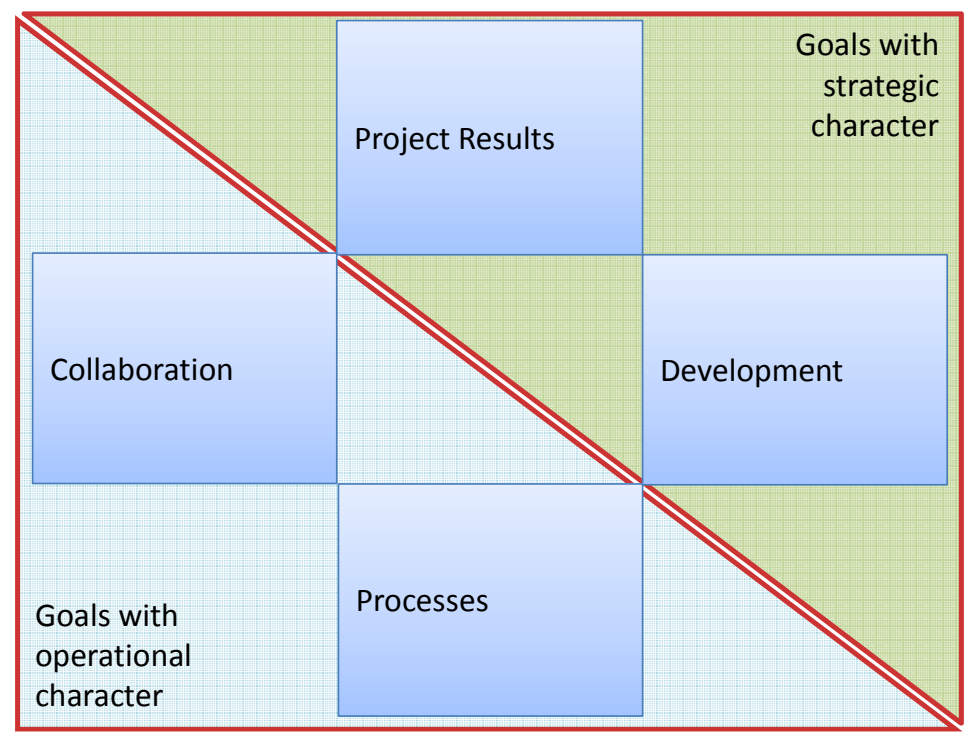

FIGURE 7.5: OPERATIONAL VERSUS STRATEGIC GOALS

Several objectives that have a development character, such as team trust or innovation, are also related to the collaboration context. However, trust cannot be created quickly and needs to be achieved by the help of long-term initiatives. Team satisfaction on the other side can be achieved in a shorter time and often during the duration of the project by organizing team workshops or increasing incentives. Therefore, objectives that are related to development and learning are goals with long-term prospects rather than short-term collaboration prospects (Figure 7.6).

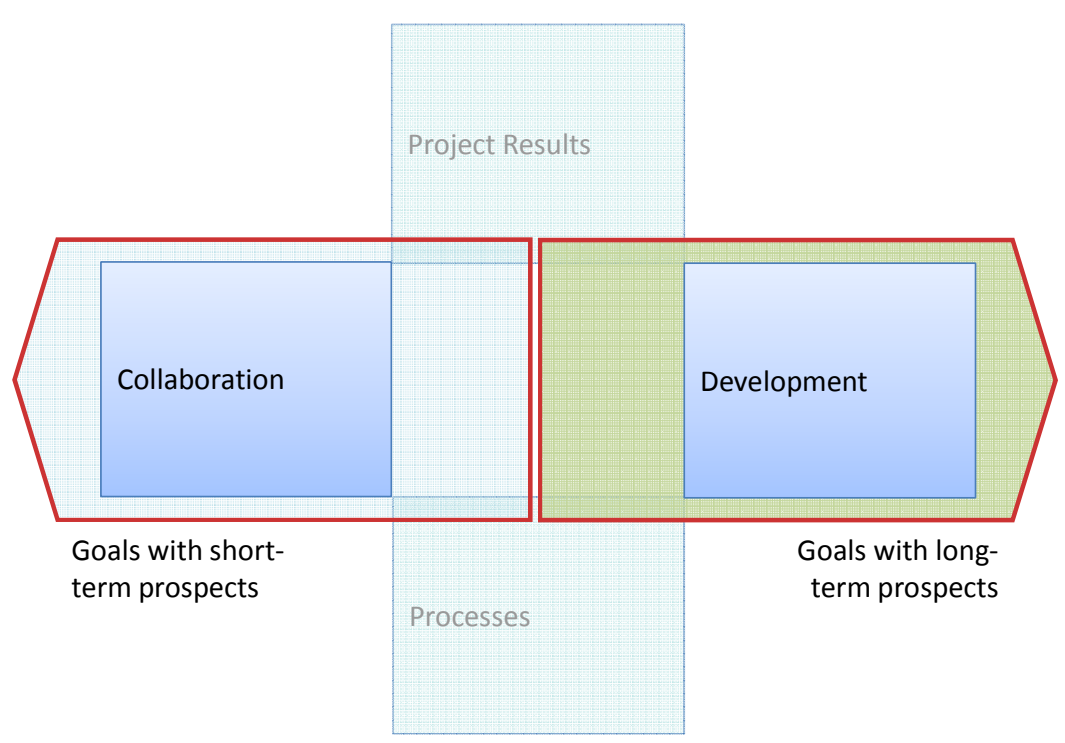

FIGURE 7.6: SHORT VERSUS LONG TERM PROSPECTS 
The distinction from project results and processes has been demonstrated as the easiest task in developing a CPS. It is a process that enables the achievement of certain project results (Figure 7.7). However, the differentiation from processes, collaboration and development is often more difficult as there are, e.g., collaboration processes or development processes, such as a continuous improvement process. Here it is important to categorise every process, whether it has a collaboration or development character, into the process perspective. Development objectives with longterm prospects do not necessarily have a process involed. Examples are the creation of innovation that can be measured by the number of implemented ideas or the improvement of team trust that may be enhanced by regular project team discussions or workshops.

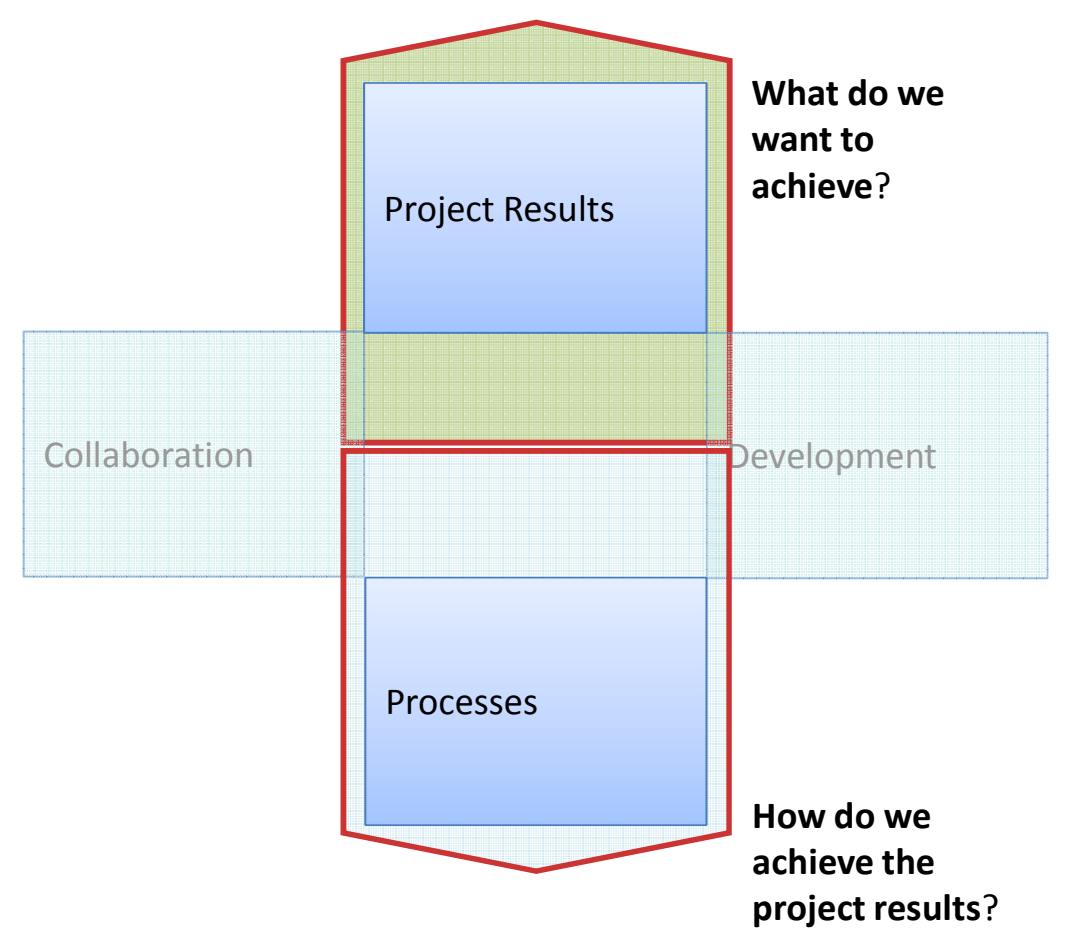

FIGURE 7.7: PROJECT RESULTS VERSUS PROCESSES

The strict definition of each perspective is not crucial for the success of a CPS as long as all relevant objectives are integrated but a clear understanding where a certain objective needs to be placed avoids time consuming discussion during the development in workshops and enables the project team to understand the character and impact on a project and partnership of each objective. 


\subsection{CPS development procedure}

The definition of a collaborative project strategy is the core of the CPS and also the first step before the common goals are defined and further categorised into the respective perspectives. The strategy includes the agreement on how the main objectives are achieved and how, e.g., the time to market period can be shortened. Measure and KPIs are then defined for each goal and target values or corridors set. Possible corrective actions in case a target corridor cannot be achieved need to be discussed and documented in a CPS so that the project partners can react quickly and decide, which corrective action is optimal in the current situation. This avoids unnecessary delays during a project and the selection of wrong actions caused by time pressure and the need to react quickly. Figure 7.8 illustrates the procedure to develop a CPS.

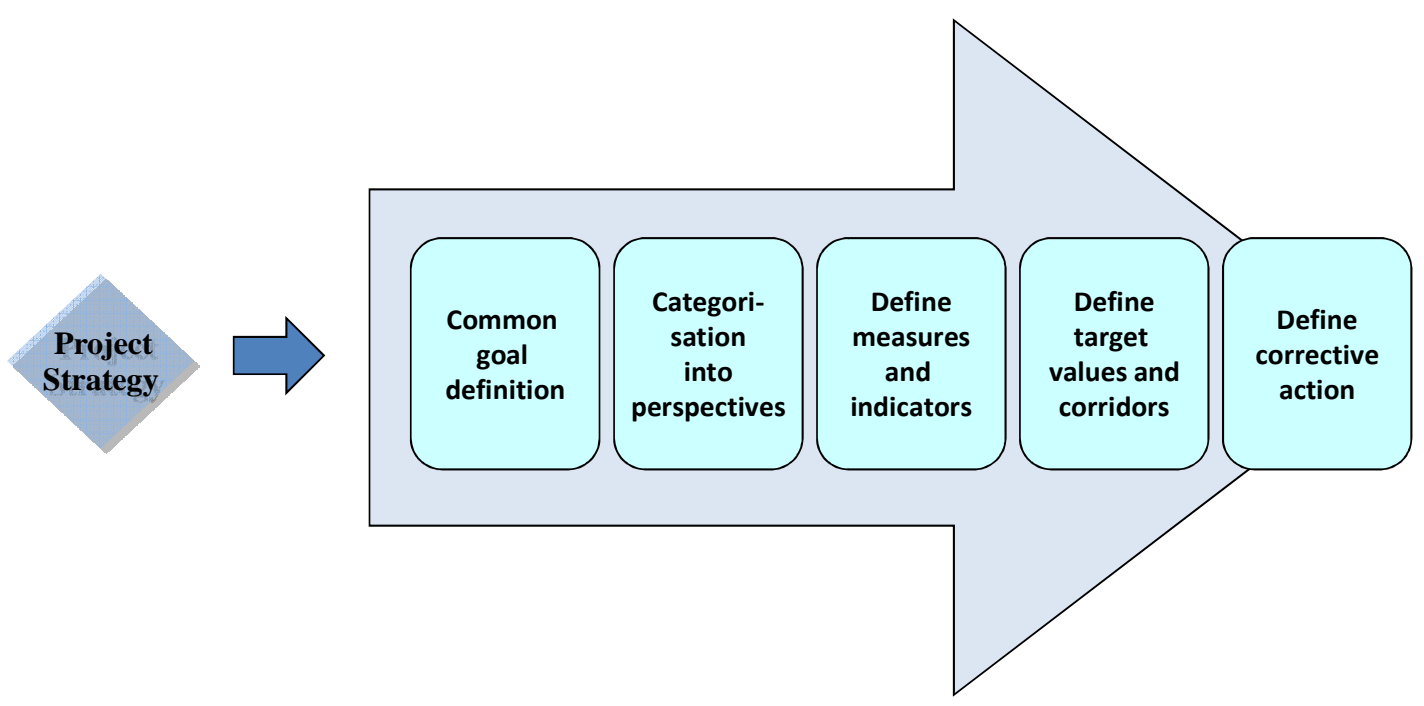

Figure 7.8: Procedure to DEVELOP A CPS

\subsubsection{Collaborative project strategy}

The collaborative project strategy is the core of each project and its definition the first stage in a beginning project partnership. Strategies can be developed in a systematic approach that is supported by tools and checklists and that integrates the project stakeholder sufficiently. The relation between strategy and project management can be summarised in the following steps shown in Figure 7.9. 


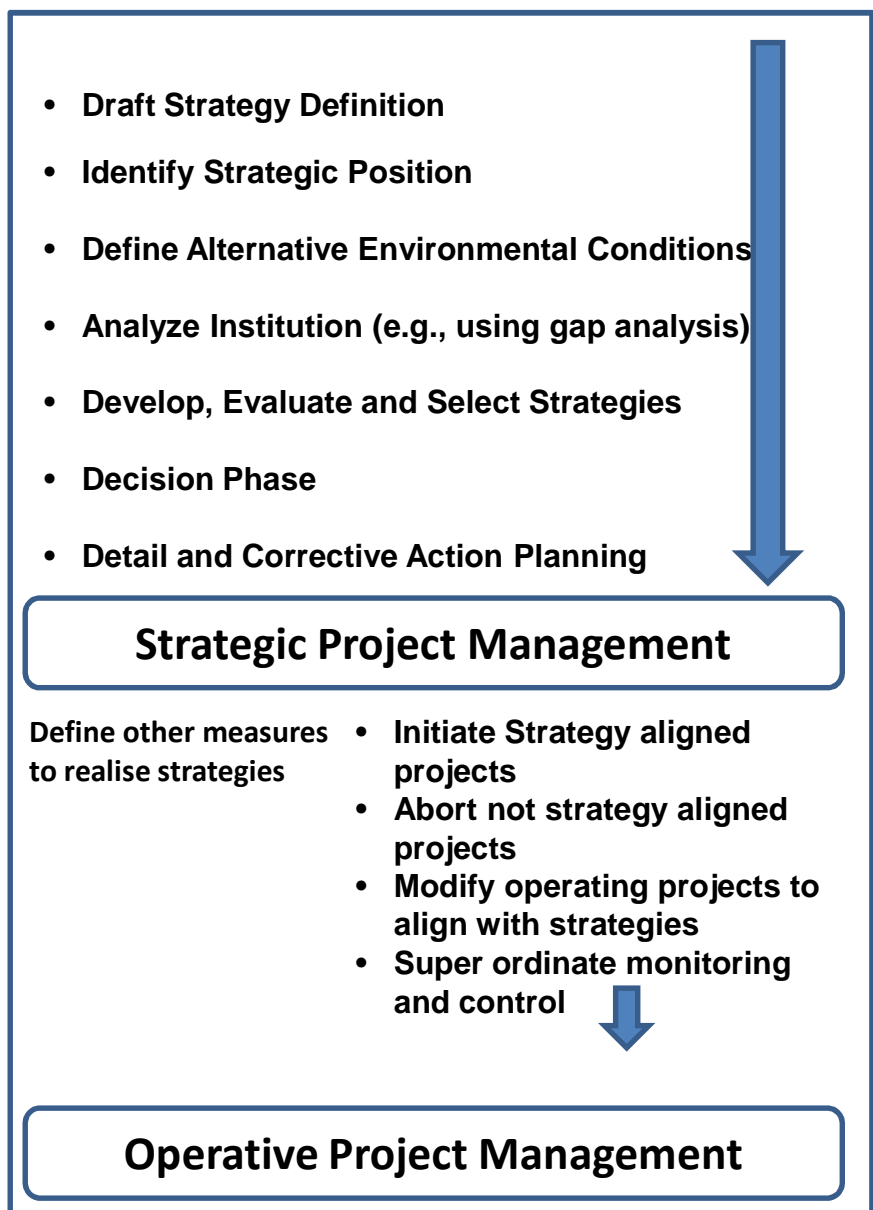

FiguRE 7.9: ReLATION BETWEen STRATEGy AND PROJeCt MANAGEMENT (SCHELLE, 2008, P.135)

Schelle (2008) identified several deficits in aligning project management with the business strategies, e.g., that in many maturity models such as CMMI or SPICE business strategies are not integrated and rather isolated from the operative project management level.

Project management has been considered as a management concept on the operative level only and organisations separate strategic planning divisions from project management units. The creation of portfolios may be one solution or tools such as the Boston Matrix developed by the Boston Consulting Group. However, there is a risk that present trends are translated to the future.

The concept of the Balanced Scorecard enables the institutionalisation of strategy controlled project selection. Schelle (2008) compares the concept with Rietiker's understanding of the Chief Project Officer (Rietiker, 2006). An Office of Strategy Management (OSM) integrates the strategic planning of the contracted units of an OSM and translates the strategy with a BSC. The tasks of an OSM may be: 
- Reporting to CEO about strategic topics.

- Organisation of strategy meetings to control implemented strategies.

- Inform employees about business strategies.

- Initiate, prioritise and control projects that implement strategies.

- Agreement on projects with employee development functions and knowledge management.

In a collaborative project both partners have to clarify their own strategies first and select a project partner that supports their strategies best. This can be done based on the concept of the Strategic Partnership Scorecard (SPSC) that is described in the following sections. Once the strategic project partner is chosen for a series of projects or for an individual project, the strategies to achieve the desired project results need to be developed. This includes, e.g., the definition of clear project objectives, collaboration methods, and the target agreement process.

\subsubsection{From Common goal definition to corrective action}

The collaborative target agreement process can be supported by workshops to discuss possible target conflicts and clarify misunderstandings before a project starts. In an ideal situation the compatibility of objectives lasts until the end of a project. Wagner (2006) categorises the compatibility of project partners into goal competition, goal neutrality and goal identity to measure how compatible the partners are. Wagner recommends to discuss differences of individual goal understandings extensively and to communicate own interests for a sustainable cooperative relationship during a project or whole partnership.

To develop a CPS it is essential to organise workshops, tele- or video conferences to clarify the project goals. It is important that the partners discuss all relevant goals that support a sustainable collaboration. These include the goals of all four perspectives of a CPS.

Figure 7.10 shows the goal finding process for a project between an OEM and a supplier. 


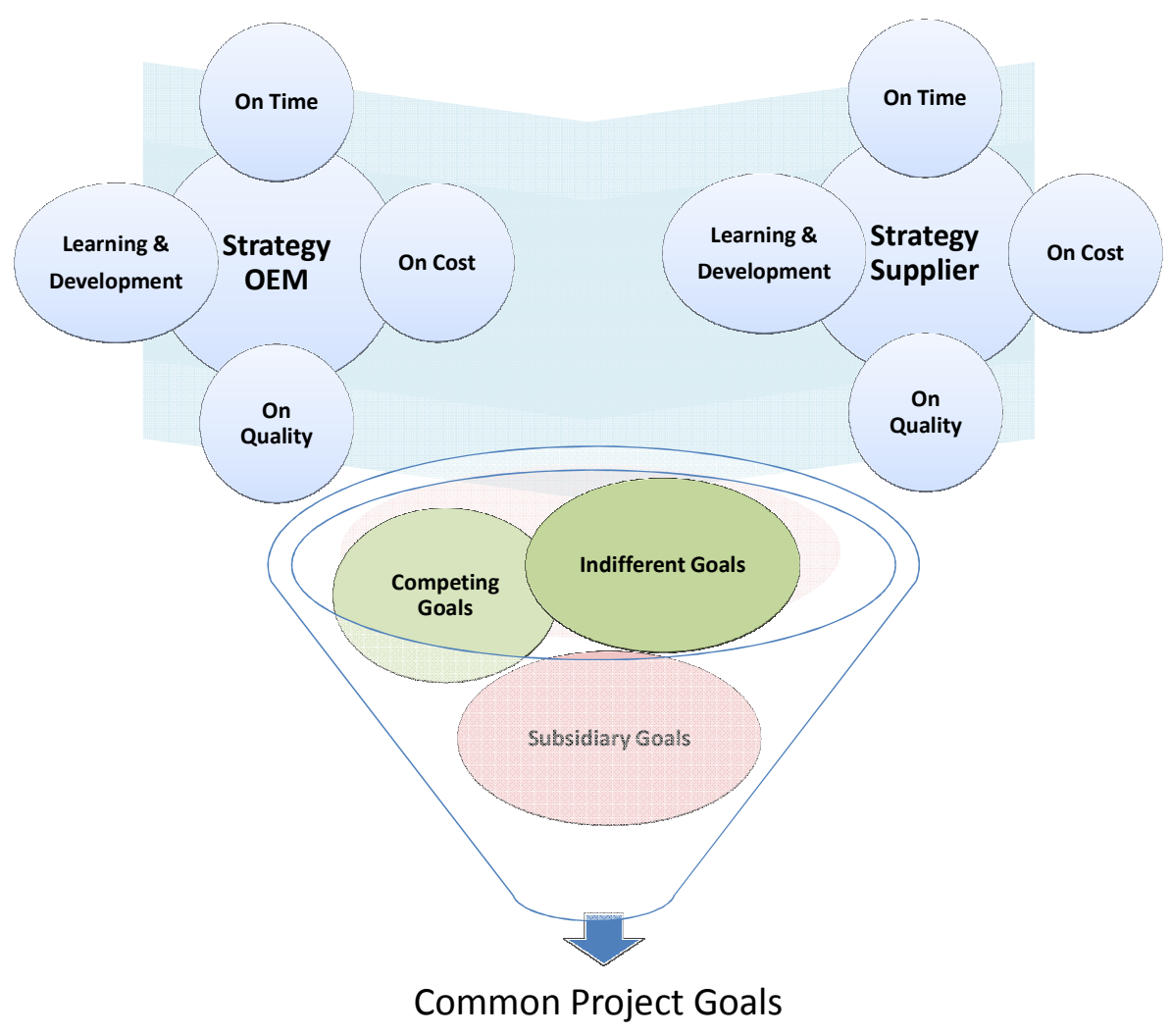

FIGURE 7.10: DEFINING COMMON GOALS

Once the project results are clear, the processes to achieve these goals need to be defined and translated into measurable objectives. Brainstorming or the use of a Strategic Collaborative Scorecard, a framework including generic objectives describing a certain project partnership (see next sections), may be beneficial to achieve agreements quickly. After all relevant goals are discussed they need to be categorised into the perspectives using the definitions of the previous section as guidance. During the goal definition process it is essential that each goal is measurable or can be translated into a measurable goal. There are various possibilities for measuring goals. KPIs or key goal indicators (KGls) are the most common names for indicators describing the status of a goal such as budget and time adherence or quality targets.

The next chapter discusses the indicators typically used in an automotive product development project in more detail. Each indicator requires the setting of a target value or target corridor. If the current value of an indicator is out of the corridor or exceeds or falls below a fixed value corrective measures have to be taken. By applying trend analysis, such as a milestone trend analysis or earned value methods, the future trend of a value can be estimated and corrective action implemented before the value is out of the desired corridor. For each indicator measures may vary, also regarding whether it is a preventive measure due to a result from a trend analysis or it is corrective action when 
the problem has already occurred. This is also part of an integrated risk management further described in Chapter 13. Figure 7.11 shows the framework that can be used to integrate preventive and corrective measures to evaluate and avoid risks.

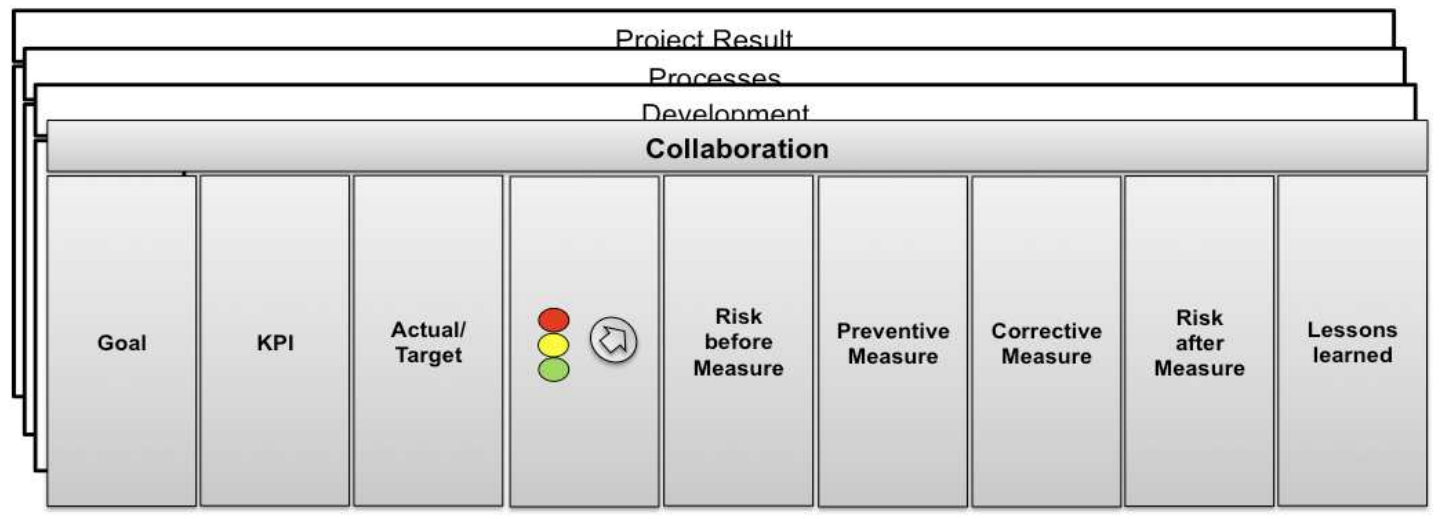

FIGURE 7.11: RISK MANAGEMENT AS AN INTEGRATED PART OF THE CPS

A more detailed figure and description of the CPS risk management can be found in Chapter 13.

\subsection{Integration of the CPS into project networks and environments}

A CPS can be applied between two or more companies in a networked collaboration environment of several project partners. The Collaborative Project Management Reference Model developed by the ProSTEP iViP Association uses a similar approach to apply methods for task, communication, and time management in product development projects (ProSTEP iViP, 2007a). The model is based on the assumption that a collaborative project management model is applied between two project partners only but as often as required.

\subsubsection{Reducing relationships to one-to-one partnerships}

Typically, an OEM has several suppliers that work together for a specific project. These can involve hundreds of different suppliers and coordination may become complex and intransparent quickly. If one can think of four or five project partners working with one CPS together and providing designated information for the defined objectives it can become difficult with hundreds. Figure 7.12 shows how the CPS may be used if all partners work with the same scorecard. This also implies that an OEM may be informed 
about the goals and contribution of the sub suppliers. However, this information could be hidden for selected project partners.

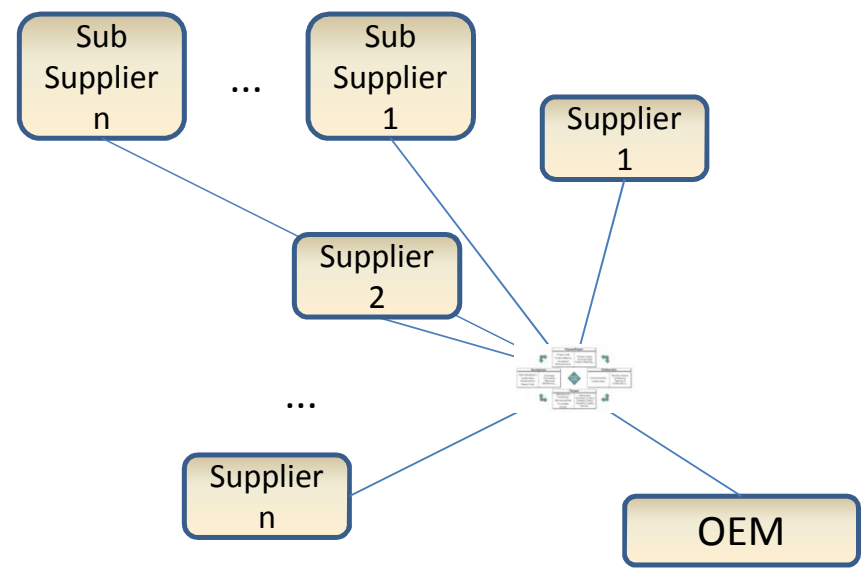

FIGURE 7.12: A SINGLE CPS FOR ALL PROJECT PARTNERS

The reduction to one-to-one relationships may become important when many partners are involved. Similar as proposed in the ProSTEP iViP Reference Model the reduction to one-to-one CPS relationships is shown in Figure 7.13.

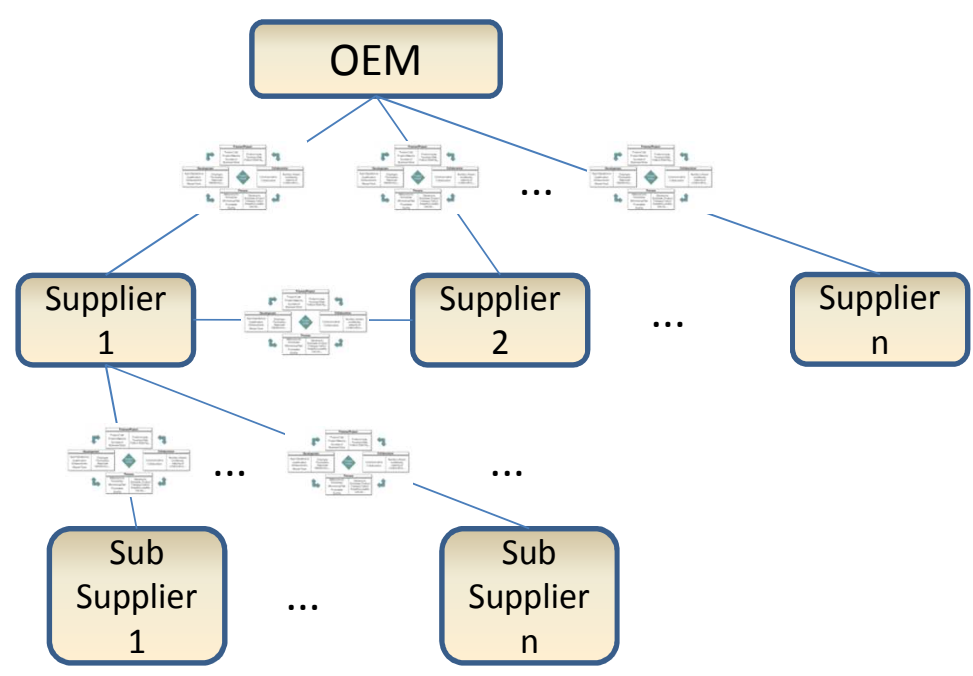

FIGURE 7.13: REDUCTION TO ONE-TO-ONE CPS RELATIONSHIPS

One-to-one partner relationships facilitate the application of a CPS by reducing its complexity. Some networks with more than two partners may be replaced by one-to-one relations but also combined with a centralised, collaborative CPS. The central CPS includes all relevant information shared by all project partners, and the one-to-one CPS only includes KPIs and strategies between two partners not relevant to the other participants. 
In a joint venture project the project partners operate on an equal level, the CPS can be applied as shown between two suppliers or sub suppliers. For example, an OEM can work together with its supplier (tier 1 , tier 2 , or tier $n$ ) but also with other OEMs. It is conceivable that if one CPS is deployed between many partners that each one-to-onepartnership creates its own isolated controlling system.

Figure 7.14 illustrates possible network constellations for the application of a CPS.

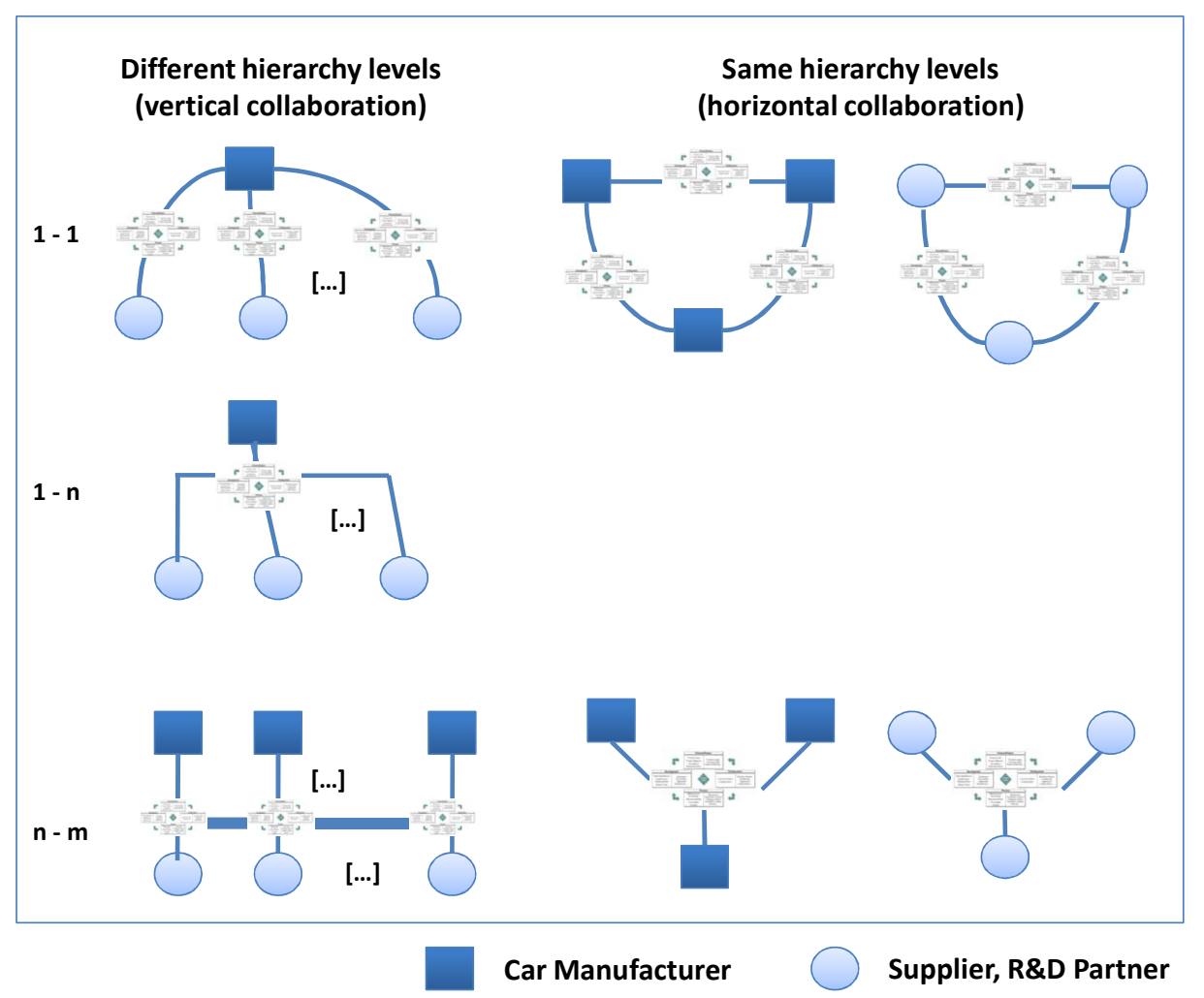

FIGURE 7.14: POSSIBLE NETWORK CONSTELLATIONS FOR THE INSTALLATION OF A CPS

While the creation of a network of multiple (one-to-one) Collaborative Project Scorecards over several steps in the supply chain is likely to be the most transparent variant, the implementation of a single integrated system for the whole network, which is managed by the OEM, has the best prerequisites for optimising the value creation network. If a CPS is applied between different divisions or departments within an organisation, the CPS relationships are similar to those between an OEM and supplier or between two equal partners depending on the hierarchical position of a department. 


\subsection{Organisational integration of a CPS}

The organisational integration of the CPS and the derivation from business strategies of each organisation and project partner is shown in Figure 7.15.

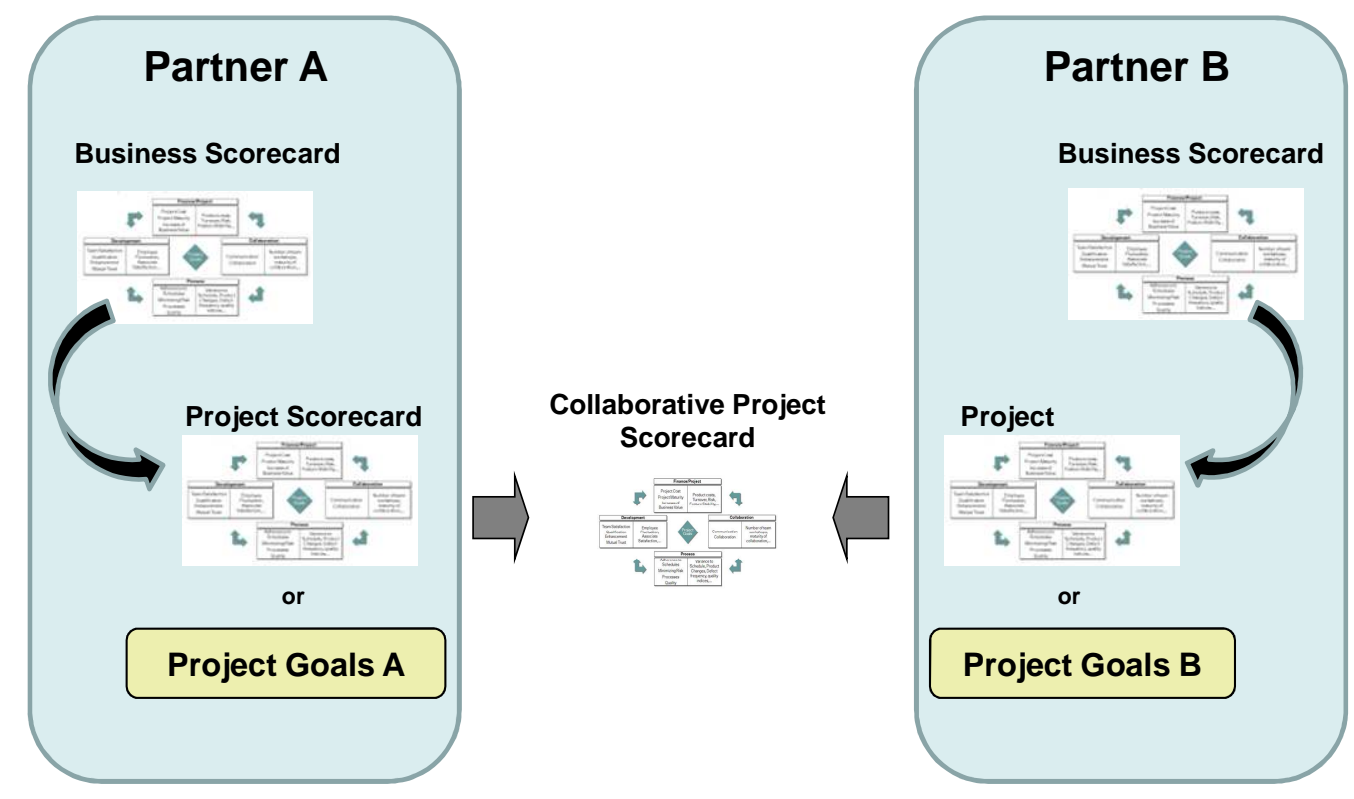

FIGURE 7.15: DERIVATION OF A CPS FROM A BSC AND PSC

The PSC is derived from the Business Scorecard (e.g., BSC) and the CPS is then developed based on the common goals of a chosen cross-company project. Although, Figure 7.15 shows an ideal situation, it cannot be assumed that every company has already adopted a BSC for their business management or a project scorecard for internal project management that is based on and derived from a Balanced Scorecard. Therefore, a CPS can also be developed on the basis of project goals only. Both companies typically define their individual project strategies and goals first and then identify and consolidate common strategies and goals with their partner. The following sections describe the experience and theoretical contribution to the CPS methodology that was based on the collaborative project between the OEM and the supplier in the USA. Therefore, it includes theory derived from practice.

\subsubsection{Creating a common vision and a strategic framework}

Together with an OEM and a supplier in the USA, a project specific CPS was developed for a new vehicle launch. Twelve participants of each company defined common goals, measures, and corrective action for the launch and change management of a new 
model of a vehicle with respect to the integration of a certain part that has to be manufactured and delivered by the supplier. In several individual interviews and discussions of the CPS concept with project managers from the quality, logistics, procurement, sales, and management department the relevant steps for a successful scorecard introduction were extended.

Chapter 9 describes the results in more details, however, one of the main findings was that it is beneficial to create a strategic partnership framework first that includes a collaborative vision. The vision is then translated into strategic objectives categorised into the four perspectives. The assumption was that most of the project goals in a certain project are not unique and there are some basic objectives the partners can find in all of their common projects. Typically, the Strategic Collaborative Scorecard is a result of past project experience of the partners. Detailed research results can be found in Chapter 9.

Figure 7.16 shows a Strategic Collaborative Scorecard (SCS) that includes strategic project goals shared between an OEM and a supplier and provides a fundamental framework to derive project and project phase specific goals.

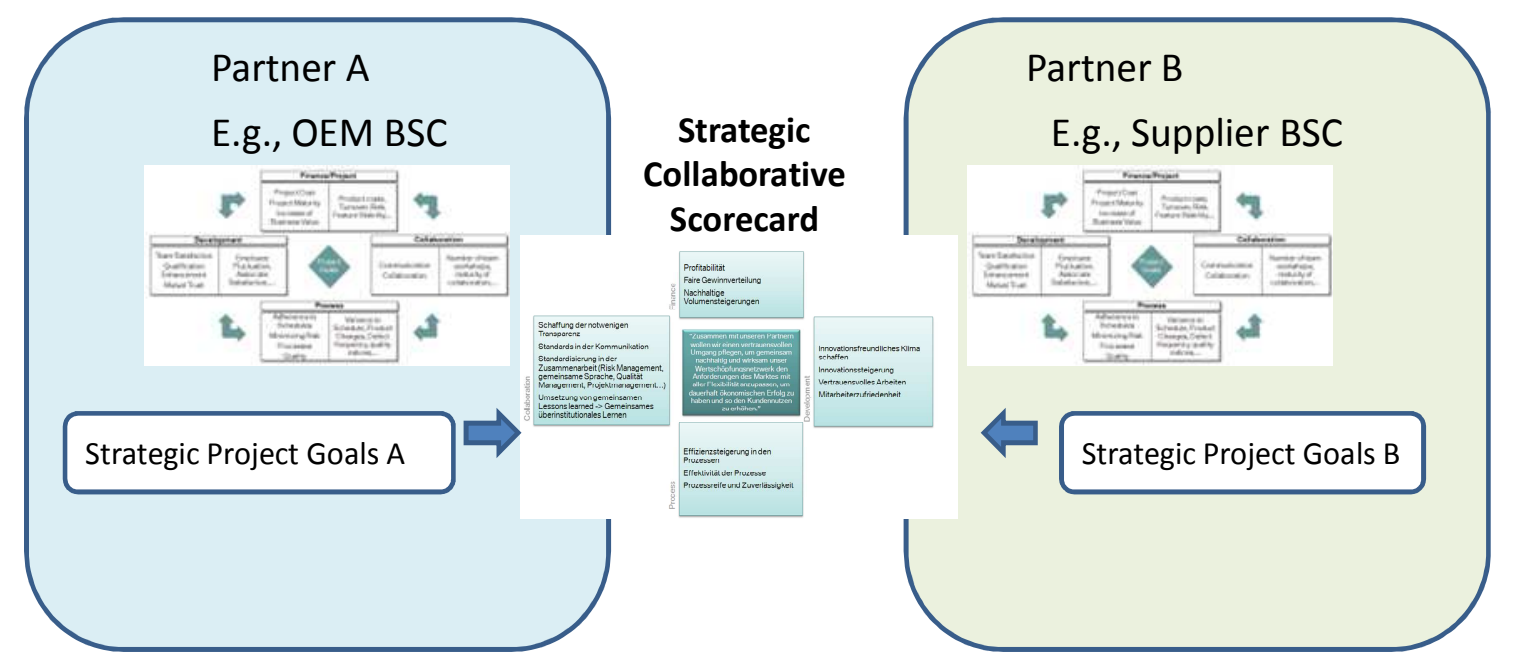

Figure 7.16: Strategic Collaborative SCORECARD (OEM-SUPPLier)

The SCS is then applied to a specific project and supports the team in finding the relevant project goals and measures more efficiently. Afterwards, the CPS may be applied to every project phase, from the concept to the series production by periodically updating the project goals and KPIs within a phase or from one phase to another. Figure 7.17 illustrates the steps and structure of the strategic framework and the project specific CPS. 


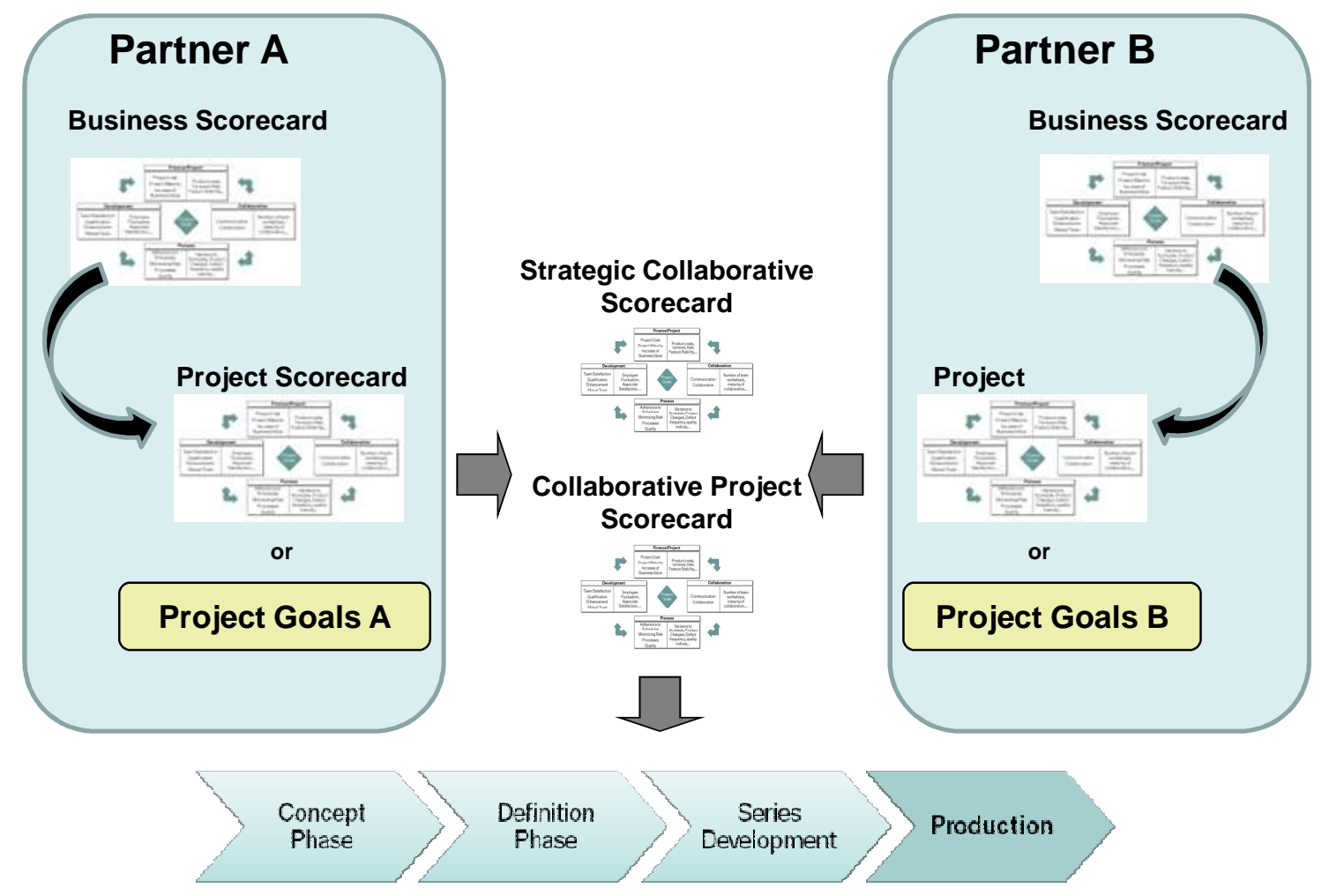

FIGURE 7.17: STRATEGIC SCORECARD AND CPS APPLICATION

The goals agreed in the SCS need to be translated into project specific goals and measured with key performance indicators. The definition of corrective measures on discrepancies of an actual project status from defined targets or target corridors is the final step to complete the CPS development.

\subsection{The CPS for project portfolio and partnership management}

Project partners may not only have a common vision regarding a single or a multiple of projects, they may also share a vision on a strategic partnership level. The partners define their strategic goals in a Strategic Partnership Scorecard (SPSC) that is derived from a common set of their individual Balanced Scorecards. As each partner usually operates a project portfolio the SPSC facilitates the identification of an optimal partner for a specific portfolio that is further defined in a SCS (Figure 7.18). 


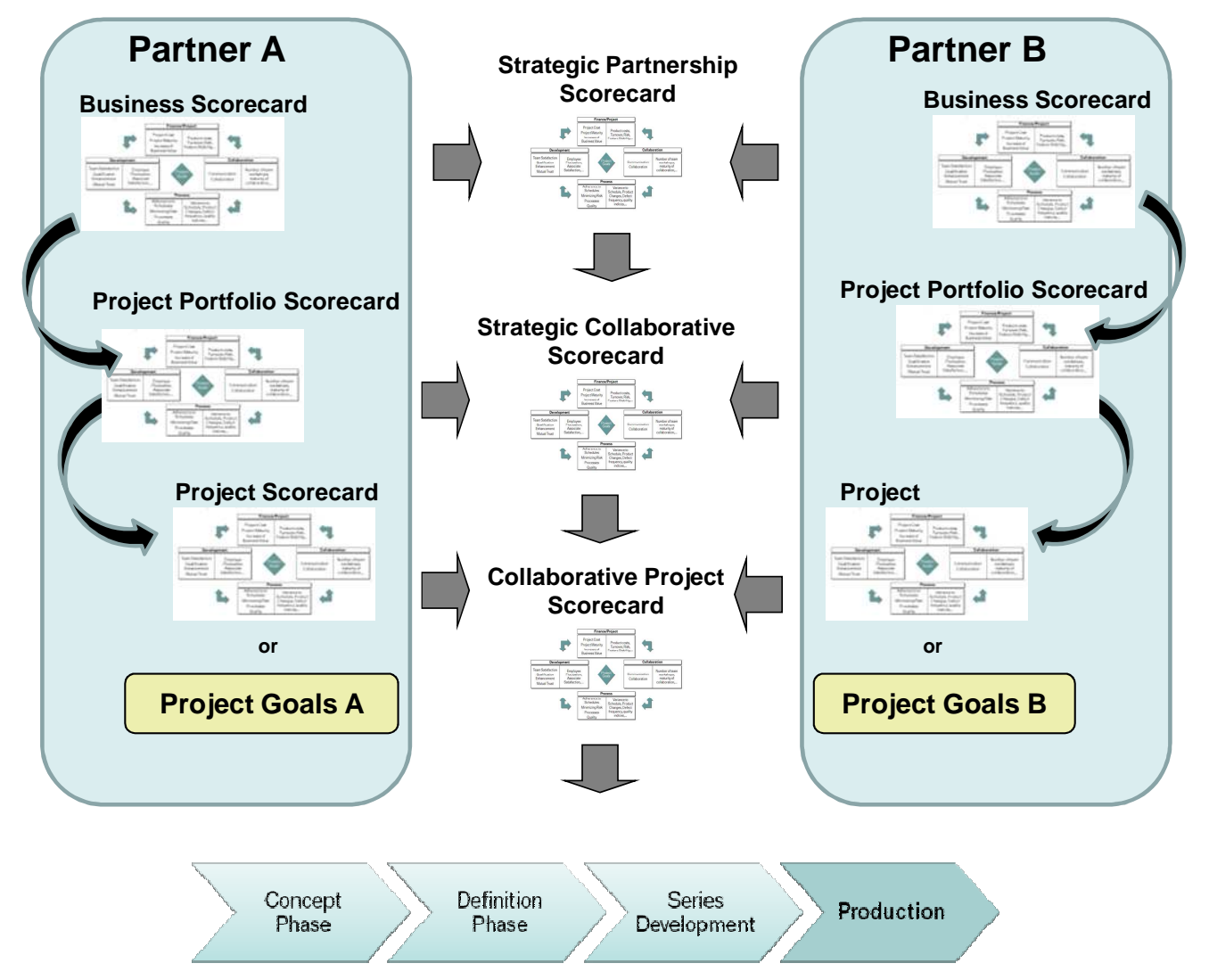

Figure 7.18: THE Strategic Partnership SCORECARD

\subsection{The project impact matrix and strategy map}

A method to map networked and complex coherences, interdependencies and dynamics in project management was developed to identify active and passive variables, as well as their controllability to identify and evaluate cause-and-effect relationships (Raschke, 2007). This method can be modified and applied to a BSC, PSC and CPS to develop strategy maps. This section illustrates how the collaborative project impact matrix can be developed based on an impact matrix analysis.

\subsubsection{The collaborative project impact matrix analysis}

An impact matrix relates each project variable with the other variables in regard to its impact intensity on those variables. An intensity scale from 0 (no impact) to 3 (great impact) quantifies the intensity to be able to estimate the activity, passivity or criticality of a variable. The impact matrix for Project Scorecards was already described in Chapter 6 and, therefore, the application to a CPS is part of this section. The active variables (high values of $Q$ ) have the greatest impact on other variables and are the least open to 
influence or able to be influenced. Project control with critical variables (high values of $P)$ is difficult as they have great impact but are highly open to influence or able to be influenced and could cause a series of unforeseen reactions. Variables with low values of $Q$ are merely indicators for success rather than control variables as they have low impact on other variables but are strongly influenced.

In a collaborative project the strategy map can be developed based on a Collaborative Project Impact Matrix (CPIM) that uses the framework and perspectives of a CPS. The result is a Collaborative Project Strategy Map (CPSM) that visualises the relevant interdependencies of common and shared goals. Similar to the Project Impact Matrix the Collaborative Project Impact Matrix (CPIM) consists of indicators with respect to their perspectives (Figure 7.19).

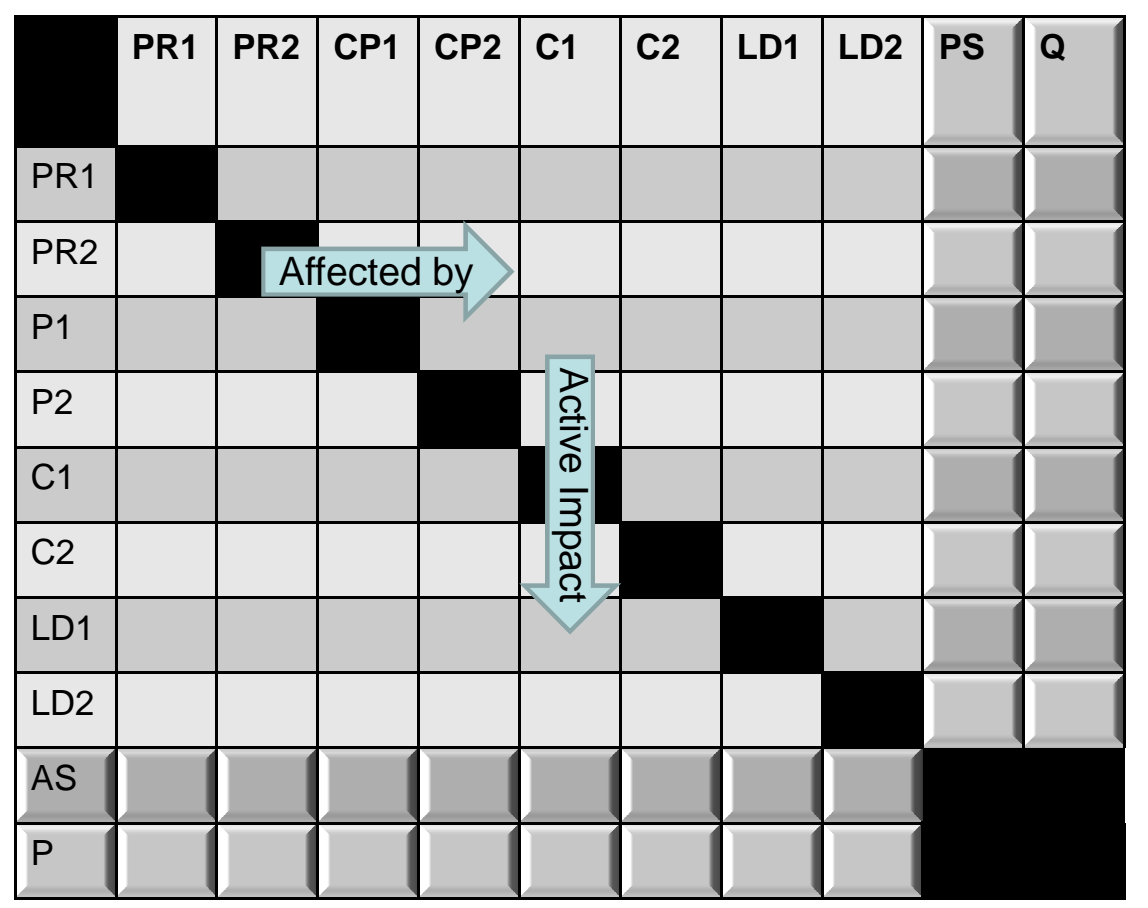

PR: Project Results, CP: Collaborative Processes, C: Collaboration, LD: Learning \& Development PS: Passive Sum, AS: Active SUM, Q=ASx100/PS, $P=$ ASxPS

Figure 7.19: Framework of the Collaborative Project Impact Matrix (CPIM)

Figure 7.19 shows the framework of the CPIM for two objectives of each perspective only.

An example of a CPIM for an automotive cross-company project with arbitrary objectives is shown in Figure 7.20. 


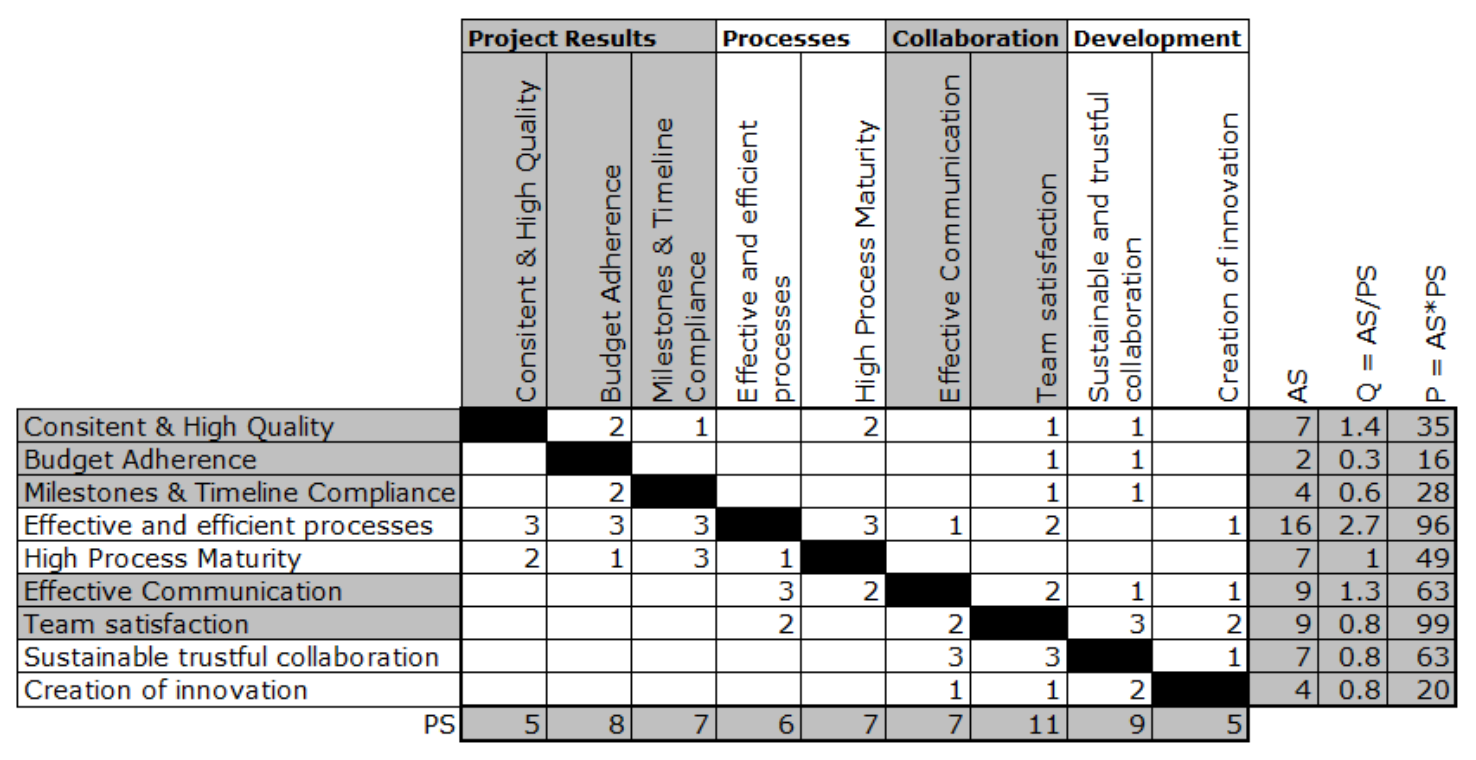

FIGURE 7.20: CPIM EXAMPLE

As a result of the GPM workshops and the workshop at the BMW production facility in South Carolina, it is recommended to develop a CPSM first and then verify and adapt the CPSM with a CPIM. The CPIM also facilitates the selection of relevant interdependencies as some may not have sufficient impact intensity to be effective in operation. Additionally, it can be avoided to invest effort to control KPIs with low $Q$ values as they have nearly no impact on other KPIs. Therefore, the method supports the avoidance of unnecessary tasks and costly efforts.

\subsubsection{Developing a collaborative project strategy map}

The first step to build the strategy map is to define the drivers based on at least two or more KPIs. Interdependencies of the KPIs are then evaluated with the impact matrix analysis. As an example, the driver "employee satisfaction" may be controlled by the "rate of employee fluctuation" and "overtime", whereas the "rate of employee fluctuation" also influences the driver "customer satisfaction". Leading and lagging indicators can be identified by evaluating their interdependencies. The development of a Collaborative Project Strategy Map (CPSM) is an essential part of the project planning process and should be discussed with all project members in a CPS kick-off meeting together with the relevant KPIs and drivers. After a carefully designed CPSM, measures can be defined based on cause-and-effect relationships for efficient project control. The CPSM is a graphical representation of the CPIM. The $P$ and $Q$ values give an indication about the impact intensity of each objective. This can be represented by the thickness of an 
arrow or a scaled number value. An example of a CPSM without intensity evaluation is shown in Figure 7.21.
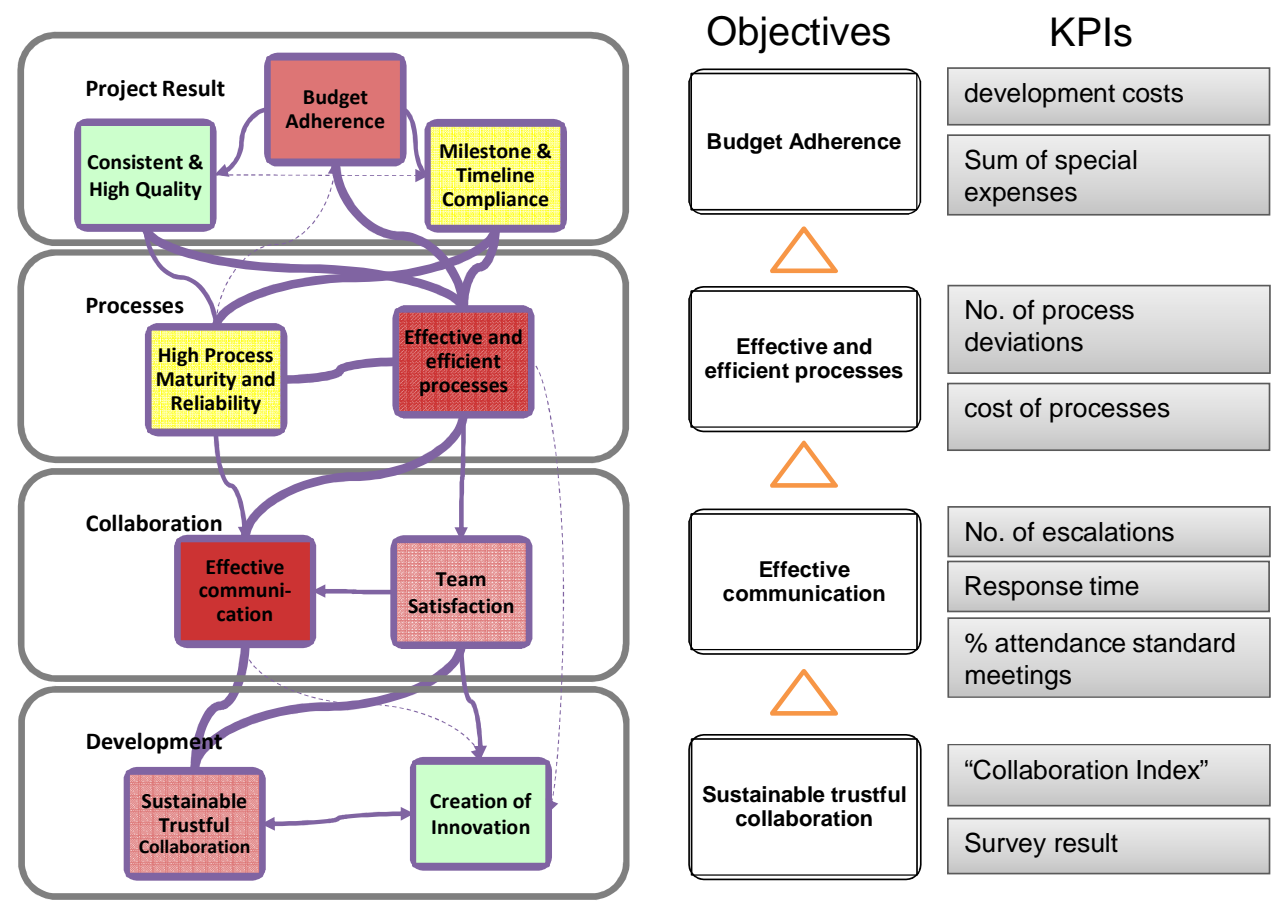

FIGURE 7.21: EXAMPLE OF A COLLABORATIVE PROJECT STRATEGY MAP (CPSM)

Examples of objectives and related KPIs are also shown in this figure. A sustainable trustful collaboration may facilitate the communication between partners and increase its effectiveness as project members are familiar with each other and do not avoid confrontation. An effective communication ensures that everyone understands the relevant processes that are necessary to stay within the planned budget.

\subsection{Integrating soft facts for sustainable collaboration}

Key Performance Indicators are the central elements to monitor the objectives of a scorecard as they quantify the progress towards common objectives. Kaplan and Norton (1992) identified risks when a company uses indicators to monitor its performance and status. The measurement system strongly affects the behaviour of managers and employees.

An indicator is an abstract representation of the reality and if it does not fit with the real business, it may lead to undesirable employee deviance. Additionally, cross-company teams that are managed with a scorecard system are highly influenced by the defined 
metrics and measures. In the CPS, the dependencies between hard facts such as costs, schedule deviation or the number of defect parts per million and soft facts, e.g., mutual trust or team satisfaction become evident. This section describes how soft facts can be quantified and measured continuously. Soft facts are a key to success for a sustainable collaboration. Open and frank communication and mutual trust are relevant to create transparency. Transparency on the other hand enables the team to identify difficulties and future problems early so that preventive measures rather than mere corrective measures can be taken. Soft facts can be broken down into several dimensions. Bennis (1999) divides trust in care, competence, reliability, authenticity and frankness. This is relevant as everyone may have a different understanding of trust. The aim is to translate a soft fact into measurable hard facts to obtain objective results when a soft fact needs to be measured. As an example, Figure 7.22 shows a template how to measure trust in a project team survey.

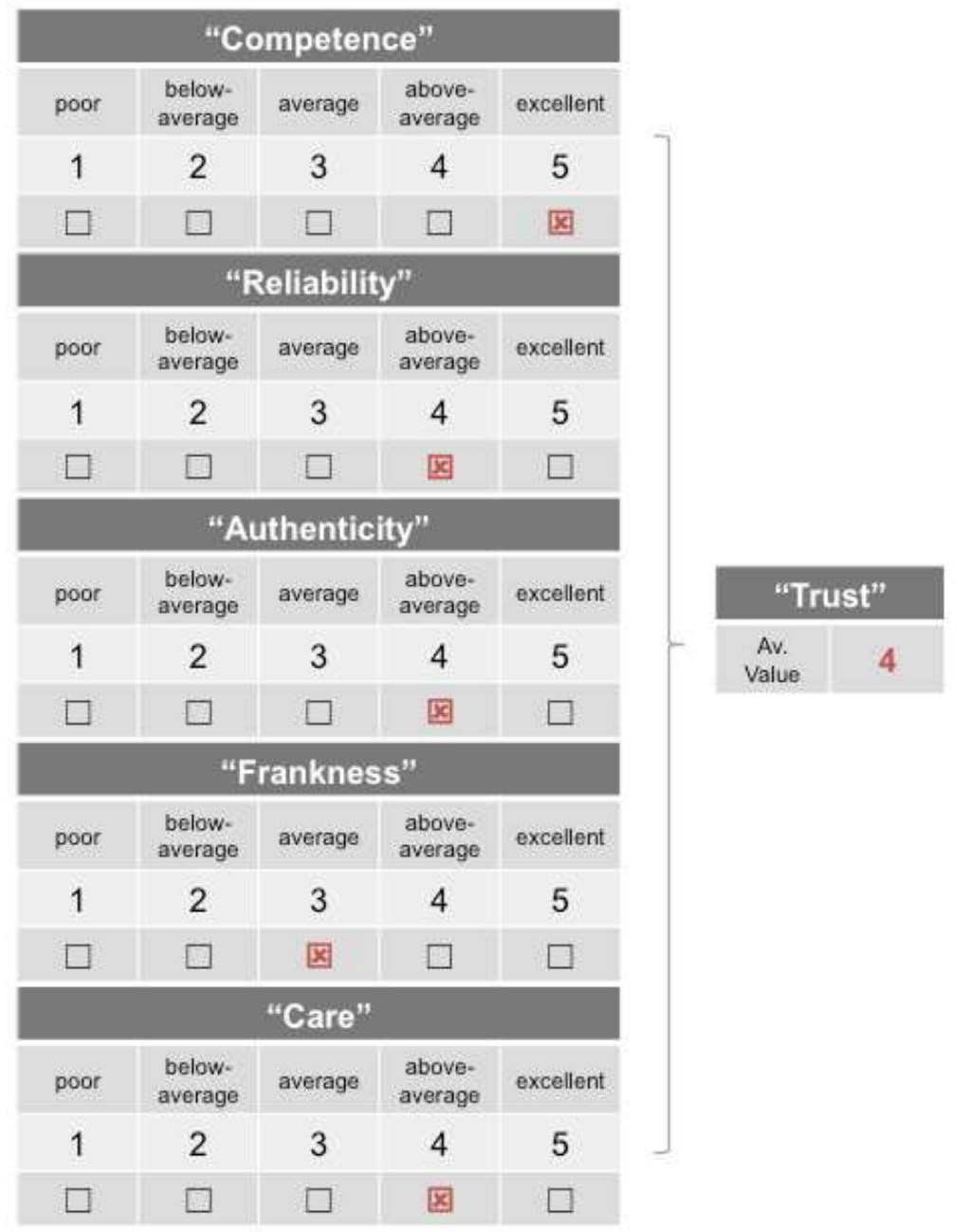

FIGURE 7.22: TEMPLATE TO MEASURE PROJECT TEAM TRUST 
Frost and Sullivan (2006, p. 4), e.g., developed a "collaboration index". This index measures how collaborative an organisation is, whereas collaboration is composed of collaboration capability and collaboration quality. A translation into a collaboration index that measures how collaborative a project team is may facilitate the identification of weaknesses for a long-term project team and partnership improvement. This index can then be integrated into a CPS. 


\section{The CPS for automotive projects}

The analysis of advantages, benefits, disadvantages and limitations requires an application of the CPS concept to an operational level of project management. As the way projects are managed may vary from each industry sector, the automotive industry was chosen as an exemplary sector to develop and extend the CPS methodology. The framework based on the Balanced Scorecard needs an adaptation to the automotive environment and, therefore, a practical approach to develop and extend the concept by the help of workshops and interviews with project managers from the automotive industry. This chapter gives further insight into the results of two workshops that were organised with the GPM e.V. Automotive Chapter and illustrates the results of an industry survey (Figure 8.1).

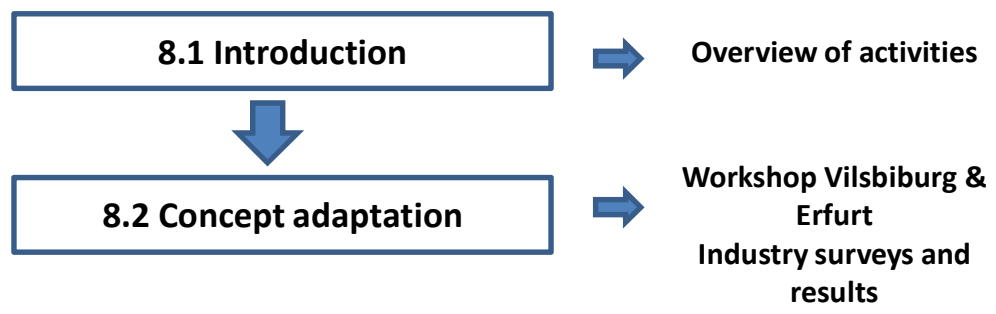

FIGURE 8.1: OVERVIEW OF CHAPTER 8

\subsection{Introduction}

The adaptation of the CPS concepts to the automotive environment requires the identification of project goals and KPIs for a cross-company project. The first GPM workshop was organised on $17^{\text {th }}$ July 2007 in Vilsbiburg, Germany, and included the definition of the CPS perspectives, the relevant KPIs to measure typical project goals, and a discussion about the introduction and implementation of a CPS to an organisation. During the workshop a questionnaire was distributed to collect more data and information relevant to the CPS methodology. The next GPM workshop took place on $4^{\text {th }}$ October 2007 in Erfurt and had a focus on KPIs relevant to small and mediumsized businesses, a procedure model that describes relevant steps necessary to synchronise the project partners, and further details about the success factors to introduce a CPS to an organisation. 
The two workshops were followed by two more automotive industry surveys. Further details about the results are presented in the following sections. To validate the theoretical results a use case between an automotive OEM and a chosen supplier was identified and the CPS concept applied to a selected project with a focus on the launch and change management phase followed by a workshop questionnaire (Chapter 9). Figure 8.2 shows the steps towards the CPS automotive adaptation.

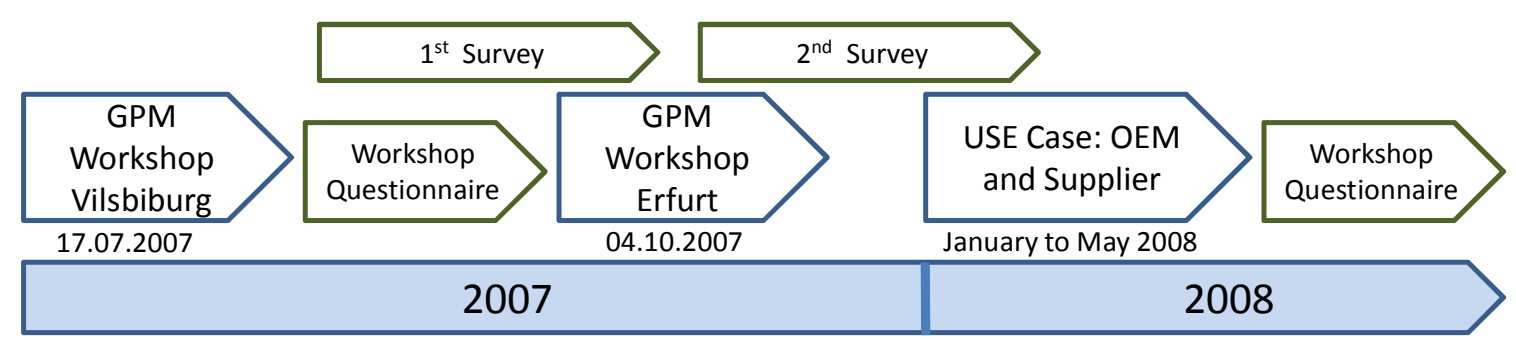

FIGURE 8.2: DEVELOPMENT STEPS TOWARDS AN AUTOMOTIVE CPS

\subsection{Concept adaptation to automotive environment}

A major criterion for the development of a CPS is the integration of differing and ambiguous perceptions and project goals. According to the workshop participants of the GPM e.V. Automotive Chapter, the CPS is most beneficial when applied between two different organisations such as between an OEM and a supplier, or in joint ventures. However, the application to inter-departmental and geographically dispersed divisions and project teams within an organisation may also improve internal collaboration.

The consideration of aspects of the "magic triangle" does not satisfy the concept of the BSC as room for improvement can especially be found in the potential of collaboration, communication and efficient use of innovation, learning, and development goals. These are important extensions to the "magic triangle" and are enablers to achieve efficiency and effectiveness in cross-company and collaborative projects. Therefore, it is essential to identify and describe room for improvement and to ascertain related goals with your partners. An effective way to accomplish this is by the means of workshops, either in real presence (preferably) or virtually using video conferencing.

Next to large enterprises, small and medium-sized organisations rely on the most relevant measures and indicators to preserve manageability and understandability. According to the workshop participants, the CPS should include the following four perspectives: 
- Project Results.

- Collaborative Processes.

- Collaboration.

- Learning and Development (Innovation/Potentials).

The first perspective covers the agreed result goals between the partners, the second one the processes related goals to achieve these results and their performance, and the third one focuses on collaboration aspects between the partners, such as efficient communication, quick problem resolution, or team satisfaction. The fourth perspective addresses the potentials for a continuous development in a project partnership. This may include the employee (qualification, motivation, etc.) as well as the development of new processes and the integration of cultural aspects.

The experience from workshops has demonstrated to be most beneficial to the CPS development as there was enough time to introduce the participants to the CPS concept and to discuss relevant questions. Therefore, the two GPM workshops have contributed greatly to the concept adaptation to the automotive environment.

Comparatively, the two industry surveys have not been as beneficial as previously expected as most participants were not able to contribute to the new concept due to a lack of understanding that could not be sufficiently reduced by a detailed concept introduction in the beginning of the survey. Nevertheless, the major results that could contribute to the concept were integrated. The next sections present the workshop and survey results that were most relevant to the CPS methodology.

\subsubsection{First workshop results Vilsbiburg}

The workshop took place in Vilsbiburg on $17^{\text {th }}$ July 2007. After a presentation of the CPS concept and framework, three work groups were formed to develop relevant attributes of the CPS structure. The participants were composed of 25 project managers with an average of 10 years project management experience in the automotive industry. They represented car manufacturers (OEMs), suppliers, consultancies, and universities. 


\subsubsection{Work group results}

The first work group discussed the relevant dimensions and perspectives of a CPS. Regarding the perspectives, it was found necessary to cover the "magic triangle" of quality, cost, and time first. However, as mentioned before the coverage of these three aspects was considered as insufficient. Learning and development aspects are key drivers to sustainable success and need to be monitored and controlled as well. In a collaborative project, the goals of two or more project partners may be conflicting. Therefore, it is important to integrate also conflicting goals to assure the understanding of each partners' objectives before initiating the project. This should not only be represented in the project goals but also in the point views of all participating partners and, therefore, should already take place in the definition process. The integration of stakeholder commitment by defining values and target corridors for strategic project goals is often neglected but it is a requirement of the CPS.

The collaborative monitoring of processes and their maturity has priority but also innovation and safe-guarding of continuity of learning and development aspects are relevant for a successful collaboration. In addition to that, a maturity level of collaboration in the collaboration perspective was identified as key success factor. The traditional financial perspective was considered as a controversial one as the discussion on prices may result in a protective and non productive attitude. Therefore, the project results that include objectives describing product maturity and quality numbers are more beneficial in a project partnership. However, the definition and monitoring of budgets and costs was seen as non critical and even essential elements of a scorecard.

The second work group discussed relevant KPIs for a collaborative project. The project result perspective includes objectives that define the desired outcome of the collaborative project in terms of a product, assuming collaboration is part of a product development project. Next to product maturity, the product costs and target costs are relevant objectives that need to be achieved. Typically, the costs are structured into several budget costs such as development, manufacturing, labour, logistics, or material costs.

Other objectives that were identified are time related, e.g., milestones adherence, or feature related, e.g. feature adherence and stability, as well as its feasibility. Regarding the process perspective the following additional indicators were identified: 
- Change index.

- Time adherence (delivery/implementation).

- Error life cycle time.

- Frequency of errors.

- Risk management/common indicators.

- Risk matrix (amount of loss/probability).

- Proposals to improve quality.

- Test rates.

The learning and development perspective should also include a fluctuation rate at communication interfaces, adherence to agreed reflection loops, and a common lessons learned indicator that may be created based on previous lessons learned workshops.

The third work group discussed the introduction and implementation of a CPS and identified the following success factors:

- Learning of BSC and CPS method required.

- Integrate top management.

- Develop coaching.

- Clarify what we want to achieve with a CPS (targets, benefits, etc.).

- Kick-off meeting (external).

- Align goals with business goals (BSC-PSC-CPS).

- Bottom-up or top-down strategy.

- Learning by doing.

- Pilot project beneficial.

- Frankness of project partners.

- Create transparency.

\subsubsection{Feedback results}

At the end of the workshop a questionnaire was handed out (included in Appendix B) and 10 of the 25 questionnaires were returned. All participants were from organisations with more than 1000 employees and a turnover greater than 250 Million Euros. 
The most relevant results are shown in the following figure, whereas only answers to questions of which $50 \%$ or more of the participants chose a similar answer were taken. Figure 8.3 shows the results of the questionnaire.

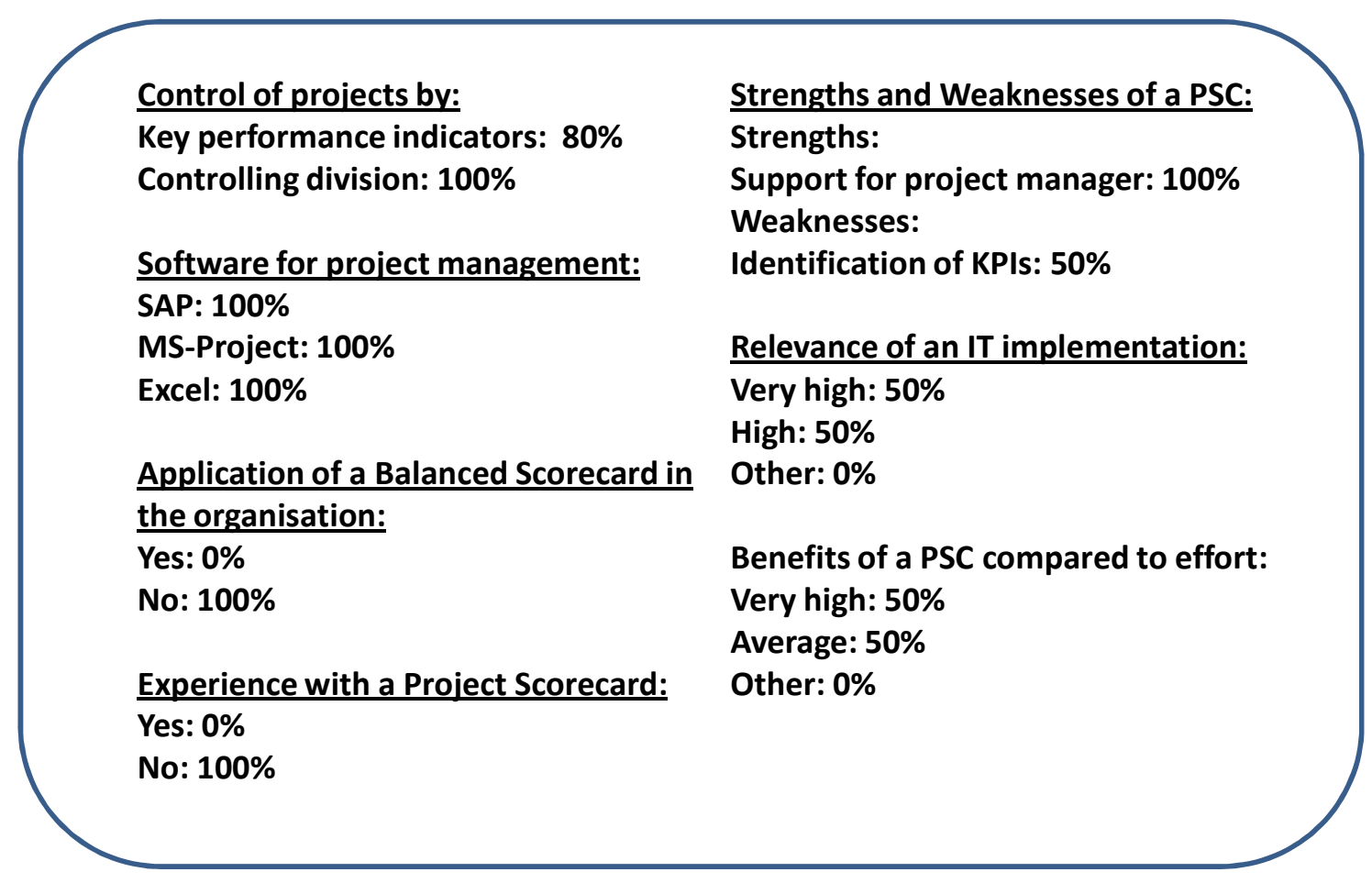

FIGURE 8.3: WORKSHOP QUESTIONNAIRE RESULTS VILSBIBURG JULY 2007

\subsubsection{Second workshop results Erfurt}

The second GPM e.V. Automotive Chapter workshop took place in Erfurt, Germany, on $4^{\text {th }}$ October 2007. 20 project managers from the automotive industry (OEMs, suppliers, consultancies, and universities) participated and were grouped into three work groups after an initial presentation of the last workshop results and an update of the CPS concept development.

The first work group discussed further KPIs relevant to small and medium-sized organisations and the additional KPIs were identified with a focus on time, costs, and quality (Figure 8.4). 


\section{Time and milestones:}

- Adherence to milestones and delivery dates

- Different time prioritisation with tolerances respectively

- Time effectual risks

\section{Costs:}

- Part price

- Cost effectual changes (risk/benefit sharing model)

- Development and tool costs

- Cost effectual risks

\section{Quality:}

- Product maturity (Fulfilment of tender specification document,

- Approval status, PPM-rate)

- Process maturity (post processing effort, error life cycle time, complaint rate, special approval status)

- Delivery adherence and loyalty

- System maturity and risks

- RPZ indicator (FMEA)

FIGURE 8.4: 2ND WORKSHOP RESULTS GROUP I

\subsubsection{CPS development and adaptation procedure model}

Requirements for a successful CPS operation are that the effort is kept at a minimum and that both partners are cooperative and support each other in providing relevant information. The second work group developed relevant steps that are necessary for a CPS adaptation between the project partners. Figure 8.5 shows the developed procedure model. 


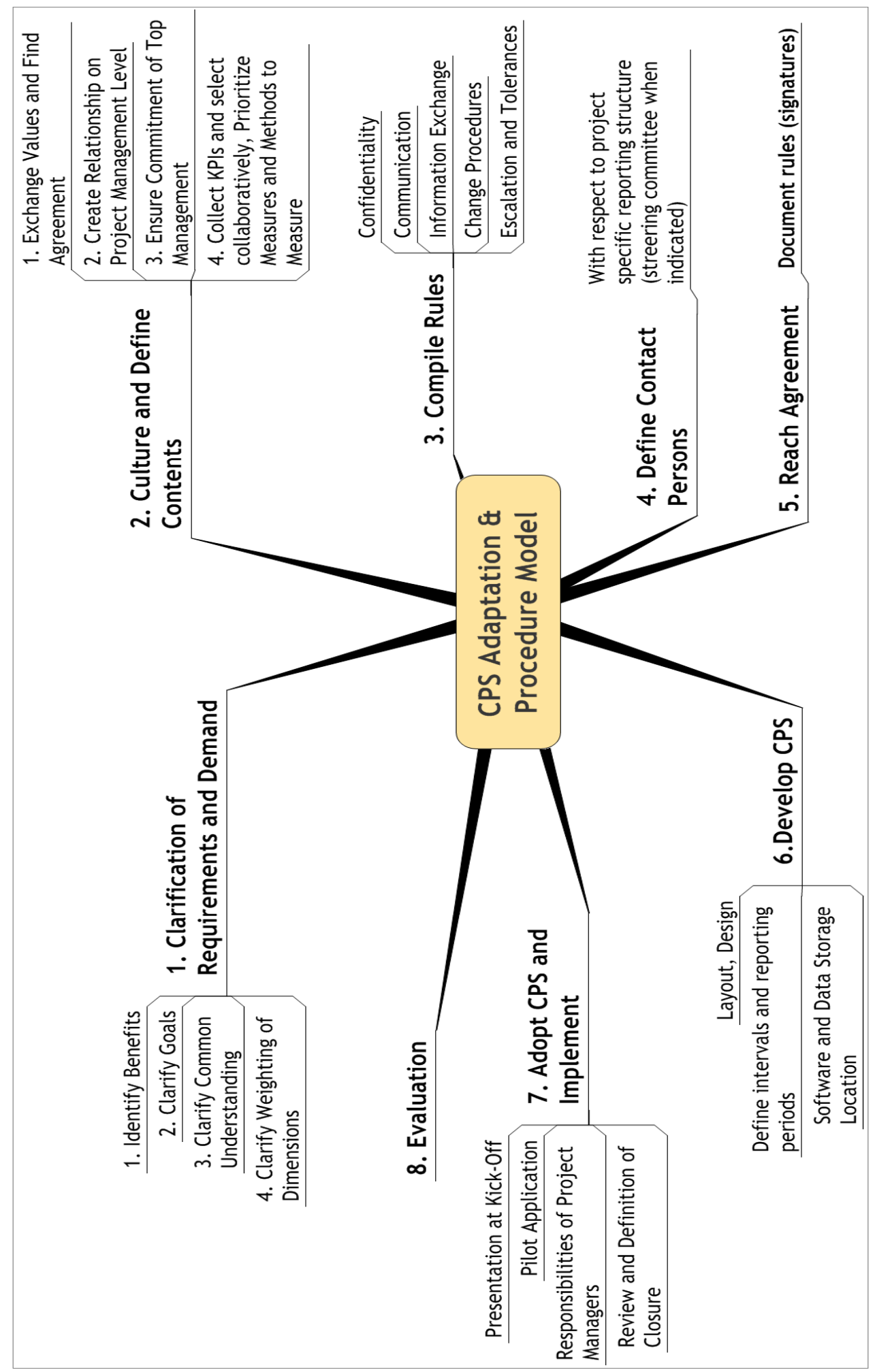

FIGURE 8.5: PROCEDURE MODEL TO ADAPT AND CHANGE A CPS

The procedure model begins with the clarification of the requirements and the demand of a CPS. This includes the identification of its benefits, the clarification of goals and a common understanding, as well as the emphasis of the CPS dimensions. The second step is the definition of its contents and culture. The exchange of values and their 
agreement is as important as the development of a common ground on the project manager level. Integrating the stakeholders and top management helps to achieve a sustainable commitment of all project stakeholders during the project. A collection of all relevant KPIs and measures needs to be followed by a collaborative selection and prioritization of indicators but also methods to measure them. The third step is the development of common rules and guidelines. Trust, communication, confidentiality, information exchange, procedures of change and escalation with respective tolerances dominate step three. The fourth step is the assignment of relevant contact persons and the definition of roles by taking into account the existing project specific reporting structures, usually defined by the steering committee. The fifth step is the documentation of those guidelines and the approval of commitment by signatures. When these five steps are completed, the development process of the CPS can begin. This is defined by the sixth step and includes the design of the CPS and its layout, the reporting intervals of the common KPIs, a selection of a possible software solution to implement the concept and the choice of an appropriate database and data storage location. Once this done, the CPS can be approved and implemented in a kick-off meeting. The workshop participants recommend an initial pilot project to gain more insight into the methodology first and to be able to train and coach successive projects. This is the seventh step and also includes necessary reviews and the definition of the responsibility the project managers have. The final step is the evaluation of the concept and a continuous improvement of the methodology by lessons learned, which can be done in special workshops.

\subsubsection{Introducing a CPS to an organisation}

The third work group discussed the success factors relevant to introduce a CPS to an organisation. A comprehension and understanding of the exigency is the most essential task before beginning an implementation according to the participants. The following guidelines were compiled:

- Avoidance of technical terms related to the BSC.

- Create a win-win situation.

- Frankness of both sides regarding processes, failures, etc.

- Clarification of terminology.

- Create comparability and reproducibility of goals and measures.

- Determine benefits compared to effort. 
The project partners should approach each other early before project start to discuss relevant goals and criteria to measure them. A common definition is essential to avoid discussions and time consuming misunderstanding during the project. It appears to be beneficial to use a neutral moderator who understands the methodology and the process when developing a CPS so that the project partners can focus on the CPS contents and achieve an agreement in a short time.

The requirements for a successful application of a CPS are comparable to those of a PSC. The support of top management is essential as the application of a PSC as a basis for the CPS is usually derived in a top down approach and, finally, top management has to approve the CPS. In addition to that, the CPS requires additional resources for its development and maintenance as well as the periodical adaptation. As the CPS is a fairly new concept of project monitoring and control the users need education and training that they understand the procedures. The introduction of a software solution may support the users during operation and may also ensure its sustainability within the controlling and reporting division. According to the participants, a few requirements for a successful application of a CPS need to be fulfilled: the identification of difficulties and problems in existing project collaboration (without the use of a CPS) as well as the common desire to achieve a continuous improvement. To motivate both sides, a win-win situation needs to be created that uncovers the advantages for all partners.

\subsubsection{Automotive industry surveys}

Between the first and second GPM e.V. Automotive Chapter workshops a survey was sent to all members of the chapter (about more than 500 members). The survey questionnaire can be found in Appendix $B$. The next sections present the results of the two automotive industry surveys as part of this research project.

\subsubsection{First automotive survey}

The survey aimed to broaden the understanding of a Project Scorecard first, and to identify the existing experience with scorecards and measure-based project management concepts. This was mainly to facilitate the preparation and to refine a second survey on the CPS based on the identified knowledge situation in the automotive industry. Some of the survey questions included: 
- The significance of project management in their organisation.

- How projects are controlled holistically.

- What project management standards are implemented.

- Experience and application of a BSC in their organisation.

- The application of a indicator based system for project management.

- Experience with a Project Scorecard.

- Strengths and weaknesses of a PSC.

- The derivation of a PSC from a BSC.

- Relevant measures for each perspective.

- Leading and lagging indicators.

- The benefits and limitation of an IT implementation.

- Benefits of a PSC compared to its effort.

- The possibility to integrate risk management.

- Interfaces to internal and external processes.

The response to the survey was low and the analysis of the responses would not have lead to scientific valuable results. After contacting some members and enquiring about the reasons for not providing feedback they stated the following reasons:

- As the PSC concept is fairly new most project managers had no previous experience with the Project Scorecard and not even with other types of scorecards.

- Many members had no knowledge about the Balanced Scorecard and indicator systems to manage an organisation; therefore they did not understand the application to project management sufficiently.

- They recommended giving an introduction of the concept first, preferably in a workshop, and then sending the survey again.

\subsubsection{Second automotive survey}

Learning from this experience, the second survey on the CPS was prepared taking the facts above into account. Only selected project managers were chosen who received a presentation about the CPS concept first, followed by a question and answer session on the telephone or in personal meetings. Next to a presentation that was sent to the 
participants, an additional introduction to the concept including examples based on previous experience was included in the survey.

The survey was available in German and English language and located online using the tool SurveyMonkey (www.surveymonkey.com) that is accessible with a standard internet browser. The survey started in October 2007 and was online until February 2008.

\subsubsection{Results of the second survey}

During that time 20 of the 30 chosen project members participated in the survey. The survey questionnaire can be found in Appendix B including the introduction. The most relevant questions with respect to the CPS concept were about:

- The application of a BSC in their organisation.

- Type of indicator system to control their organisation.

- Experience with PSC or project cockpit.

- KPIs to monitor and control project based BSC with respect to project phase.

- The proposed perspectives of the CPS.

- Indicators to measure collaboration and communication in a project partnership.

- Advantages of CPS IT implementation.

- CPS benefits compared to efforts.

- Significance of CPS for risk and quality management in projects.

- Indicators to monitor project risks and quality.

- General risks and opportunities with a CPS.

The questions were dominantly of qualitative nature and a summary of the introductory question results is shown in Table 8.1. The results are based on 20 participants from Germany (15), USA (2), Japan (2), and Australia (1) with an average experience of 10 years in project management (question 9). 


\begin{tabular}{|c|c|c|c|}
\hline No & Question & Choice & Answer (\%) \\
\hline \multirow[t]{2}{*}{1} & \multirow{2}{*}{ Language of participants } & German & $73 \%$ \\
\hline & & English & $27 \%$ \\
\hline \multirow[t]{2}{*}{2} & \multirow{2}{*}{$\begin{array}{c}\text { Number of employees in } \\
\text { organisation }\end{array}$} & Less than 500 & $25 \%$ \\
\hline & & More than 1000 & $75 \%$ \\
\hline \multirow[t]{2}{*}{3} & \multirow{2}{*}{$\begin{array}{l}\text { Size of organisation } \\
\text { (Mio Euro) }\end{array}$} & Less than 50 & $25 \%$ \\
\hline & & More than 250 & $75 \%$ \\
\hline \multirow[t]{3}{*}{4} & \multirow{3}{*}{ Type of organisation } & OEM & $50 \%$ \\
\hline & & Consulting Firm & $40 \%$ \\
\hline & & Supplier & $20 \%$ \\
\hline \multirow[t]{3}{*}{5} & \multirow{3}{*}{$\begin{array}{c}\text { Holistic Control of } \\
\text { Organisation }\end{array}$} & Multi Project Management & $71 \%$ \\
\hline & & Controlling Department & $10 \%$ \\
\hline & & Program Management & $57 \%$ \\
\hline \multirow[t]{4}{*}{6} & \multirow{4}{*}{$\begin{array}{c}\text { Application of a BSC in } \\
\text { Organisation }\end{array}$} & In whole organisation & $33 \%$ \\
\hline & & On business division level & $50 \%$ \\
\hline & & Project management level & $5 \%$ \\
\hline & & No BSC & $33 \%$ \\
\hline
\end{tabular}

TABLE 8.1: INTRODUCTORY QUESTION RESULTS (QUESTION 1-6)

Question 7 targeted the application of project management tools and indicator systems to control projects. $50 \%$ of the participants stated that they use MS Office and Excel for their project management control with individual solutions and indicator methods such as the traffic light definition (red/amber/green lights). The use of SEP gate reviews and a definition of synchronisation points for a certain project status such as defined by the specification document were stated by 25\%. In a rating from 1 (satisfied) to 5 (unsatisfied) the participants rated their satisfaction of the existing systems. The results are shown in Figure 8.6 (question 8). The information given in the following figures is given in the percentage of responses. That means, for example, $37 \%$ of the participants rated the satisfaction of existing project management tools with "2", where "1" means entirely satisfied, and " 5 " means not satisfied. The information is relevant to identify, whether new tools are required. 


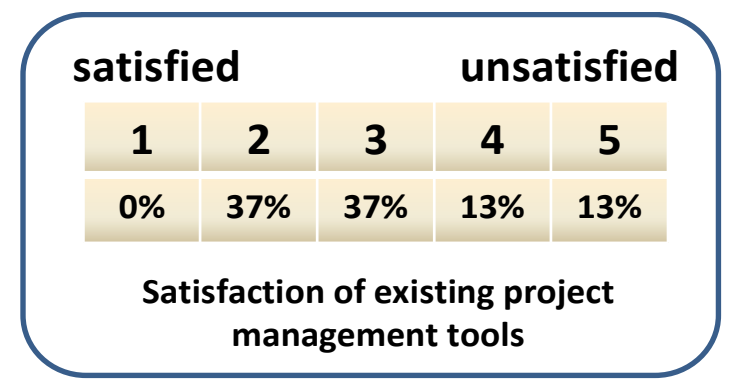

FIGURE 8.6: SATISFACTION OF EXISTING PROJECT MANAGEMENT TOOLS FOR INFORMATION EXCHANGE

The next questions had a focus on the CPS concept itself. An important aspect is the evaluation of a project partnership and collaboration maturity based on indicators (question 10). The following suggestions were made:

- Measure collaboration based on maturity of electronic data interchange (EDI) connection of electronic data exchange.

- Milestone adherence with respect to the achievement of common milestones to evaluate effectiveness and efficiency of collaboration.

- Degree of defined common processes (e.g., according to CMMI).

- Flexibility of possible process adaptations (e.g., building blocks can be shifted towards project partners without threatening the own process).

- Number of complaints.

- Goal accomplishment.

- Milestone compliance.

- Meeting frequency (appropriate attendance and involvement).

- Innovation.

- Premise stability (e.g., volumes, lead time, specified suppliers).

- Shared consequences.

Communication (question 11) may be measured by the definition of a corporate language KPI, honesty, proactivity, punctuality, information not withheld, official documentation, e-mail, phone, and one-to-one personal meetings. One aspect of communication is the reachability of a contact person. Proposed measures are the degree of participation in common meetings, and the time of responds to enquiries (question 12).

Advantages of a CPS software implementation were the increase of transparency and the controllability, the strategy communication of common achieved results, the creation 
of a common picture and that the comparability of previous or parallel projects is facilitated. Additionally, the effort to maintain the CPS decreases and the access to real time information is enhanced (question 13).

In a rating from 1 (very high) to 5 (very low) the advantages over effort of a CPS implementation and maintenance was rated at 2 from $100 \%$ of the participants (Figure 8.7 and question 14).

\begin{tabular}{|c|c|c|c|c|}
\hline \multicolumn{2}{|c|}{ very high } & \multicolumn{3}{c|}{ very low } \\
\hline 1 & 2 & 3 & 4 & 5 \\
\hline $0 \%$ & $100 \%$ & $0 \%$ & $0 \%$ & $0 \%$ \\
\hline Benefits of CPS compared to efforts \\
\hline
\end{tabular}

FIGURE 8.7: BENEFITS OF A CPS COMPARED TO ITS EFFORTS

In some interviews with project managers of OEMs and suppliers the issue of transparency was seen as a very critical aspect of a CPS. Some suppliers thought that they are already too transparent to their customers with respect to their existing processes, competitive advantages, or project status information. However, the impact of a CPS on project transparency was generally rated positive in the survey. Figure 8.8 shows the correspondent results.

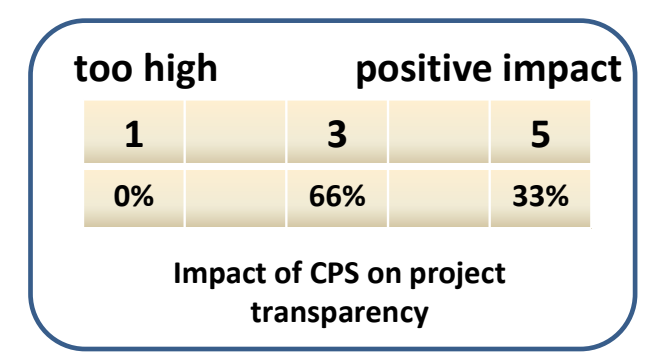

FIGURE 8.8: IMPACT OF CPS ON PROJECT TRANSPARENCY

The understanding of project goals, and especially common project goals, was rated to be improved by the application of a CPS. $100 \%$ of the project members rated the improvement of a better and clearer understanding of project objectives for project members and stakeholders by a CPS as "high" (rating ranged from "high improvement" to "no improvement"). With respect to an improved alignment of project objectives with business strategies and objectives the results are similar (Figure 8.9). 


\begin{tabular}{|c|c|c|c|c|}
\hline high & imp & ove & ent & no \\
\hline 1 & 2 & 3 & 4 & 5 \\
\hline $50 \%$ & $50 \%$ & $0 \%$ & $0 \%$ & $0 \%$ \\
\hline
\end{tabular}

FIGURE 8.9: IMPROVEMENT OF ALIGNMENT OF PROJECT WITH BUSINESS OBJECTIVES

The question (18) related to the capability of the CPS to monitor cross-company processes such as provided by the ProSTEP iViP CPM Reference Model (ProSTEP iViP, 2007a) was rated by $100 \%$ as "very suitable". Finally, recommendations on the risks, opportunities and threats that may occur with a CPS are summarised below:

- First try the concept and analysis the risks based on first experiences.

- Information may be withheld and hidden, it is the stakeholder's responsibility to reduce this risk.

- Strict compliance and adherence to predefined indicators may lead to a wrong representation of the project reality.

- Over-involvement of customer (inquisitive attitude).

- Conflicting CPS between OEMs or different car lines of same OEM.

- Conflicting CPS between different products of same car line.

The results of the GPM workshops and the surveys were discussed with project managers from different departments of a chosen supplier and OEM in the USA. The advantages and benefits of the CPS concept were promising enough to initiate a workshop to develop a CPS for a specific vehicle project. Chapter 9 describes the research activities in more detail. 


\section{The CPS for an automotive supplier and OEM}

The results from the GPM e.V. workshops, surveys, and interviews have contributed to the CPS methodology and were derived from theoretical assumptions, personal experience, and knowledge of the participating project managers. To apply the concept to an automotive project for evaluating the experience when developing a CPS with a project partner a supplier of the OEM in the USA was chosen. A supplier in Germany was already interested in the application of a PSC and later a CPS in a pilot project. One of its production plants in South Carolina is a major supplier for the OEM and also has a production facility in the same state.

This chapter includes the criteria for a project partner selection and describes the relevant steps of the CPS development. Team briefing and the choice of the project phases is followed by the identification of common strategies. Within the CPS workshop, the strategic collaborative project scorecard and the related strategy map was developed and then applied to the launch and change phase of the chosen project (Figure 9.1).

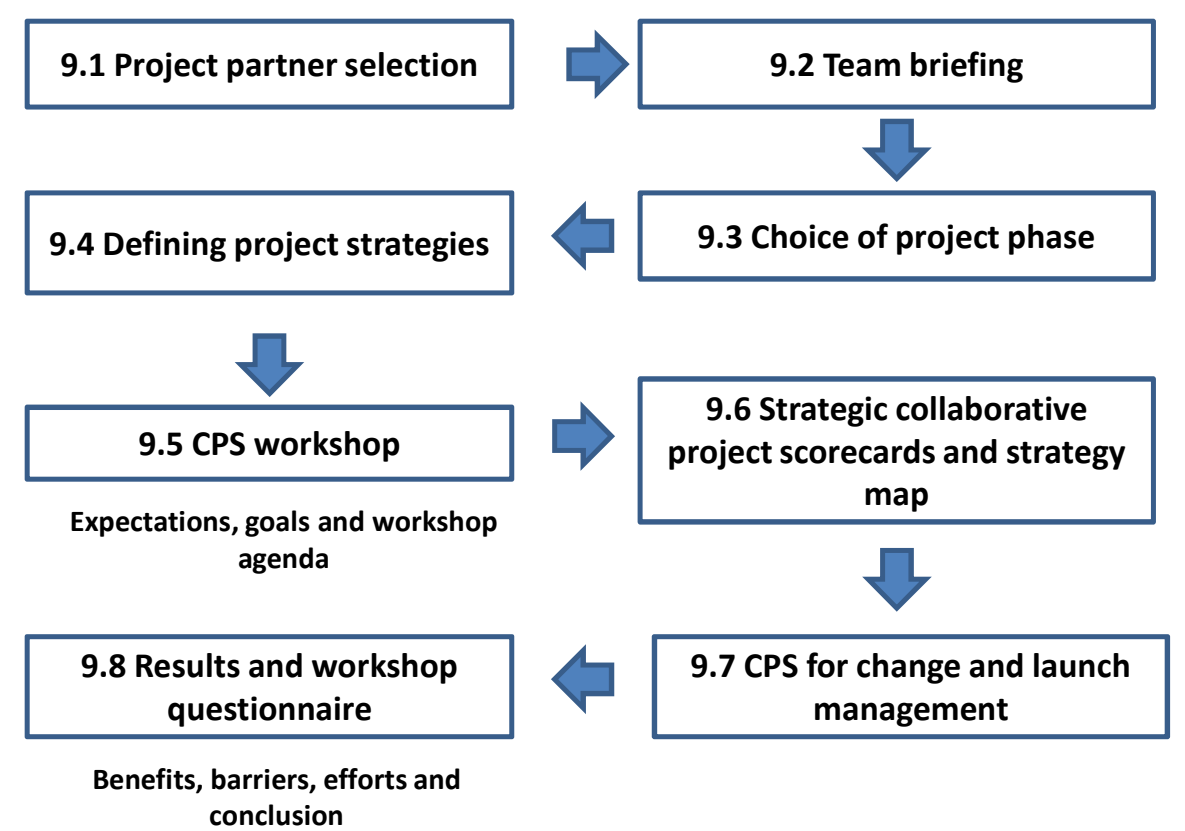

FIGURE 9.1: OVERVIEW OF CHAPTER 9

Finally, the results were analysed and evaluated in the last section of this chapter. The eight step approach of the research pilot project is shown in Figure 9.2. 


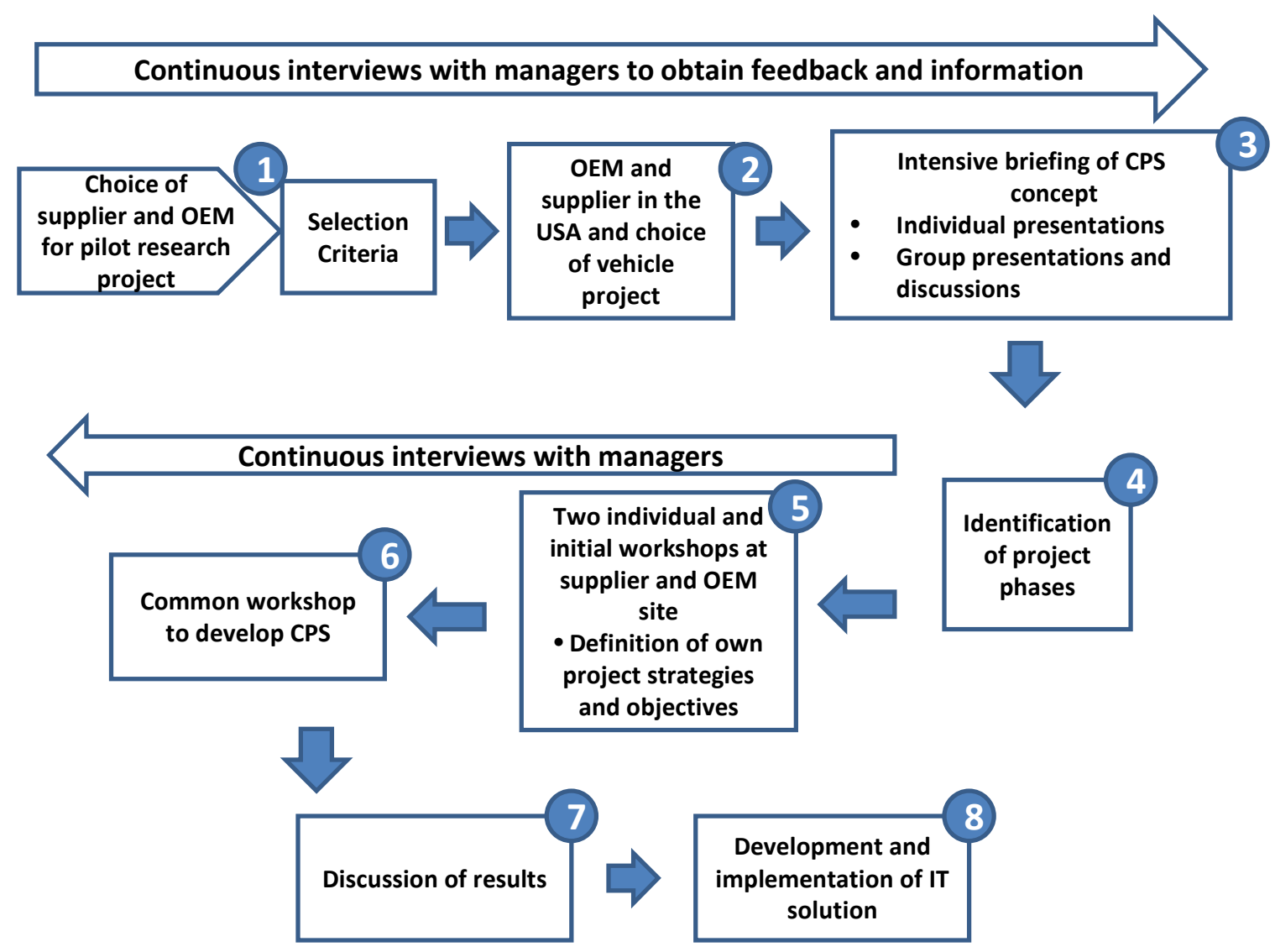

FIGURE 9.2: EIGHT STEP APPROACH OF THE RESEARCH PILOT PROJECT IN THE USA

The start of production (SOP) of a new series model was planned for 2010 and the supplier was nominated to deliver the wire harness for the model. Both project partners agreed on developing a CPS for this collaborative project in a first step and then decide upon its final application. Due to the limited time frame of this research the research project with the supplier had a focus on the development as part of the planning process of a CPS. Based on that, it was possible to use real project data and to evaluate whether the concept development is feasible for that type of project. As the launch phase of the project was planned for 2010 the evaluation during the CPS operation was out of the time line of this research project.

\subsection{Project partner selection criteria (step 1 to 2 )}

For a first application of the CPS the research project should be of a simple structure, therefore, it is limited to a one-to-one partner relation between an OEM and a supplier. The project goals were to gain experience with the CPS methodology, to identify potential areas of application and to identify benefits and limitations. For the choice of a project partner three main criteria were considered as important. Primarily, the supplier 
should be a major project partner of the OEM that delivers non-trivial parts of the vehicle. The supplier should deliver a critical module in a just-in-sequence (JIS) or justin-time (JIT) concept and it should deliver their products standardised and synchronised with the production line in the plant. Secondly, the partnership between the OEM and the supplier should be characterised by mutual trust. Mutual trust is the basis for frankness, which is important to discuss all relevant aspects of the CPS openly. Additionally, the partner should be proficient in his own processes. The criteria are shown in Figure 9.3.

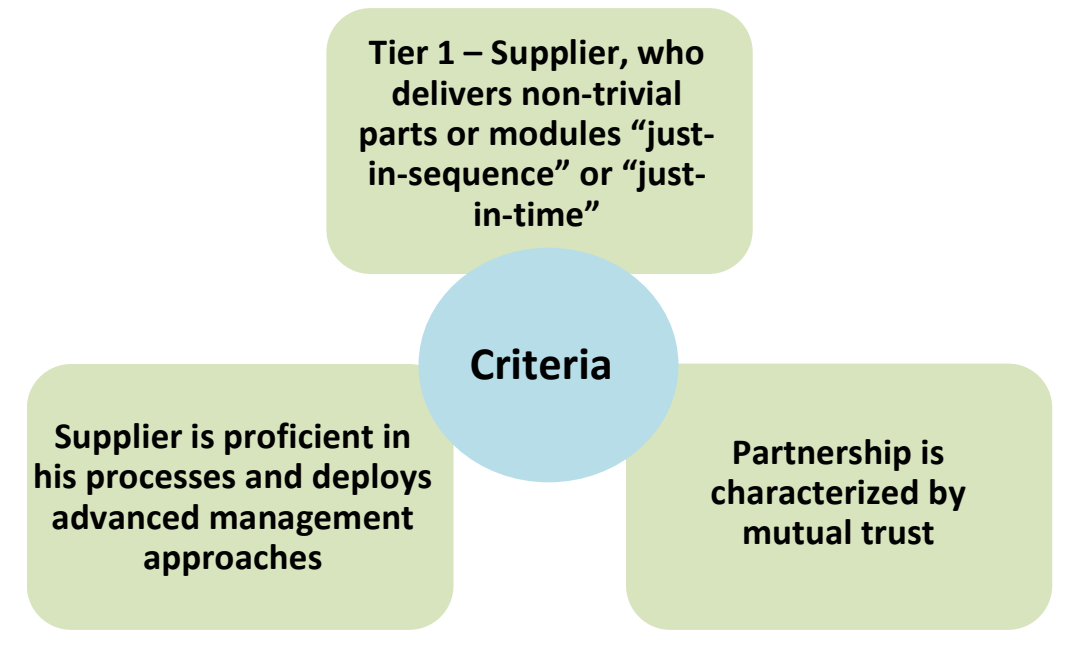

Figure 9.3: CRITERIA FOR A PROJECT PARTNER TO DEVELOP A CPS IN A PILOT PROJECT

These criteria apply to this first research project only as the concept can be transferred to the whole collaboration network of the OEM or supplier in a later step. It is important to gain experience with this methodology before critical partners get involved. This avoids some of the threats identified in the survey before, e.g. withholding of relevant project information. The fulfilment of the criteria mentioned above by the chosen supplier, their long tradition of trustful collaboration with the OEM, and their cooperation in previous similar research projects within the GPM as well as their willingness and enthusiasm to support this research project were an excellent starting position of the CPS development. The cooperation between the two companies can be characterised as a vertical, operative collaboration. The supplier is also a development partner of the OEM and areas of cooperation are, e.g., research and development or production. The supplier delivers high quality interior equipment and the main wire harness of two of the vehicles produced by the OEM in the US. 


\subsection{Briefing and discussing the CPS concept (step 3)}

Before the research pilot project was started, several meetings and interviews were organised to ensure that everyone understands the CPS concept and to find out to which degree the two project partners were willing to collaborate and accept the open and frank discussion in a workshop. Although, it was reckoned with resistance of both parties to exchange sensitive data, it was positive that both sides showed willingness to talk and exchange thoughts with their project partner. The long tradition of project collaboration, a similar business culture, and mutual respect for the partner's sustainable success in their business were preconditions that facilitated the project execution.

\subsection{Choice of project phase (step 4)}

The application of the CPS begins in the concept phase where the CPS itself is developed and it ends with the end of production of a vehicle. Therefore, the CPS is scalable and adaptable to all project phases but best results are expected when a CPS is applied continuously from project initiation (concept phase) until production (Figure 9.4).

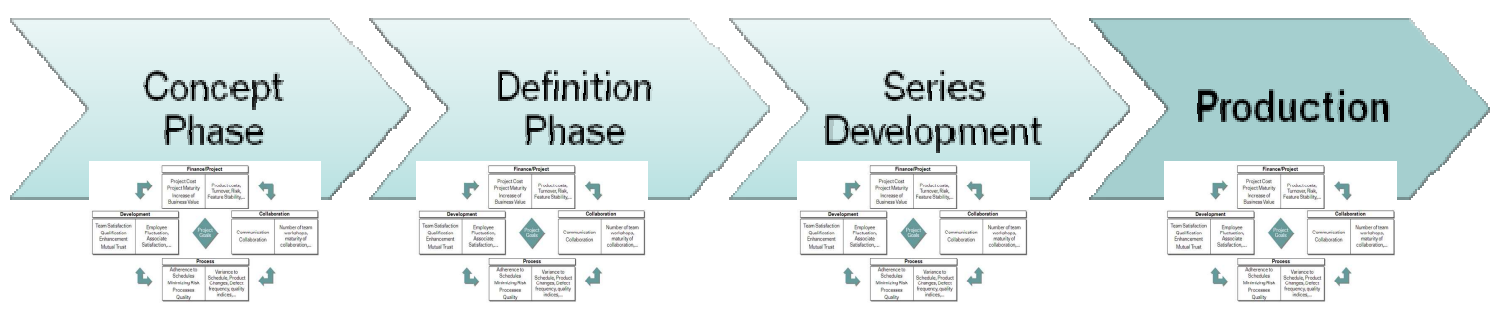

Figure 9.4: ApPLICATION OF A CPS to EACH PROJECT PHASE

The development of the CPS takes place in the concept and definition phase where project objectives and measure are defined for the subsequent phases. As objectives differ significantly from phase to phase it was important to focus on one or two phases only to limit the scope of the pilot research project. The series development of the wire harness was already in progress for the chosen vehicle project, therefore, the launch and production phase that includes a continuous change management were selected. Figure 9.5 shows the launch management phase that starts after the series development and before the SOP. During the production phase a continuous change management is required that can be monitored and controlled with a CPS. 


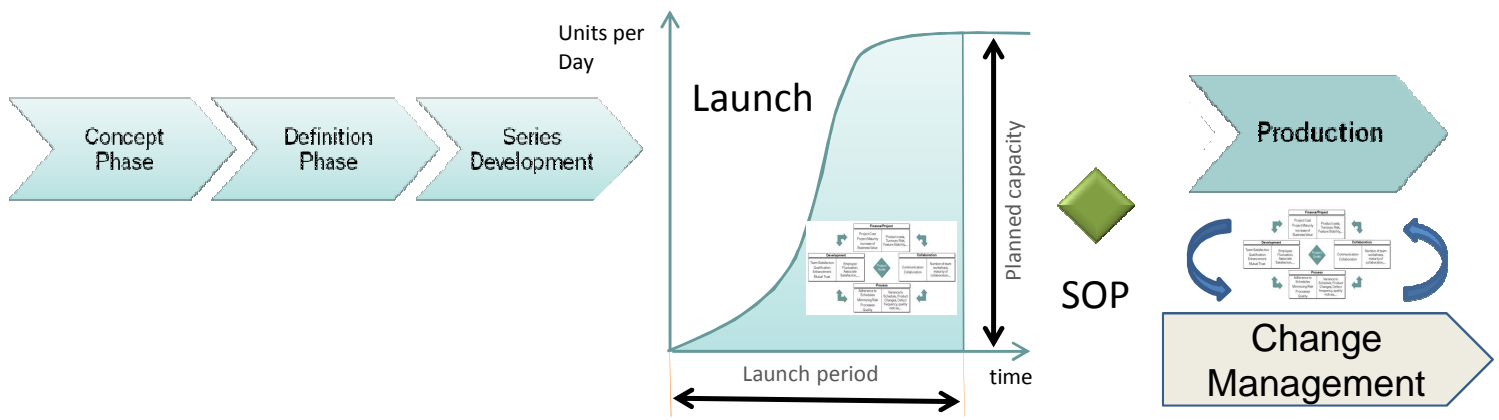

FIGURE 9.5: LAUNCH AND CHANGE MANAGEMENT PHASE

Considering the main logistic processes at the OEM plant in South Carolina, a close collaboration with all involved project partners is a critical success factor of a failure-free and uninterrupted production of a series vehicle. Especially, for the launch of a new car, the challenge of an efficiently coordinated project requires advanced management tools. All relevant data and processes have to be clarified and have to be made transparent on each side of the project partnership.

\subsubsection{Definition of launch phase}

During the launch phase the vehicles are built under series conditions. An important characteristic of this phase is the verification that all parts of the car can be produced, delivered, and assembled under the agreed conditions. The volume of parts in the determined quality delivered in the right time to the right place. A new product launch is especially critical if the following criteria of the planned production process features apply:

- New production plant, production facilities, tools, technologies, materials.

- New developments, complex units.

- New production location, production re-location.

- New processes, high-risk processes.

At the plant of the OEM the launch duration takes usually about three months. In this research project the attendees defined the launch period as the timeframe between the 
first activities in the OEM production plant until the SOP. Typical tasks of the operational launch management are concentrated on the launch phase and include the development of an open points list (LOP), list of missing parts, quality reports, and daily management meetings. Strategic launch management is not limited to the launch period only but it deals with all activities in the run-up to the launch, which are necessary to call attention on deficiencies of the product maturity and includes the monitoring of the milestones adherence in particular.

The expectations of the OEM towards its supplier are:

- To achieve process capability and guarantee for all characteristics that affect customer requirements.

- To furnish proof that the manufacturing process is able to produce the required numbers at the required quality level with the planned staffing and machine capacities.

- Proof that the process chain is able to achieve the required quality.

Before the research project was initiated several interviews with managers from the supplier and OEM addressed the identification of typical difficulties and challenges during the launch process. Some of them are:

- Demand for continuous reduction of the launch time and timely and efficient communication.

- Synchronisation of the start-ups of production all over the supply network.

- Scheduling variance and unpredictability for logistical planning.

- Quality variances and variance of planned and short-term demand.

- Availability of parts and change management.

- Insecure production processes.

\subsubsection{Change management phase}

The geometry of the wire harness requires a continuous change management during the whole product life cycle. Each relocation of a component and module in particular in a vehicle results in an adjustment of the harness design. Most of the changes and requirements are made at the main branch of the OEM and also of the supplier in 
Germany. The situation of a global information exchange and material flow demands for advanced communication management and collaboration strategies to provide constantly consistent and actual data. In previous projects, a simultaneous engineering team was formed that was composed of all required experts of both organisations.

Regarding previous projects professionals from the logistics, planning, and procurement department were interviewed to identify critical success factors of the product launch. The following recommendations were derived from lessons learned:

- Maintain the core team from the beginning until the end of one project.

- Multiple changes and undefined responsibilities had a negative impact on the performance of previous projects.

- Reduce fluctuation within the team members and name experts who remain responsible for the whole project duration.

- Define project handovers if responsibilities change and keep in close proximity with upper management.

- Define goals and measures with the supplier before project start and enforce an open and frank communication to enhance planning.

- A lack of transparency in critical situations and the complexity of influencing factors impede decision making.

- Simplify the project reporting and status monitoring: a new monitoring tool may not cause additional effort but should facilitate the project planning and reporting with an efficient workflow.

- Avoid cost intensive trouble-shooting in production and logistic processes by an anticipatory and sustainable planning.

- Develop a corporate culture for open communication: a timely and comprehensive information flow is often disrupted due to unclear authorization of cross-company information transfer.

- Affirm pro-active behaviour of the suppliers and ensure an understanding of common processes.

- Encourage pro-active communication to avoid errors and integrate the supply network partners in the planning process as early as possible.

- Assess agreements in periodical audits on site at suppliers' facilities. 


\subsection{Definition of own project strategies and objectives (step 5)}

In two individual workshops at the OEM and supplier's site, project strategies and objectives were discussed and documented in a Strategic Project Scorecard and later in a Project Scorecard. This helped the project teams to be prepared for a common workshop with their partner. Common objectives should then be derived from their own defined project objectives.

The workshops also helped to reflect upon the objectives the project partner may want to achieve and, therefore, reduced the risk that internal conflicts may arise on the day of the CPS workshop. Figure 9.6 shows the procedure described above.

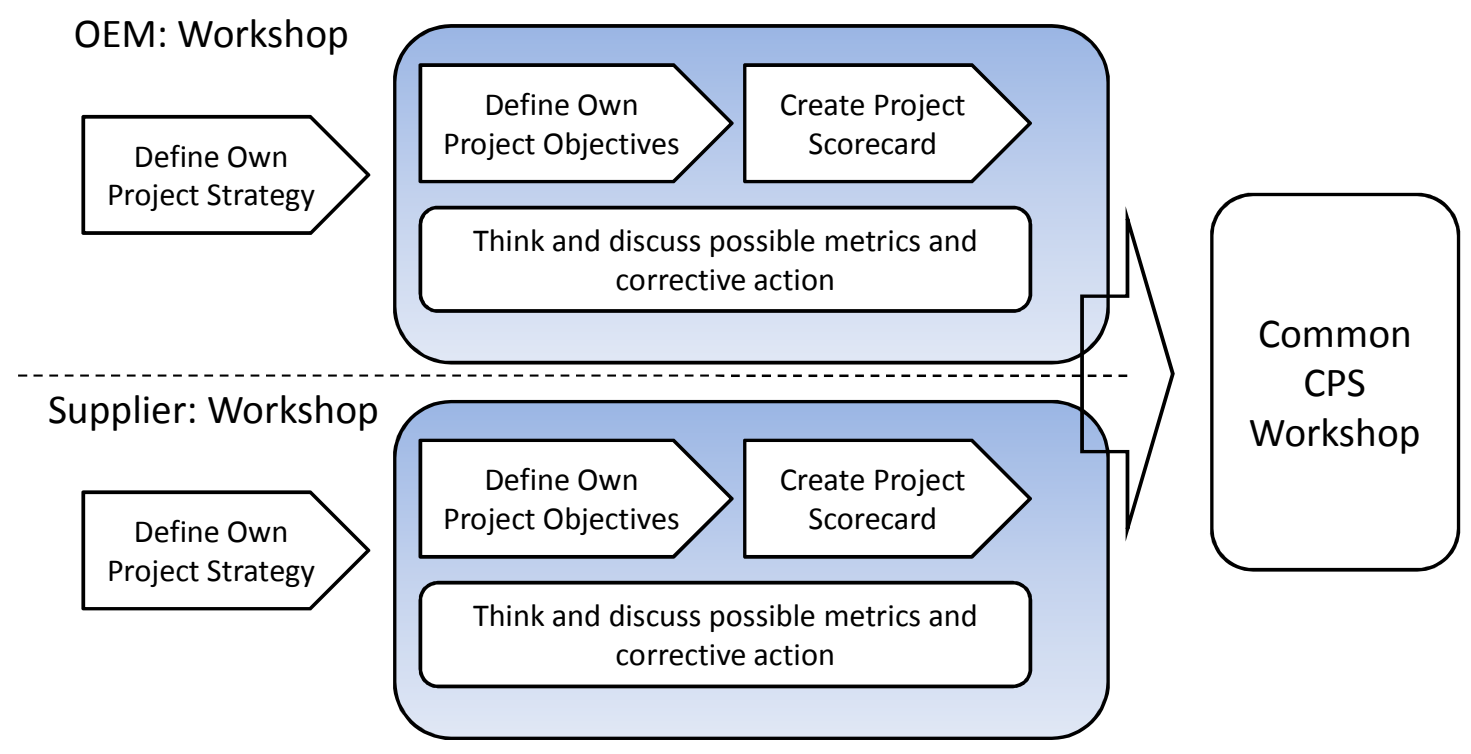

FIGURE 9.6: SUBSEQUENT INDIVIDUAL WORKSHOPS

Individual strategies of the OEM and supplier are confidentially, therefore, only an overview of the CPS evaluation based on the response of both partners is shown in Figure 9.7. The results are categorised using a SWOT analysis approach. 


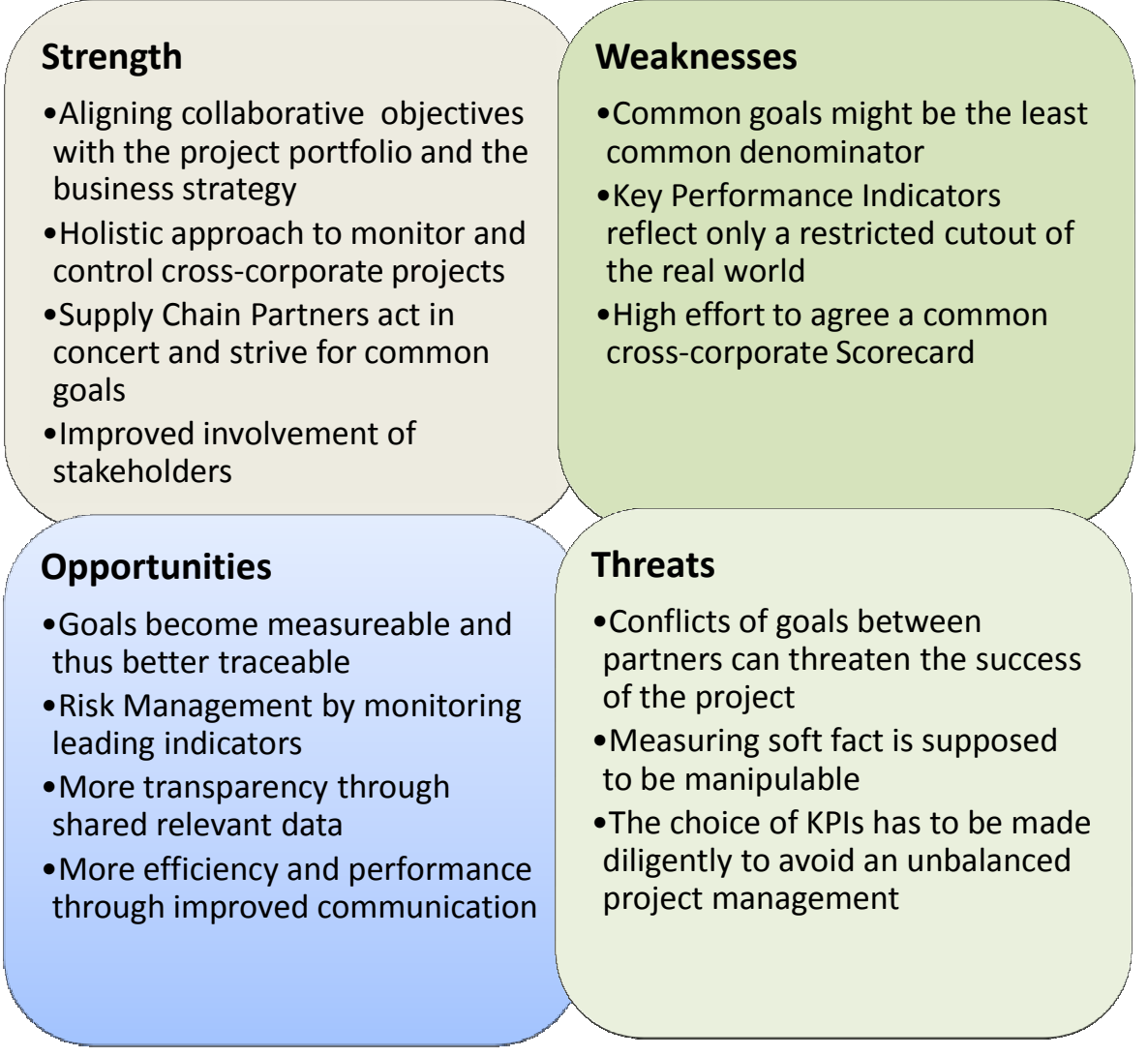

FIGURE 9.7: SWOT ANALYSIS RESULTS OF THE INDIVIDUAL WORKSHOPS

\subsection{The CPS workshop (step 6)}

After defining the individual project strategies and goals, the project partners agreed on a common CPS workshop to develop a Strategic Collaborative Scorecard, a Collaborative Project Strategy Map, and finally, to develop a CPS for the launch and change management phase together.

\subsubsection{Expectations, goals and agenda of CPS workshop}

The expectations on both sides of the OEM and supplier were to gain experience with the CPS concept and to develop a prototype that is capable to demonstrate its benefits but also limitations for a further decision whether the concept will be applied in 2010 . The developed CPS should then serve as a basis for a successive IT implementation. 
Goals of the CPS workshop were:

- Realistic draft of a Strategic Collaboration Scorecard (SCS) between the OEM and supplier.

- Two Collaborative Project Scorecards for the launch and change management of the wire harness.

- Summary of benefits, advantages, limitations, and barriers of the methodology.

It was essential that all participants were prepared with respect to an understanding of their own processes, weaknesses, and critical success factors. The CPS workshop took place on $11^{\text {th }}$ March 2008 with 15 members ( 9 associates from the OEM and 6 from the supplier). It started with an introduction and presentation of the previous results and the workshop agenda. This was followed by the development of a SCS by all participants.

The SCS was the basis to develop the project phase specific CPS and was created by two individual groups that were comprised of a balanced distribution of associates with respect to their management tasks. A detailed agenda of the workshop can be found in Appendix C.

The representatives of both organisations originated from the departments of procurement, sales, quality, logistics, and management. The positions of the associates were from the functions of management (42\%), project management $(25 \%)$, and indirect functions (33\%). The ratio between employees of the OEM and the supplier was 7:6 as two participants were part of the CPS research team. The average number of years of experience was 5.4 years in project management. In a first step the Strategic Collaborative Scorecard and Collaborative Strategy Map was created on the basis of the Balanced Scorecards of the OEM and the supplier as well as the project experience of the participants (Figure 9.8). 

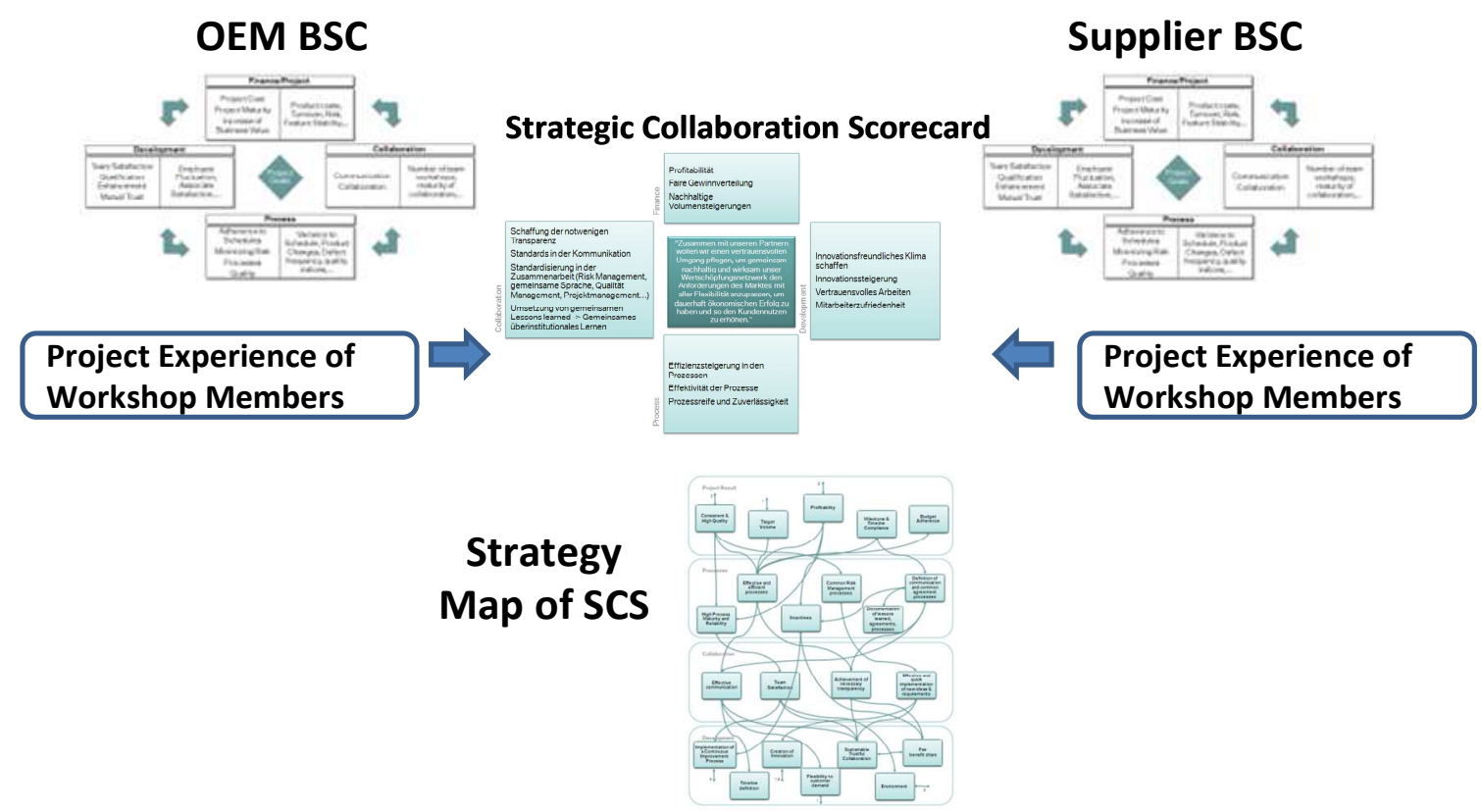

Figure 9.8: DEVELOPMENT OF A SCS AND STRATEGY MAP

The previous step of creating a Strategic Partnership Scorecard as described in Chapter 7 was skipped as the time of the workshop was limited. Therefore, the vision of the Balanced Scorecards of both organisations were taken to create the vision of the SCS. The objectives and strategies of the SCS derived from the project experience of the workshop members.

In the next step, the participants were grouped into two work groups to develop a CPS for the launch and change management phase. After one hour, the launch management group changed to the change management and vice versa. The moderator presented the current results to the new group and in the following hour the CPS was further developed. Figure 9.9 shows the complete procedure of the workshop. 


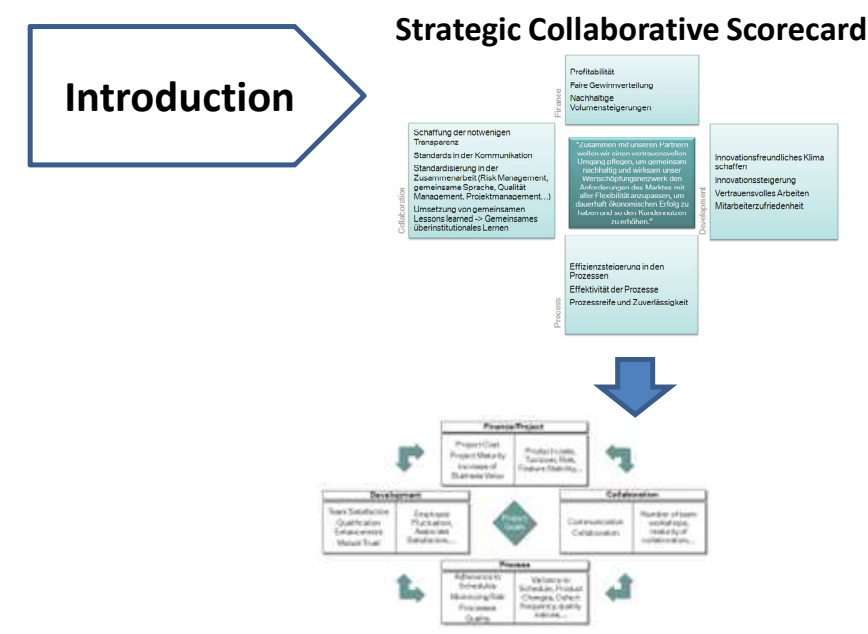

Group A (1h):
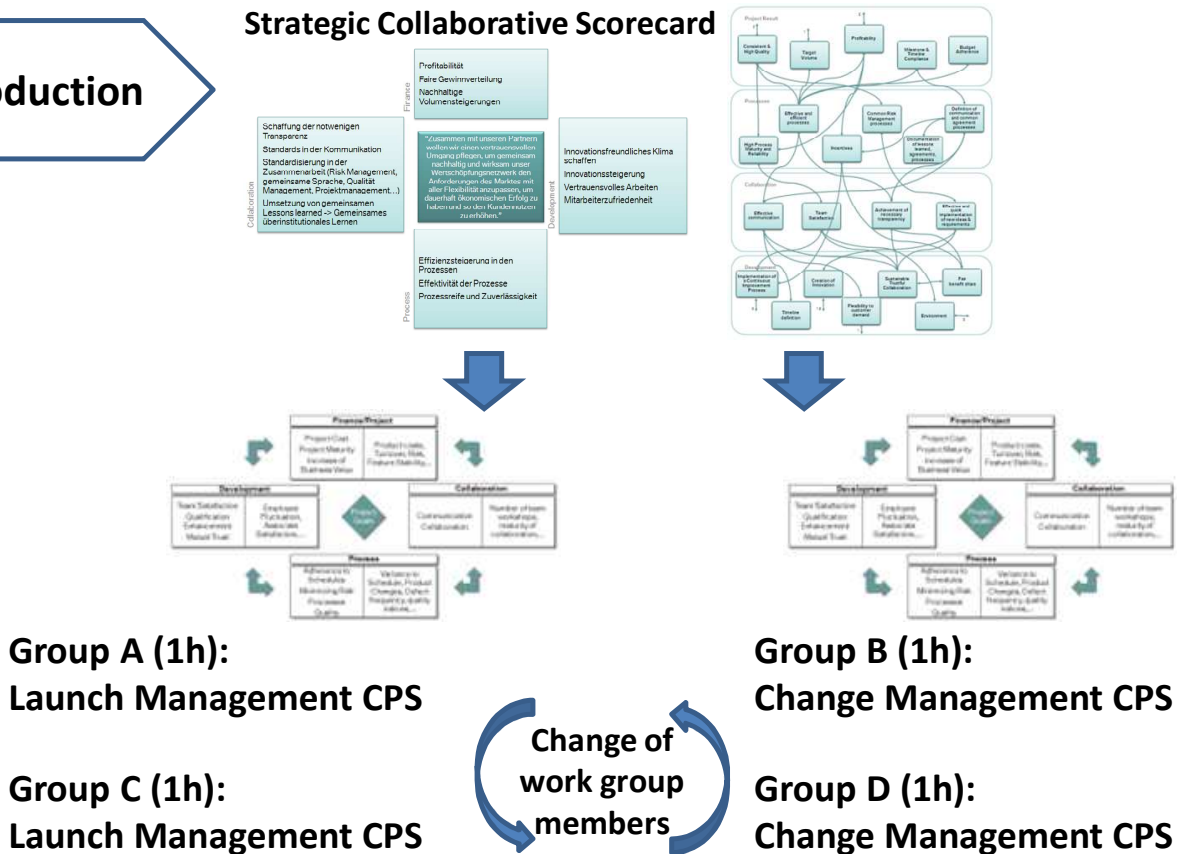

Group B (1h):

Change Management CPS

Group D (1h):

Change Management CPS
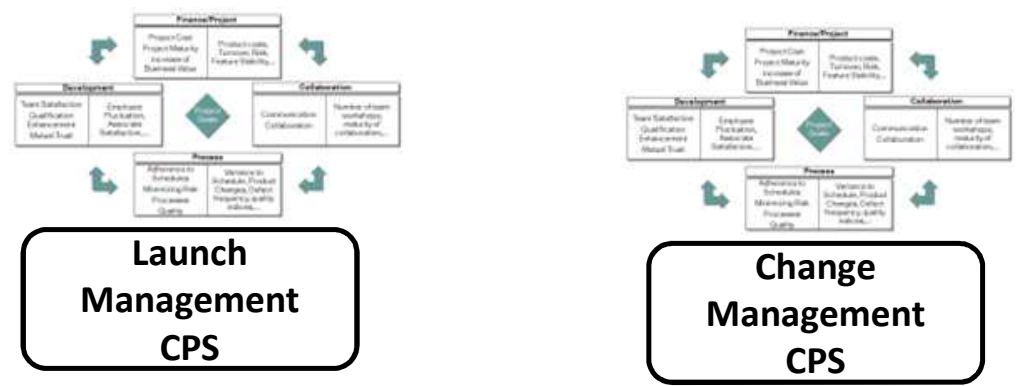

FIGURE 9.9: PROCEDURE OF THE CPS WORKSHOP

\subsection{The Strategic Collaborative Project Scorecard and Collaborative Strategy Map}

The representatives of both companies came to the workshop with an understanding of their own company strategy and with their particular collaboration tactic in mind. Given the strategies of both companies, it was possible to identify similar principles and a collaborative vision. The vision was defined as shown in Figure 9.10. 


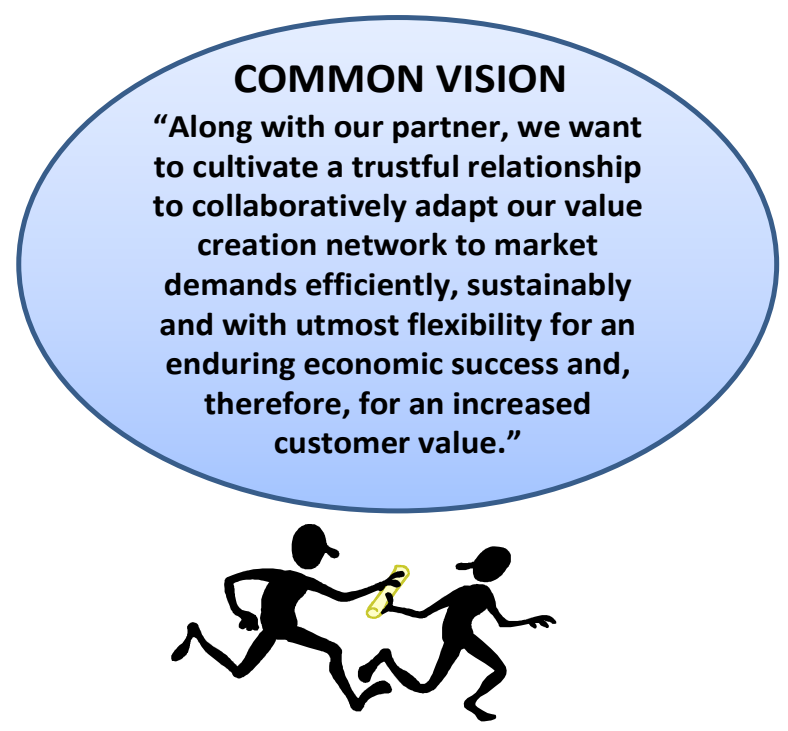

FIGURE 9.10: COMMON VISION OF THE PROJECT PARTNERSHIP

The vision represents the strategic core of the project partnership and all project objectives should address the core. Based on this vision the typical goals in a collaborative project were commonly identified and categorised according to the SCS structure and perspectives (Figure 9.11).

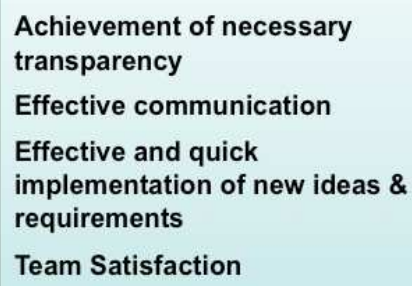

\section{Profitability \\ Consistent \& High Quality \\ Milestone \& Timeline \\ Compliance \\ Achievement of target volume \\ Budget Adherence}

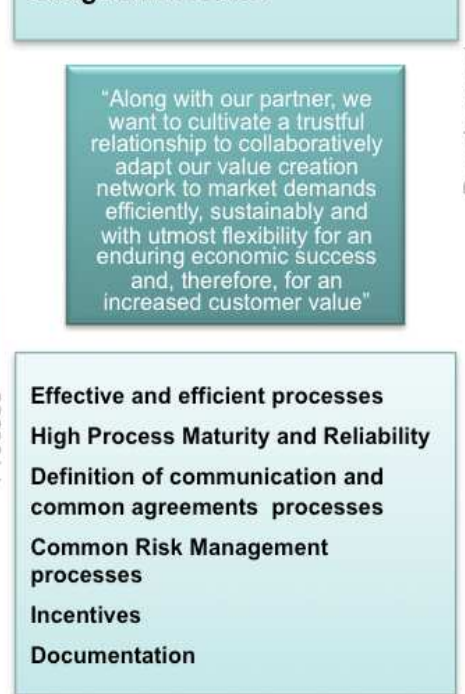

Creation of Innovation

Sustainable Trustful

Collaboration

Flexibility to customer demand

Fair benefit share

Implementation of a

Continuous Improvement

Process

Environment

Timeline Definition

Figure 9.11: The Strategic Collaborative Scorecard 
To facilitate the discussion and the agreement process, and to increase the transparency of the interdependencies of the defined objectives, the project goals were tagged on a plain whiteboard and structured according to the Strategy Map concept. As a first result, the Strategic Collaboration Scorecard and the related Strategy Map were created. The Collaborative Project Strategy Map is shown in Figure 9.12.

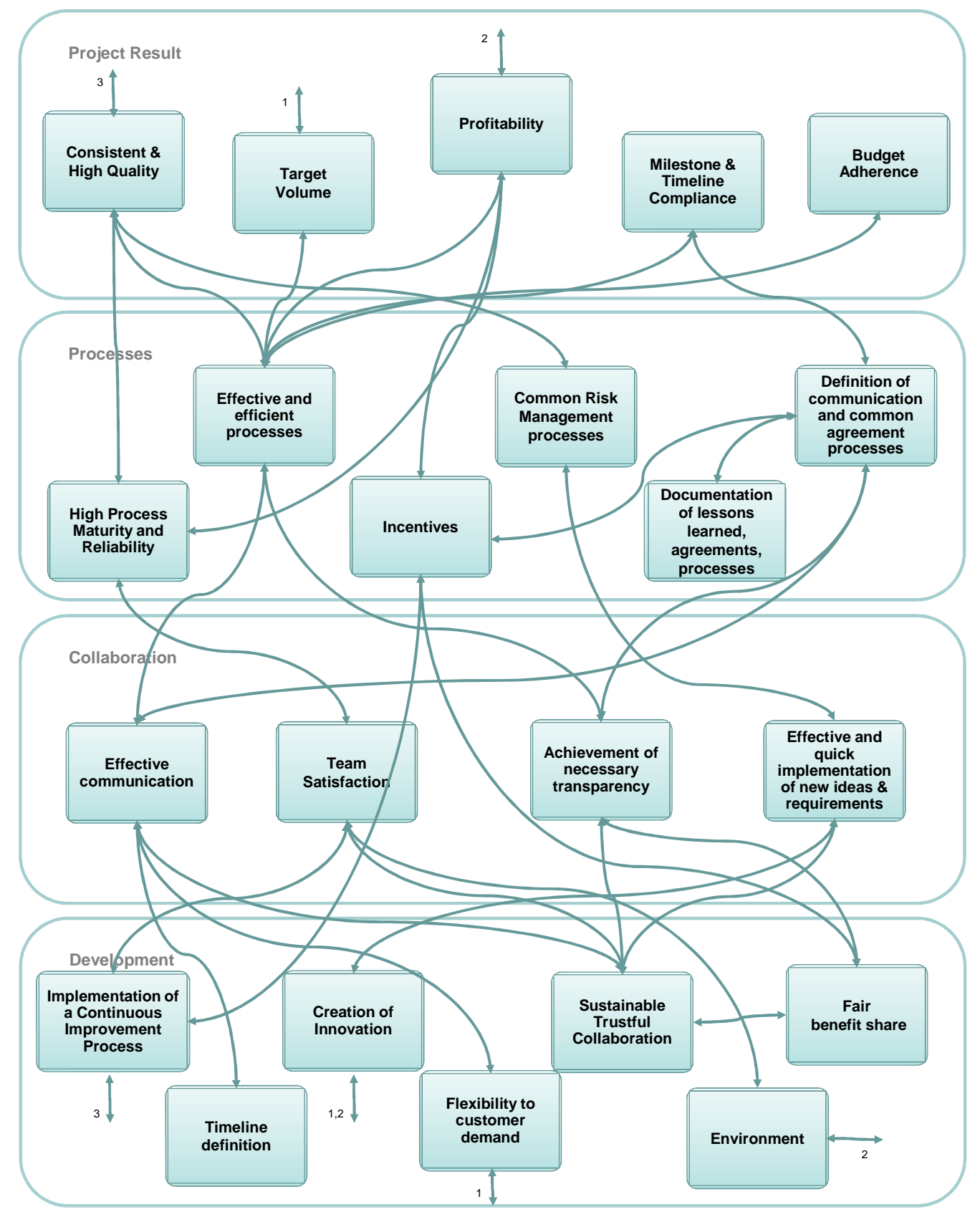

Figure 9.12: Strategy MaP of the Strategic Collaborative Scorecard

The original picture of the Collaborative Project Strategy Map can be found in Appendix C. This was done after the workshop in consolidation with the team. Typically, 
the project team would start with an initial strategy map, and refine the strategy map by applying the project impact matrix analysis in a second step.

\subsection{The CPS for change and launch management}

After a short break the defined objectives were applied to the launch and change management phase of the project. Two groups were formed and they discussed how the objectives are related to change and launch management. To create the project specific collaborative scorecards, the procedure described in Chapter 7 was applied. Metrics, KPIs, and measures on discrepancies were identified and written on whiteboards with respect to their category (Figure 9.13).

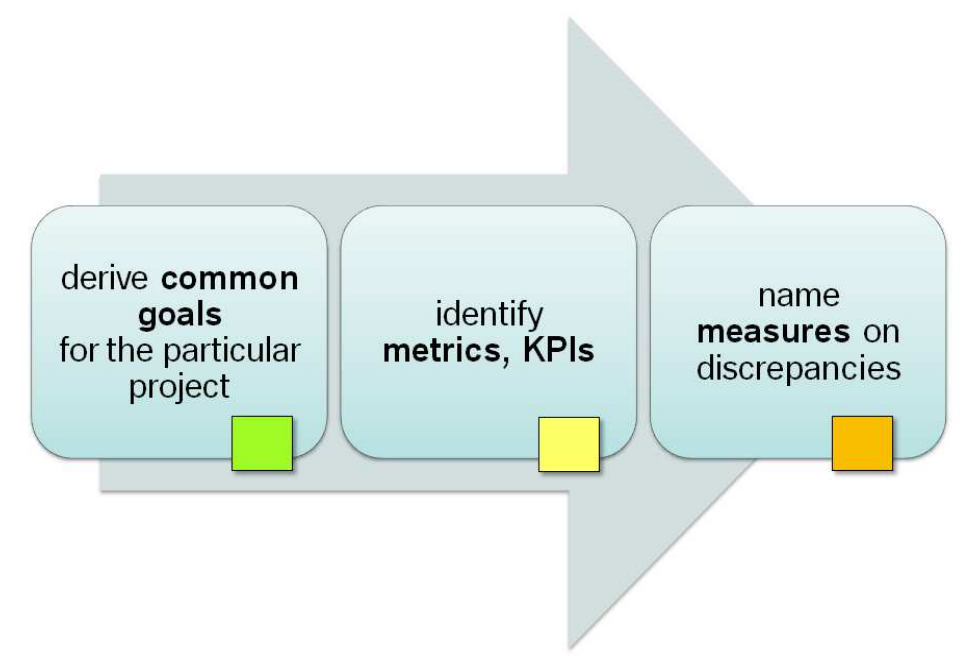

Figure 9.13: Procedure to deVelop a CPS

Due to the limited time of the workshop not all relevant objectives could be identified. Additionally, not for every objective a measure and corrective action was found. Therefore, the developed CPSs are considered as drafts for a further development and another workshop once the application of a CPS for the project in 2010 is decided. The results of the launch management CPS are shown in Table 9.1 to Table 9.4. 


\begin{tabular}{|c|c|c|}
\hline \multicolumn{3}{|l|}{ Project Results } \\
\hline Objectives & Metrics & Corrective Action \\
\hline cost Avoidance & total cost per unit per phase & analysis of the root costs \\
\hline$<$ budget target & Budget reports & \\
\hline $\begin{array}{l}\text { budget adherence tracking } \\
\text { per launch phase }\end{array}$ & $\begin{array}{l}\text { budget delta (part price, logistic } \\
\text { costs, dev. costs, tooling costs) }\end{array}$ & \\
\hline series revenue & PPMs, Customer Satisfaction & $\begin{array}{l}\text { no revenue profitability - } \\
\text { alternative processes }\end{array}$ \\
\hline meet target volume on time & number of late cars / total cars & $\begin{array}{c}\text { fish bone analysis } \\
\text { escalation rules }\end{array}$ \\
\hline \multirow[t]{3}{*}{ high parts quality } & ppm & \multirow{3}{*}{$\begin{array}{c}\text { quality escalation process } \\
\text { Checkpoints (Quality) }\end{array}$} \\
\hline & complain reports & \\
\hline & warranty & \\
\hline
\end{tabular}

TABLE 9.1: PROJECT RESULTS LAUNCH MANAGEMENT CPS

\begin{tabular}{|c|c|c|}
\hline \multicolumn{3}{|l|}{ Collaborative Processes } \\
\hline Objectives & Metrics & Corrective Action \\
\hline $\begin{array}{l}\text { SE team for information } \\
\text { sharing }\end{array}$ & $\begin{array}{l}\text { start-up reporting; actual vs. } \\
\text { planned against milestone }\end{array}$ & checklist \\
\hline $\begin{array}{l}\text { technical date at current } \\
\text { level for launch process }\end{array}$ & ETA & \\
\hline part availability by milestone & part availability for project phase & \\
\hline \multirow{3}{*}{$\begin{array}{l}\text { transparency of processes } \\
\text { and interfaces }\end{array}$} & \multirow[t]{3}{*}{ surveys (regular basis) } & responsibility matrix \\
\hline & & process documentation \\
\hline & & workshops \\
\hline \multirow{2}{*}{$\begin{array}{l}\text { clear premises at project } \\
\text { start }\end{array}$} & \multirow{2}{*}{$\begin{array}{l}\text { frequency of changes in } \\
\text { premises }\end{array}$} & revision tracking \\
\hline & & GAMS \\
\hline $\begin{array}{l}\text { effective and efficient } \\
\text { common processes }\end{array}$ & adherence to defined landscape & $\begin{array}{l}\text { regular review of processes/ } \\
\text { effectiveness }\end{array}$ \\
\hline \multirow{2}{*}{$\begin{array}{l}\text { mutual common risk } \\
\text { evaluation process }\end{array}$} & checklists & regular reviews \\
\hline & timeline & \\
\hline
\end{tabular}

TABle 9.2 Processes launch management CPS 


\begin{tabular}{|c|c|c|}
\hline \multicolumn{3}{|l|}{ Collaboration } \\
\hline Objectives & Metrics & Corrective Action \\
\hline $\begin{array}{l}\text { integration of demand } \\
\text { schedules into SE Team } \\
\text { meetings }\end{array}$ & $\begin{array}{l}\text { weekly confirmation of latest } \\
\text { demands }\end{array}$ & $\begin{array}{l}\text { inclusion in SE Team Meeting } \\
\text { Minutes }\end{array}$ \\
\hline efficient communication & percentage attendance & escalation process \\
\hline fast problem resolution & number of overdue open points & \\
\hline team satisfaction & regular feedback/ surveys & \\
\hline $\begin{array}{l}\text { involvement in pilot } \\
\text { production (transparency) }\end{array}$ & checklist & $\begin{array}{l}\text { travel to pilot location/ } \\
\text { hands-on }\end{array}$ \\
\hline
\end{tabular}

TABLE 9.3: ColLABORATION LAUNCH MANAGEMENT CPS

\begin{tabular}{|c|c|c|}
\hline \multicolumn{3}{|l|}{ Learning \& Development } \\
\hline Objectives & Metrics & Corrective Action \\
\hline trustful collaboration & quarterly survey & escalation team workshop \\
\hline $\begin{array}{l}\text { technical releases complete } \\
\text { before build phase }\end{array}$ & number of releases by deadline & \\
\hline \multicolumn{3}{|l|}{$\begin{array}{l}100 \% \text { virtual development } \\
\text { prior to plant activities }\end{array}$} \\
\hline $\begin{array}{l}\text { synchronisation timeline } \\
\text { (incl. supplier) }\end{array}$ & latest synchronisation run & $\begin{array}{l}\text { incentive plan, percentage of } \\
\text { savings }\end{array}$ \\
\hline \multirow[t]{2}{*}{ creation of innovation } & $\begin{array}{l}\text { number of new ideas/ } \\
\text { suggestions implemented }\end{array}$ & $\begin{array}{l}\text { installation of a suggestion } \\
\text { box }\end{array}$ \\
\hline & savings/ improvement benefits & incentive program \\
\hline
\end{tabular}

TABLE 9.4: LEARNING AND DEVELOPMENT LAUNCH MANAGEMENT CPS

The results of the CPS change management are presented in the following four tables. Table 9.5 represents the results for the project result perspective followed by Table 9.6 (Collaborative Processes), Table 9.7 (Collaboration), and Table 9.8 (Learning and Development). 


\begin{tabular}{|c|c|c|}
\hline \multicolumn{3}{|l|}{ Project Results } \\
\hline Objectives & Metrics & Corrective Action \\
\hline profitability & $\begin{array}{l}\text { quantity of technical changes per } \\
\text { time period }\end{array}$ & prioritise \\
\hline budget adherence & $\begin{array}{l}\text { budget: } \\
\text { development costs, logistics } \\
\text { costs, part price, scrap, rework }\end{array}$ & monitor business plan \\
\hline timeline compliance & time to implementation & $\begin{array}{l}\text { "business plan" for technical } \\
\text { changes }\end{array}$ \\
\hline no obsolete material & costs for obsolete material & \\
\hline high quality & $\begin{array}{l}\text { low warranty cost or customer } \\
\text { complaints } \\
\text { defect limits }\end{array}$ & $\begin{array}{l}\text { low ppm, low 0-km defects } \\
\text { quality approval before } \\
\text { implementation }\end{array}$ \\
\hline no rework & rework costs & \\
\hline
\end{tabular}

TABLE 9.5: PROJeCt RESULTS CHANGE MANAGEMENT CPS

\begin{tabular}{|c|c|c|}
\hline \multicolumn{3}{|l|}{ Processes } \\
\hline Objectives & Metrics & Corrective Action \\
\hline $\begin{array}{l}\text { all changes documented and } \\
\text { validated }\end{array}$ & $\begin{array}{l}\text { no of changes, no of changes } \\
\text { validated }\end{array}$ & \\
\hline process efficiency & $\begin{array}{l}\text { response time (less than } 10 \\
\text { days), priority index }\end{array}$ & clear definition of processes \\
\hline $\begin{array}{l}\text { low risk due to optimal risk } \\
\text { management }\end{array}$ & $\begin{array}{l}\text { business plan process - impact } \\
\text { on risk assessment }\end{array}$ & core SE-team \\
\hline \multicolumn{3}{|l|}{$\begin{array}{l}\text { establish and maintain } \\
\text { change management team }\end{array}$} \\
\hline communication efficiency & $\begin{array}{l}\text { meet one time per week, } \\
\text { meeting minutes } \\
\text { attendance statistics }\end{array}$ & meeting frequency, LSV \\
\hline $\begin{array}{l}\text { lessons learned meeting } \\
\text { before every phase }\end{array}$ & no of lessons learned meetings & \\
\hline incentives & partnership - supplier rating & audit (e.g. LOG) \\
\hline
\end{tabular}

TABLE 9.6: Processes CHANGE MANAGEMENT CPS 


\begin{tabular}{|c|c|c|}
\hline \multicolumn{3}{|l|}{ Collaboration } \\
\hline Objectives & Metrics & Corrective Action \\
\hline transparency & team feedback & $\begin{array}{l}\text { process flow, clear roles and } \\
\text { responsibilities }\end{array}$ \\
\hline team satisfaction & $\begin{array}{l}\text { fluctuation of project team } \\
\text { members } \\
\text { survey }\end{array}$ & $\begin{array}{l}\text { regular workshops } \\
\text { contact list }\end{array}$ \\
\hline on-time delivery $100 \%$ & $\begin{array}{l}\text { missed shipment, expedite and } \\
\text { PFA costs }\end{array}$ & \\
\hline definition of expectations & $\begin{array}{l}\text { response time (less than } 10 \\
\text { days) }\end{array}$ & \\
\hline no escalations & no of escalations & audit \\
\hline
\end{tabular}

TABLE 9.7: ColLABORATION CHANGE MANAGEMENT CPS

\begin{tabular}{|c|c|c|}
\hline \multicolumn{3}{|c|}{ Learning \& Development } \\
\hline Objectives & Metrics & Corrective Action \\
\hline $\begin{array}{l}\text { new ideas (product and } \\
\text { process) }\end{array}$ & $\begin{array}{l}\text { no of new ideas implemented } \\
\text { savings, and cost avoidance }\end{array}$ & $\begin{array}{l}\text { innovation workshop (regular } \\
\text { basis) }\end{array}$ \\
\hline $\begin{array}{l}\text { sustainable trusting } \\
\text { collaboration }\end{array}$ & feedback survey & regular review KPIs \\
\hline time line definition & adherence to project timing plan & $\begin{array}{l}\text { compare project developmen } \\
\text { and timing plan }\end{array}$ \\
\hline $\begin{array}{l}\text { flexibility to customer } \\
\text { demand }\end{array}$ & KOVP Adherence & \\
\hline fair benefit share & number of QUAKO ideas & GAMS, QUAKO \\
\hline
\end{tabular}

TABLE 9.8: LEARNING AND DEVELOPMENT CHANGE MANAGEMENT CPS

The findings of the second session of the workshop are based on brainstorming and previous experience of the participating associates and make no claim to be entirely complete. Additionally, the target values and corridors could not be disclosed due to confidentiality reasons. 


\subsection{Discussion of results and workshop questionnaire (step 7)}

The final session of the workshop was a discussion about the results and the consequences for the CPS concept. Benefits, advantages, limitations and barriers were identified and summarised. A questionnaire was handed out and completed before the workshop ended. The questionnaire can be found in Appendix C. Question 4 addressed the evaluation of the CPS impact on collaboration. The scale ranged from "too much overhead work" (1) to "effective impact" (5). The overall average rating was 4.25. Thus, the feedback was generally positive. The following aspects in the next section summarise the statements of the attendants (question 5). The statements were divided into two categories: "benefits" and "barriers and efforts" of the CPS concept.

\subsubsection{Benefits of the CPS concept}

Benefits identified during the research pilot project were:

- Reinforces the needs and expectations of both companies.

- Opens up opportunities for collaboration improvements.

- Alignment of the whole team to the agreed common goals.

- Communication between supplier and OEM improved with workshops like this.

- Good exercise to meet and discuss goals and measures directly with supplier.

- It is beneficial that all are together in a workshop to talk about common goals.

- Approach helps to coordinate and the synchronisation of the daily business of both companies.

- The implementation and use of a tool could lead to more transparency, e.g., by monitoring premises.

- KPIs could be a driver for the core team.

- Improved planning, and the clarification of dependencies between goals facilitates the identification of cost lead factors. That holds team members accountable to their cost targets.

- The scorecard approach brings everybody into an overall picture.

- Defining common goals could avoid mistakes and unnecessary tasks. 
- Review of the scorecard once a year: framework discussion makes it transparent to upper management.

\subsubsection{Barriers and efforts of the CPS concept}

The following is a list of barriers and efforts necessary to develop, implement, and maintain the CPS.

- Concerns about integration into existing reporting systems: is the CPS user friendly? Not a burden? Can it be used to facilitate the core team meetings?

- It was difficult to find KPIs for what we do. This could be a barrier when the CPS should become more detailed.

- Difficult to translate soft facts in measurable hard facts.

- Installation and maintenance of the system could be difficult.

- Predefinition of the categories lead to laborious assignment of goals into perspectives.

- Who is the champion within the organisation, who will drive the project?

- Key to success will be regular ongoing review of agreed goals.

- Capacity requirement for maintaining the CPS.

- Periodical meetings would be necessary and beneficial.

- The OEM will have to train its suppliers to use and maintain this new system.

- Big effort estimated for maintenance of the scorecard due to continuous changes of collaboration.

- Do this new approach and the related system cause additional overhead work?

\subsubsection{Conclusion of research pilot project in the USA}

The following conclusion of the research pilot projects is based on the interviews and statements of the project members after the workshop. 
Generally, the CPS supports the creation of mutual trust within the partnership and creates transparency with respect to agreements on objectives, responsibilities, processes, the actual performance and the success of collaboration. Therefore, it contributes to the avoidance and reduction of complexity in the project environment. It can serve as the basis for an incentive system and for an enhanced supplier selection system on the basis of continuous benchmarking. It discloses cause and effect dependencies of common goals and uncovers conflicts of concurrent objectives in project partnerships. The CPS also provides a forecasting solution through its related tools, e.g. the Project Impact Matrix and Strategy Map. By understanding coherences of the goal related network, leading indicators can be identified. Their impact can be preventive in the future by initiating counter measures timely. The concept also reduces the risk of projects through an integrated countermeasure and risk management and serves as basis for a cross-company and continuous improvement process.

The CPS concept quantifies the subjective perception of a mature and trustful collaboration and transforms it into measurable hard facts by supporting a holistic view over supplier selection. However, there is resistance that needs to be overcome. The introduction of a new collaboration wide controlling system creates resistance not only within the cross-company team of an OEM but also within the project members of a supplier unwilling to apply the concept. The key to success is to convince upper management of both partners and to demonstrate that the benefits may be overshadowed by the limitations and efforts. Project members who are strongly involved with operational tasks often ignore the impact of a strategic tool. In the contrary, they consider a new strategic tool as mere additional effort until they understand its impact.

Benefits of the CPS methodology identified by project members of the OEM and supplier in the USA are that it opens up opportunities for collaboration improvements and aligns the whole team to the agreed common goals. It improves communication between the OEM and supplier, and the clarification of dependencies between goals facilitates the identification of cost lead factors. That holds team members accountable to their cost targets. Defining common goals could avoid mistakes and unnecessary tasks. On the other hand, it is difficult to find KPIs for what we do and to translate soft facts in measurable hard facts. The installation and maintenance of an IT system could be difficult and the training of project members to use and maintain the new system leads to additional effort. Key to success will be a regular ongoing review of agreed goals, measures and corrective action. 


\section{CPS IT implementation}

An IT implementation is likely to improve the sustainability of the CPS concept and it may increase the user friendliness by providing a transparent platform that enables the user to quickly access relevant and actual information and data. This reduces the effort to exchange multiple documents by e-mail. On the basis of the results of the CPS workshop in the USA, a prototype of the CPS concept was implemented with one of the business intelligence software solutions on the market. This chapter begins with an introduction to the process of selecting a software solution including the relevant selection criteria. Other software tools are considered and reason for the chosen software identified. The implementation of the workshop results is then analysed and evaluated in the last section of this chapter (Figure 10.1).

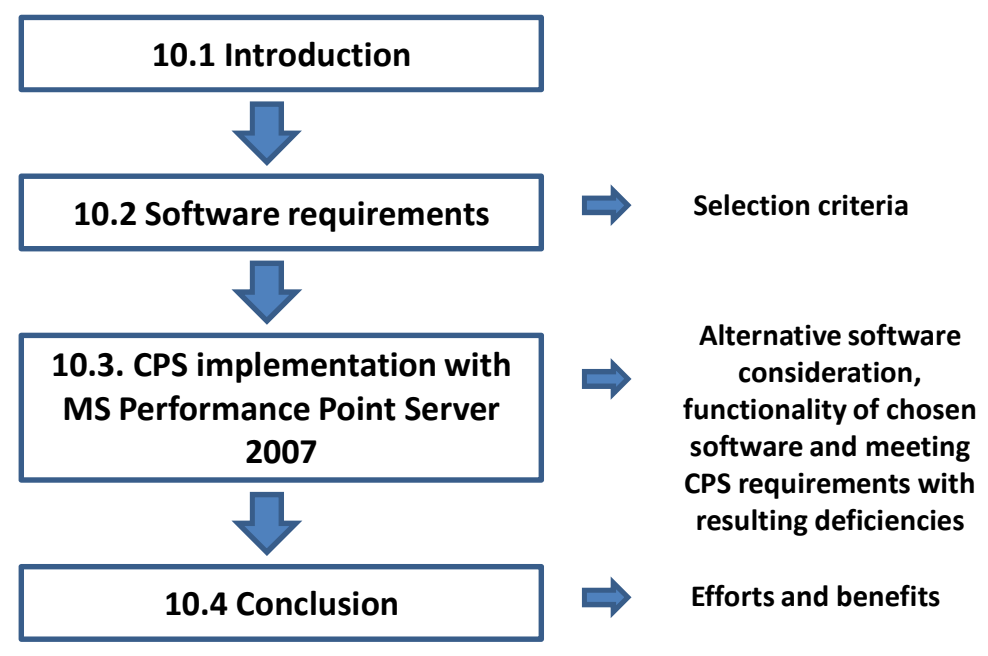

Figure 10.1: OVERVIEW OF CHAPTER 10

\subsection{Introduction to IT implementation}

The software prototype should provide a collaboration platform that is connected with all suppliers involved in the project and that is capable to send and receive project relevant data and information. Consequently, the concept had to be implemented on a serverbased computer system. To select an appropriate software tool, the first step was to identify the requirements based on the workshop results. A market research revealed that at this time there was no tool on the market that could satisfy all aspects and requirements of the CPS. The best solution available with respect to availability, ease of implementation, and functional specifications had to be chosen. Afterwards, the CPS 
was implemented, tested, and the results analysed and presented to the workshop participants. Figure 10.2 shows the procedure of the IT implementation.

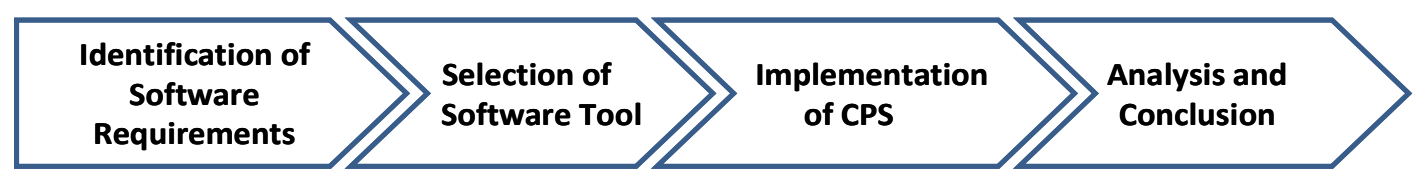

FIGURE 10.2: STEPS OF IT IMPLEMENTATION

\subsection{Software requirements}

The selection criteria were mainly based on the requirements of the CPS concept but also on the availability and support of the chosen solution. A fairly new software tool was Microsoft's Performance Point Server 2007 that is based on SharePoint Services and the Scorecard Manager. The advantage of the software was that the OEM had a Microsoft senior consultant within the company who could provide direct support. As the research took place at the OEM's site the hardware and software facilities was also limited to the existing IT infrastructure including firewall settings and memory limitations. In the following, it is described why the Performance Point Server 2007 solution was chosen for the concept implementation.

\subsubsection{Selection criteria of chosen tool}

The visualisation of project data with an IT solution is a common monitoring instrument but it can also enable the transfer of responsibility from top management to the project team. A basic requirement of a software based CPS solution is its ability to connect to a consistent database that contains all data to evaluate the actual and future project status based on forecasts and trend analyses. Automated processes ensure the maintenance of the database and a connection of existing databases within the company is a prerequisite to provide an owner of a KPI with consistent and actual data.

The following requirements are relevant for a successful CPS implementation:

- Visualisation of project data using scorecards and dashboards.

- Definition of KPIs that can be re-used in other scorecards and dashboards.

- Connection to all other relevant data bases within the organisation (e.g., SAP databases, SQL Server, ODBC, Excel documents). 
- Visualisation of a Strategy Map based on project objectives defined in the scorecards.

- Definition of interdependencies between KPIs and objectives based on the Strategy Map.

- Definition of target values and corridors for each KPI.

- Connecting multiple KPIs to one objective.

- Easy creation of charts and figures for project analysis.

- Illustration and calculation of forecasts based on trend analysis (e.g., milestone trend analysis, earned value method).

- Linking counter measures to KPIs and project objectives.

- Rights management: each user has different rights to access only user relevant data.

- Scalability of scorecards: creation of portfolio and program scorecards based on the company BSC and further creation of project scorecards aligned with portfolio scorecards.

- Reporting system that produces adjustable and scalable management reports and automated sending of these reports (e.g., by e-mail).

- Workflow capability.

The following figure (Figure 10.3) shows the requirements on the workflow capability.

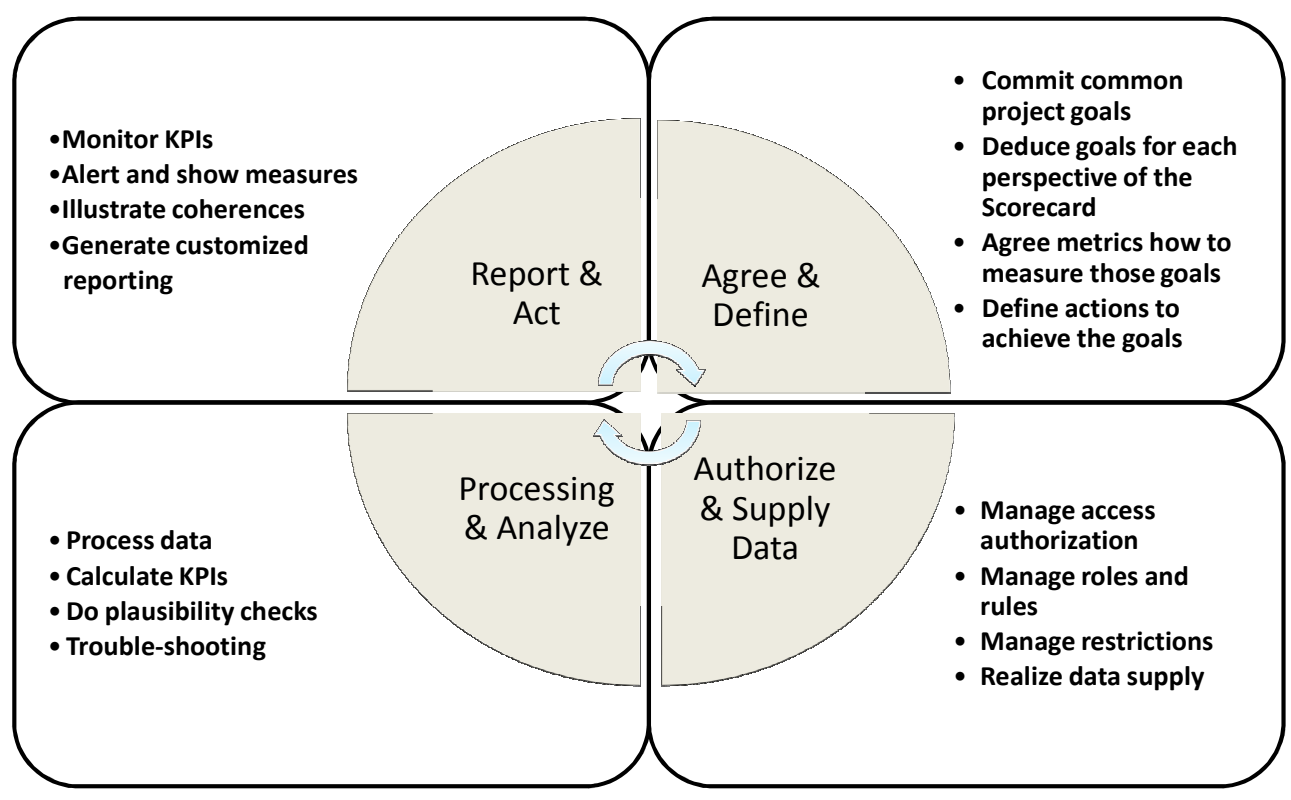

FIGURE10.3: WORKFLOW CAPACITY REQUIREMENTS 
The first step is to agree on common goals and categorise them into the relevant perspectives. Metrics to monitor and action to control the goals are also part of one step that is followed by an authorisation and data supply procedure. It is essential to establish rights management that allows access to certain data for selected personal only. It should also provide smart data processing, visualisation, analysis tools, automated plausibility checks, and trouble-shooting capability.

To implement the defined specifications of the project team, the system should offer tools, which allow a design of dynamic, multi-dimensional databases. The management of access authorisation, rules, user profiles, roles and restrictions is necessary to ensure a proper application of the tool.

A prerequisite for collaboration is a shared database to which all project partners have access. An IT based CPS has to be accessed by associates of different organisations and requires a shared system that may be internet-based with a strict security concept. Some questions arise quickly regarding the hardware architecture of the system. The physical location of the server where the application is installed and how the server can be protected from unauthorised access are only a few of significant questions (Figure 10.4).

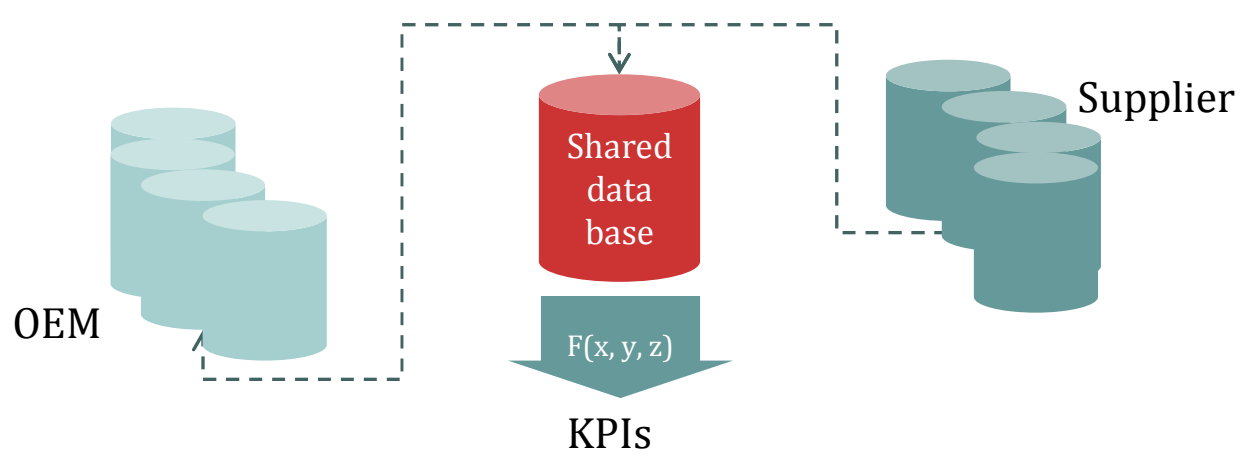

Figure 10.4: SHARED DATA BETWEEN OEM AND SUPPLIER TO CREATE KPIS

Besides the basic concept of existing scorecard systems the CPS requires a continuous and partially automated counter measure management, integrated risk management, project status in real time, advanced forecasting, and the aspects mentioned above such as the project strategy map and impact matrix. 


\subsection{CPS implementation with MS Performance Point 2007}

Considering the selection criteria and aspects related to access and support, the implementation of the consolidated CPS workshop results took place on a research lab server using the software Microsoft Performance Point Server 2007. This section describes the functionality of the tool briefly and illustrates the implementation results.

The following figure (Figure 10.5) shows the architecture of the lab environment and its connection to the OEM internal and external network, such as supplier networks.

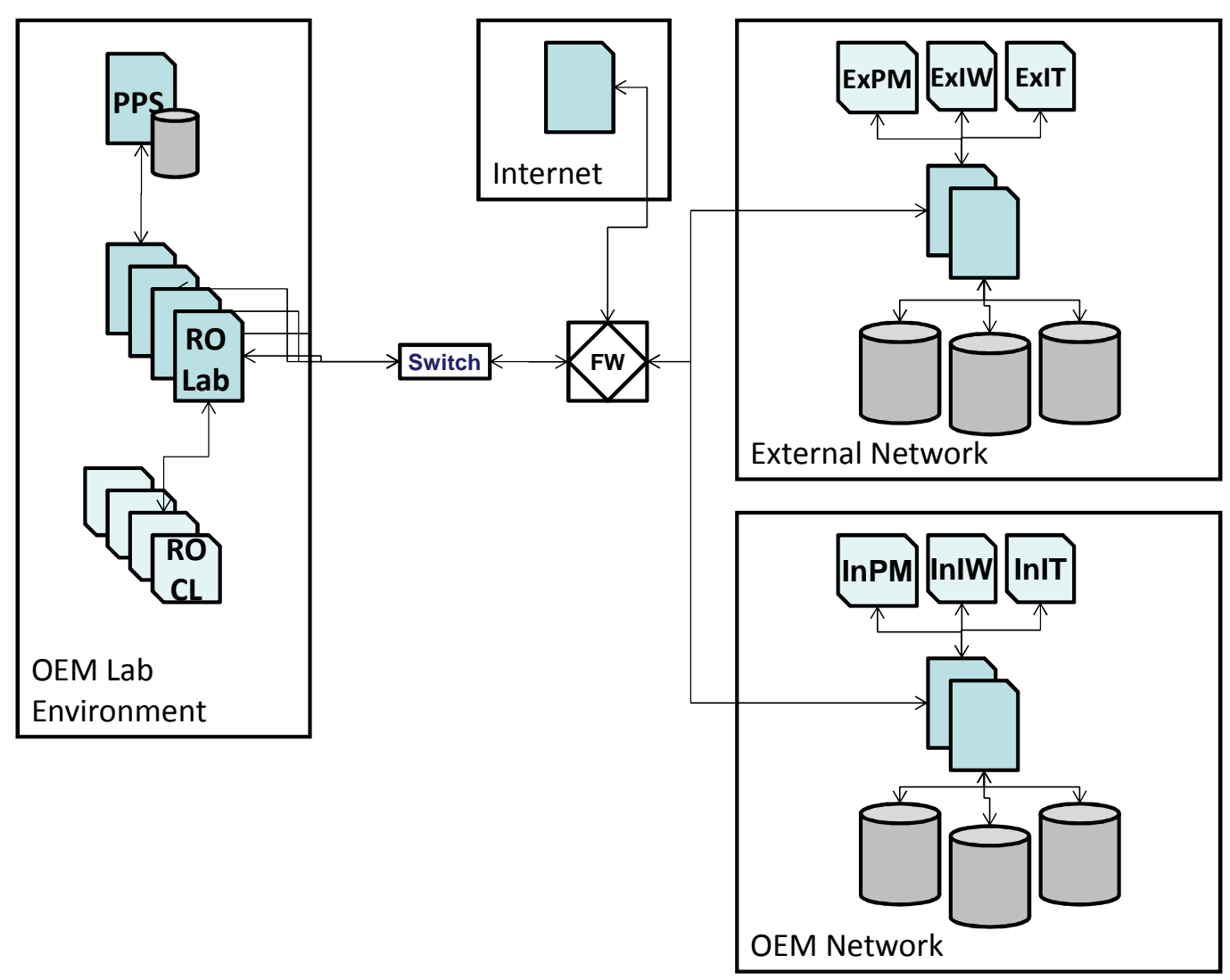

FIGURE 10.5: ARCHITECTURE OF LAB ENVIRONMENT FOR CPS IMPLEMENTATION

\subsubsection{Alternative software consideration and limitations}

The Business Intelligence (BI) solution market is broad and many software companies sell customised tools that are specified and adjusted to the customer's requirements and demand. The selection of Microsoft Performance Point Server 2007 was not only made on the basis of its functionality with respect to the CPS concept but also on the possibility of its availability to the OEM and its IT infrastructure and lab environment as 
well as the direct support of IT experts. Additionally, the selection was limited to the tool set of standard tools as there was no project budget for a customised solution. Other tools that would have been of interest are, e.g., IBM Cognos 8 BI, SAS Strategic Performance Management, and SAP Strategy Management. All tools feature KPI monitoring and customised reporting, connection of existing databases, analysis tools, OLAP multidimensional data analysis, Microsoft Office integration and visualisation. Taking these factors into account the decision was made to proceed with MS Performance Point Server 2007 as the lab environment and direct support of the software vendor promised results that were quickly achievable and keeping the limitations to a minimum compared to other solutions.

\subsubsection{Functionality of MS Performance Point Server 2007}

Microsoft Performance Point Server 2007 is a server application that connects databases of an organisation and structures them into a dynamic OLAP database. It provides an advanced data processing, analysing and visualisation functionality, some of them are:

- Monitoring using scorecards (a scorecard is a visual representation of an organisation's strategy), dashboards (a dashboard is a collection of graphs, reports, and KPIs that facilitate monitoring of, e.g., progress on a specific initiative, the effectiveness of operations, and progress against sales forecasts).

- Analysing and advanced visualization (performance maps, decomposition trees etc.).

- Planning by importing data from multiple sources, feed data automatically into a centralised and trusted data store, embedded standardised business rules and processes, providing each user with a single interface, tracking changes automatically, and managing planning and budgeting processes.

The software includes a monitoring server for centralised data access, view rendering, storage, parameterisation, security, caching, scaling, and a monitoring server configuration manager. The monitoring server is connected to the data sources, e.g. SQL server, SharePoint lists, ODBC and soon SAP databases. It can create reports by OLAP charts, pivot charts, strategy maps, trend analysis, etc. The dashboard designer can create and modify dashboard, scorecards, reports, KPIs, indicators and parameters that are visualised in the scorecards and dashboards. Access to the functionality and 
visualisation is managed by an internet browser. The following figure (Figure 10.6) shows the interaction of the system components.

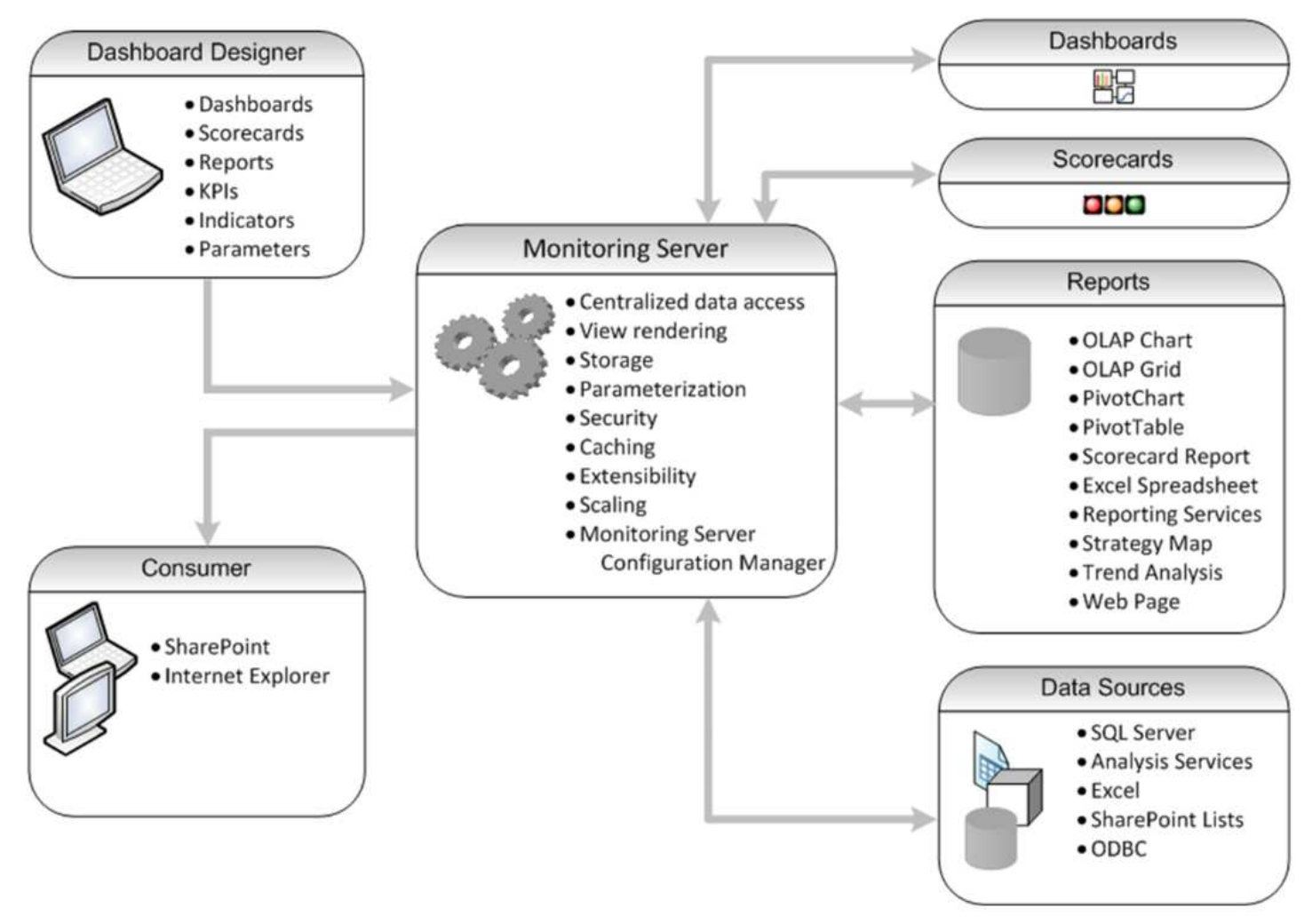

Figure 10.6: System components of the MS Performance Point Server 2007

(MICROSOFT, 2007)

\subsubsection{Meeting the CPS requirements}

The central monitoring server accepts data input via a connection to external data sources so that suppliers, e.g., KPI owners, are able to provide relevant data automatically by connecting to databases or by updating Excel sheets. The dashboard designer helps the system administrator to customise the processing of data. It also includes functions to develop personalised scorecards, dashboards and reports.

The functionality of the software theoretically covers many requirements to successfully apply the tool to a cross-company project. However, recent experience of the OEM has shown that during the roll out of such a system, many issues have not been considered and lead to difficulties and delays in its application. Therefore, a proof of concept is typically necessary to ensure a problem free introduction of a software tool. Additionally, 
several open issues with respect to technical requirements need clarification. Some of them are:

- A blueprint of a comprehensive security concept is required that satisfies the demands of the OEM IT security standards.

- Proof if relevant databases of OEM and suppliers' networks can be connected factually.

- System proof that it can perform well under stress of a typical amount of daily server requests.

Together with Microsoft a first draft of a CPS was implemented to be able to communicate the workshops results visually and functionally.

\subsubsection{Identified deficiencies of the system}

It was not possible to realise a counter measure management as required by the CPS concept (installation of automated emails or alert messages on a defined status of a KPI to the KPI owner. The messages should include agreed counter measures, a visualisation of the cause and effect relationships, and a feedback form). The possibility to conduct team surveys is essential due to the demand to measure soft facts in collaborative projects. However, surveys can only be carried out with SharePoint lists only. Therefore, the user friendliness is not expected to encourage these surveys sustainably. CPS risk management has similar restrictions as the counter measure management.

A connection of textual information to key performance indicators is not feasible and the tool does not support any automated processes. A SWOT analysis and impact matrix could not be implemented without additional effort as the software only provides the integration of the MS Visio 2007 software. This enables the user to create SWOT analysis and strategy maps visually but not as an integrated and interrelated function. The process to create a strategy map is laborious as every strategy map of each dashboard needs to be drawn manually.

Figure 10.7 shows a partial screenshot of the implemented CPS concept and shows the project result perspective. 


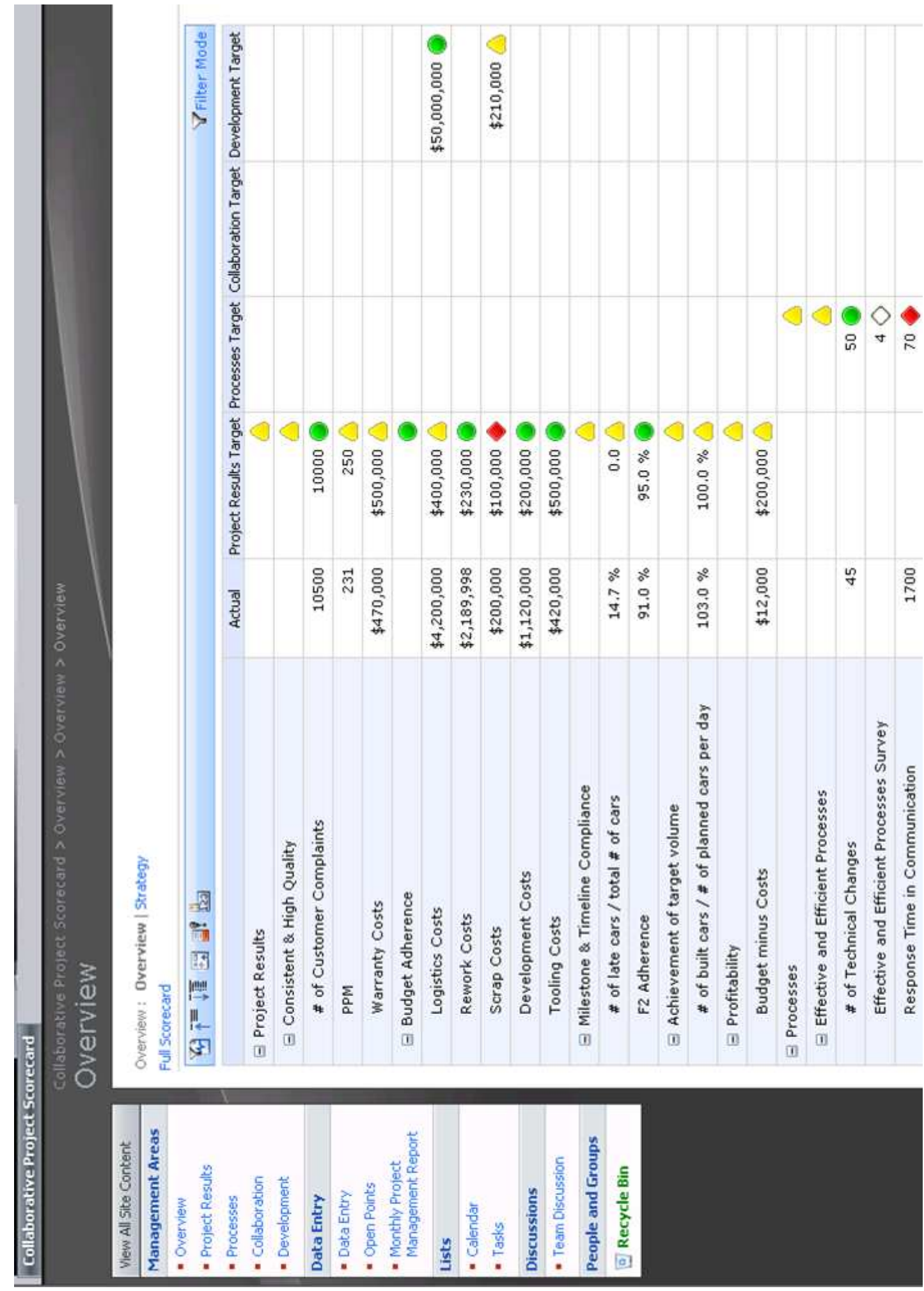

FIGURE 10.7: SCREENSHOT OF CPS IMPLEMENTATION

For example, if the system user clicks on "PPM", the software creates a graphical plot of the recent PPM values as shown in Figure 10.8. 


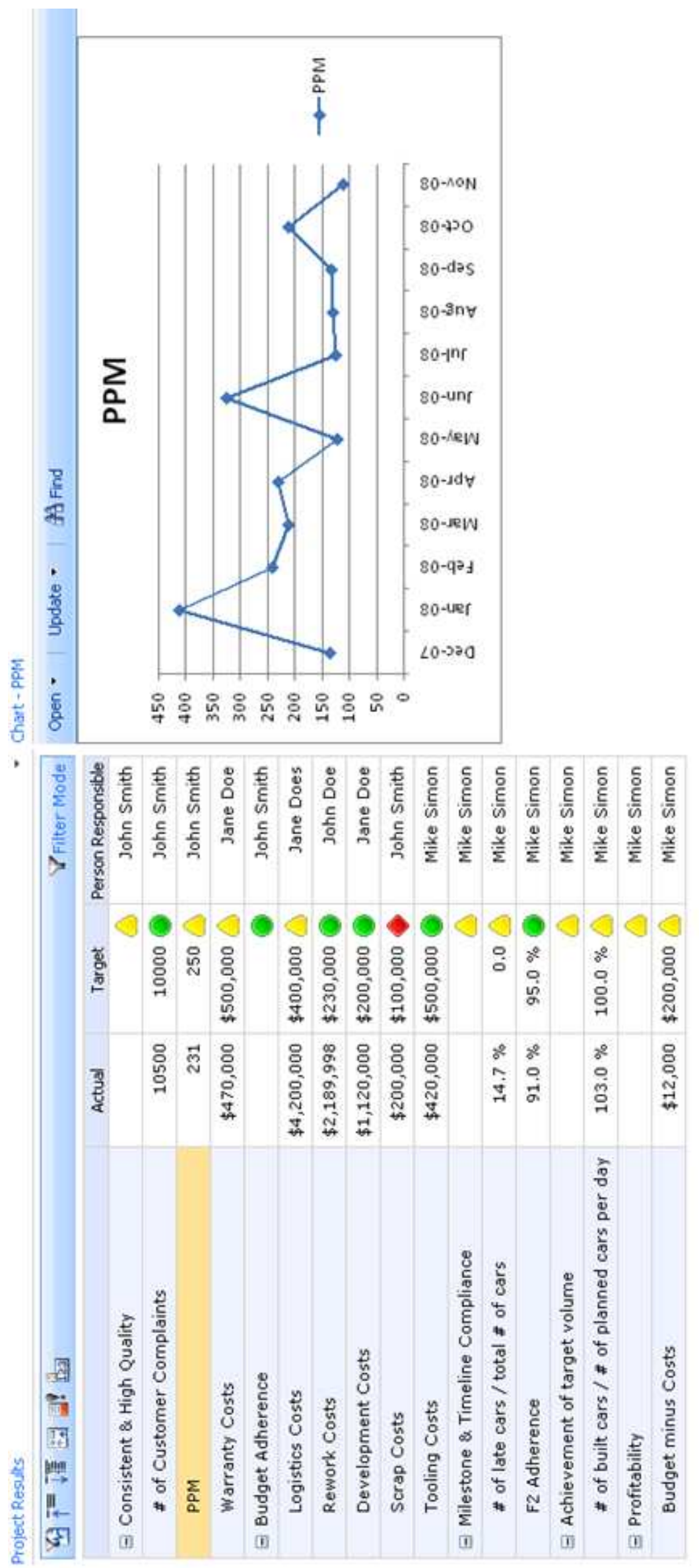

FIGURE 10.8: GRAPHICAL PLOT OF PPM VALUES IN TIME 


\subsection{Conclusion}

The development of a visual representation of the CPS for launch and change management was achievable and included the integration of common agreed goals, implemented key performance indicators with actual and targeted values, a logical connection of the KPI and the KPI owner, and the plot of different diagrams and other textual content. It was not accomplishable to realise a dynamic and event driven counter measure management, risk management or the implementation of lessons learned. The software provided no solution for an application of an impact matrix. A SWOT analysis and a Project Strategy Map could be created graphically by integrating MS Visio but without dynamic functionality. Furthermore, the software did not feature advanced forecasting or trend analysis. Figure 10.9 lists the advantages and disadvantages of the tool.

\begin{tabular}{|l|}
\hline \multicolumn{1}{|c|}{ Advantages } \\
- Connection to existing databases \\
- Working with consistent data \\
- Re-use and carry over of existing KPIs \\
to different dashboards \\
- Rules and roles management \\
- Intuitive navigation through database \\
- Useful integrated analysing tools \\
\hline
\end{tabular}

\begin{tabular}{|l|}
\hline \multicolumn{1}{|c|}{ Disadvantages } \\
- Effort to implement one single KPI is \\
high (1-2h, if database is available) \\
- High planning functionality but \\
considerable effort \\
- No dynamic strategy map as it has to \\
be designed for each dashboard \\
- Excel add-in necessary for each \\
client who uses Performance Point \\
reports and forms \\
- Extension of the CPS with integrated \\
measure and risk management not \\
included in standard software \\
- Several errors occurred during \\
installation and operation
\end{tabular}

FIGURE 10.9: AdVANTAGES AND DISADVANTAGES OF SELECTED TOOL FOR CPS CONCEPT

A performance and stress test was not done as the connection to real project data could not be achieved due to the lack of an established security concept that impeded the connection to all relevant OEM and supplier databases. The feedback of the CPS workshop participants was positive with regard to the software implementation as it increases transparency and facilitates the exchange of project relevant information and data analyses. The term positive is related to the fact the an IT implementation automates and standardises the relevant processes, such as KPI reporting and data analyses. This is further supported by the possibility to connect the IT solution to already existing data bases and to establish a rule and role management. However, the selected tool does not fully satisfy the CPS requirements. This means that some 
requirements could not be met, some of them are that next to a workflow management, a corrective action management, risk management, and a dynamic representation of a strategy map was not possible. For a future CPS project another tools is highly recommended based on the facts mentioned above. Nevertheless, the efforts and benefits of an IT implementation in general could be analysed and are presented in the next section.

\subsubsection{Efforts and benefits of an IT implementation}

The CPS workshop participants rated the application of an IT implementation as beneficial and some even as a key to success. However, it is essential that the solution does not create overhead work and does not duplicate existing reporting and monitoring systems. Consequently, there is a challenge in the IT community to develop a tool that finds broad acceptance in daily project management operations.

There is a higher effort in the beginning of the implementation process as the connection to all databases needs to be established, rights management defined, the KPIs defined and created. However, this is mainly an initial effort that can be considered as front loading compared to the long term benefits. Those are the possibility to carryover already defined KPIs and rely on consistent databases as well as a transparent workflow management. The efforts and benefits are shown in Figure 10.10 and based on the experience and appraisal of the workshop members.

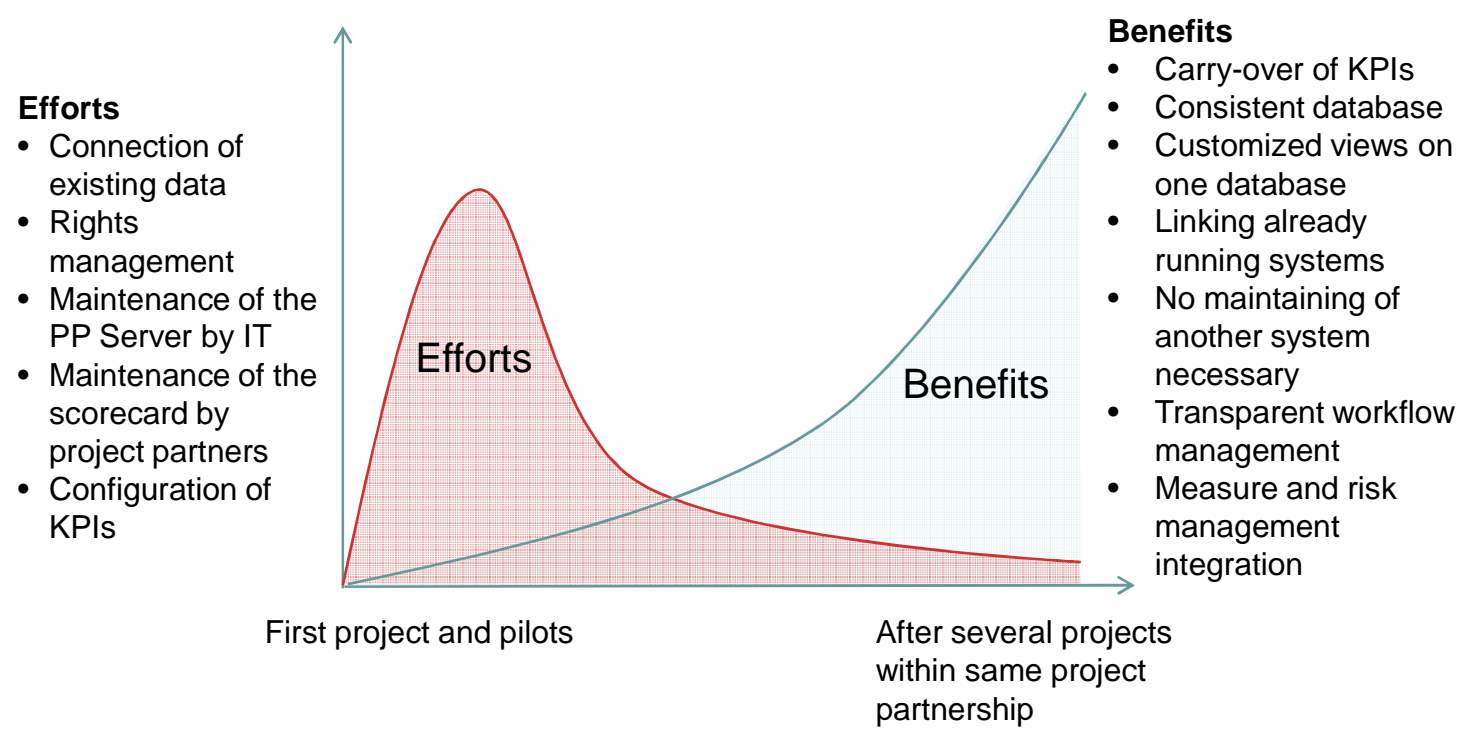

Figure 10.10: CHRONOLOGICAL EVALUATION OF EFFORTS AND BENEFITS OF AN IT IMPLEMENTATION 


\section{Integrating a collaborative management model into the CPS}

The Collaborative Project Scorecard aims to reduce difficulties in a cross-company project by providing a framework for a strategic approach to project collaboration that is linked with the strategies and objectives of an organisation. The ProSTEP IViP CPM Reference Model (ProSTEP iViP 2007a) on the other hand, provides a set of processes and tools to manage time, tasks, and communication on an operational level. This chapter presents a combined concept based on the CPS and the ProSTEP IViP CPM Reference Model and demonstrates how the reference model supports the CPS by creating useful measures as a key to success for an efficient and effective collaboration. Figure 11.1 gives an overview of this chapter that starts with an introduction to the integrated approach. In the second section it is described how the model and the CPS concept can be combined to create operational KPIs that can be strategically monitored by the CPS.

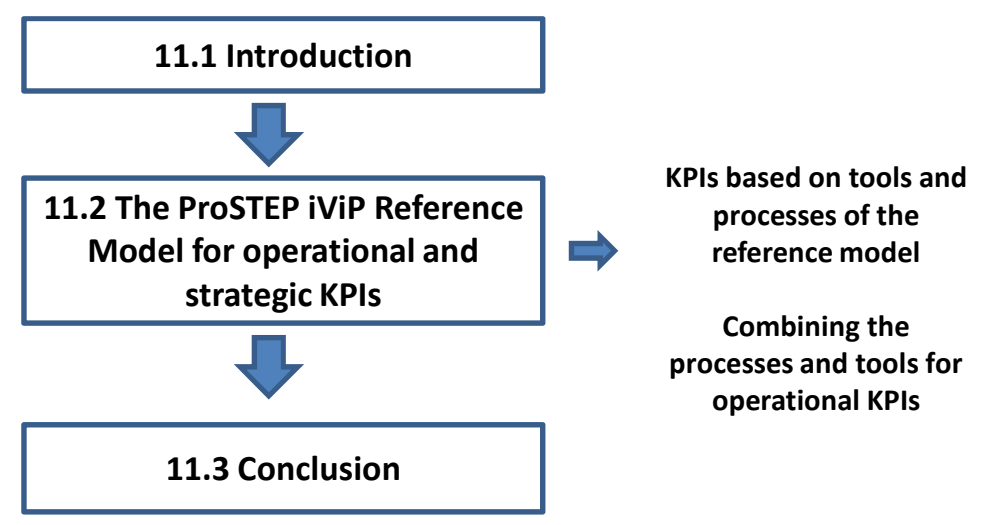

Figure 11.1: OVERVIEW OF CHAPTER 11

The last section includes a discussion of its benefits and disadvantages and further recommendations.

\subsection{Introduction}

Cross-company teams have become increasingly important for the success of product development projects. Although, the use of virtual teams is not entirely new, the demand and opportunities for an efficient management have increased due to improved communication technologies (Gierhardt 2001). The growth of virtual project 
environments requires the development of new methods to manage barriers due to distance of project teams but also due to cultural aspects (Kahn 2005). Projects with geographically dispersed team members have emerged in order to reduce costs and the duration of projects while still being able to control the quality and scope of the projects accordingly (Rad 2003). The CPS and the CPM Reference Model were both developed due to recently identified difficulties in the management of automotive projects. Both concepts can be jointly applied for higher efficiency in project collaboration. Benefits, advantages but also limitations and barriers were identified that need to be considered for a sustainable and successful adoption of the concepts.

The shift of project and development responsibility towards partner companies and temporary networked structures requires a stronger connection between information exchange and project coordination. Shorter development cycles and higher product complexity can only be managed by an effective cooperation with partners. The coordination and integration of mechanics, electronics and software become increasingly detailed and lead to a growing number of project partners with different corporate cultures and development methods (Plischke et al., 2007). The situation has initiated the project group "Collaborative Project Management (CPM)" of the ProSTEP iViP association in 2005 that consisted of 15 industry partners mostly from the automotive industry. The objective was to develop solutions for communication and documentation of project data, and for the control of time lines and activities in development networks.

The software implementation of the ProSTEP iViP CPM Data Exchange Model, published as "Collaborative Project Management (CPM) - Data Exchange Model" (PSI 1-2), and its processes and tools is a prerequisite for a successful application to daily collaborative project management. Within the CPM project group several system vendors developed tool specific solutions to demonstrate how the processes and tools can be integrated into existing project management software with little modifications. The solutions were presented to different users with positive feedback. On the basis of an application scenario, the selected users were convinced that the CPM procedure model can improve collaboration considerably assumed it is integrated into a system (Boy et al., 2008). 


\subsection{The ProSTEP iViP CPM Reference Model as a source for operational and strategic KPIs}

The system integration of the CPM model opens a wide range of opportunities to derive valuable information and collaborative KPIs that can be integrated into a CPS. Therewith, the CPM model provides a standardised framework and source of project data to support project management and to be able to assess performance of several cross-company projects on a comparable level. Relevant processes are already defined so that the project partners have a set of consolidated procedures when issues arise. On an operational level, the reference model provides processes and tools that can create project collaboration relevant measures and indicators. These KPIs can be integrated into a CPS that monitors and controls the KPIs and respective objectives on a strategic level. Figure 11.2 shows the how these two level interact.

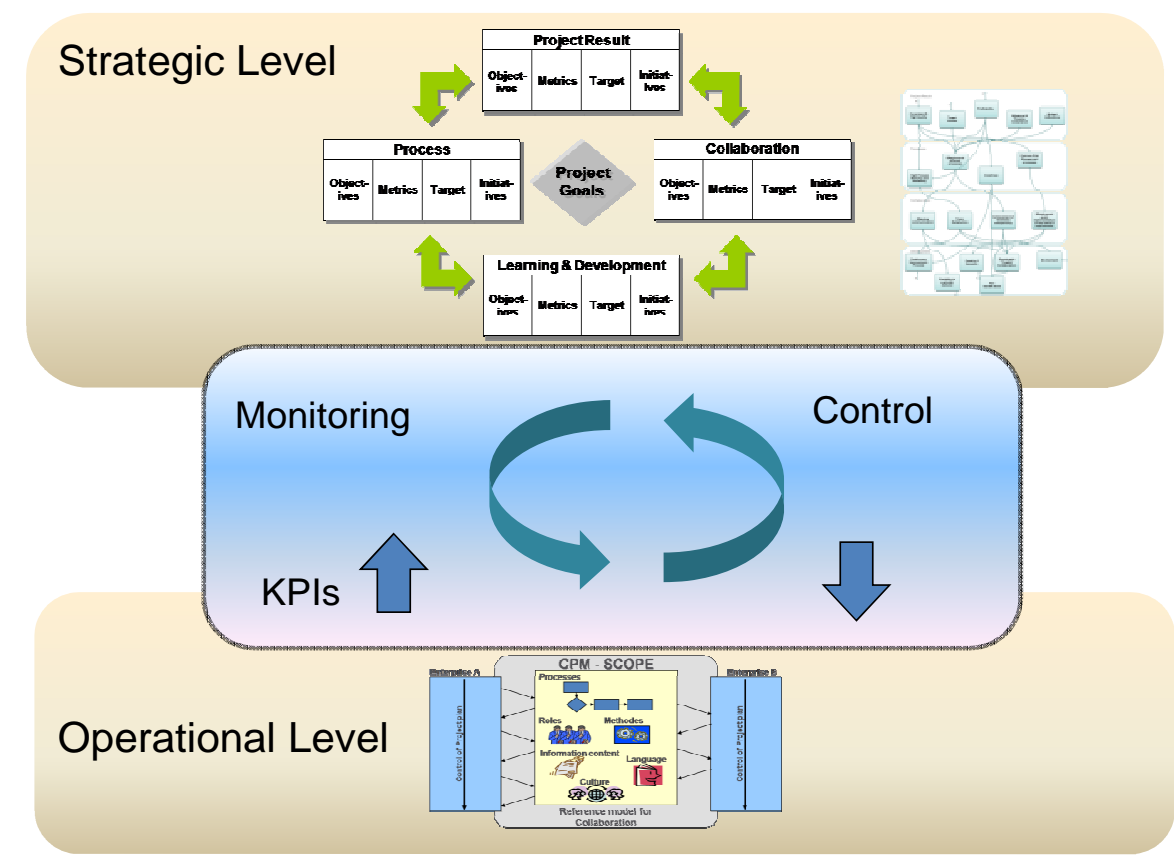

Figure 11.2: INTERACTION OF CPS AND PROSTEP IVIP REFERENCE MOdEL ON STRATEGIC AND OPERATIONAL LEVEL (NiebeCKer ET AL., 2008C, P. 10)

\subsubsection{KPIs based on CPM tools}

When a milestone cannot be adhered to the defined time, the traffic light of the KPI for milestone adherence may turn red and an escalation process is initiated. All project members are then aware of the process and know who needs to be informed. Other 
project result relevant information, such as common milestones and synchronisation points are included in the CPM interaction chain, and the number of points in the issue list with red traffic lights indicates whether the synchronisation points or milestones can be met and can, therefore, serve as an indication of the project status. Figure 11.3 indicates how possible KPIs can be created based on the CPM tools.

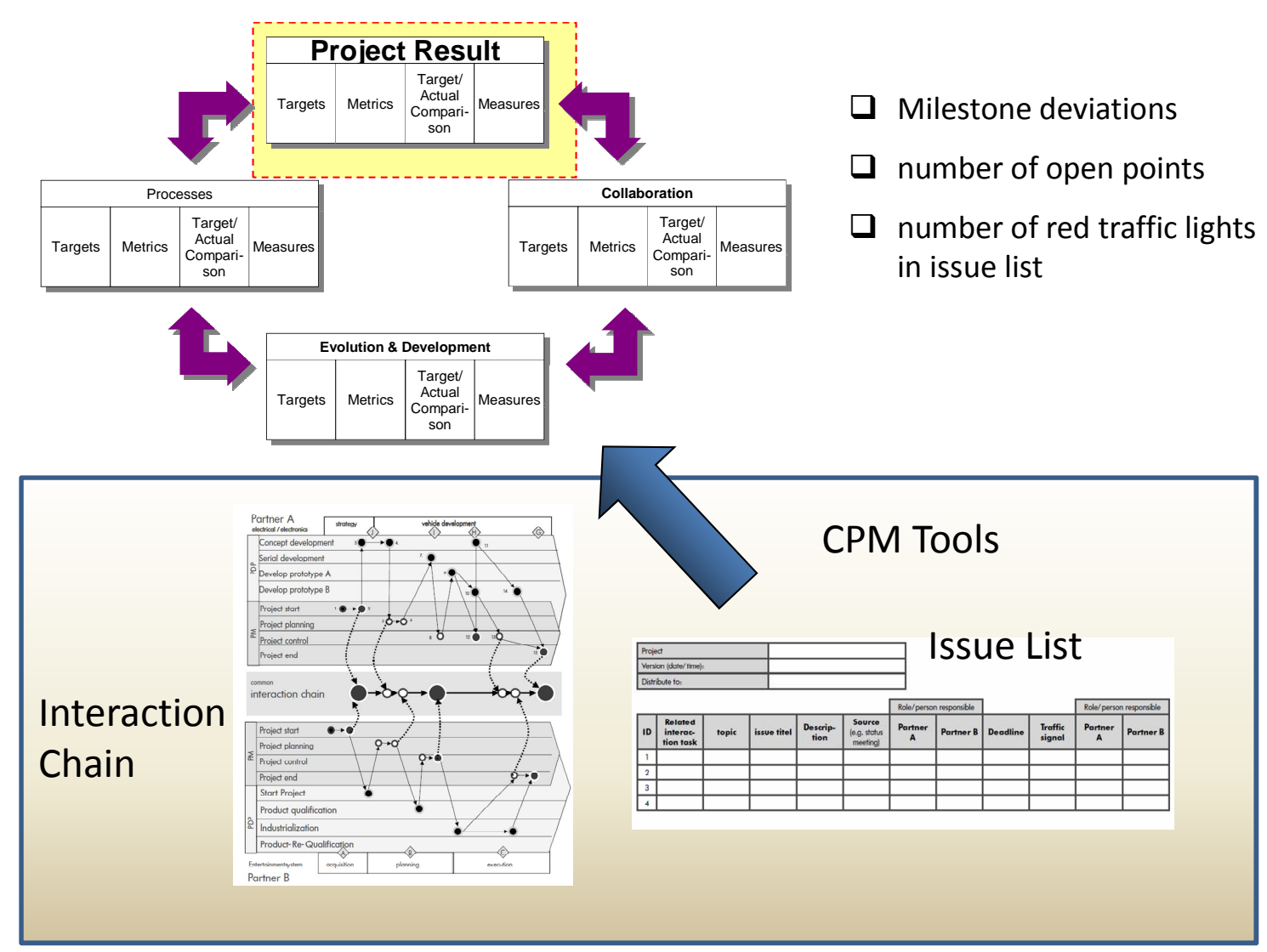

FIGURE 11.3: KPIS BASED ON CPM TOOLS FOR PROJECT RESULT PERSPECTIVE

A possible KPI for the project status is the number of project changes that are monitored on the basis of the project change process. Deviations from this process indicate whether the project partner complies with the defined processes or not. It is a KPI of the process perspective of the CPS. A deviation is initiated by a change with a related interaction task. The issues are a source to define corrective action for the deviations from the CPS targets. The CPM model supports the CPS in the area of time, task, and communication management and creates opportunities for integrating collaborative risk management. 


\subsubsection{KPIs based on CPM processes}

There are more than ten processes defined in the CPM reference model that can serve as a source of the KPI for process deviations. As an example, project role changes can have an impact on the team satisfaction and, therefore, the KPI is a leading indicator to measure collaboration and also long-term goals, such as team trust, which can be found in the development perspective. CPM processes have an impact on all four perspectives of the CPS but on the process perspective in particular. Figure 11.4 shows the creation of KPIs based on CPM processes for the process perspective.

\section{KPIs based on CPM processes:}

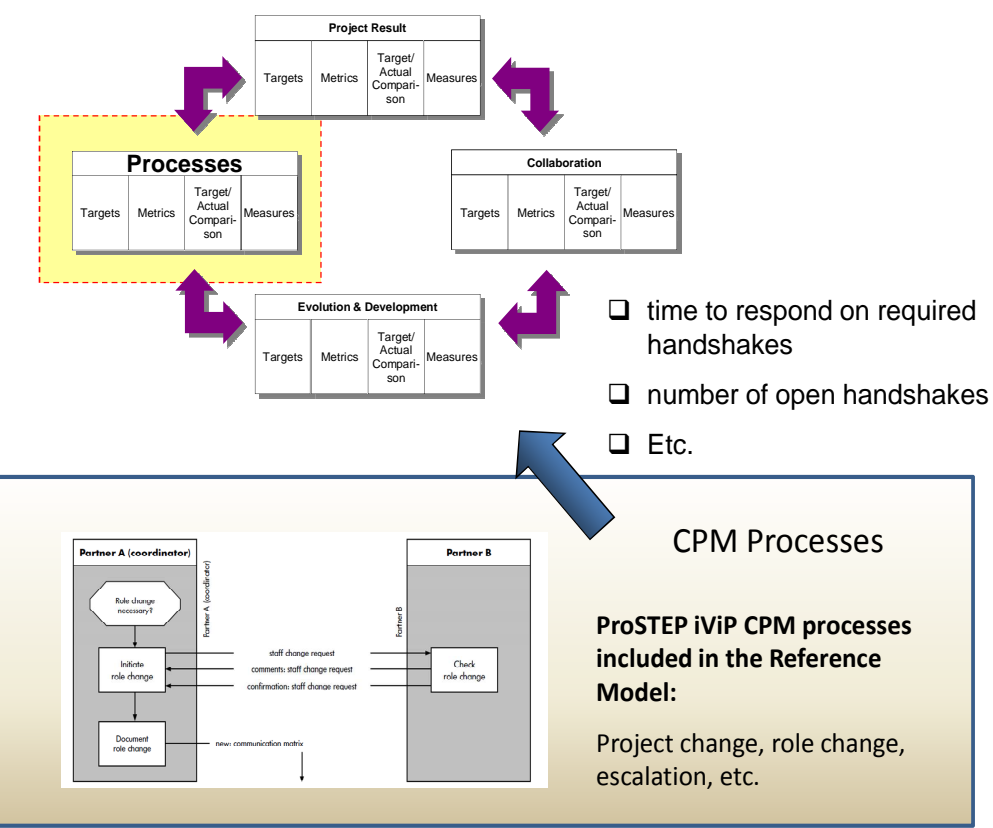

FIGURE 11.4: CREATION OF KPIS FOR THE PROCESS PERSPECTIVE BASED ON CPM PROCESSES

Role changes may also influence the project result perspective directly as a new team member needs time to get familiar with the project. This may be a threat for the achievement of the next milestone.

\subsubsection{Combining CPM processes and tools for operational KPls}

Next to the CPM processes, the provided tools can be integrated into the scorecard as mentioned in the previous section. The communication matrix not only assigns the project members relevant for an escalation but also for particular project tasks. This facilitates the definition of the responsible persons to deliver certain KPIs and also the 
assignment of predefined corrective measures. If the communication matrix is not updated regularly or had never been defined properly problems can arise due to the lack of transparency with respect to responsibilities.

Figure 11.5 shows communication matrix partially.

\begin{tabular}{|c|c|c|c|c|c|c|c|}
\hline & & Role & $\begin{array}{c}\text { Project St } \\
\text { Commi }\end{array}$ & eering & & t manager & Sub project manager \\
\hline & & Internal role & Head Partner B & Member 1 & Head & Project office & \\
\hline Role & : Internal role & Person & & & & & \\
\hline $\begin{array}{l}\text { Project } \\
\text { Steering }\end{array}$ & Head Partner A. & & $\begin{array}{l}\text { topic } A, B, \operatorname{dec} \\
\text { case off .... }\end{array}$ & sions in & & & \\
\hline Committee & Member 1 & & & & & & \\
\hline Project & Head & & & & topic C & Topic D,E & \\
\hline manager & Project office & & & & & Topic F & \\
\hline Sub Project & & & & & & & \\
\hline
\end{tabular}

FIGURE 11.5: CPM COMMUNICATION MATRIX (BASED ON PROSTEP IVIP, 2007A, P. 55)

A missed update of the matrix can be measured and can be translated into a KPI that describes the adherence of communication processes or communication efficiency.

The issue list is used to monitor deviations from the original plan that affects both partners. Figure 11.6 shows the issue list template.

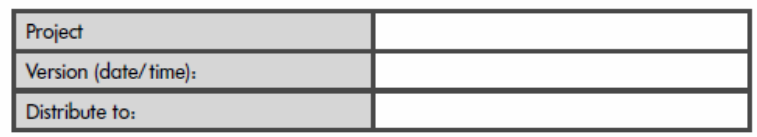

\begin{tabular}{|c|c|c|c|c|c|c|c|c|c|c|c|}
\hline \multirow[b]{2}{*}{ ID } & \multirow[b]{2}{*}{$\begin{array}{l}\text { Related } \\
\text { interac- } \\
\text { tion task }\end{array}$} & \multirow[b]{2}{*}{ topic } & \multirow[b]{2}{*}{ issue titel } & \multirow[b]{2}{*}{$\begin{array}{l}\text { Descrip- } \\
\text { tion }\end{array}$} & \multirow[b]{2}{*}{$\begin{array}{l}\text { Source } \\
\text { (e.g. status } \\
\text { meeting) }\end{array}$} & \multicolumn{2}{|c|}{ Role/person responsible } & \multirow[b]{2}{*}{ Deadline } & \multirow[b]{2}{*}{$\begin{array}{l}\text { Traffic } \\
\text { signal }\end{array}$} & \multicolumn{2}{|c|}{ Role/person responsible } \\
\hline & & & & & & $\underset{\text { A }}{\text { Partner }}$ & Partner B & & & $\underset{\text { A }}{\text { Partner }}$ & Partner B \\
\hline 1 & & & & & & & & & & & \\
\hline 2 & & & & & & & & & & & \\
\hline 3 & & & & & & & & & & & \\
\hline 4 & & & & & & & & & & & \\
\hline
\end{tabular}

Figure 11.6: PART OF CPM ISSUe LIST TEMPLATE (ProSTEP IVIP 2007A, P.53)

Other examples for the collaboration and learning and development perspective are shown in Figure 11.7. 


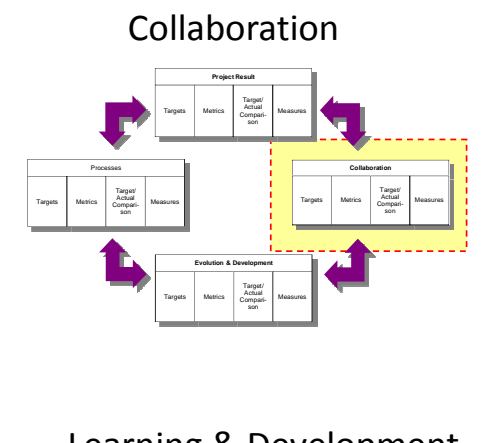

\begin{tabular}{|l|l|l|l|}
\hline Targets & KPI & Target & Measures \\
\hline $\begin{array}{l}\text { Team } \\
\text { Satisfaction }\end{array}$ & $\begin{array}{l}\text { No of role } \\
\text { changes } \\
\text { No of project } \\
\text { changes }\end{array}$ & tbd. & $\begin{array}{l}\square \text { Minimise role changes } \\
\square \text { Team workshops }\end{array}$ \\
\hline $\begin{array}{l}\text { Effective } \\
\text { Communication }\end{array}$ & $\begin{array}{l}\square \text { Adherence to } \\
\text { communication } \\
\text { matrix } \\
\text { No of escalations }\end{array}$ & Tbd. & $\begin{array}{l}\square \text { Increase no of team } \\
\text { meetings } \\
\text { Organise social events }\end{array}$ \\
\hline$\ldots$ & $\square \ldots$ & $\ldots$ & $\square \ldots$ \\
\hline
\end{tabular}

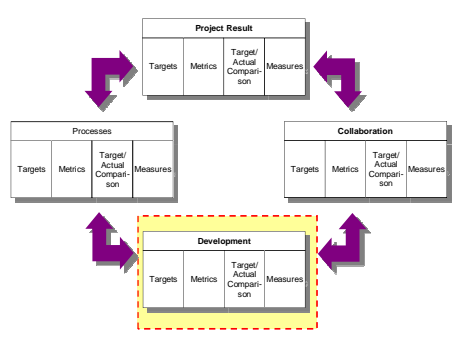

\begin{tabular}{|l|l|l|l|}
\hline Targets & KPI & Target & Measures \\
\hline Team Trust & $\begin{array}{l}\square \text { No of role } \\
\text { changes } \\
\square \text { No of escalations }\end{array}$ & tbd. & $\begin{array}{l}\square \text { Minimise role changes } \\
\square \text { Team workshops }\end{array}$ \\
\hline.. & $\square .$. &.. & $\square .$. \\
\hline
\end{tabular}

FIGURE 11.7: EXAMPLES OF KPIS BASED ON CPM FOR COLLABORATION AND LEARNING \& DEVELOPMENT

\subsection{Comments on the integrated approach}

The identification of possible risks related to the defined corrective actions and to the identified leading indicators is facilitated by an existing collaborative system and predefined processes that project managers can monitor and control in real time and with consistent and consolidated data. First results and feedback of the CPS and the CPM model has been obtained and there is reason to belief that both concepts have great impact on the efficiency and effectiveness of future collaborative project management. However, the barriers and limitations need to be considered carefully and further pilot projects are necessary to investigate the benefits and opportunities the combined concepts can create in more detail.

The ProSTEP iViP CPM Reference Model supports the CPS in providing collaboration relevant KPIs and standardised tools for communication, time, and task management. A software implementation of the data model is a prerequisite for its success and a basis to produce data that are integrated into a CPS. Both concepts have been developed recently within the automotive industry and require further pilot projects to obtain more knowledge about their impact on cross-company project management. 


\section{Assessing performance of cross-company projects}

The assessment of cross-company and collaborative projects based on a project assessment model is fundamental to improve collaboration sustainably. Combined with a CPS, it supports the identification of common project goals and need for action to achieve high collaborative project performance. In the following, the CPS and a project assessment model predicated on the Project Excellence Award of the German Project Management Association (GPM e.V.) is described and it is demonstrated how both concepts can be linked for an efficient project management and performance assessment of cross-company projects. Figure 12.1 shows the structure of this chapter.

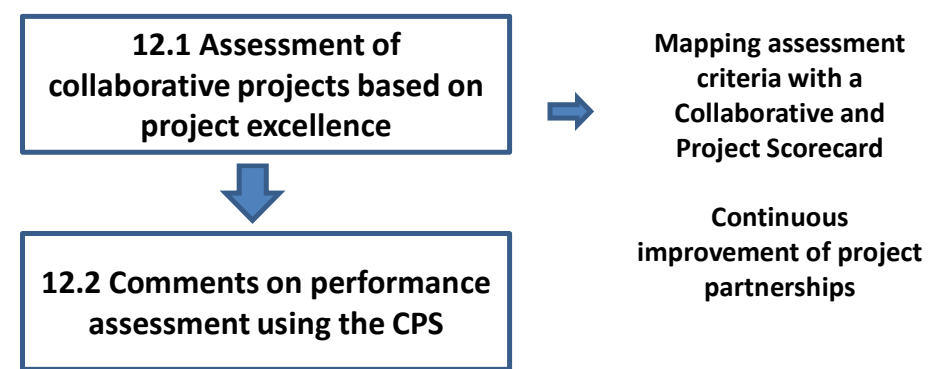

FIGURE 12.1: OVERVIEW OF CHAPTER 12

\subsection{Assessment of collaborative projects based on project excellence criteria}

A project performance assessment based on a maturity model supports the project manager to improve subsequent projects by identifying need for action and by learning from previous mistakes and a structured evaluation of problem zones. The European Foundation for Quality Management (EFQM) developed a framework to assess an organisation based on nine criteria, which are categorised into "enablers" (what does an organisation) and "results" (what achieves an organisation). The developed criteria reflect a consensus of the formerly participating companies in respect to best practices. The framework was based on existing standards such as the Deming Price or the Malcolm Baldrige National Quality Award (Hakes, 2007). The Project Excellence Award, assigned by the German Project Management Association (GPM e.V.), is based on the EFQM model and provides a benchmarking of individual projects. Strengths and weaknesses of project teams are identified and compared to other projects so that future project work can be improved and optimised. Structured into nine criteria and 22 sub criteria, the model assesses room for improvement to increase project quality 
continuously (GPM, 2008). The nine criteria are shown in Figure 12.2 and categorised with respect to the EFQM model into project management ("enablers" - how an organisation achieves results) and project results ("results" - what an organisation wants to achieve), whereas innovation and learning is implemented in successive projects based on the assessment results.

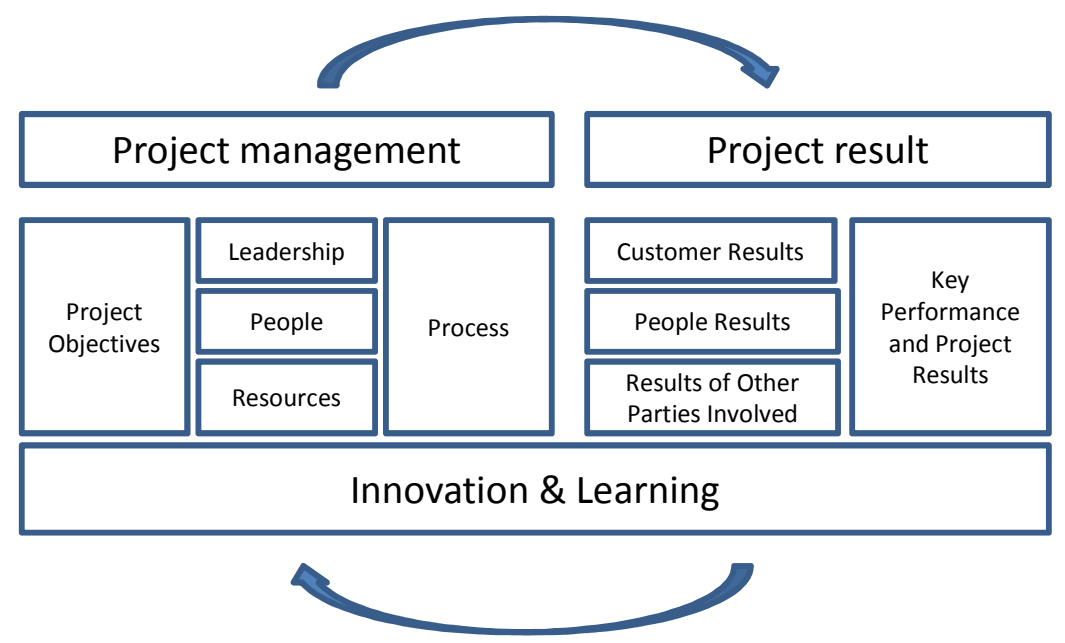

Figure 12.2: Framework of the Project Excellence Model (IPMA, 2008)

\subsubsection{Mapping the assessment criteria and sub criteria with the Project Scorecard}

The results of the project assessment are translated into additional project objectives and measures, which focus on identified weaknesses to perform better in subsequent projects. These measures are derived from the model's criteria so that the related goals are monitored and controlled more effectively and project performance is increased.

The integration of these goals and measures into a PSC or a CPS enables the project manager to quickly assess the current status of his project with respect to all relevant objectives including those contributing to project excellence. The nine criteria are mapped with the perspectives of the scorecard and project goals categorised accordingly. Figure 12.3 shows the mapping of the Project Excellence Model with a Project Scorecard. 


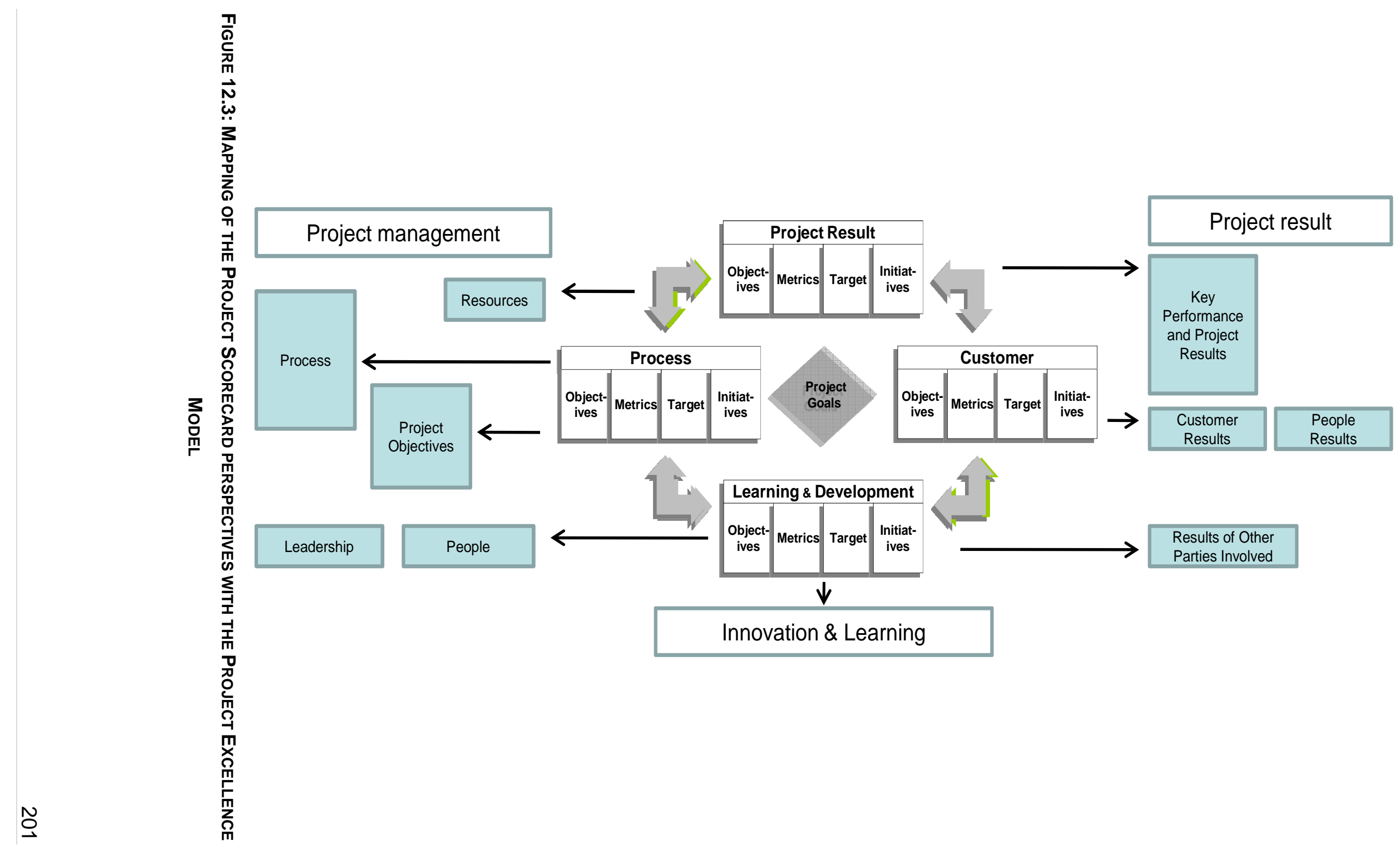


Each scorecard perspective includes several objectives that are aligned with the Project Excellence (PE) criteria and sub criteria. Table 12.1 includes examples of how the Project Scorecard perspectives and objectives are mapped with the PE criteria.

\begin{tabular}{|c|c|c|c|c|}
\hline $\begin{array}{c}\text { PSC } \\
\text { Perspective }\end{array}$ & PSC Objective & PSC Metrics & PE Criteria & PE Sub Criteria \\
\hline Project Result & $\begin{array}{c}\text { budget } \\
\text { adherence }\end{array}$ & $\begin{array}{c}\text { development } \\
\text { \& production } \\
\text { costs }\end{array}$ & $\begin{array}{c}\text { key performance } \\
\text { and project } \\
\text { results }\end{array}$ & budget \\
\hline Process & process & $\begin{array}{c}\text { no of process } \\
\text { deviations }\end{array}$ & process & $\begin{array}{c}\text { communicate } \\
\text { process changes }\end{array}$ \\
\hline Customer & quick response & $\begin{array}{c}\text { response time } \\
\text { to change } \\
\text { to customer } \\
\text { demands }\end{array}$ & $\begin{array}{c}\text { Customer } \\
\text { Results }\end{array}$ & $\begin{array}{c}\text { support: } \\
\text { frequency of } \\
\text { contacts }\end{array}$ \\
\hline Learning \& & employee & no of & people & continuous \\
learning
\end{tabular}

TABLE 12.1: MAPPING OF PSC OBJECTIVES WITH PROJECT EXCELLENCE CRITERIA

In the development stage of a PSC, the Project Excellence Model criteria can already be considered and translated into PSC objectives and measures. This supports the project leaders to monitor and control project excellence at an early stage and to change the focus during the project if deviations to PE criteria occur. This consequentially leads to higher project performance as defined by the Project Excellence Model. When a project is completed and assessed, the identified difficulties are translated into new goals and adopted in a modified Project Scorecard. The updated scorecard helps the project leaders to monitor and control their weaknesses more effectively in next projects (Figure 12.4). 


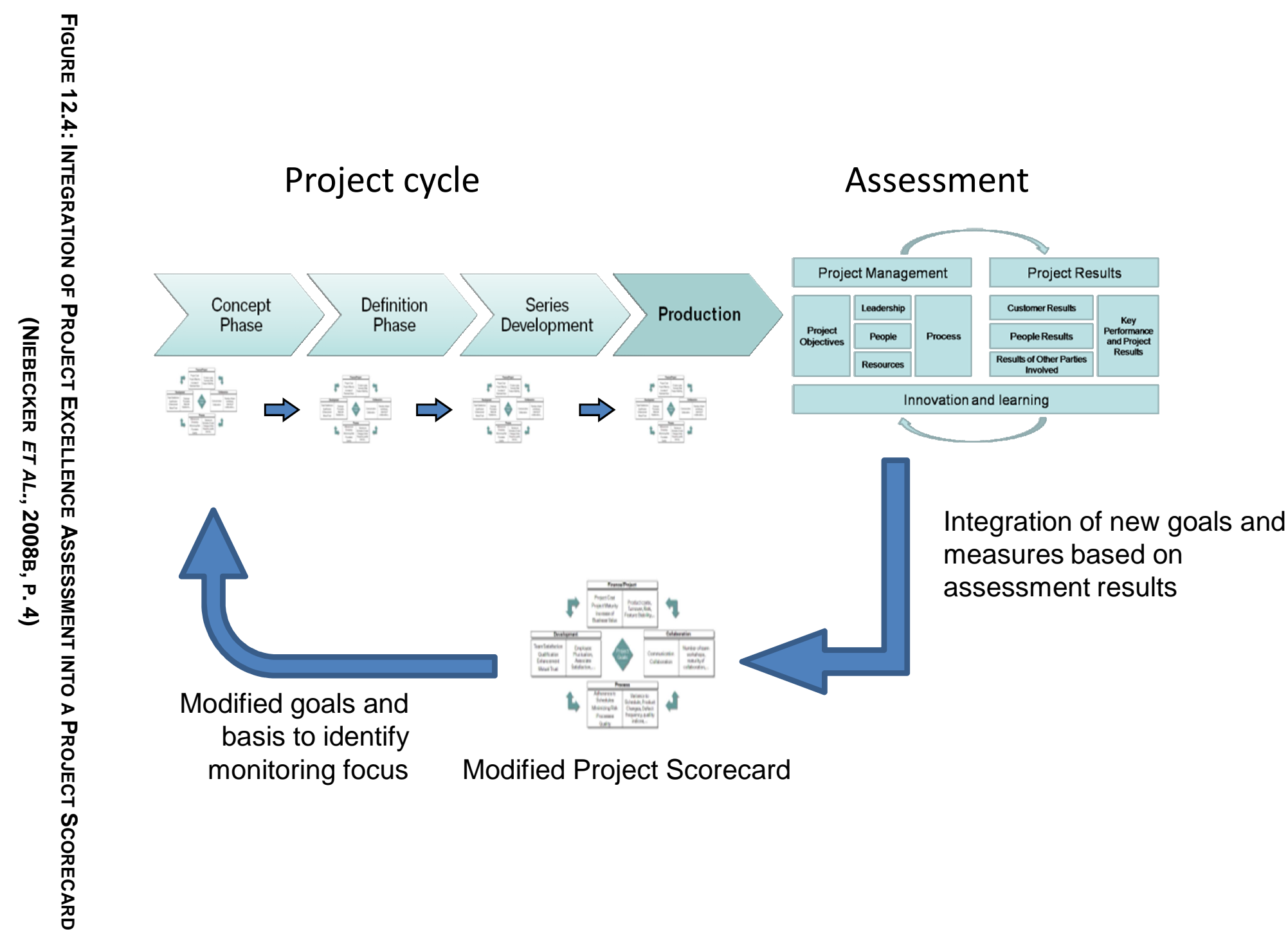




\subsubsection{Mapping the Project Excellence Model with the Collaborative Project Scorecard}

Collaborative and cross-company project teams can also be assessed by the Project Excellence criteria. Although, the metrics of the original framework are easily integrated into a PSC, the framework needs a modification for cross-company project management assessment.

To map the Project Excellence Model with a CPS, the customer results become collaboration results, whereas all other results and enablers are considered in a collaboration context. Figure 12.5 shows the modified assessment model.

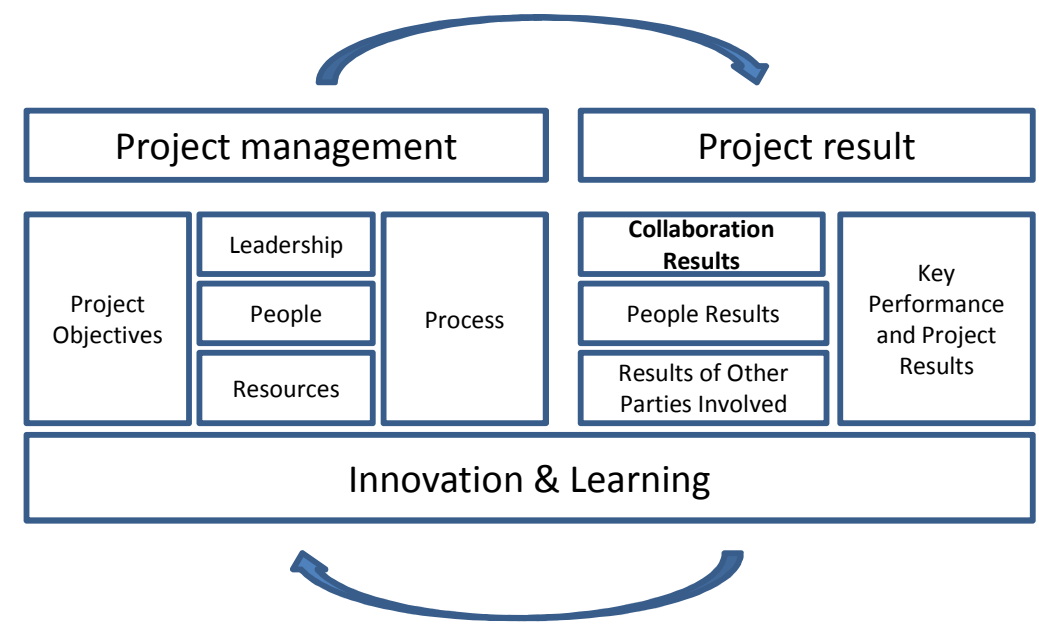

FIGURE 12.5 MODIFIED ASSESSMENT MODEL

The mapping of the criteria is similar to that of the PSC; however, the criteria need to be considered from a collaboration point of view. Figure 12.6 shows the modified mapping. 


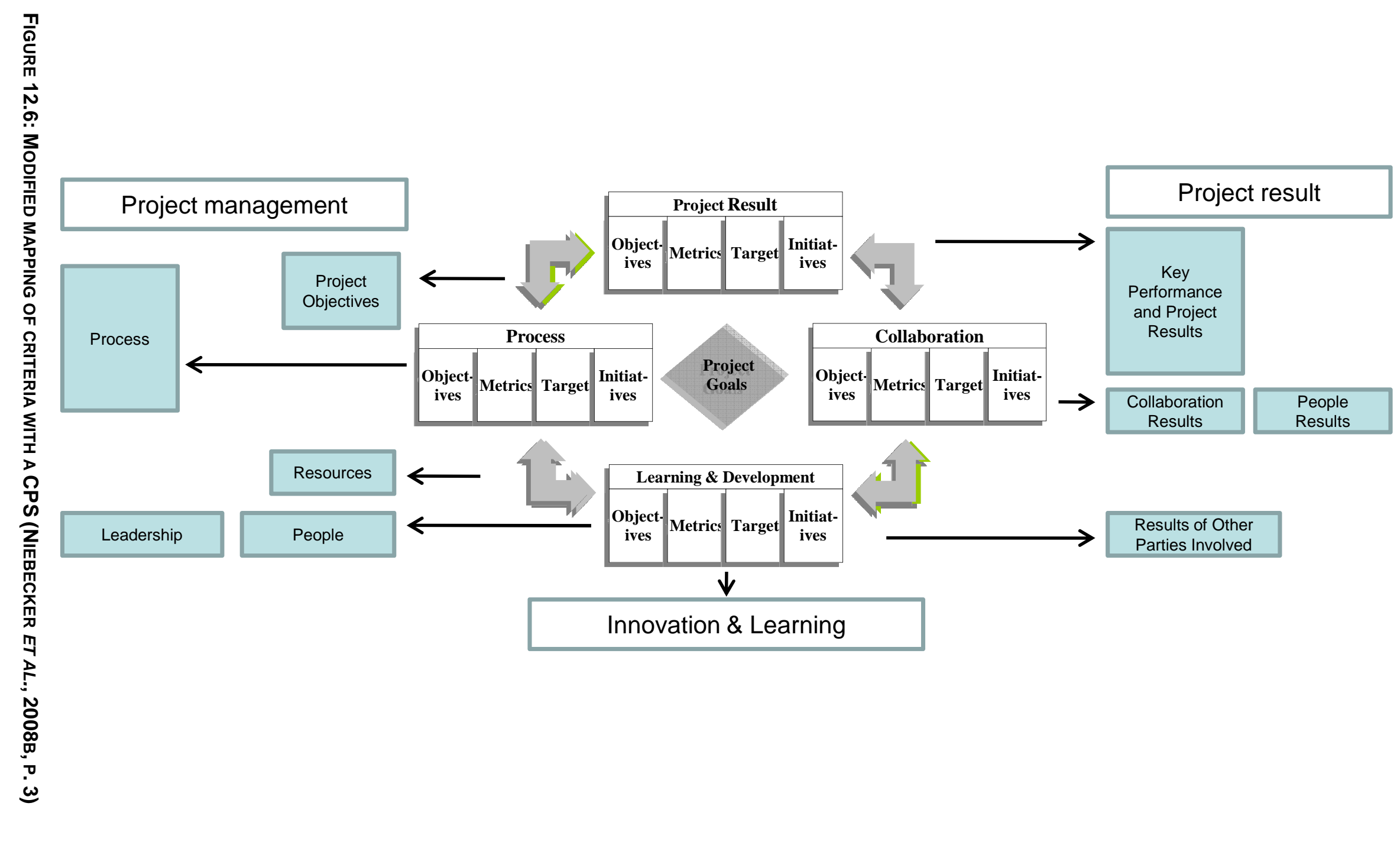


The integration of the identified criteria into the subsequent CPS within an individual partnership enables the project members to achieve high level of project performance on a collaborative level assuming that the selected criteria of the Project Excellence model lead to high project performance as well.

Figure 12.7 shows how the integrated criteria can be re-assessed for another similar project within the same project partnership.

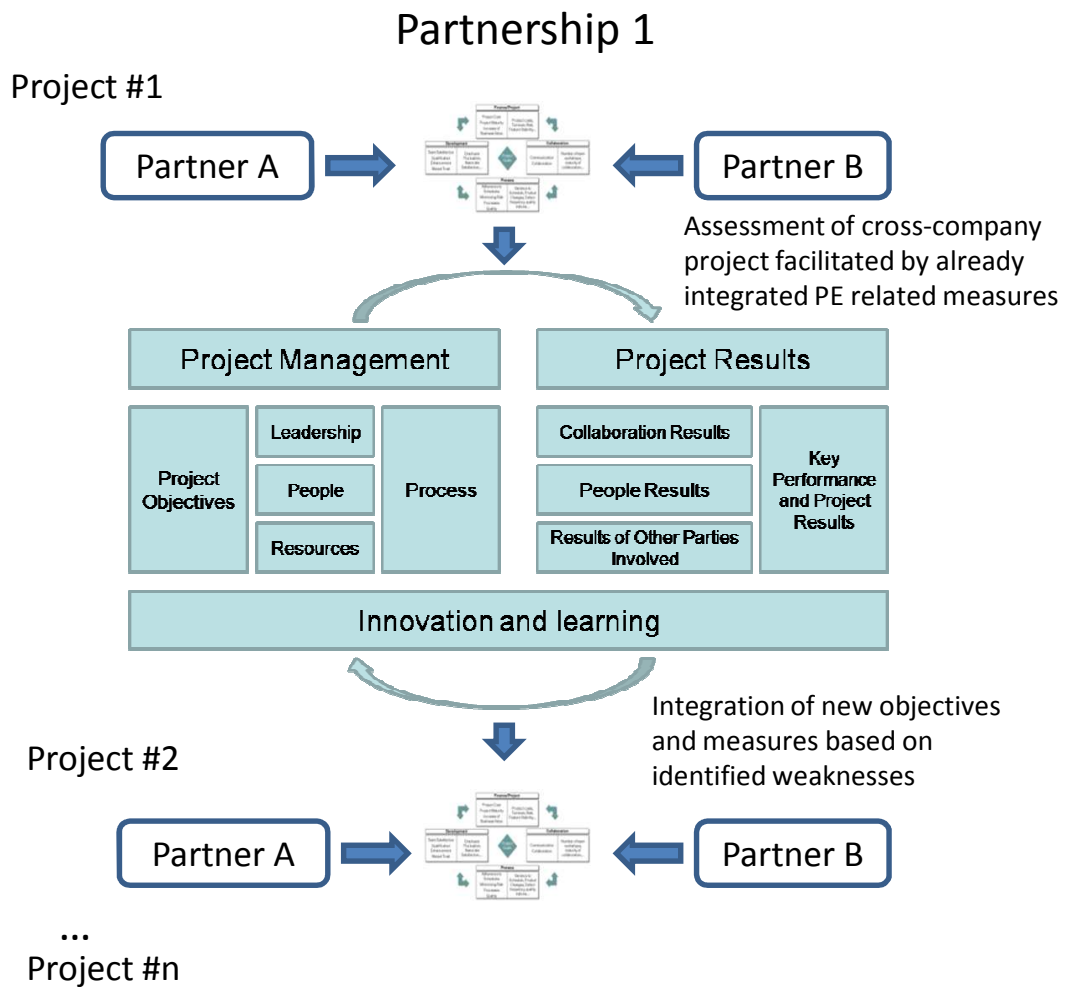

FIGURE 12.7: INTEGRATING COLLABORATIVE PROJECT ASSESSMENT RESULTS INTO A CPS (NIEBECKER ET AL., 2008B, P. 5)

The Project Excellence Model already provides a fundamental framework with criteria that are relevant to achieve high project management maturity and excellence in a partnership. Especially, long-term partnerships are likely to profit from the assessment results as changes and improvements can be implemented step by step. Additionally, the assessment model can help to identify the quality of a certain project partner on a structured and comparable level. If relevant criteria are already monitored and controlled from the beginning of a project, the project manager can evaluate objectively whether the project partner fulfils the necessary requirements or not. Early interaction and control helps to avoid project failure, and early identification of certain weaknesses in project excellence can lead to a reorientation towards possible future project partners. The 
greatest challenge is the right choice of appropriate criteria that need to be monitored during a project. Too many sub criteria may hinder the project manager to focus on the main objectives and project results, whereas too few may not contribute to a great change towards improvement.

Table 12.2 shows examples how CPS objectives are mapped with the Project Excellence criteria in a collaboration context.

\begin{tabular}{|c|c|c|c|c|}
\hline $\begin{array}{c}\text { CPS } \\
\text { Perspective }\end{array}$ & $\begin{array}{c}\text { CPS } \\
\text { Objective }\end{array}$ & CPS Metrics & PE Criteria & PE Sub Criteria \\
\hline $\begin{array}{l}\text { Project } \\
\text { Result }\end{array}$ & $\begin{array}{l}\text { adherence to } \\
\text { SOP }\end{array}$ & $\begin{array}{l}\text { milestone } \\
\text { adherence }\end{array}$ & $\begin{array}{c}\text { key performance } \\
\text { and project } \\
\text { results }\end{array}$ & cycle times \\
\hline Process & $\begin{array}{c}\text { process } \\
\text { adherence }\end{array}$ & $\begin{array}{c}\text { no of } \\
\text { process } \\
\text { deviations }\end{array}$ & Process & milestone control \\
\hline Collaboration & $\begin{array}{c}\text { effective } \\
\text { communication }\end{array}$ & $\begin{array}{l}\text { response } \\
\text { time to } \\
\text { enquiries }\end{array}$ & $\begin{array}{c}\text { collaboration } \\
\text { Results }\end{array}$ & $\begin{array}{c}\text { acceptance of } \\
\text { mutual } \\
\text { expectations }\end{array}$ \\
\hline $\begin{array}{c}\text { Learning \& } \\
\text { Development }\end{array}$ & $\begin{array}{c}\text { create } \\
\text { innovation }\end{array}$ & $\begin{array}{c}\text { no of } \\
\text { implemented } \\
\text { ideas }\end{array}$ & People & $\begin{array}{c}\text { innovative } \\
\text { strategies for work } \\
\text { organisation and } \\
\text { methods to improve } \\
\text { operations }\end{array}$ \\
\hline
\end{tabular}

TABLE 12.2: MAPPING OF CPS OBJeCtIVES WITH PROJECT EXCELLENCE CRITERIA

Collaboration has been identified as a key driver of business performance and impacts several drivers of performance variably. A collaboration index that measures how collaborative an organisation is has been developed for a research study and includes the components "collaboration capability" and "collaboration quality". The study demonstrated that the collaboration index contributes $36 \%$ to a business' performance (Frost and Sullivan, 2008). An extension of the PE Model to assess performance of collaboration objectives can be based on the collaboration index used in this study. Collaboration capability such as technological aspects and culture of openness, and collaboration quality that describes the nature and extent of collaboration as well as how effectively the capabilities are applied, are relevant dimensions of collaborative project management. Recent studies demonstrate that collaboration is becoming increasingly important to a company's success. A commonly defined and recognised standard to 
assess cross-company projects and collaboration appears to be necessary to evaluate performance and identify own and mutual weaknesses. The integration of relevant collaboration criteria identified by the industry and recent studies to an existing model that already provides a profound set of project management assessment criteria should be the next step to collaborative success.

\subsection{Remarks on CPS performance assessment}

Performance assessment of cross-company projects is fundamental to identify strengths and weaknesses in a partnership and the early integration of criteria that support the achievement of high project management maturity levels is a prerequisite to monitor and control cross-company projects effectively.

Clearly and commonly defined long and short-term goals measured by a balanced choice of leading and lagging indicators as well as hard and soft facts are the key to a sustainable project partnership. The Collaborative Project Scorecard is a new concept that helps the project manager to clarify and define common project goals in advance, and supports the agreement on common metrics and corrective action when problems occur. To ensure that the right goals to achieve high project performance are targeted, a standardised assessment model based on the Project Excellence Model provides relevant criteria and sub criteria to assess how efficient and effective project management is carried out and helps the team to identify their own performance status at an early stage. This chapter demonstrated how the Collaborative Project Scorecard is combined with a modified Project Excellence Model. To obtain optimal results in project performance, the interactive application of both concepts requires a project partnership with successive projects and the monitoring and control of long-term goals with commonly agreed measures.

The CPS with integrated Project Excellence criteria enables the project manager to focus on the project goals including excellence related goals more effectively and ensures the alignment of these goals with business strategies. The assessment at the end of each project is fundamental to compare several project partners objectively and facilitates a transparent implementation of initiatives for improvements. Therefore, not only collaboration can be assessed but also internal weaknesses or those of the partner. Collaboration capability may be one of the dimensions that need a greater focus. With this in mind, the assessment of supplier performance and the identification 
of the best strategic partners are other options accomplishable with the combined concepts. However, the selection of appropriate criteria applicable to a partnership and the correct mapping with the CPS objectives is an effort that should not be neglected. Careful selection and consequent monitoring is a key to success for all project partners. Taking into account that there is no industry wide standard to assess cross-company projects, it is recommended to start an interdisciplinary discussion about the development of an assessment standard to achieve higher project performance for all project partners and to facilitate the introduction and application of a measure based scorecard such as the CPS that improves communication and goal definition. 


\section{Collaborative project risk management with a Collaborative Project Scorecard}

Uncertainty and unpredictability in project management has caused delays and high costs in a high number of projects due to an insufficient consideration of risk management. The monitoring and control of possible and known project risks lead to the development of methods and processes to minimise project failures and to develop strategies to avoid costly measures for risk prevention. Risks are not only considered as threats but also as opportunities that can have a positive effect on project results (Jaafari, 2001). This chapter illustrates how the Collaborative Project Scorecard can support an integrated approach to risk management in project partnerships. The chapter begins with an introduction to general project risk management and with a focus on the automotive industry in the second section. This is followed by an analysis of the Balanced Scorecard and Project Scorecard approach to risk. The structure of this chapter is shown in (Figure 13.1).

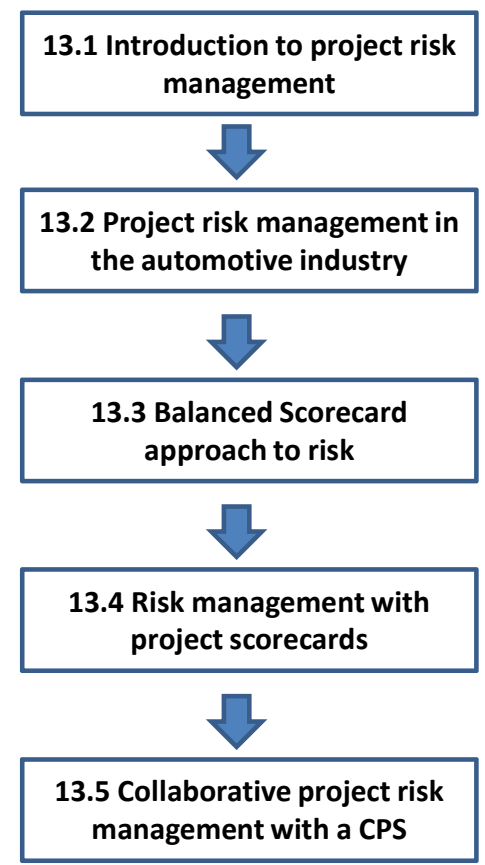

FiguRE 13.1: OVERVIEW OF CHAPTER 13

Finally, the application of CPS concept is discussed and a possible approach illustrated. 


\subsection{Introduction to project risk management}

Project risk management has become a fundamental discipline in most of the industry sectors worldwide. Especially, the IT industry experienced the impact of risks on their projects where only $28 \%$ of all software development projects were rated as successful according to a report of the Standish Group in 2004. Typically, IT project risks have an impact on costs, time, and performance of a project, and a list of 92 risk factors has been identified and ranked according to their severeness (Tesch et al., 2007). With respect to project performance, the six dimensions of software project risks are organisational environmental risk, user risk, requirements risk, project complexity risk, planning and control risk, and team risk (Wallace et al., 2004). Another example is the construction industry where high risk exposure due to a rapidly changing environment strongly influences the profitability of construction projects. Results are schedule delays and cost overruns that could have been avoided with an integrated risk management and an early risk identification and assessment (Zayed et al., 2008).

A survey with 50 project managers revealed that $85 \%$ of their projects had an integrated risk management and most of the participants were unhappy about the insufficient application of risk management in their projects. Seventy percent of the identified risks are discussed in a status meeting but only $45 \%$ of those risks are communicated to other project members. As a result only $5 \%$ of the project managers have considered risk management in their budgets (Volland, 2006). Therefore, risk management needs to have more attention and the development of new methods and processes requires a consequent application. Whereas, the identification of risks is the first step, a realistic forecasting of project costs, demand and other impacts is also important and was identified as a major source of risks. Bent Flyvbjerg observed that there have been no improvements in forecasting accuracy and analysed the potentials and barriers of a new method that uses reference class forecasting (Flyvbjerg, 2006).

\subsection{Project risk management in the automotive industry}

Automotive projects are typically characterised by high risk exposure due to a high number of parallel processes in the supply chain and product development. Recently the likelihood of those risks has been further increased due to a growing complexity of the supply chain and the development partner network. 
The high demand for innovations to stay competitive has caused the production of immature products and a high number of product recalls (Hab and Wagner, 2006).

Typical risks in the automotive industry are:

- Economical risks (currency risks, bankruptcy of suppliers, credit worthiness of customers, transport risks).

- Technical risks (new tools, immature technical components, process instability).

- Interpersonal risks (employees are not qualified, team conflicts).

- Milestone/Time risks (milestones not achieved, late SOP).

- Socio-cultural risks (moral concept, cultural conflicts).

- Act of nature beyond control (flooding, thunderstorm, strike, terror).

- Political risks (impact of interest groups, import restrictions, new laws and regulations).

In the policy towards risk the top management defines the fundamental view of a company's risk philosophy. It includes the structure of the philosophy, the principal readiness to assume risk with respect to the business objectives, the quantification of risk related objectives, and the documentation in a risk management handbook. In general, risk management in the automotive industry consists of a risk analysis, risk measures, and control of success. The risk analysis is structured into risk identification (identification of possible risks, consequences of risks, risk causes) and risk evaluation (incidence rate, measure of damages), whereas risk measures include risk avoidance, risk mitigation, risk transfer, and risk acceptance. Control of success is defined by a continuous monitoring of risk measures, comparison to policy towards risk objectives, and transparency of risk costs. The risk management process supports the identification, evaluation and avoidance of risks, wherein preventive measures are highly relevant for a project's success.

The foundation of the risk process is the risk analysis that evaluates technical, commercial, and organisational risks with respect to probability and impact on costs and deadlines. The checklists for a systematic identification of risks include the product structure, project structure, and milestone plans. 
The identified risks and measures may then have an impact on project organisation, as wells as the cost, milestone, and activity planning and are shown in Figure 13.2 (Schuh, 2000).

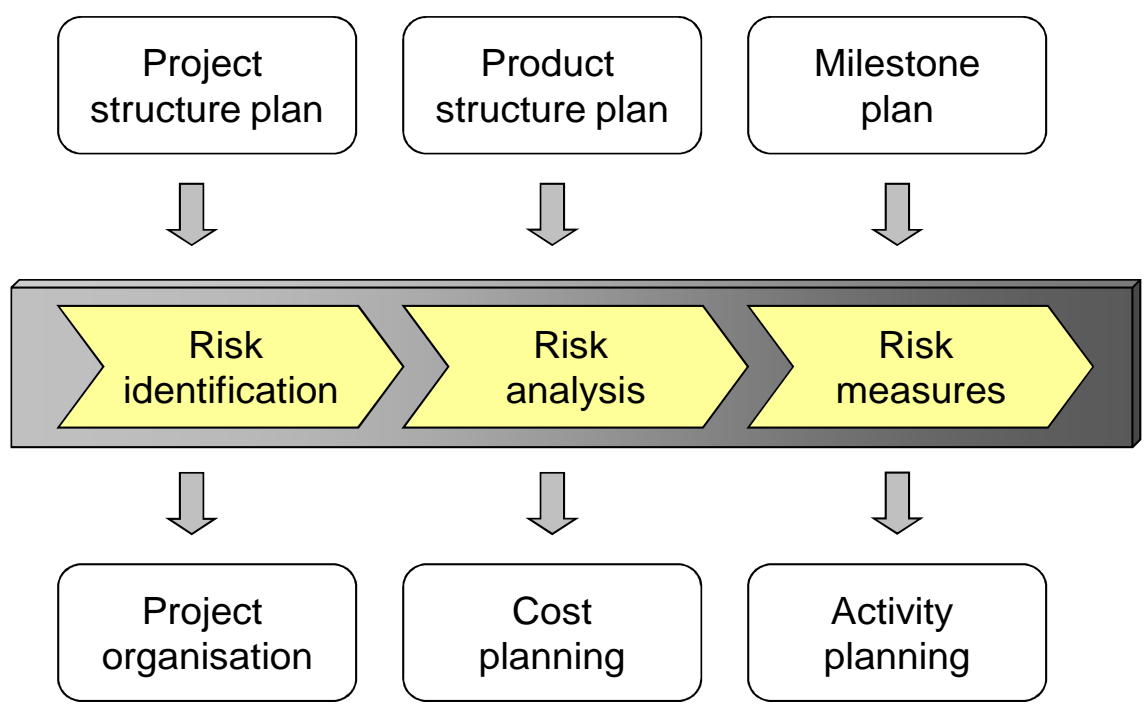

FIGURE 13.2: RISK MANAGEMENT PROCESS IN THE AUTOMOTIVE INDUSTRY (SCHUH, 2000, P. 181).

For an analysis of technical risks in the product development phase of a project, the Failure Mode and Effect Analysis (FMEA) is the most common and accepted method. The process FMEA of production processes has been further developed to a development FMEA that describes the whole vehicle development process and extends the traditional project risk management with vehicle development specific aspects (Figure 13.3).

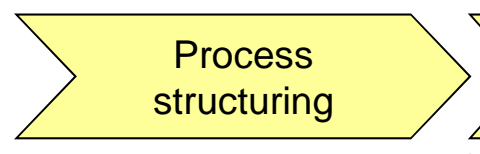

Structuring of development process:

- Integration to process landscape

-Tasks, dependencies, interfaces

-Quality gates

-...

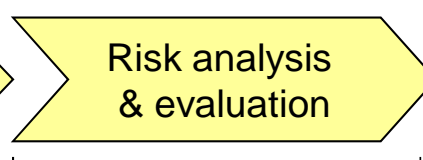

Identification of incidents:

-Performance loss

-Technology change

-Loss of supplier

....
Measure to Minimise risks

Definition of measures for risk mitigation:

-Preventive

-Reactive (fall back strategies)

-...

FIGURE 13.3: DEVELOPMENT PROCESS FMEA AS AN EXTENSION TO TRADITIONAL PROCESS FMEA 
There is a variety of different methods applied during the risk management process. The execution of risk management is supported by risk check lists that include also project phase related risk aspects. Already in the offer phase, a project manager needs to analyse possible risks and evaluate probability and impact. These two criteria allow the manager to categorise risks into three types: A (high), B (moderate), and C (low) risks. Another method, for example, is the Strengths, Weaknesses, Opportunities, and Threats (SWOT) analysis (Hill, 1997). Whereas, the SWOT analysis usually supports strategic decisions, it can also help to improve a project during the life cycle by identifying implied chances and opportunities of risks that may higher the performance of project results.

The early definition and agreement of requirements has a great impact on risks during a project. Unfortunately, requirements with project partners and suppliers are often defined very late or not all. This may appear beneficial to a manufacturer in the beginning as requirements change can be done without costly change requests but typically the planning quality and development quality decrease due to a limited time to implement changes at later stages of the project (Bullinger et al., 2003). Next to higher costs and time it also increases potential risks and strains the relationship of the project partners. An early agreement of requirement specifications in a tender document reduces the change effort during the product development phase. However, in addition to an early defined requirements specification, the definition of commonly agreed project goals is essential to avoid conflicts and inefficiency during the project.

Strategic and operational goals need to be translated into measurable goals that enable the project manager to evaluate the status and to take necessary measures. Due to the complexity of vehicle projects, the technical goals and requirements are structured into product components and functions, often supported by the Quality Function Deployment (QFD) method that determines the project goals in a two stage process: the goal identification and the goal agreement process (Akao, 2004). The QFD translates consumer requirements into company requirements at each project stage. During the goal identification process, the "House of Quality" can be applied to relate customer requirements with product specification (technical) and market requirements (comparison of competition). On the basis of lists, tables and matrixes, the project goal catalogue is created and translated into technical requirements during the goal agreement process. This catalogue can then be used to do a FMEA for a more detailed analysis. 


\subsection{A Balanced Scorecard approach to risk}

The improvement of forecasting methods and risk processes needs greater attention; however, their company-wide and consequent application is a prerequisite for a sustainable success. To implement business strategies, the Balanced Scorecard (BSC) has been demonstrated as an effective and efficient method since its development in the 1990s (Kaplan et al., 2004). A balanced choice of indicators that indicate a future development (leading) and those that are based on past results (lagging) together with financial and non-financial measures provides a fundamental framework for a short- and long-term goal achievement. Additionally, strategy maps increase the transparency of a business by visualising cause-and-effect relationships of the strategic goals. Since the introduction of the Balanced Scorecard, its application has been extended to various disciplines and purposes. An example is the Sustainability Balanced Scorecard that translates the sustainability visions and strategies into action and integrates environmental and social aspects into the core management of companies (Bieker, 2002). The integration of risk management into a BSC for a value orientated control system demonstrated the improvement of efficiency, quality and acceptance of both systems, the control and risk management system. When KPIs and corrective actions are defined for a BSC, managers already discuss the possible causes that may impact future plans. As a result, leading indicators and risks for the risk management system are already identified (Gleissner, 2002). The BSC concept has been applied to project management and demonstrated that performance of project teams can be improved (Norrie et al., 2004).

\subsection{Risk management with a Project Scorecard}

Due to globalisation and an increasing competition on the international market, project management experiences a change towards a complex network of project partners where project teams are geographically dispersed and cross-company projects become more relevant for achieving better performance, saving project costs and time. Next to these benefits, there are a number of difficulties project managers have to face when they manage projects in such collaboration networks. Barriers of communication, low transparency of project structures, and an ambiguous understanding of project goals are some of the problems that need to be solved. Especially, the management of collaborative risks and the establishment of commonly defined risk processes are essential and have not been addressed sufficiently until today. The integration of project 
risk management into a Project Scorecard and a Collaborative Project Scorecard has similar benefits as already identified by Gleissner's (2002) combined risk management and BSC concept. On the basis of the automotive industry, this section illustrates how project risk management can be integrated into a CPS and it demonstrates how collaborative projects risks can be mitigated by a more effective and efficient monitoring and control, a consequent risk management application, and the early identification and assessment of possible risks.

\subsection{Collaborative project risk management with a CPS}

Planning, monitoring and control of project risks have not been considered sufficiently in cross-company projects. This is mainly because the number of partnerships and complexity of networks have increased steadily without an appropriate adaptation of project management methods and processes. Today, many project managers know that project risk management is not considered sufficiently when they begin a project with one of their partners. A reason, for example, is that they do not know what methods to apply or how to integrate collaborative project risk management into their existing process landscape. When implementing a Collaborative Project Scorecard, possible risks are already considered in the planning and concept phase of a project. Risks are formulated into measurable indicators that may impact a certain project goal, and with leading and lagging indicators, the future development of a risk or opportunity can be analysed and evaluated. Corrective action is already defined for each measure, and with the help of predefined quality gates, the impact on project progress can be evaluated at an early stage of a project. Figure 13.4 illustrates the concept of CPS risk management. 


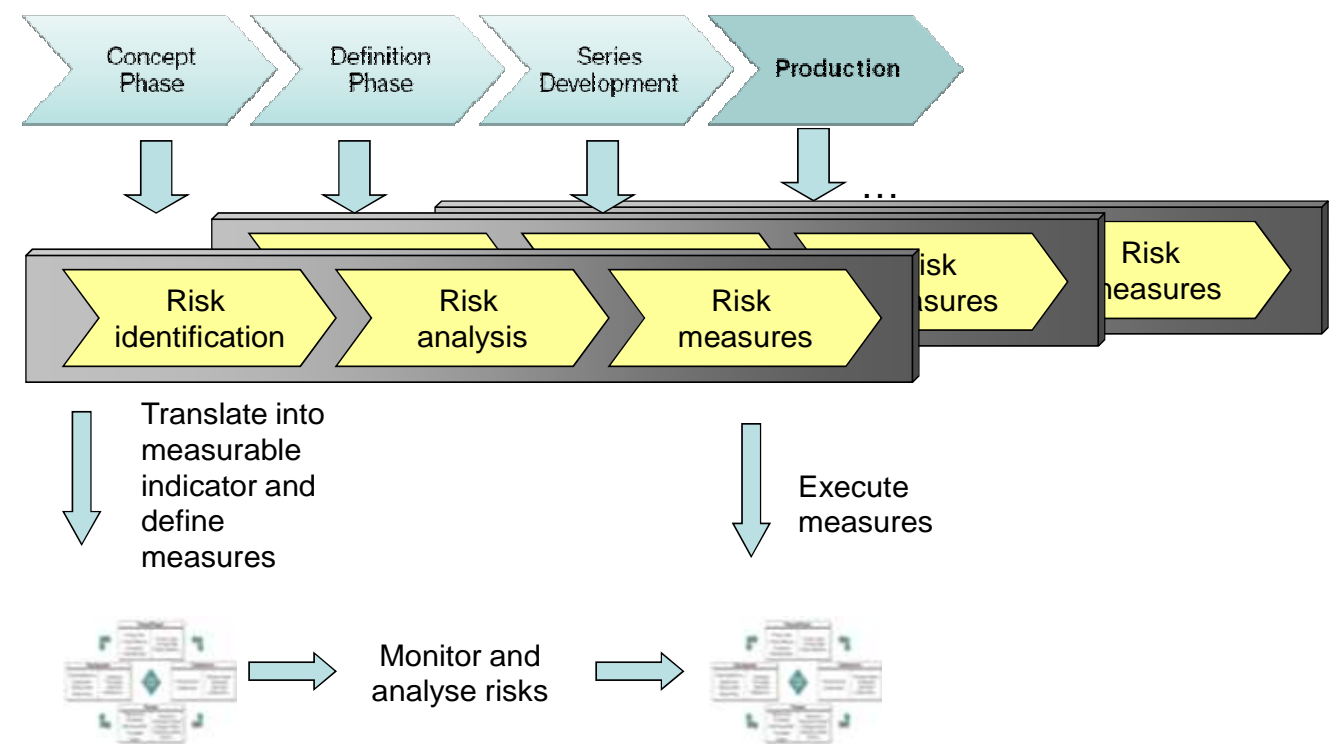

Figure 13.4: Risk management With a Collaborative Project Scorecard

Collaborative risk management can be incorporated within the scale of the CPS methodology. The framework of each perspective needs an extension of risk management categories. The analysis of risk before any measures are taken is essential for the identification and evaluation of preventive and corrective counter measures. The identification of risk that may still occur after the execution of counter measures is part of the counter measure evaluation procedure. An optional "lessons learned" category may be useful for future projects and similar risk events. The risks the project teams are aware of increase during the risk identification process. After defining preventive risk counter measures the risks may become less effective on the project team's awareness. However, when some preventive counter measures do not minimise the risks the corrective counter measures have to be taken to minimise the risks. Nevertheless, there are usually always risks that cannot be controlled. Figure 13.5 shows a systematic relation between awareness of risk occurrences and the CPS risk management procedure. 


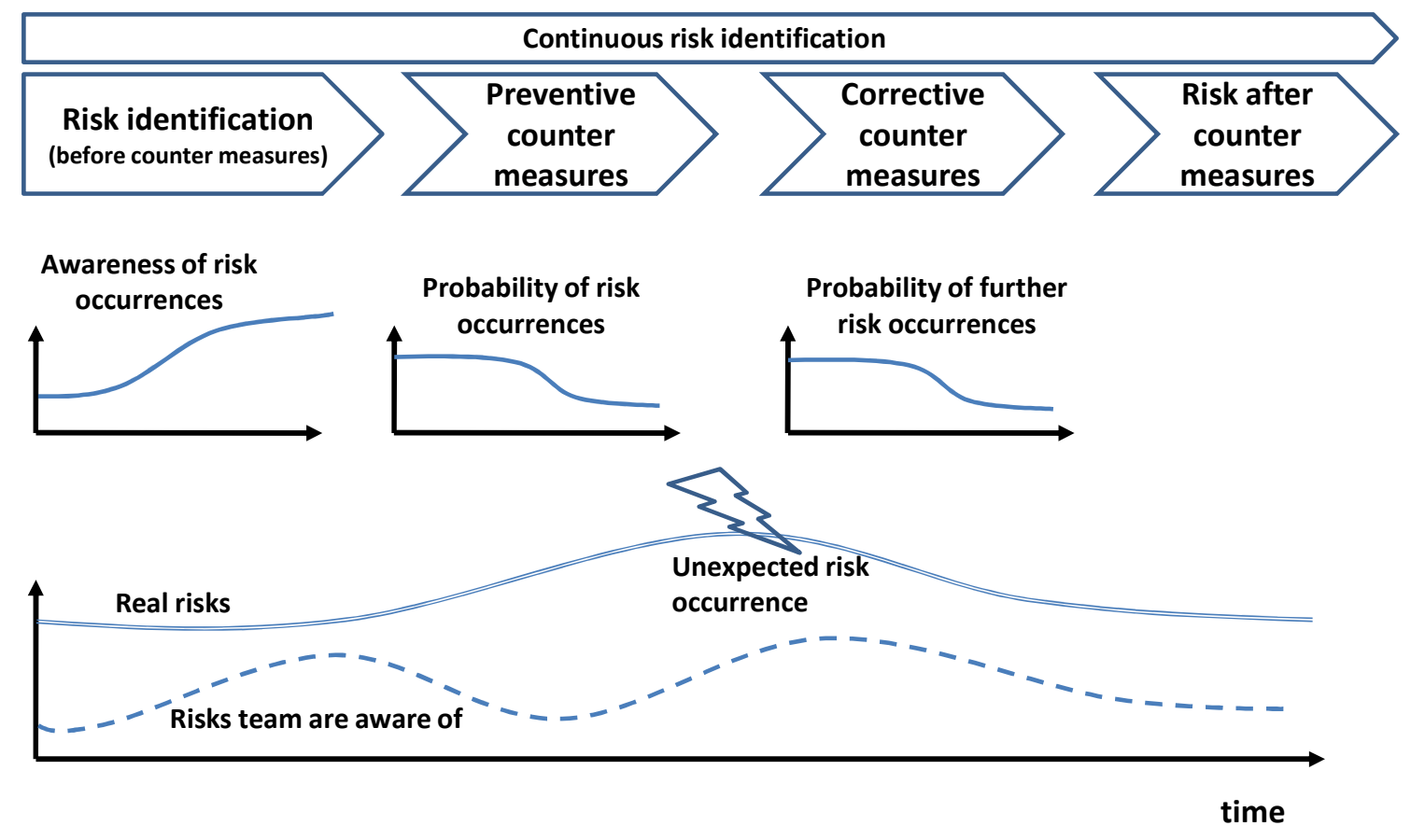

FIGURE 13.5: RISK OCCURRENCE AND CPS RISK MANAGEMENT PROCEDURE

Preventive counter measures can only be defined if the project members are aware of the related risks. Some risks may occur without any early indication and counter measure need to be identified, evaluated, and commonly agreed during the risk occurrence. The following figure shows how the CPS framework can be extended with the additional risk management categories (Figure 13.6).

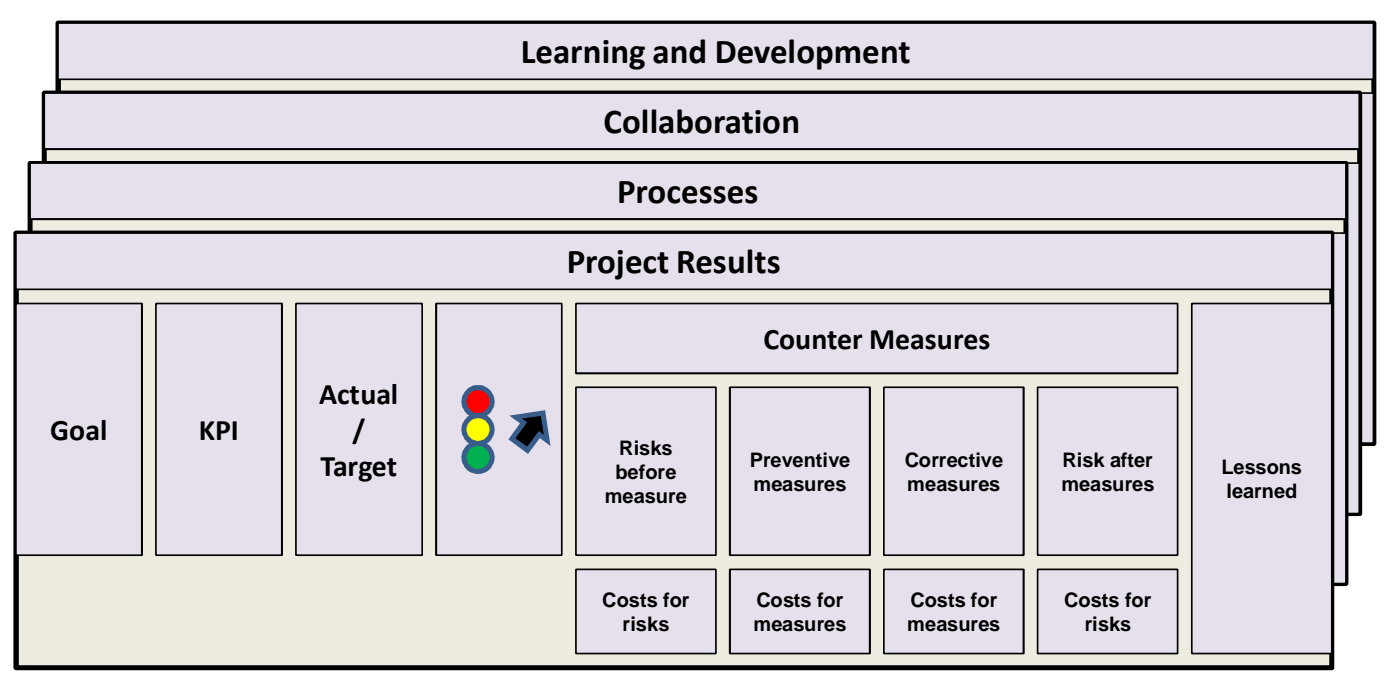

Risk Management Extension

FIGURE 13.6: CPS RISK MANAGEMENT CATEGORY EXTENSION

The costs for preventive and corrective counter measures are relevant for the evaluation process. Some risk measures may cost more than the financial loss of the related risk. 
Additionally, not every preventive measure can eliminate the risk completely but limit and reduce the probability of its occurrence. The experience with implemented preventive and corrective measures regarding effectiveness and (cost) efficiency should be documented in the "lessons learned" category of the CPS. This enables the continuous improvement of the combined risk and measure management approach. Whenever certain internal risks of a project partner organisation have influence on the other partner's business and project it should be included in the CPS to create transparency at the interfaces and to create reliability, accountability but also trust on both sides. 


\section{Conclusion}

Cross-company project management has become a vital discipline for success in the automotive industry as an increasing number of project partners and project partnerships are necessary to decrease development and production costs, increase quality, and shorten product life-cycles. However, the quick move towards project partnerships has also caused difficulties as traditional project management methods haven't had a sufficient focus on a cross-company or collaborative application. This chapter is a conclusion about this research project and begins with a summary of the identified difficulties in automotive collaborative project management. In a next step, the Balanced Scorecard approach to project management is evaluated and illustrated why the Collaborative Project Scorecard was chosen as a main element of the concept. This is followed by a conclusion of the research steps (see also Figure 5.6) and results from workshops, surveys, interviews and the pilot project in the USA. The concept extensions as illustrated in Figure 5.10 are then discussed and final remarks and recommendation on future research can be found in the last section (Figure 14.1).

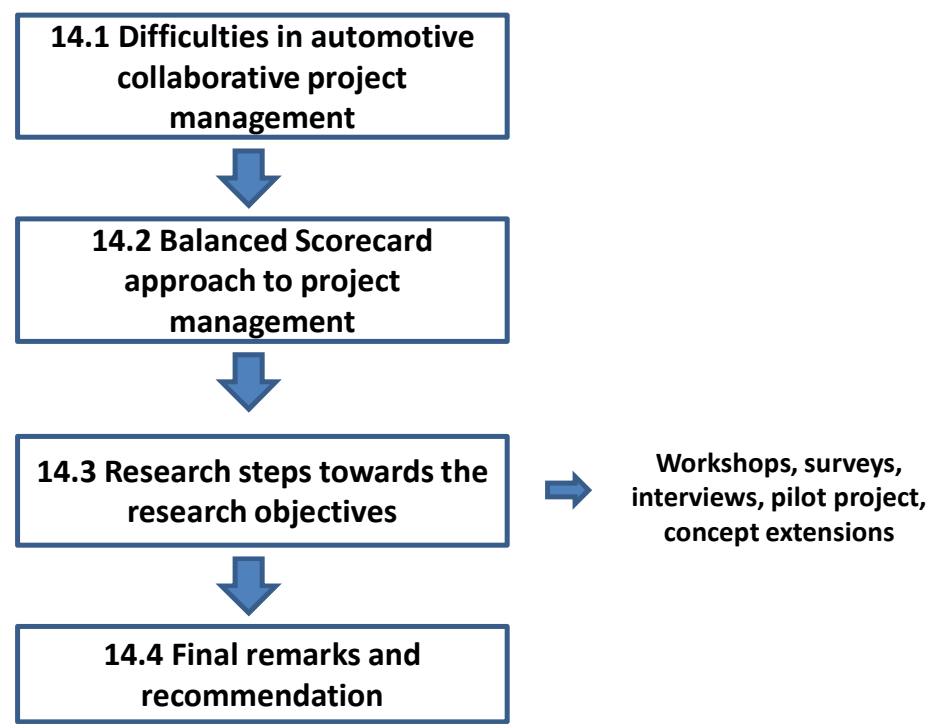

Figure 14.1: STRUCTURE OF CHAPTER 14

\subsection{Difficulties in automotive collaborative project management}

Project failure due to unclear requirements, project goals, and communication problems have become some of the greatest problems in the automotive industry. Deficient 
management is also one of the reasons that caused an increased number of product recalls in the last years. The growing number of project partners has also lead to lower transparency in the project organisations due to higher complexity in the project structures. This also impedes the integration of relevant stakeholders as well as the status measurement of a project. The process of finding common goals and a mutual understanding of the partners' objectives has become more difficult and often ends in an ambiguous definition of project objectives. A lack of collaborative risk management and predefined corrective and preventive measures and corrective action together with problems in communication are some of the main reasons for projects to fail. The demand for new concepts that improve these deficiencies in a collaborative and crosscompany project environment was the reason to develop a concept based on the Balanced Scorecard. The framework has already been successful when applied to business and single project management, and therefore, it was promising enough to begin deeper research into its cross-company application.

\subsection{The Balanced Scorecard approach to collaborative project management}

The Balanced Scorecard developed by Kaplan and Norton has had widespread acceptance through their set of books and papers. The BSC has already been used in project management applications by Wendy Stewart (2001), Stewart and Mohammed (2001), Stewart (2007), Derek Walker and James Norrie (2004), and Norrie (2006). The extension to their work is the collaborative and cross-company approach of the BSC concept, the Collaborative Project Scorecard. The CPS is a new method to monitor and control cross-company projects by aligning collaborative project objectives with the project portfolio and business strategies of each company. The application of an impact matrix to identify the key measures and how they are related is one of the contributions to the traditional concept that facilitates the development of a project and collaborative project strategy map.

\subsection{Steps towards an achievement of the research objectives}

The core difficulties were identified with a combined approach of a literature review and additional interviews with project managers (see also Figure 5.7) from an OEM and project members of the ProSTEP iViP Collaborative Project Management project. The research project took mainly place at an OEM site in Germany and the US. The initial 
idea of applying a Balanced Scorecard to a cross-company project environment was followed by two workshops of the German Project Management association Automotive Chapter. Within the scope of these two workshops the CPS concept was applied specifically to automotive projects and the feedback of 30 senior project managers was integrated. Their feedback was a valuable contribution to the concept as their experience of approximately 10 years in project management helped to identify relevant key performance indicators and project objectives, as well as the relevant requirements, benefits, and limitations. Results can be found in section 8.2 .

\subsubsection{Initial workshop results}

According to the appraisal of the workshop participants (see also section 8.2.1 and 8.2.2), the one-off effort to implement a CPS may be outweighed by measurable targets with higher controllability, improved monitoring and control of project status, performance and maturity, improved communication and transparency between the project teams, and an increased integration of stakeholders. An online survey and feedback from the two workshops mainly contributed to the detailed development of the concept including a procedure model that describes how to introduce the CPS to an organisation. Typical automotive project objectives and measures as well as advantages and limitations of the concept were identified. As a main result the participants were convinced that the CPS supports a project manager to increase transparency, monitor and control the proper objectives, and integrates all relevant stakeholders. However, an IT implementation is necessary for an efficient and effective application.

\subsubsection{Evaluation by applying to a vehicle project}

After the CPS concept was developed it was evaluated by an application to a pilot project. Further concept development and evaluation took place in South Carolina USA in a cross-company project between the OEM and a major supplier to develop and manufacture a wire harness of a chosen vehicle (production launch in 2010). The result was the development of a Strategic Collaborative Scorecard and two Collaborative Project Scorecards for the launch and change management project phase. Several interviews and individual workshops at the OEM's and supplier's site were followed by a joint workshop to identify common project goals, measures, corrective action and a Collaborative Project Strategy Map. Some of the results were that the CPS reinforced the needs and expectations of both companies, it opened up opportunities for 
collaboration improvements and it created an alignment of the whole team to the agreed common goals. On the other hand, concerns about integration into existing reporting systems came up, and it was sometimes difficult to find KPIs for what they do.

In addition, it was also difficult to translate soft facts in measurable hard facts and the OEM will have to train its suppliers to use and maintain the new system. The results of the pilot project were implemented in a tool using Microsoft Performance Point Server 2007. The application of an IT implementation was rated as beneficial for the users and $\mathrm{KPI}$ reporting responsible, however it is essential that the solution does not create overhead work and does not duplicate existing reporting and monitoring systems. A high effort to create the system and to incorporate KPIs was estimated in the beginning but once typical KPIs are defined they can be carried over to other projects with their specific values. Other advantages were the capability of workflow management and the visualisation of strategy maps.

\subsubsection{Concept extensions}

The CPS concept was then extended (as shown in Figure 5.10) by an integration of a collaborative project management reference model to create operational KPIs, and a performance assessment model that enables the project manager to evaluate performance of a cross-company project by integrating relevant criteria into a CPS. The integration of a CPS with collaborative project management processes supports the project manager to standardise relevant project tasks and to create operational KPIs that can be strategically controlled by a CPS. The integration of leading indicators enables a collaborative and preventive risk management so that problems can be solved before they occur. The ProSTEP iViP CPM Reference Model supports the CPS in providing collaboration relevant KPIs and standardised tools for communication, time, and task management. Performance assessment of cross-company projects is fundamental to identify strengths and weaknesses in a partnership and the early integration of criteria that support the achievement of high project management performance levels is a prerequisite to monitor and control cross-company projects effectively and efficiently. To ensure that the right goals to achieve high project performance are targeted, a standardised assessment model based on the Project Excellence Model provides relevant criteria and sub criteria to assess how efficient and effective project management is carried out. To obtain optimal results in project performance, the interactive application of both concepts requires a project partnership 
with successive projects and the monitoring and control of long-term goals with commonly agreed measures. However, the selection of appropriate criteria applicable to a partnership and the correct mapping with the CPS objectives is an effort that should not be neglected. Careful selection and consequent monitoring is a key to success for all project partners.

Finally, the CPS concept was extended by a risk management framework. The analysis of risk before project start is essential for the identification and evaluation of preventive and corrective counter measures. The identification of risk that may still occur after the execution of counter measures is part of the counter measure evaluation procedure. It is important to include risks in the scorecard to continuously monitor and control them accordingly. However, risk management of technical risks should not be included in a project management scorecard; therefore, a technical risk analysis such as FMEA is still required.

\subsection{Final remarks and recommendation on future research}

The application of a CPS to other project phases such as series development is necessary to evaluate the concept's ability for all project phases of an automotive project. As the CPS concept is scalable and adaptable it should also be considered to be applied to other industry sectors as it promises improvement wherever crosscompany or collaborative project teams are involved. This also includes its application to inter-departmental projects or projects between two OEMs or two suppliers. When more than two partners are involved it is recommended to focus on one-to-one relationships to maintain transparency and to be able to clearly assign KPI reporting responsibilities. The selection of the right objectives and KPIs is one of the most difficult parts when developing a CPS as only a focus on the most relevant objectives will help to achieve the desired project goals efficiently. To achieve these objectives the right measures need to be chosen that enable the project manager to monitor and control a certain objective holistically and not only an aspect of it. The choice of these KPIs and objectives can become a competitive advantage of a project partnership. Although, the concept can be applied to any type of project it should be decided carefully when it is beneficial to a project partnership. Larger and more complex projects may benefit more from an increased transparency than less complex ones where transparency cannot be increased significantly. Finally, the alignment with and connection to existing project portfolio management is an important step to increase the concept's effectiveness to 
overall business performance. A continuous reporting structure from the project to portfolio and business level is feasible and enables the organisation to implement its strategy with fewer limitations due to an improved strategic and operational alignment. 


\section{Appendix $A$}

\subsection{Capability maturity model integration}

The Capability Maturity Model Integration (CMMI) is a model for improving and appraising the performance of development organisations by providing organisations with the essential elements of effective processes. It is an improvement of CMM, which was originally commissioned by the American Department of Defence to qualify software vendors' capabilities. Today, it is a method to guide process improvement initiatives, not only for software development but also for many related fields such as systems engineering, product acquisition, team management, research and development. Five levels of organisational maturity are defined, whereas each level represents a coherent set of best practices that organisations are expected to implement to achieve continuous improvement. Each maturity level is concerned with process areas (PA), which can be considered as detailed checklists describing the goals, activities, and the artefacts created and maintained to satisfy the requirements for a specific part of the overall development process. There are 25 process areas that are categorised into each maturity level (Chrissis et al., 2006) listed in Figure 15.1.

Maturity Level 1: No specific process area for this leve

Maturity Level 2: Requirements Management, Project Planning, Project Monitoring and Control, Supplier Agreement Management, Measurements and Analysis, Process and Product Quality Assurance, Configuration Management

Maturity Level 3: Requirements Development, Technical Solution, Verification, Validation, Product Integration, Organizational Process Focus, Organizational Process Definition, Organizational Training, Integrated Project Management for IPPD, Integrated Supplier Management, Risk Management, Decision Analysis and Resolution, Integrated Teaming, Organizational Environment for Integration

Maturity Level 4: Quantitative Project Management, Organizational Process Performance

Maturity Level 5: Causal Analysis and Resolution, Organizational Innovation and Deployment

FIGURE 15.1: CMMI PROCESS AREAS AND MATURITY LEVELS

Appraisals of organisations using the CMMI model must conform to the requirements defined in the Appraisal Requirements for CMMI (ARC) document. Appraisals focus on 
identifying improvement opportunities and comparing the organisation's processes to CMMI best practices. Appraisal teams use a CMMI model and ARC-conformant appraisal method to guide their evaluation of the organisation and their reporting of conclusions. The appraisal results are used (e.g., by a process group) to plan improvements for the organisation. There are three different classes of appraisals, class A, B, and C. All CMMI models contain multiple process areas with one to four goals. They are called specific goals and practices, as they describe activities that are specific to a single process area. An additional set of goals and practices applies across all of the process areas; this set is called generic goals and practice (Goldenson and Gibson, 2003).

\subsection{Projects in controlled environments (Prince2)}

Prince 2 (Projects in Controlled Environments) is a widely used project management method that navigates a project manager through all the essentials for running a successful project. Prince2 is a process based approach to project management and capable of tailoring and scaling to suit specific projects types and sizes. In this methodology, each process is completed and defined with its inputs and outputs, as are the specific objectives that have to be achieved and the activities that are to be carried out. Prince2 results from the previous Prince method, which was originally developed in 1989 by the Central Computer and Telecommunications Agency (CCTA) as a standard for Information Technology (IT) project management in the UK. Prince2 was released in 1996 as a basic project management methodology and then has become increasingly accepted by many organisations worldwide (OGC, 2005). The characteristics of Prince2 are that it has a focus on business validation, classifies organisation structure with respect to the project management team, it is a product-based planning approach, it has an emphasis on dividing the project into manageable and controllable stages, has flexibility to be applied at a level appropriate to the project, and can be tailored and is generic and simple to follow.

Prince2 is a structured approach to project management. It provides a method for managing projects within a clearly defined framework. It describes procedures to coordinate people and activities in a project, how to design and supervise the project, and what to do if the project has to be adjusted if it doesn't develop as planned. Each process is specified with its key inputs and outputs and with specific goals and activities 
to be carried out, which gives an automatic control of any deviations from the plan. Divided into manageable stages, the method enables an efficient control of resources. On the basis of close monitoring the project can be carried out in a controlled and organised way. Being a structured methodology widely recognised and understood Prince 2 provides a common language for all participants in the project. The various roles and responsibilities involved in a project are fully described and are adaptable to suit the complexity of the project and skills of the organisation. Prince2 is a process driven project management method and advocates product based planning which means that the first task when planning is to identify and analyse products. Once the activities required to create these products are identified then it is possible to estimate the effort required for each and then schedule activities into a plan. Prince 2 may be considered as inappropriate for small projects, due to the work required in creating and maintaining documents, logs and lists. This is often a misunderstanding of the scalability that Prince 2 offers because of the various roles and responsibilities involved (OGC, 2005).

\subsection{The V-Modell XT}

"The V-Modell is a process model for planning and executing projects. The V-Modell improves project transparency, project management and the probability of success by defining concrete practices with associated results and responsible Roles. The V-Modell XT is a further development of the V-Modell 97" (V-Modell, 2007, p. 1-4).

The V-Modell XT is a process model ("V" stands for the German word "Vorgehensmodell"), and "XT" stands for extended tailoring and means that the methodology is usable to handle projects of all kinds and sizes (Birowicz, 2005). The VModell XT focuses on "who" has to do it, "what" has to be done, "when" it needs to be done, "how" it has to be done, and "using what" to do it. There are three different types of projects according to the V-Modell XT:

- The customer project starts with the project proposal that initiates the project, and then defines the requirements and the tender process to find a supplier for the required solution (V-Modell XT, 2007, pp. 3-17 - 3-19).

- The supplier project is initiated by evaluating the tender documents that support with the customer's bidding process and the decision to submit a bid (V-Modell 
XT, 2007, pp. 3-19-3-21).

- The organisation specific V-Modell project shortens the process of tailoring for future projects by adjusting the V-Modell XT to that specific organisation's needs (V-Modell XT, 2007, pp. 3-21 - 3-23).

\begin{abstract}
A baseline set of system requirements then supports system design. The hardware and software are implemented at the bottom of the "V", and the components of the system are then integrated and verified in iterative fashion on the right. Ultimately, the completed system is validated to measure how well it meets the user's needs. Thus time proceeds from left to right in the V-Modell. The "V" diagram is punctuated by a series of major milestones where the output of the previous step is reviewed and the customer and project team determine whether the project is ready to move to the next step in the process. The project moves forward only if the criteria for the decision point have been satisfied
\end{abstract}

\title{
15.4 International Organisation for Standardization (ISO)
}

There are numerous standards of physical products, consortium and single firms and all of them produced by International Organisation for Standardization (Seaver, 2001). The International Organisation for Standardization (ISO) is a worldwide set of collected standard organisations from 157 different countries. In addition, ISO can be seen as a non-governmental organisation which has created a connection between the public and is more authoritative rather than other non-governmental organisation due to its capability to arranging standards that mostly become important rules either through agreements or national standards.

\subsubsection{ISO 9000 family}

One of the main responsibilities of ISO is the improvement of the 9000 standard series which is directed to integrate the quality perspective into business routine (Guinee, 2002). The ISO 9000: 2000 approaches the systems of management, which is used by organisation to create, assemble, distribute and support the productions of all general product divisions such as hardware, software and services. The ISO standards supply quality management conduction, quality guarantee need or contributing technology for management system of an organisation (Seaver, 2001). 
A reconsideration of the 1987 standard is ISO 9001:1994. This prepares direction to quality management and quality certainty for all fields and industries. ISO 9001:1994 demands corporations to prove and apply their operations for objective, product and management product quality (Guinee, 2002). An inadequate design would be an important reason for lack of products quality.

ISO 9001 comprises an established, authentic and broad assay of a plan to appraise the need for design and the ability of the design to supply these requisites and to analyse the problem and purpose the solutions. The latest version is ISO 9001:2000 quality management system (QMS) which is an international quality framework. ISO 9001, quality systems-model applies for quality certainty in design advancement, product, establishment and servicing (Guinee, 1996).

According to Peach (1997), there are five fundamental operating assumptions, which determine the needs in ISO 9001 :

- Categorise the way of organisation quality assurance.

- Constantly follow actions. In other word, do what you say.

- Document what you accomplished.

- Analyse the results against requirements and values for quality.

- Take action on discrepancies and act when results are inadequate.

\subsubsection{Earned value management}

According to AS4817 "project performance measurement using Earned Value outlines the principles and requirements for implementing Earned Value Management (EVM). A major feature of using EVM for measurement purposes is the unique way it integrates the cost, schedule, and technical aspects of a program. An EVM system will result from the application of the specified requirements integrating planning, scheduling, budgeting, work authorization, accounting and managerial control" (AGDF, 2006, p.1). What Earned Value Performance Measurement (EVPM) does is measuring the status of the project, measuring progress of a project against the baseline and forecasting the future performance. Finally, it assists the project manager to report the cost and schedule performance and to analyse the variances between planned and actual 
progress. EVMP is a useful method to monitor the cost and time of a project as it can forecast the performance of the project during the project takes place. The project manager can determine the condition of the project whether it is on schedule, behind schedule or under budget.

\subsection{Process workflow "execute escalation"}

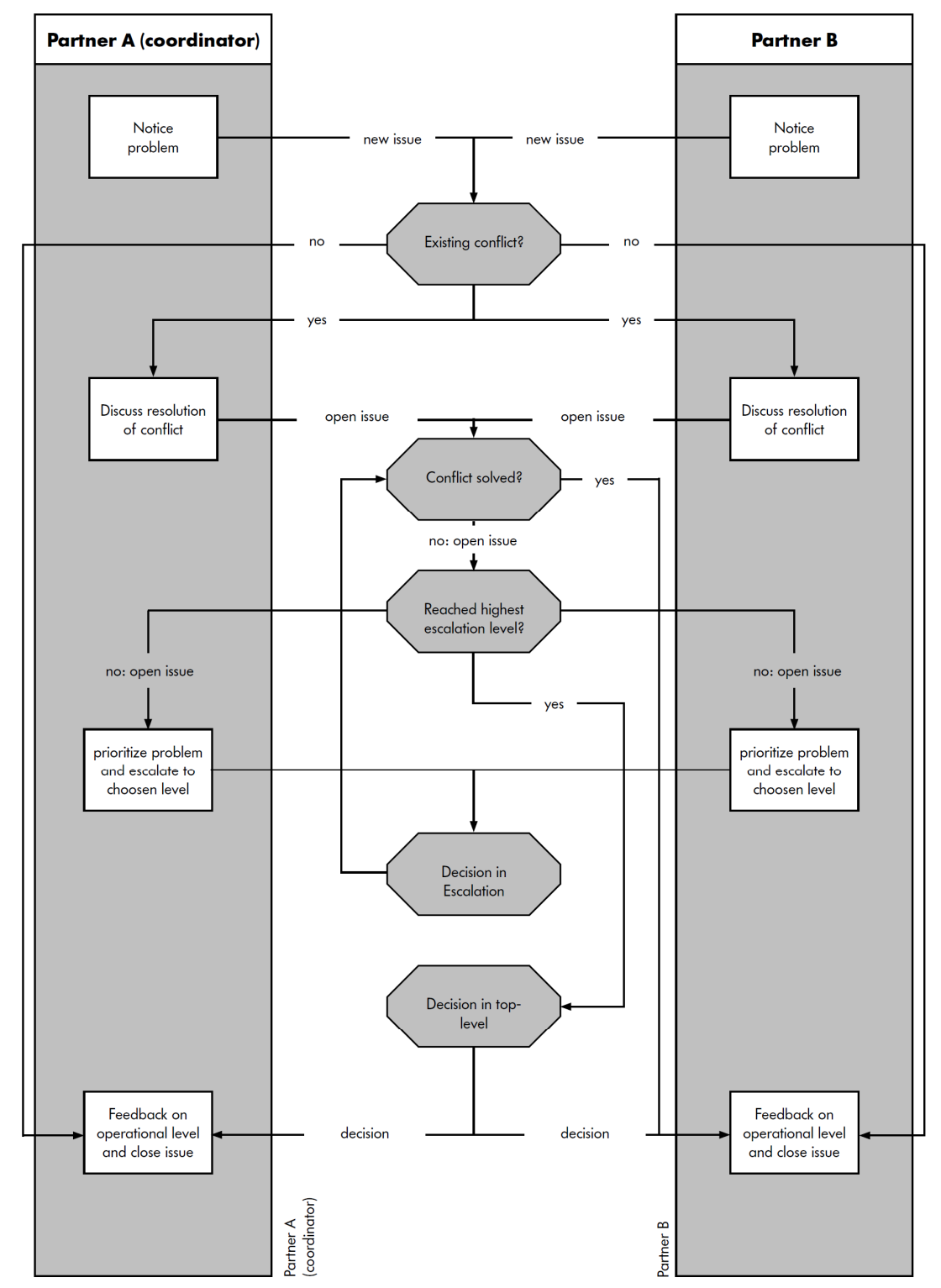

Figure 15.2: Process WORKFLOW “EXeCUTE escalation” (ProSTEP IVIP 2007A, P. 51) 


\section{Appendix B}

\subsection{Workshop questionnaire Vilsbiburg July 2007}

The following questionnaire is available in German language only.

\section{Umfragebogen}

1. Wie groß ist Ihr Unternehmen?

\begin{tabular}{llllll}
\hline Mitarbeiterzahl: & $\square<500$ & $\square$ & $500-1000$ & $\square$ & $>1000$ \\
Umsatz in Mio. €: & $\square<50$ & $\square$ & $50-250$ & $\square$ & $>250$
\end{tabular}

2. Wie viele Standorte hat Ihr Unternehmen, ungefähr?

\begin{tabular}{llllll}
\hline Deutschlandweit: $\square<2$ & $\square$ & $2-6$ & $\square$ & $>6$ \\
Weltweit: $\quad \square<2$ & $\square$ & $2-6$ & $\square$ & $>6$ \\
(außerhalb Deutschlands) & & & &
\end{tabular}

3. Wie steuern Sie Ihre Projekte gesamtheitlich im Unternehmen?
a. anhand von Projektkennzahlen
b. Multiprojektmanagement
C. Controllingabteilung
d. sonstiges

4. Welche Software ist für das Projektmanagement im Einsatz?

5. Gibt es viele standort-/ unternehmensübergreifende Projekte?

sehr viele
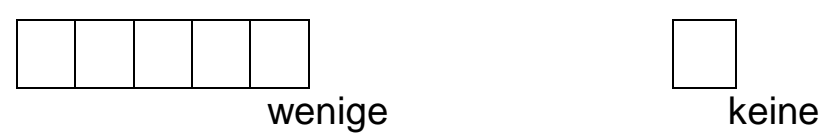
6. Wo in Ihrem Unternehmen wird eine Balanced Scorecard verwendet?

$\square$ Unternehmensweit

$\square$ Geschäftsbereichsebene

$\square$ andere :

$\square$ keine

7. Benutzen Sie in Ihrem Unternehmen bereits ein Kennzahlensystem im Bereich Projekt Management? Wenn ja, wie zufrieden sind Sie damit?

sehr

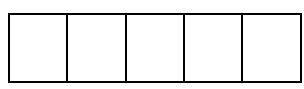

überhaupt nicht

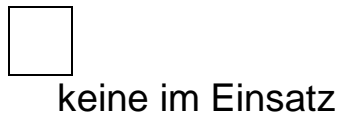

8. Welches Kennzahlensystem ist im Einsatz?

(Projektcockpit, etc.)

9. Welche Erfahrungen haben Sie zum Thema Project Scorecard bereits gesammelt?

gute Erfahrungen:

schlechte Erfahrungen:

keine:

10. Wo sehen Sie die Stärken bzw. Schwächen einer Project Scorecard?

Stärken:

Schwächen: 
11. Ist eine 5. Perspektive sinnvoll? Wenn ja, welche? (z.B. Risiko oder Qualität) keine weitere Perspektive sinnvoll

12. Welche Kennzahlen halten Sie bei einer projektspezifischen BSC für wichtig in der

a. Kundenperspektive

b. Prozessperspektive

c. Lernen/Innovation/Mitarbeiterperspektive

d. Finanzperspektive

13. Inwieweit lässt sich eine projektbezogene BSC von der Unternehmens-BSC ableiten?

sehr gut

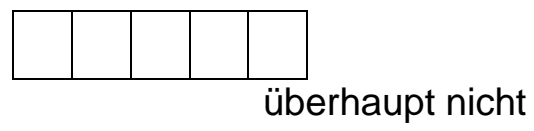


14. Gibt es Projektziele, die sich nicht von der Unternehmens-BSC ableiten lassen können? Wenn ja, z.B. welche?

15. Welche Kennzahlen sollten sinnvollerweise zwischen den Projektpartner zur Steuerung ausgetauscht werden?

a. Kundenperspektive

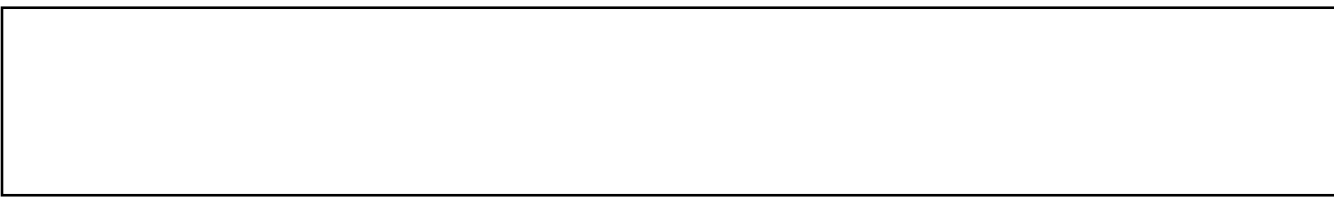

b. Prozessperspektive

c. Lernen/Innovation/Mitarbeiterperspektive

d. Finanzperspektive 
16. Welche dieser Kennzahlen können dabei als Frühindikatoren („leading“) verwendet werden?

17. Welche Unterschiede gibt es zwischen den Partnerprojekten OEM und Zulieferer sowie zwischen „gleichgestellten“ Projektpartnern (z.B. verteilte Projekte einer Firma an verschiedenen Standorten weltweit)

a. bezüglich Projektziele

b. bezüglich der zu verfolgenden Kennzahlen (z.B. aus Know-how Schutz Gründen)

18. Für wie wichtig halten Sie eine IT-Implementierung zur Nachhaltigkeit der PSC?

sehr wichtig

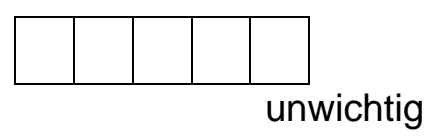

19. Wie hoch sehen Sie den Nutzen einer PSC im Vergleich zum Aufwand?

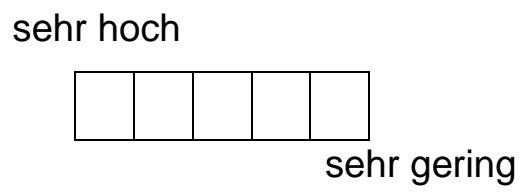

20. Für wie geeignet halten Sie die PSC zum Risikomanagement von unternehmensübergreifenden Projekten?

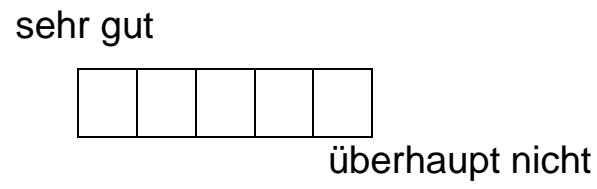


21. Für wie geeignet halten Sie die EFQM Methode zur Bewertung der strategischen Position von partnerschaftlichen Produktentstehungsprojekten zwischen bestimmten Projektpartnern?

sehr gut

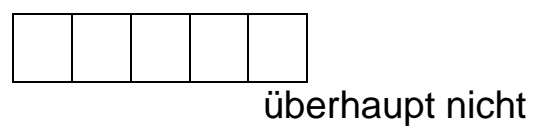

22. Wo sehen Sie Anknüpfungspunkte zu firmeninternen Prozessstandards wie (PMI PMBoK, CMMI, etc.)?

23. Wo sehen Sie Anknüpfungspunkte der PSC zu partnerschaftlichen ProzessMethoden wie z.B. Prostep iViP CPM?

Vielen Dank für Ihr Bemühen und Teilnahme an dieser Umfrage! 


\subsection{Project Scorecard survey questionnaire (GPM)}

The following survey questionnaire is available in German language only.

\section{Umfrage zur Anwendung der Balanced Scorecard im Rahmen von unternehmensübergreifenden Projekten}

Sehr geehrte Damen und Herren,

die Fachgruppe „Automotive-Projektmanagement“ der GPM Deutsche Gesellschaft für Projektmangement e.V. führt in Zusammenarbeit mit der Hochschule Darmstadt sowie den Unternehmen BMW Group und DräxImaier eine Untersuchung zur Anwendung der Balanced Scorecard (BSC) im Rahmen von unternehmensübergreifenden Projekten durch.

Mit diesem Fragebogen sollen relevante Informationen über die generelle Verbreitung der Balanced Scorecard in Unternehmen sowie im Projektgeschäft und deren Anwendung auf unternehmensübergreifende Projekte ermittelt werden. Wenn Sie über entsprechende Erfahrungen verfügen würden wir uns über eine Beantwortung des Fragebogens sehr freuen!

Ziel der unternehmensübergreifend abgestimmten Scorecard („Collaborative Project Score-card") ist, einen Konsens zwischen den beteiligten Partnern bezüglich der gemeinsamen Ziele zu erreichen und damit bessere Voraussetzungen für eine erfolgreiche Zusammenarbeit im Rahmen von unternehmensübergreifenden Projekten zu schaffen.

Ansprechpartner für die Befragung sind:

Herr Klaus Niebecker: Klaus.Niebecker@eng.uts.edu.au

Jeder Teilnehmer dieser Umfrage bekommt nach Abschluss der Untersuchung eine Zusammenfassung der Ergebnisse zugeschickt. 
Selbstverständlich werden die Informationen vertraulich behandelt. Es werden keine personenbezogenen Daten weiter veröffentlicht, noch auf einzelne Aussagen verwiesen.

\section{Vielen Dank für Ihre Mühe und Interesse!}

Anmerkungen, Kommentare oder Verbesserungsvorschläge bzgl. dieser Umfrage: 
1. In welcher Branche ist Ihr Unternehmen tätig?

2. Wie groß ist Ihr Unternehmen?

$\begin{array}{lllll}\text { Mitarbeiterzahl: } & \square<500 & \square 500-1000 & \square>1000 \\ \text { Umsatz in Mio. €: } & \square<50 & \square \quad 50-250 & \square>250\end{array}$

3. Wie viele Standorte hat Ihr Unternehmen, ungefähr?

$\begin{array}{llllll}\text { Deutschlandweit: } \square<2 & \square & 2-6 & \square & >6 \\ \text { Weltweit: } & \square<2 & \square & 2-6 & \square & >6\end{array}$

4. Welche Bedeutung hat Projektarbeit für Ihr Unternehmen?
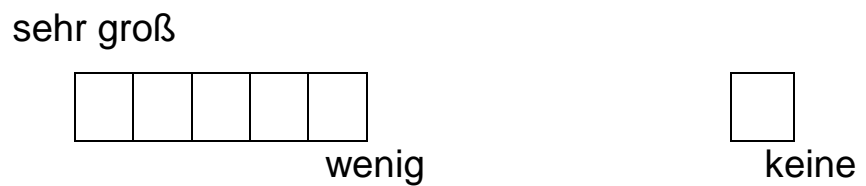

5. Wie steuern sich Ihre Projekte gesamtheitlich im Unternehmen?
a. anhand von Projektkennzahlen
b. Multiprojektmanagement
c. Controllingabteilung
d. sonstiges

6. Welche PM-Standards verwenden Sie in Ihrem Unternehmen und durch welche Software werden diese eventuell unterstützt? 
7. Werden PM-Standards in Projekten auch aktiv angewandt?

sehr oft
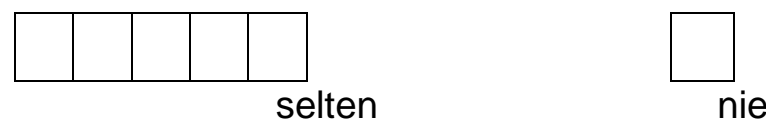

8. Gibt es viele standort-/ unternehmensübergreifende Projekte?
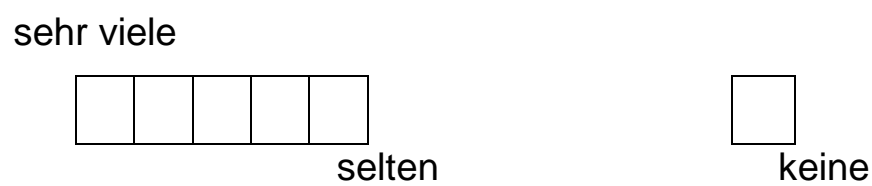

9. Wo in Ihrem Unternehmen wird eine Balanced Scorecard verwendet?

$\square$ Unternehmensweit

$\square$ Geschäftsbereichsebene

$\square$ andere :

$\square$ keine

10. Benutzen Sie in Ihrem Unternehmen bereits ein Kennzahlensystem im Bereich Projektmanagement? Wenn ja, wie zufrieden sind Sie damit?

sehr
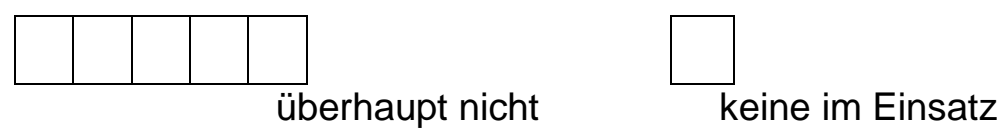

11. Welche Erfahrungen haben Sie zum Thema Project Scorecard bereits gesammelt?

gute Erfahrungen:

schlechte Erfahrungen:

keine 
12. Welches System ist im Einsatz?

(Projektcockpit, etc.)

13. Wo sehen Sie die Stärken bzw. Schwächen einer Project Scorecard?

Stärken:

Schwächen:

14. Ist eine 5. Perspektive sinnvoll? Wenn ja, welche? (z.B. Risiko oder Qualität)

$\square$ keine weitere Perspektive sinnvoll

15. Welche Kennzahlen halten Sie bei einer projektspezifischen BSC für wichtig in der

a. Kundenperspektive

b. Prozessperspektive

c. Lernen/Innovation/Mitarbeiterperspektive 
d. Finanzperspektive

16. Inwieweit lässt sich eine projektbezogene BSC von der Unternehmens-BSC ableiten?

sehr gut

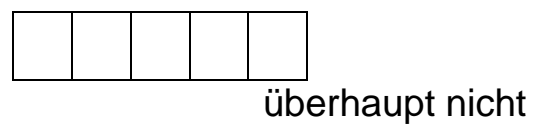

17. Gibt es Projektziele, die sich nicht von der Unternehmens-BSC ableiten lassen können? Wenn ja, z.B. welche?

18. Welche Kennzahlen sollten sinnvollerweise zwischen den Projektpartner zur Steuerung ausgetauscht werden?

a. Kundenperspektive

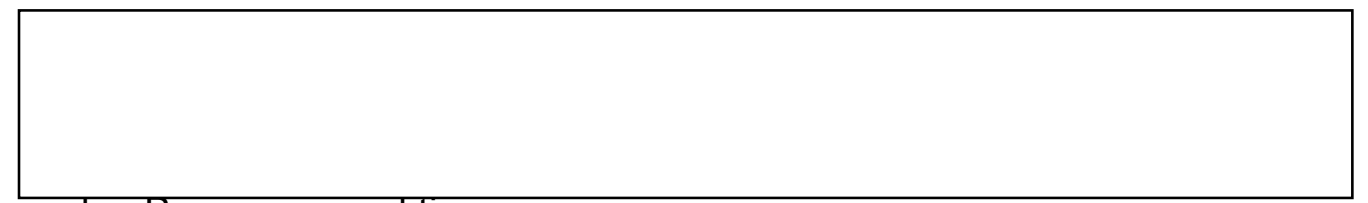

b. Prozessperspektive

c. Lernen/Innovation/Mitarbeiterperspektive 
d. Finanzperspektive

19. Welche dieser Kennzahlen können dabei als Frühindikatoren („leading“) verwendet werden?

20. Welche Unterschiede gibt es zwischen den Partnerprojekten z.B. OEM und Zulieferer sowie zwischen „gleichgestellten“ Projektpartnern (z.B. verteilte Projekte einer Firma an verschiedenen Standorten weltweit)

c. bezüglich Projektziele

d. bezüglich der zu verfolgenden Kennzahlen (z.B. aus Know-how Schutz Gründen)

21. Für wie wichtig halten Sie eine IT-Implementierung zur Nachhaltigkeit der PSC?

sehr wichtig

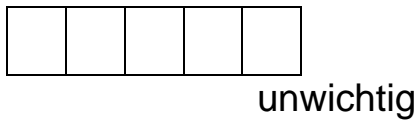

22. Wie hoch sehen Sie den Nutzen einer PSC im Vergleich zum Aufwand?

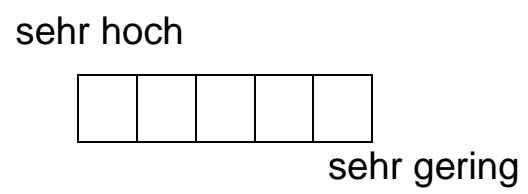


23. Für wie geeignet halten Sie die PSC zum Risikomanagement von unternehmensübergreifenden Projekten?

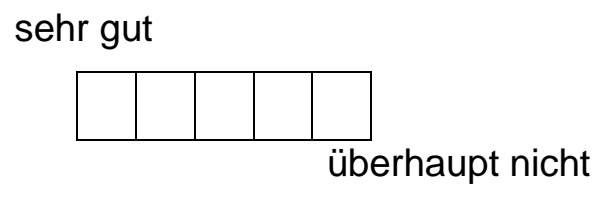

24. Wo sehen Sie Anknüpfungspunkte zu firmeninternen Prozessstandards?

(z.B. Terminplan, Produktreifegrad, etc.)

25. Welche unternehmensübergreifende Prozessmethoden/-standards sind Ihnen bereits bekannt und wird in Ihrem Unternehmen angewandt? (z.B. VDA, Prostep iViP)

bekannt:

in Anwendung:

26. Gibt es in unternehmensübergreifenden Projekten gemeinsame Strategien? Wenn ja, wie bewerten Sie diese und leiten den Handlungsbedarf ab (z.B. anhand einer Methode wie EFQM)?

Vielen Dank für Ihr Bemühen und Teilnahme an dieser Umfrage! 


\subsection{Collaborative Project Scorecard survey questionnaire (online)}

The online survey was available in English and German language. This section shows the English questionnaire only.

\section{The Balanced Scorecard: A Method for Cross-Company Project Management}

Collaboration within networked project environments increases constantly. Due to the high complexity of cross-company project structures, project management faces new challenges. Unclear project objectives, insufficient project control, and mistrust between team members are some of the common project management problems, which need to be solved, and management methods adapted to the new requirements.

The Balanced Scorecard, originally designed for business management, has resulted in the following advantages:

- Measurable business targets due to defined indicators

- Identify relevant cause-and-effect relationships of business objectives

- Reduction of complexity in project control

- Integration of stakeholders

- Improved management of measures

- Integration of non financial indicators to increase business potentials

To benefit from the advantages of a Balanced Scorecard next to strategic business control, it is essential to apply its concept down to the project management level. At the moment, this has already taken place with the use of "Project Cockpits" in many enterprises. The Project Cockpit is a concept that allows the manager to monitor all project related key performance indicators with one system. The implementation of the Balanced Scorecard method on a project level can be achieved with a Project Scorecard, which facilitates the alignment of project objectives with business targets and a company's vision, and a balanced selection of indicators ensures that all relevant project aspects are considered. 
The University of Technology in Sydney and the University of Applied Sciences in Darmstadt currently investigates the application of a cross-company project scorecard, the Collaborative Project Scorecard for cross-company project management. In collaboration with the Automotive Chapter of the German Project Management Association (GPM e.V.), two workshops have already shown the significance of this topic. As the method is a new approach without any prior experiences, this survey aims to contribute to the further development of this concept.

The Balanced Scorecard replaces the traditional approach to control a business with financial indicators only. The business targets are represented in the four perspectives of finances, client, processes, and employees, and are based on selected key performance indicators. The project objectives in a

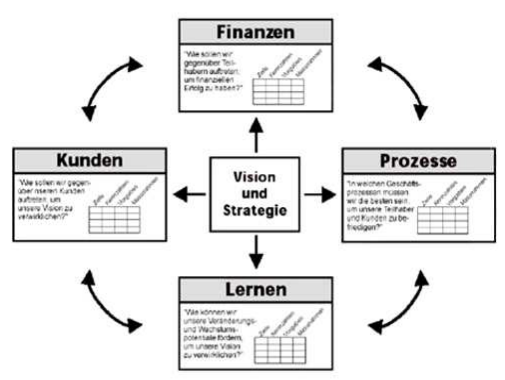
Project Scorecard are derived from the business targets and are measured with key performance indicators, which are categorised according to the four perspectives. Due to the increasing number of cross-company projects, the extension to a collaborative and cross-company project scorecard, the Collaborative Project Scorecard (CPS), stands to reason. In a CPS, the selected internal key performance indicators (KPIs) are synchronised with the project partners and new KPIs generated, and then controlled collaboratively. The following figure illustrates the derivation of the CPS from a Balanced Scorecard and a Project Scorecard.

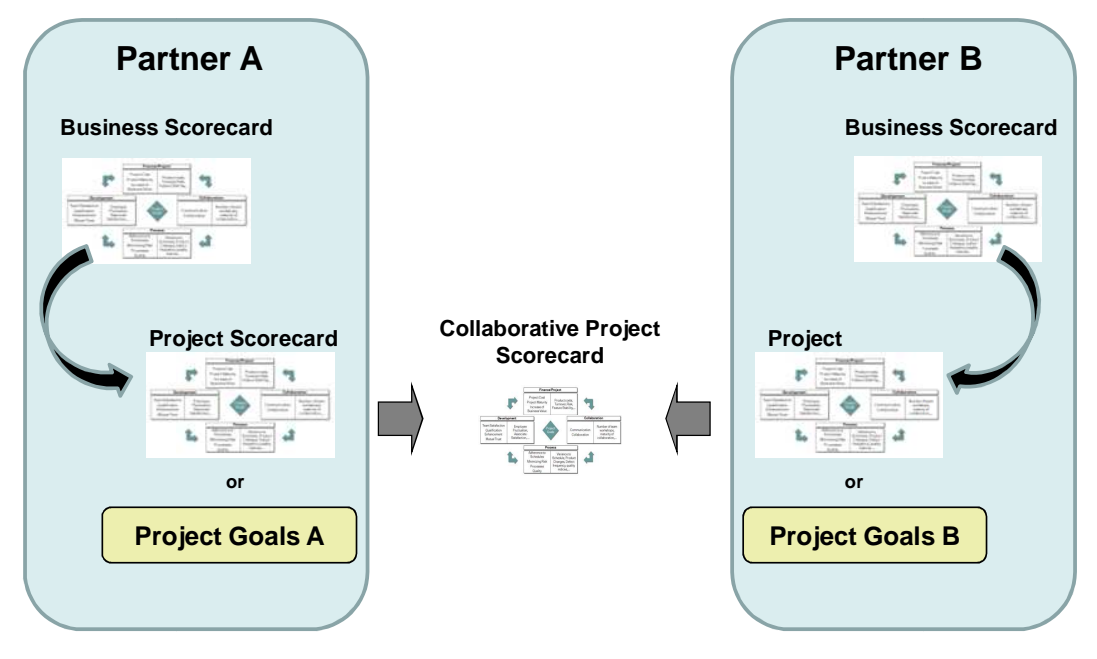

First experiences could be gained from two workshops organised by the GPM in July and October 2007. Some of the results were the modification of the four traditional 
perspectives, and the identification of relevant KPIs for collaborative projects. The following two perspectives were modified:

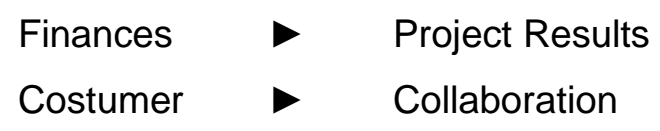

In a collaborative project, the common project results are more important than the financial goals only as these are mainly dependent on the type of partnership (joint venture, OEM/Supplier, etc.). Additionally, the client is not always in the main focus of collaboration and is rather represented in all four perspectives.

The aim of the method is to increase the project transparency of cross-company projects and to provide a basis for communication by defining common goals, processes and strategies. Another advantage of the CPS is that measures are defined in advance and in agreement with all participating partners, which is likely to avoid project delays when certain KPIs exceed a predefined value.

The concept of a CPS (including relevant KPIs and perspectives) is the main focus of this survey. 
1. How many workers are employed in your company?

$<500$ Emp. $\quad 500-1000$ Emp.

$>1000$ Emp.

No. of employees

( )

( )

2. What is your company's turnover?

$<50$ Billion US\$ $\quad 50-250$ Billion US\$ $>250$ Billion US\$

Billion US\$

( )

3. Is your company a:

( ) Supplier

( ) OEM

( ) Consulting

Other (please specify):

4. How do you control your company holistically?

( ) Multi Project Management

( ) Controlling Department

( ) Program Management

other:

5. In how many cross-company/collaborative projects have you been involved?

( ) equal partnerships

( ) dependent partnerships (e.g., OEM/supplier)

6. Where do you apply a Balanced Scorecard in your company?

( ) Company-wide

( ) Departmental level

( ) Project Management

( ) No application

other:

7. What indicator system do you use in your department or for your projects?

(IT solution/ Project Cockpit, exchange of Office documents, etc.):

8. Are you satisfied with the application of this system?

satisfied

unsatisfied

no application

Satisfaction

$\left(\begin{array}{llll}) & (\end{array} \quad(\mathrm{l}) \quad(\mathrm{l})\right.$


9. What experience have you gained with a Project Scorecard or Project Cockpit (advantages/disadvantages/limitations)?

Project Scorecard:

Project Cockpit:

10. What key performance indicators to monitor and control with a project based BSC (Project Scorecard) are relevant for each project phase?

Initialization phase:

Planning Phase:

Execution Phase (incl. Monitoring and Control):

Project closure phase:

11. What key performance indicators should be exchanged/synchronised between the partners for project control (Collaborative Project Scorecard)?

(With respect to the four perspectives)

Project Results Perspective:

Process Perspective:

Collaboration Perspective:

Potential/Employee Perspective:

12. Do you agree with the proposed perspectives or would you modify them differently?

13. What further adaptation steps of the CPS process is relevant to you (next to the adaptation of KPIs in each project phase)?

14. What are the differences between collaborative projects of OEM and supplier and projects of equal partners (joint ventures, distributed project teams within a company)?

According to project objectives?

According to KPIs (e.g., due to know-how/information protection)?

15. To evaluate a partnership, it is necessary to measure collaboration. What indicators could be used to measure collaboration and the maturity of a partnership? 
16. A focus of the CPS is to improve communication. How would you define indicators to measure the quality of communication between project partners?

7. A possible way to define communication is by the reachability of project members. How would you define the indicator measure reachability?

8. What is the best type of partnership for an application of a CPS in your opinion?
( ) OEM and supplier
( ) Joint Ventures
( ) equal project partners
( ) cross-departmental projects
other reasons:

9. What is the advantage of a CPS software solution?

10. How important is the incorporation of the CPS method into a software solution to ensure its sustainability? very important unimportant ensure sustainability:
( )
( )

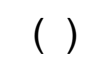
( )

11. How do you estimate the advantages/benefits of a CPS compared to the effort of implementation and maintenance?

$$
\text { very high very low }
$$

Benefits compared to effort ( ) ( ) ( ) ( ) ( )

12. Do you think that the transparency of your project may become too high with a CPS; or does it have a positive impact on your project collaboration?

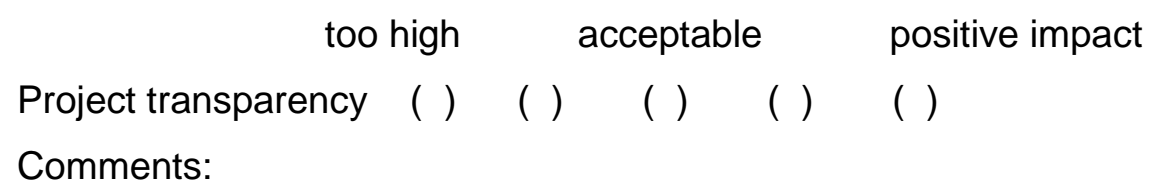

13. Do you think a CPS is adequate to manage risks of cross-company projects? very adequate not adequate

Adequacy ( ) ( ) ( ) ( ) ( ) 
14. What key performance indicators are relevant for a collaborative monitoring and control of project risks?

15. Do you think a CPS is adequate to manage quality aspects of cross-company projects?

$$
\text { very adequate not adequate }
$$

Adequacy ( ) ( ) ( ) ( ) ( )

16. What key performance indicators are relevant for a collaborative monitoring and control of quality aspects?

17. What risks, opportunities, and threats may occur with a CPS? 


\section{Appendix C}

\subsection{Agenda of the CPS workshop 11th March 2008}

\begin{tabular}{|c|c|c|c|}
\hline $1.00-1.15$ & \multicolumn{2}{|c|}{ Warm-up: round of introduction and prospects } & All \\
\hline $1.15-1.45$ & \multicolumn{2}{|c|}{$\begin{array}{l}\text { The Concept of a Collaborative Project Scorecard; } \\
\text { Procedure and Goal Definition for the Workshop }\end{array}$} & $\begin{array}{l}\text { Researcher of } \\
\text { OEM \#1+2 }\end{array}$ \\
\hline $1.45-2.30$ & \multicolumn{2}{|c|}{$\begin{array}{c}\text { Development of a Strategic Collaboration Framework } \\
\text { between OEM and supplier }\end{array}$} & All \\
\hline $2.30-2.45$ & \multicolumn{2}{|c|}{ Short Break - coffee and snacks } & All \\
\hline $2.45-4.45$ & $\begin{array}{l}\text { Creation of a CPS for the } \\
\text { Launch (Moderation: } \\
\text { Manager of Supplier, } \\
\text { Researcher of OEM \#1) }\end{array}$ & $\begin{array}{c}\text { Creation of a CPS for } \\
\text { Change Management } \\
\text { (Moderation: Manager } \\
\text { Supplier, Researcher of OEM } \\
\text { \#2) }\end{array}$ & Group Work \\
\hline $2.45-3.45$ & $\begin{array}{c}\text { Group A: } \\
2 \text { Supplier and } 3 \text { OEM } \\
\text { representatives }\end{array}$ & $\begin{array}{c}\text { Group B: } \\
4 \text { OEM and } 2 \text { supplier } \\
\text { representatives }\end{array}$ & \\
\hline $3.45-4.45$ & $\begin{array}{l}\text { Group C: } \\
4 \text { OEM and } 2 \text { supplier } \\
\text { representatives }\end{array}$ & $\begin{array}{l}\text { Group D: } \\
2 \text { Supplier and } 3 \text { OEM } \\
\text { representatives) }\end{array}$ & \\
\hline & \multicolumn{2}{|c|}{ Short Break } & All \\
\hline $4.45-5.00$ & \multicolumn{2}{|c|}{ Presentation of Results "Change" } & $\begin{array}{l}\text { Moderator } \\
\text { Change }\end{array}$ \\
\hline $5.00-5.15$ & \multicolumn{2}{|c|}{ Presentation of Results "Launch" } & $\begin{array}{l}\text { Moderator } \\
\text { Launch }\end{array}$ \\
\hline $5.15-6.00$ & \multicolumn{2}{|c|}{$\begin{array}{c}\text { Discussion: Pros and Cons, Potential and Business Impact } \\
\text { of the Methodology }\end{array}$} & All \\
\hline
\end{tabular}

TABLE 17.1: USA WORKSHOP AGENDA 
17.2 Original Strategy Map of the Strategic Collaborative Scorecard (whiteboard)

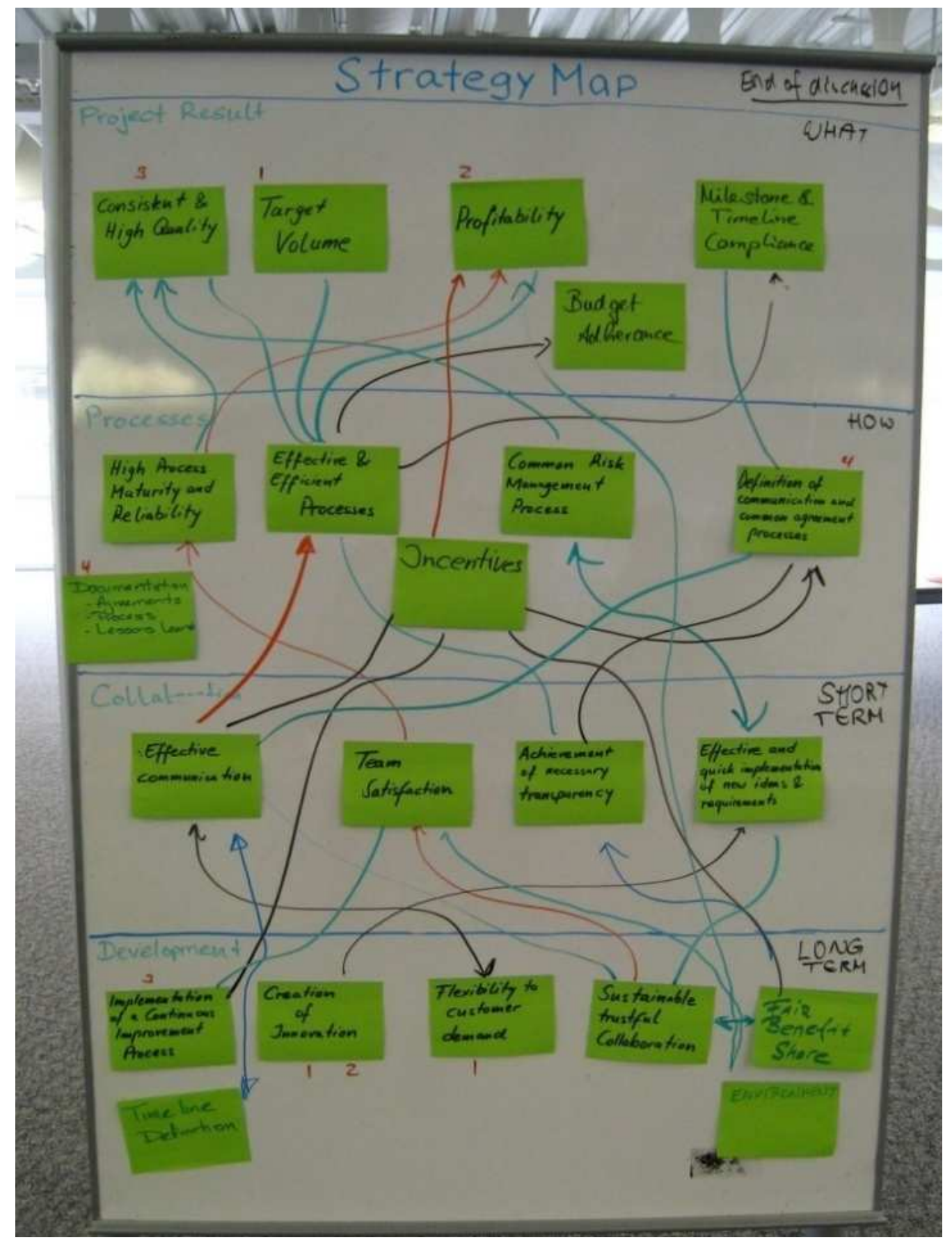

FIGURE 17.1: STRATEGY MAP CPS WHITEBOARD 


\subsection{CPS workshop questionnaire}

The following is the questionnaire that was handed out after the CPS workshop in South Carolina.

\section{The Collaborative Project Scorecard (CPS)}

ITRC, 11th March 2008

\section{Questionnaire}

1. What is your current position?
a. Management
( )
b. Project Management
( )
c. Indirect function

2. Are you working for a
a. Supplier
( )
b. OEM
( )

3. Years of project management experience:

a.

4. What is your appraisal to improve collaboration with a common Balanced Scorecard (CPS)?

Effective impact

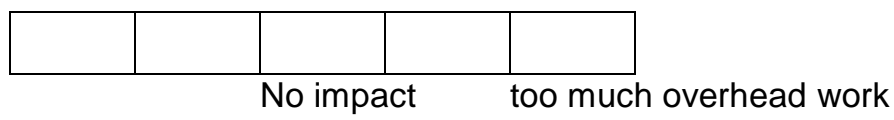

5. Your feedback to this workshop: 


\section{Bibliography}

AIAG (1995), "Advanced Product Quality Planning \& Control Plan (APQP)”, Automotive Industry Action Group, 1st edition.

AGDF (2006), "Defence supplement to AS4817-2006 - project performance measurement using earned value", Australian Government, Department of Defence, Defence Material Organisation, document version 1.0, Australia.

Akao, Y. (2004), "QFD: quality function deployment - integrating customer requirements into product design", Productivity Press, New York.

Akhilesh, K. and Prasad, K. (2002), "Global virtual teams: what impacts their design and performance?", Team Performance Management, An International Journal, vol. 8, no. $5 / 6$.

Alleman, G. (2003), "Using balanced scorecard to build a project focused IT organisation", Balanced Scorecard Conference Oct 28-30 2004, IQPC, San Francisco.

Andersen H, Lawrie G and Savic N (2004), "Effective quality management through thirdbeneration balanced scorecard", International Journal of Productivity and Performance Management, vol. 53, No. 7, pp. 634-645.

Australian Government Department of Defence (2006), "Defence supplement to AS4817-2006 - project performance measurement using earned value", Defence Material Organisation, document version 1.0, Australia.

Behrend, F. (2005), "The socio-cultural challenge of effective knowledge management in virtual project environments", University of Southern Queensland, Faculty of Business, Australia.

Bennis, W. (1999), "Old dogs, new tricks: on creativity and collaboration", Executive Excellence Publishing.

Bergheim, S. (2005), „Globale Wachstumszentren 2020 - Formel-G für 34 Volkswirtschaften“, Aktuelle Themen 313, Deutsche Bank Research, Frankfurt. 
Bieker, T. and Waxenberger, B. (2002), "Sustainability balanced scorecard and business ethics - using the BSC for integrity management", paper presented at the 10th International Conference of the Greening of Industry Network, Göteborg, Sweden.

Birkhofer, H. (2000), „Skriptum zur Vorlesung Produktentwicklung“, Technische Universität Darmstadt, Germany.

Birowicz, U. (2005), "Evaluating standard software with V-Modell XT, a case study", The University of Liverpool, UK.

Bourgault, M., Lefebvre, E., Lefebvre, L., Pellerin, R. and Elia, E. (2002), "Discussion of metric for distributed project management: preliminary findings", Proceedings of the 35th Hawaii Conference on System Sciences, HICSS-35 02, IEEE, USA.

Brewer, P. and Speh, T. (2001), "Adapting the balanced scorecard to supply chain management", Supply Chain Management Review, vol. 5, no. 2, pp. 48-56.

Bullinger, H., Kiss-Preussinger, E. and Spath, D. (2003), „Automobilentwicklung in Deutschland - wie sicher in die Zukunft? Chancen, Potenziale und Handlungsempfehlungen fuer 30 Prozent mehr Effizienz“, Fraunhofer IRB, Stuttgart.

Byrne, J., Brandt, R. and Port, O. (1993), "The virtual corporation", Business Week, $8^{\text {th }}$ February, pp. 98-102.

Calandro, J. and Lane, S. (2006), "Insights from the balanced scorecards", Measuring Business Excellence, vol. 10, no. 3, pp. 31-40.

Chao, G. and Moon, H. (2005), "The cultural mosaic: a metatheory for understanding the complexity of culture", Journal of Applied Psychology, vol. 90, no. 6, pp. 1128-1140.

Chen, F., Romano, N., Nunamaker, J. and Briggs, R. (2002), "A collaborative project management architecture", Proceedings of the 36th Hawaii International Conference on System Sciences (HICSS'03), USA, pp. 12.

Chrissis, M., Konrad, M. and Shrum, S. (2006), "CMMl: guidelines for process integration and product improvement", SEI series in software engineering, Addison Wesley, Boston, USA. 
Cobbold, I. and Lawrie, G. (2002), "The development of the balanced scorecard as a strategic management tool", Proceedings of the PMA2002, Boston.

Coghlan, D. (2001), "Insider action research projects: implications for practising managers", Management learning, vol. 21, no 1, pp. 49-60

Connaughton, S. and Shuffler, M. (2007), "Multinational and multicultural distributed teams", Small Group Research, vol. 38, no.3, pp. 387-412.

Crawford, L., Morris, P., Thomas, J. and Winter, M. (2006), "Practitioner development: from trained technicians to reflective practitioners", International journal of project management, vol. 24, pp. 722-733.

Creswell, J. (2002), "Research design: qualitative, quantitative, and mixed methods approaches", $2^{\text {nd }}$ edition, Sage Publications.

Daenzer, W. and Huber, F. (1997), "Systems Engineering, Methodik und Praxis“, 9. Auflage, Verlag Industrielle Organisation, Zürich, Switzerland.

Diensberg, C. (2001), "Balanced Scorecard und House of Quality“, Schriftenreihe des Bundesinstituts für Berufsbildung, Bundesinstittut für Berufsbildung, Heft 53, Bertohld Schobert, Bonn.

DIN 69901 (1987), "Projektmanagement, Begriffe“, German institute for standardization.

Dixius, D. (1998), "Simultane Projektorganisation - Ein Leitfaden fuer die Projektarbeit im Simultaneous Engineering“, Springer, Berlin, Germany.

Ebel, B., Hofer, M. and Al-Sibal, J. (2004), "Automotive Management - Strategie und Marketing in der Automobilwirtschaft," Berlin, Springer Verlag.

Eckerson, W. (2006), "Performance dashboards: measuring, monitoring, and managing your business", John Wiley and Sons Inc., Hoboken, New Jersey.

Eigner, M. and Stelzer, R. (2004), "Produktdatenmanagementment-Systeme - Ein Leitfaden fuer Product Development und Life Cycle Management", Springer, Berlin, Germany. 
Eisenhardt, K. (1989), "Building theories from case study research", Academy of Management Review, vol. 14, no. 4, pp. 532-550.

Engel, C. and Holm, C. (2007), "Ergebnisse der Projektmanagement Studie 2007 Schwerpunkt Kosten und Nutzen von Projektmanagement", gemeinsame Studie der GPM Deutsche Gesellschaft fuer Projektmanagement e.V. und PA Consulting Group, Germany.

Evaristo, R. and van Fenema, P. (1999), "A typology of project management: emergence and evolution of new forms", International Journal of Project Management, vol. 17 , no. 5 , pp. $275-281$.

FAST-2015 (2004), "Future Automotive industry Structure (FAST) 2015 - die neue Arbeitsteilung in der Automobilindustrie“, Studie von Mercer Management Consulting un den Fraunhofer-Instituten IPA und IML in VDA - Materialien zur Automobilindustrie, no. 32, Germany.

Flyvbjerg, B. (2006), "From nobel prise to project management: getting risks right", Project Management Journal, vol. 37, no. 3, pp. 5-15.

Gable, J. (1994), "Integrating case study and survey research methods: An example in information systems", European Journal of Information Systems, vol. 3, no. 2, pp. 112126.

Gessner, C. (2001), „Package feutrues fuer die Kommunkation in den fruehen Phasen der Automobilentwicklung“, Dissertation, TU Berlin, Germany

Gharajedaghi, J. (1999), "Systems thinking - managing chaos and complexity", Butterworth-Heinemann, Boston.

Gierhardt, H. (2001), "Global verteilte Produktentwicklungsprojekte - Ein Vorgehensmodell auf der operativen Ebene“, Dissertation, Technische Universitaet Muenchen, Germany.

Gleissner, W. (2002), "Risikomanagement und Balanced Scorecard im Kontext wertorientierter Managementsysteme", Future Value Group AG, 05/2002, Germany. 
Goldenson, D. and Gibson, D. (2003), "Demonstrating the impact and benefits of CMMI: an update and preliminary results", CMU/SEI-2003-SR-009, Software Engineering Institute. Special report, Pittsburgh, USA.

Goldratt, E. (1997), “Critical Chain: a business novel”, North River Press, USA.

Goldratt, E. (1999), "Theory of constraints”, North River Press, USA.

Gordon, G. (2006), "Uniform maker sews up success with scorecard”, Quality Progress, vol. 39 , no. 10 , pp. 37-42.

GPM (2008), "Der Deutsche Project Excellence Award“, GPM Deutsche Gesellschaft für Projektmanagement e.V., viewed 1st October 2008, http://www.gpmipma.de/docs/fdownload.php?download=GPM Award-Broschure final.pdf.

Gray, C. and Larson, Ee (2000), "Project management: the managerial process", $1^{\text {st }}$ edition, Irwin, McGraw-Hill, Boston.

Gray, C. and Larson, E. (2002), "Project management: the managerial process", 2nd edition, McGraw-Hill, Irwin.

Guba, E. and Lincoln, Y. (1994), "Competing paradigms in qualitative research", Handbook of Qualitative Research, Denzon and Lincoln, Sage, Thousand Oaks.

Guinee, J. (2002), "Handbook of lifecycle assessment: pperation guide to ISO standards", Kluwer Academic Publisher, The Netherlands.

Hab, G. and Wagner, R. (2005), "Projektmanagement in der Automobilindustrie Herausforderungen in einer dynamischen Branche“, projectMANAGEMENT, edition 3/2005, Germany.

Hab, G. and Wagner, R. (2006), "Projektmanagement in der Automobilindustrie Effizientes Management von Fahrzeugprojekten entlang der Wertschoepfungskette“, Gabler, $2^{\text {nd }}$ edition, Germany

Hakes, C. (2007), "The EFQM Excellence Model to assess organisational performance a management guide (best practice)", 1st edition, Van Haren Publishing, Netherlands. 
Hass, K. (2007), "The blending of traditional and agile project management", PM World Today, May 2007, vol. 9, issue 5, pp. 1-8.

Herde, H., Kirchner, L. and Paessler, K. (2001), "Von der Balanced Scorecard zur Business-Excellence-Scorecard - Erfahrungen mit Methoden und Werkzeugen zur systematischen Strategieentwicklung und -umsetzung auf Basis des EFQM-Modells“, Holger Luczak, Lehrstuhl fuer Arbeitswissenschaften der RWTH Aachen, $3^{\text {rd }}$ edition, Aachen, Germany.

Hill, T. and Westbrook, R. (1997), "SWOT analysis: it's time for a product recall", International Journal of Strategic Management, Long Range Planning, vol. 30, issue 1, pp. $46-52$.

Hofmann, J., Rollwagen, I. and Schneider, S. (2007), "Deutschland im Jahr 2020 Neue Herausforderungen für ein Land auf Expedition“, Aktuelle Themen 382, Deutsche Bank Research, Frankfurt.

Herzog, V. (2001), "Trust building on corporate collaborative project teams", Project Management Journal, vol. 32, no 1, pp. 28-37.

Horvath, P. (2003), "X-Engineering - Ohne Balanced Scorcard und Performance Measurement nicht wirksam", Controlling, Edition 07/08 2003, Verlage C.H. Beck, Vahlen, Germany.

Horvath and Partner (2005), Balanced Scorecard Studie 2005, Germany.

Hrebiniak, L. (2005), "Making strategy work: leading effective execution and change, Upper Saddle River, New Jersey.

Humphrey, W. (2002), "Winning with software, an executive strategy", Addison-Wesley.

IPMA (2008), "Moving winners forward - IPMA international project excellence award", International Project Management Association, Switzerland.

Jaafari, A. (2001), "Management of risk, uncertainties and opportunities on projects: time for a fundamental shift", International Journal of Project Management, Vol. 19, pp. 89-101. 
Jaafari, A. (2003), "Project management in the age of complexity and change", Project Management Journal, December 2003, vol. 34, no. 4, PMI, USA, pp. 47-57.

Janulil, E., Kuhlang, P., Piff, R., 2005, Projektmanagement und Prozessmessung - Die Balanced Scorecard im projektorientierten Unternehmen, Erlangen.

Jonsson, N., Novosel, D., Lillieskold, J. and Eriksson, M. (2001), "Successful management of complex, multinational R\&D projects", Proceedings of the $34^{\text {th }}$ Hawaii International Conference on Systems Sciences, Volume 8, January 3-6, Maui, HI, USA: IEEE Computer Society Press, pp. 8044.

Kahn, K. (2005), "PDMA handbook of new product development", Second Edition, John Wiley and Sons.

Kaplan, R. and Norton, D. (1996), "Translating strategy into action: the balanced scorecard", Boston, Massachusetts, USA, Harvard Business School Press.

Kaplan, R. and Norton, D. (2001), "The strategy focused organisation - how balanced scorecard companies thrive in the new business environment", Harvard Business School Press, Boston, USA.

Kaplan, R. and Norton, D. (2004), "Strategy maps, converting intangible assets into tangible outcomes", Harvard Business School Publishing Corporation, Boston, Massachusetts, USA.

Kaplan, R. and Bower, M. (2004), "Five questions about strategy maps", Harvard Management Update, vol. 9, no. 11, p. 3.

Kaufmann, L. (2004), "X-BSC - Measuring the performance of truly strategic supplier relationships", Practix - Good Practices in Purchasing \& Supply Chain Management, CAPS Research, Tempe, AZ, USA.

Kerzner, H. (2003), "Project Management: a systems approach to planning, scheduling, and controlling", Wiley, $8^{\text {th }}$ edition, USA.

Kuhn, T. (1996), "The structure of scientific revolutions", $3^{\text {rd }}$ edition, Chicago and London, University of Chicago Press. 
Kuehnel, W. and Pinnels, J. (2002), "Projekt, Vertrag und Claim“, VFMA, Frankfurt a. M., Germany.

Kurek, R. (2004), “Erfolgsstrategien für Automobilzulieferer - Wirksames Management in einem dynamischen Umfeld“, Berlin, Springer.

Krippendorff, K. (1980), "Content analysis: An introduction to its methodology", Sage Publications, Beverly Hills.

Lawson R, Stratton W and Hatch, T. (2007), "Scorecards and dashboards - partners in performance", CMA Management, December/January issue accessed on $25^{\text {th }}$ September 2007 via CMA Management Web Side, http://www.managementmag.com/index.cfm/ci id/7355/la id/1.htm.

Leung, K., Bhagat, R, Buchan, N. Erez, M. and Gibson, C. (2005), "Culture and international business: recent advances and their implications for future research", Journal of International Business Studies, vol. 36, pp. 357-378.

Lindemann, U., and Reichwald, R. (1998), "Integriertes Aenderungsmanagement", Springer, Berlin, Germany.

Mabin, V. and Balderstone S. (2000), "The world of the theory of constraints: a review of the international literature", St Lucie Press, Boca Raton, FL, APICS Series on Constraints Management, pp. 11-12.

Malone, T. (2004), "The future of work: how the new order of business will shape your organisation, your management style, and your life", Harvard Business School Press, USA.

Mayer, M. (1998), "The virtual edge: embracing technology for distributed project team success", Newtown Square, Project Management Institute, USA.

McDonough, E., Kahn, K. and Griffin, A. (1999), "Managing communication in global product development teams," IEEE transactions on Engineering Management, vol. 46, no. 4 , p. $375-386$ 
McPhail, J. and Perry, C. (2002), "Study book: research methodology", University of Southern Queensland, Toowoomba, Australia.

Mercer Consulting and Technische Universität München (2005), "Studie Management von Unternehmensnetzwerken“, Munich, Germany.

Microsoft (2007), "Performance Point Server 2007", viewed $1^{\text {st }}$ December 2007, $<$ http://office.microsoft.com/en-us/performancepoint/FX101680481033.aspx>.

Miles, M. and Huberman, A. (1994), "Qualitative data analysis", Sage Publications, Thousand Oaks, California.

Moore, J. (1996), "ISO 12207 and related software life-cycle standards", Institute of Electrical and Electronics Engineers (IEEE), Accessed 16 April 2008, <http://www.acm.org/tsc/lifecycle.html>.

Nidiffer, K. and Dolan, D. (2005), "Evolving distributed project management", Systems and Software Consortium, IEEE Software, September/October 2005, vol. 22, pp. 63-72.

Niebecker, K., Eager, D. and Kubitza, K. (2008a), "Improving cross-company project management performance with a collaborative project scorecard", International Journal of Managing Projects in Business, Emerald Group Publishing Limited, vol. 1, no. 3, p. 368-386.

Niebecker K., Eager, D., Wagner, R. and Kubitza, K. (2008b), "Efficient project management and performance assessment of cross-company projects with a collaborative project scorecard, Proceedings of the IPMA World Congress, $9^{\text {th }}-12^{\text {th }}$ November 2008, International Project Management Association, Rome, Italy.

Niebecker, K., Eager, D., Kubitza, K. and Plischke, D. (2008c), "Integrating a collaborative management model into a project scorecard for efficient cross-company project management, Proceedings of the AIPM Conference, $12^{\text {th }}-15^{\text {th }}$ October 2008, Australian Institute of Project Management, Canberra, Australia.

Norrie, J. (2006), "Improving results of project portfolio management in the public sector using a balanced strategic scoring model", Thesis for the degree of Doctor of Project 
Management (DPM), Royal Melbourne Institute of Technology, School of Property, Construction and Project, Management, Design and Social Context, RMIT University

Norrie, J. and Walker, D. (2004), "A balanced scorecard approach to project management leadership", Project Management Journal, PMI, vol. 35 no. 4, pp. 47-56.

Nunamaker, J., Romano, N. and Briggs, R. (2000), "A framework for collaboration and knowledge management," Proceedings of the $34^{\text {th }}$ Hawaii International Conference on System Sciences, Maui, HI, USA: IEEE Computer Society Press, vol. 1, pp. 1060.

Office of Government Commerce (2005), "Prince2 manual (managing successful projects with PRINCE2)", $5^{\text {th }}$ edition, Great Britain, The Stationery Office, UK.

O'Leary, M., Orlikoski, W. and Yates, J. (2002), "Distributed work over the centuries: trust and control in the Hudson's Bay company", in Hinds, P., and Kiesler, S., Distributed Work, Cambridge, MA, MIT Press. pp. 48.

Paessler, K. and Roesler, D. (2001), „Balanced-Scorecard-unterstuetzte Fuehrungsund Anreizsysteme“, Industrie Management, edition 4, p. 18-22.

Pander, S. and Wagner R. (2005), "Unternehmensübergreifende Zusammenarbeit in der Automobilentwicklung - durch erfahrungsgeleitete Kooperation die Grenzen der Planbarkeit überwinden“, Mering, Rainer Hampp Verlag.

Papalexandris, A., loannou, G., Prastacos, G. and Sonderquist, K. (2004), "An integrated methodology for putting the Balanced Scorecard into action", European Management Journal, vol. 23, no. 2, pp. 214-227.

Peach, R. (1996), "The ISO 9000 handbook", $3^{\text {rd }}$ sub edition, McGraw-Hill, USA.

Plischke, D. (2004), "Entwicklungspartnerschaften und -kooperationen Herausforderung an die IT-Integration“, Arbeitswelten Gestalten, no. 1, ProduktDatenJournal, Germany.

Plischke, D. and S. Vettermann (2007). "Automobil-Hersteller und Zulieferer: Neue CPM-Empfehlung für eine optimierte Kooperation“, special edition 12/2007, München, Projekt Magazin. 
Project Management Institute (2004), "A guide to the project management body of knowledge (PMBOK Guide)", $3^{\text {rd }}$ edition, Four Campus Boulevard, Newtown Square, PA, USA.

Porter, M. (2001), “Anderssein ist alles“, Wirtschaftswoche 12/2001, pp. 124-126.

Prasad, B. (1996), "Concurrent engineering fundamentals", Volume I: Integrated Product and Process Organisation, Prentice Hall PTR, Upper Saddle River, New Jersey.

Prikladnicki, R., Nicolas, A. and Evaristo, J. (2004), "Global software development in practice lessons learned", Journal of software process improvement and practice, Special Issue: Global Software Development: Growing Opportunities, Ongoing Challenges, vol. 8, issue 4, pp. 267-281.

Project Management Institute (2001), "The PMI project management fact book", $2^{\text {nd }}$ edition, Project Management Institute, Newton Square, Pennsylvania

Rad, P. and Levin, G. (2003), "Achieving project management success using virtual teams", J. Ross, USA

Raelin, J. (2001), "Public reflection as the basis of learning", Management learning, vol. 32 , no. 1 , pp. 11-30.

Ramberg, J. (2000), "Six sigma: fad or fundamental?", viewed on $8^{\text {th }}$ September 2007, www.qualitydigest.com/may00/html/sixsigmapro.html.

Rietiker, S. (2006), "Der neunte Schluessel - vom Projektmanagement zum projektbewussten Management“, Berlin 2006

Rietiker, S. (2008), "Projektbewusstes Management", projektManagement aktuell, 1/2008, pp. 23-31

Romano, N., Chen, F. and Nunamaker, J. (2002), "Collaborative project management software", Proceedings of the 35th Hawaii International Conference on System Sciences, IEEE, vol. 1., pp. 20.

Salem, S. (2001), "New product development balanced scorecard', IEEE International Engineering Management Conference 2001, pp. 110-112. 
Sandstroem, J. and Toivanen, J. (2002), "The problem of managing product development engineers: can the balanced scorecard be an answer?", International Journal of Production Economics, vol. 78, no. 1, pp. 79-90.

Saynisch, M. (2004), "Results of the research programme beyond frontiers of traditional project management", paper at the $18^{\text {th }}$ IPMA World Congress, June 2004, Budapest, Hungary.

Saynisch, M. (2006), "Projekt-, Konfigurations-, und Collaborations Management Prozesse und Arbeitsstrukturen“, projektManagementaktuell, TUEV Verlag, Koeln, Germany, edition 4, pp. 23-31.

Saynisch, M. (2007), "A radical redefining of PM for mastering complex projects: the project management $2^{\text {nd }}$ order (PM-2)", paper for the ICAN Conference 2007, November $29^{\text {th }}$ and $30^{\text {th }}$, Sydney, Australia.

Sarker, S., Lau, F. and Sahay, S. (2000), "Building an inductive theory of collaboration in virtual teams: an adapted grounded theory approach", Proceedings of the 33rd Hawaii International Conference on System Sciences.

Schelle, H. (2008), "Projektmanagement und Unternehmensstrategie", Advanced Project Management, Reinhard Wagner, Berlin, Germany

Schoen, D. (1983), „The reflective practitioner - how professionals think in action“, Aldershot, UK, BasiAshgate Arena.

Scholey, C. (2005), "Strategy maps: a step-by-step guide to measuring, managing, and communicating the plan", Journal of Business Strategy, vol. 26, no. 3, pp. 12-19 .

Scholey, C. (2006), "Risk and the balanced scorecard', CMA Management, vol. 32, pp. 32-35.

Schuh, G. (2000), „Leitfaden kooperative Modulentwicklung - Abschluss-dokumentation im Projekt VIA-OK“, Aachen, WZL, RWTH Aachen. 
Seaver, M. (2001), "Implementing ISO 9000:2000, Gower, UTS Library, view on $15^{\text {th }}$ April 2008, http://site.ebrary.com.ezproxy.lib.uts.edu.au/lib/utslibrary/Doc?id=10047167.

Selders, M. and Maerkle, L. (2003), "Project scorecard: Mehr Transparenz fuer strategische Projekte", Projekt Magazin, Vol. 20 No. 1.

Selders, M. and Maerkle, L (2004), "Project Scorecard - Weiterentwicklung der Balanced Scorecard fuer strategische Projekte", viewed on $23^{\text {rd }}$ September 2007, http://www.competence-site.de/projektmanagement.nsf/artikel.html.

Software engineering Institute (2008), "ISO/IEC 15504", Carnegie Mellon University, view on $16^{\text {th }}$ April 2008, http://www.sei.cmu.edu/cmmi/faq/15504-faq.html. SME Training on Configuration Management (2000), "IBW", viewed on $16^{\text {th }}$ April 2008, http://esamultimedia.esa.int/docs/industry/SME/Configuration/Section 1-CM.pdf.

Snow, C. (1993), "The two cultures", Cambridge University Press.

Sosa, M., Eppinger, S., Pich, M., McKendrick, D. and Stout, S. (2002), "Factors that influence technical communication in distributed product development: an empirical study in the telecommunications industry", IEEE transactions on Engineering Management, vol. 49, no. 1, pp. 45-58.

Spies, E. (2003), "Effektiv kooperieren“, Beltz, Germany.

Standish Group (1999), "Chaos: a recipe for success", The Standish Group International, Report 1999

Stewart, R. (2007), "IT enhanced project information management in construction: Pathways to improved performance and strategic competitiveness", Automation in Construction, vol. 16, pp. 511-517.

Stewart, R. and Mohamed, S. (2001), "Utilizing the balanced scorecard for IT/IS performance evaluation in construction", Construction Innovation, vol. 1, pp. 147-163.

Stewart, W. (2001), "Balanced scorecard for projects", Project Management Institute, vol. 32 no 1, pp. 38-53. 
Tesch, D., Kloppenborg, T. and Frolick, M. (2007), "IT project risk factors: the project management professionals perspective", The Journal of Computer Information Systems, vol. 47, issue 4, pp. 61-69.

Thompson, A. and Strickland A (2001), "Crafting and executing strategy: Text and Readings", $12^{\text {th }}$ edition, McGraw-Hill, Boston.

Turner, J. (2000), "Do you manage work, deliverables or resources?", International Journal of Project Management, vol. 18, no. 2, pp. 83-84.

VDA (2003), "Sicherung der Qualitaet vor Serieneinsatz", Band 4.3, VDA, Frankfurt

Ministry of the Interior (2007), "Fundamentals of the V-Modell" V-Modell XT 1.21, as issued by the Federal Ministry of the Interior (BMI), viewed on $18^{\text {th }}$ March 2005, http://www.kbst.bund.de/cln 012/nn 945224/Content/Service/English/english dokume nts.html nnn=true\#doc839152bodyText3.

Volland, A. (2006), "Befragung zur Anwendung von Risikomanagement in Projekten, Projekt Management und Qualitätssicherung“, Ergebnisse einer Umfrage von pmqs.de durchgeführt im März 2006, PMQS, Rodgau, Germany.

Wagner, R. (2005), "Towards a global understanding of project management in automotive industry", Proceedings of the $19^{\text {th }}$ IPMA World Congress, 13-16 November 2005, New Delhi, India.

Wagner, R. (2009), „Automotive project management - more lessons to learn!“, Project Perspectives, The annual publication of International Project Management Association, vol. XXXI, pp. 74-78.

Wagner, R. and Niebecker, K. (2008), "Die Collaborative Project Scorecard (CPS) als zentrales Tool zur Steuerung unternehmensübergreifender Projekte“, projektMANAGEMENT aktuell, $2^{\text {nd }}$ edition, Nuernberg, Germany.

Wallace, L., Keil, M. and Rai, A. (2004), "How software project risk affects project performance: an investigation of the dimensions of risk and an exploratory model", Decision Sciences, Vol. 35, Issue 2, pp. 289-321. 
Walther, J. (1997), "Group and interpersonal effects in computer-mediated international collaboration", Human Communication Research, v. 23, pp. 342-369.

Warkentin, M. and Beranek, P. (1999), "Training to improve virtual team communication", Information Systems Journal, vol. 9, no 4, pp. 271-289.

Weaver, P. (2007), "The origins of modern project management" Proceedings of 4th annual PMI College of Scheduling Conference, 15-18 April 2007, Mariott Pinnacle Downtown, Vancouver, Canada.

Weinstein, I. (2004), "The business case for managed services for videoconferencing understanding the scope, benefits, and justification of managed service offerings", white paper, Wainhouse Research, November 2004.

Whitty, S., Schulz, M. (2007), "The impact of puritan ideology on aspects of project management”, International Journal of Project Management, 25(1), p. 10-20.

Wiklund, H. and Wiklund, P. (2002), "Widening the six sigma concept: an approach to improve organisational learning", Total Quality Management, vol. 13, no. 2, pp. 233-239.

Wildemann, H. (2004a), "Entwicklungstrends in der Automobil- und Zuliefer-industrie Empirische Studie“, TCW, Muenchen, Germany.

Wildemann, H. (2004b), "Entwicklungspartnerschaften in der Automobil- und Zulieferindustrie“, Ergebnisse einer Delphistudie, Germany.

Wolf, M., Mlekusch, R. and Hab, G. (2006), "PM-Live - Instrumente, Verfahren und Kooperationen als Garanten des Projekterfolgs“, $6^{\text {th }}$ edition, Expert, Renningen, Germany.

Yin, R. (2002), "Case study research: design and methods", Applied Social Research Methods Series, $3^{\text {rd }}$ edition, Sage Publications.

Zayed, T., Amer, M. and Pan. J. (2008), "Assessing risk and uncertainty inherent in chinese highway projects using ahp", International Journal of Project Management, Vol. 26, pp. 408-419. 
Zimmermann, K. (2007), "Supply Chain Balanced Scorecard - Eine Fallstudie aus der Automobilindustrie", Supply Chain Management, vol 1. 2007, pp. 23-29. 